\title{
Afghanistan Cucurbit Rootfuel Project Report
}

\section{Renewable}

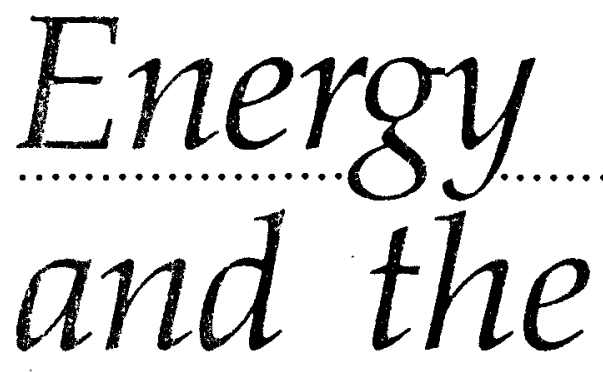

Environment 
Contractor:

Winrock International

Institute for Agricultural Development

Contract number: 306-0200-C-00-0995-00

\title{
Afghanistan Cucurbit Rootfue! Project Report
}

\author{
Authored by \\ Wayne G. Bragg, Ph.D \\ Enable International, Inc.
}

Prepared for the

Office of the AID Representative for Afghanistan Affairs

Project title: Afghanistan Cucurbit Rootfuel Activity

Project number: 306-0200

December 12,1991

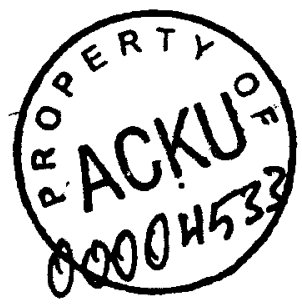




\section{AFGHAN ROOTFUEL PROJECT}

Subcontract 579-90-1

between

Enable International

and

Winrock Intemational Institute

for Agricultural Development

$$
\text { by }
$$

Wayne G. Bragg, Ph.D.

Enable International, Inc.

608 N. President Street

Wheaton, IL 60187

Telephone and Fax 708-665-5958 .

September 25, 1991 


\section{AFGHAN ROOTFUEL PROJECT}

SUMMARY

The Afghan Rootfuel Project, carried out in Pakistan, identified some local dryland plant species that have potential to produce root biomass as an alternative cooking fuel in Afghanistan which is in extremely short supply. Two species, Citullus colocinthis and Cucurbita foetidissima were tested in experimental growing plots. Even though these tests were conducted under less than ideal conditions due to external factors, they provided helpful agronomic information on the factors of soil, water, pests, and temperature (time of planting). One of the trial plots was planted in late October/so the dry winter season affected them adversely, although some plants germinated and grew for a period. The plan to replant in March 1991 was frustrated by the Gulf War (resulting in a postponed second visit to Pakistan by the rootfuel team) and by accidents like lost seed and mice attack on shipped seed. A second small trial was planted in Aprif which gave insights into soil and water conditions. Experimental trial results are summarized and recommendations are offered in the tisis report. $-1991$

Currently new planting trials are underway in the Northwest Province and Balochistan, which will provide further knowledge in varied eco-systems. Seeds were also taken into Afghanistan for trial planting in eight or ten provinces under natural conditions. By July 1992 results should be in from these trials under diverse growing conditions. Meanwhile, other arid land species have been identified which may show promise.

Cooking tests were conducted by Afghan cooks, both male and female, in Pakistan. These tests revealed that rootfuel is culturally and technically acceptable when used in traditional stoves or fireplaces. Both cooks responded positively to the ignitability, cooking time, smoke factor, and general behavior of the alternative fuel. Rootfuel was perceived as a viable and desirable option to woodfuel, crop residues, and animal-dung cakes. A video tape was made of the cooking tests, as well as the search for local species.

An initial training program for Afghan agricultural officers (of the ADT sector of Development Alternatives Inc.) was carried out in October 1990. During this training, a handbook on the identification, cultivation, preparation and use of rootfuel was used and culturally contextualized. In August of 1991, a second training program was given to 20 Afghan agricultural officers, using the handbook and video tape. A final translation and publication of the handbook in Farsi was finished. This handbook is appended, with its English draft version.

A study of the eco-systems of Afghanistan based on data from FAO and discussions with Afghan agriculturalists resulted in identifying the regions in Afghanistan that would be potential sites for growing rootfuel. Critical factors are soil class, temperature (growing degree days), and water (rainfall or irrigation). A map is included. Seeds have been sent to some of these regions for field trials.

Since the pilot trials were incomplete and further tests are being carried out both in Pakistan (in two provinces) and in Afghanistan, and since further work is needed on other species, a follow-on program for another year is recommended. Criteria and terms of reference for this follow-on program are included. 
The Afghan Rootfuel Project proposed to pilot test the introduction of rootfuel into Afghanistan in collaboration with the staff of the Agricultural Development and Training (ADT) component of Development Alternative Inc. (DAI) in Peshawar, Pakistan. Enable International's responsibilities included the following objectives within the project, to be carried out by two rootfuel consultants:

1. To locate and work with local Pakastani botanists/technicians to identify local dryland plant species that could have potential as a source of fast-growing nonwoody roots, useful as alternative cooking fuel in Afghanistan;

II. To assist the Agriculture Development and Training (ADT) sector of Development Alternatives Inc (DAI) to establish demonstration plots of these species (cucurbits);

III. To conduct acceptability tests for the use of rootfuel as cooking fuel by appropriate populations of Afghans;

IV. To train ADT project staff in the planting and harvesting/drying of cucurbit rootfuel, and design an extension and training activity to be carried out subsequently by ADT staff inside Afghanistan (including the publication of a rootfuel handbook in Farsi);

V. To record on videotape the various elements of the demonstration project, and to use for future training activities.

VI. To work with ADT staff of DAI to identify locations within Afghanistan where the agro-climate is most appropriate for cucurbit rootfuel trials.

VII. To work with the Winrock Project Coordinator to design a more extensive follow-on program of rootfuel development and use, and a draft TOR.

These objectives have been carried out as follows:

\section{SEARCH FOR LOCAL PLANT SPECIES WITH POTENTIAL AS ROOTFUEL.}

Dr. Abdur R. Beg, botanist of the Forest Research Institute of the University of Peshawar, was contracted to look for local dryland cucurbit species that produce substantial root biomass. Along with Dr. Lester Bradford, forester, and Dr. Nabi Aslamy, agronomist, both of DAI, field research for promising species was carried out before the Enable/Winrock team arrived in Pakistan in September-October, 1990. Then the team, comprised of Dr. Wayne G. Bragg, Dr. Eugene B. Shultz, Jr., and Betsy Amin-Arsala, joined Dr. Beg and colleagues for further field research in the Peshawar area.

The species that seemed most promising was Citrullus colocynthis, a cucurbit plant native to the Indian-Pakistan-Afghanistan region (and other world drylands). This wild, bitter gourd plant thrives in very harsh environmental conditions. In Bannu, $25 \mathrm{~km}$ from Peshawar, C. colocynthis was growing in abundance in a clay soil used for brick-making. Colonies were also found at Azakhel. Roots reach a depth of more than five feet as well as spreading laterally in search of water. Enough roots were gathered for comparative combustion tests with Cucurbita foetidissima (Buffalo Gourd), a New World semi-xerophytic 
species that rapidly produces massive roots. The roots from $\mathrm{C}$. colocynthis are less dense than $\mathrm{C}$. foetidissima, with pithy cellular construction, and because of this the combustion rate tests showed that these roots burn faster.

Following the October visit, Dr. Beg surveyed for other dryland plants with prodigious root growth. His attention centered on a few species including Boerhaavia difusa, Carduus nutens, Datura innoxia, Calatropis procera, Fagonia cretica, Peganum harmala, Withania somnifera, Aerua javanica, from which he gathered roots samples and checked for mass and density. In August, 1991, Drs. Nabi Aslamy and Wayne Bragg accompanied him on further field surveys. Some of the most promising seem to be a member of the milkweed family, Calatropis procera (which produces a dense taproot and flourishes in poor soils with little rainfall), Carduus nutens of the sunflower family, and Datura innoxia.

\section{CUCURBIT DEMONSTRATION PLOTS}

In October of 1990 controlled experimental trials were set up in a site outside Peshawar, using some feral C. foetidissima seeds gathered in Oklahoma in 1990 and local Citrullus colocynthis seeds and root cuttings. Cucurbita foetidissima was tested because of its proven potential for high yields of biomass for rootfuel. The site was on a farm with sandy and sandy-silty soils located about $25 \mathrm{~km}$ east of Peshawar in Azakhel, a region where Citrullus colocynthis grows naturally.

Dr. Beg laid out the plots, consisting of eight square meters for each species, half in mounds and half in rows (see Appendix $A$ for planting diagram). Spacing was $5 \mathrm{~cm}$ apart, or 20 plants per linear meter in the rows $x 4$ meters (80 plants) Five plants were allotted per mound and there were 4 mounds per square meter $\times 4$ square meters ( 80 plants). These plots were planted on October 21, 1990, despite the fact that the weather had cooled considerably and soil temperature was low, not good conditions for germination.

In addition to the seed plots of both species, a plot was set out with colocynth root cuttings to see if they would reproduce vegetatively. Purposely no water was added to the experiments, to emulate natural conditions, although October was out of synch with the normal planting season (April, in this region).

The $\mathrm{C}$. colocynthis did better than the $\mathrm{C}$. foetidissima producing six healthy plants, with runners of 4 to 7 feet long, and gourds. However, the colocynth root cuttings had not

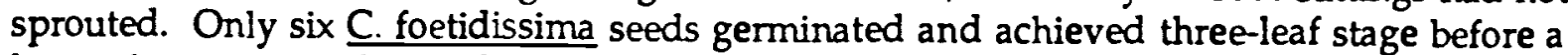
heavy frost sustained over three nights killed all but one plant. Some of the cucurbita seed that did not germinate in October/November remained dormant and when the temperature began rising in February and March, 1991, a number of them germinated in two periods about a week apart. These seedlings grew to the three-leaf stage and continued growing slowly until late May when the summer heat and drought killed them.

On August 12, 1991, Beg, Aslamy and Bragg dug into some of the mounds and rows and found still more un-germinated Buffalo Gourd seed, awaiting more conducive moisture and soil temperature conditions. They left these seeds to see if they would germinate with the summer monsoon. More $\mathrm{C}$. foetidissima seeds were planted in new rows at this time. Rains c:tme on August 18 in Azakhel with two good suaking rains, and on August 20th, they went back to see if there was any more germination. It was observed that the new seeds and 
some of the seeds remaining from last year were germinating, although the ants were taking some away. They planted two more rows with seed that had been treated with Coopex (permethrin 0.5\% ww) against crawling insects.

A second trial site was in the Project Serve tree nursery in Peshawar, where Cucurbita foetidissima was planted in April, 1991, in polyethylene tubes with sandy loam and compost. Ten plants germinated and were transplanted to a site in the nursery with compact, clay soil. The seedlings were planted on level ground with no drainage. They were kept watered regularly by nursery staff, just as they would water tree seedlings. The seedlings reached 1820 inches in length, but they eventually began to die one by one. By Augutst 1991 only two plants had survived, and they were wilting atd rellowing badlyl it is most likely that the transplanted seedlings either received too much water which induced root fungal disease or asphyxiation, or that the clay soil was too compact, or both. Herman Nyhoff, forester of Project Serve, is planting new trials of cucurbit seed on the irrigation banks of the ComDev tree farm near Zinda Khwar, $20 \mathrm{~km}$ from Peshawar.

\section{Experimental results:}

Both experimental test sites would seem to indicate that planting time is critical in terms of temperature and moisture. A spring planting would take advantage of the moisture from spring rains where available, or a summer planting (where August monsoons come) would provide the soil temperature and moisture needed to germinate and establish the plant before cold weather and dry season begin. In the Azakhel site Cucurbita foetidissima needed more moisture than Citrullus colocynthis to germinate, as the latter is truly xerophytic.

Soil is also an important factor. While $\underline{C}$. colocynthis survives compact clay soils, it does better in sandy or sandy silty soil. C. foetidissima definitely prefers sandy, well-drained soil and cannot tolerate compact, poorly-drained soils.

\section{Recommendations Based on Experimental Observations:}

1. The planting cycle should begin with the end of the winter/rains (in about April or May) so that the seeds will germinate when the soil temperature rises, and the plants will be established before the next winter. In regions where summer monsoons come early enough (August) planting can be done then with similar results.

2. Planting conditions:

a. The soil is an important factor since both species like well-drained and aerated conditions. Cucurbita foetidissima especially needs well-drained conditions. Sandy soil is best (sandy, or sandy loam). If planted in clay soil, drainage is of supreme importance to avoid asphyxiation or root rot.

b. Planting on slopes is best, whether natural inclines or, if on flat land, man-made hillocks or mounds/rows. If the roots are submersed in standing water, the roots will get root-rot or simply asphyxiate. 
c. Watering is critical in the first weeks of germination, either by rain or manually (irrigation), and the plants should get more water within a month to ensure growth. If planted in mounds or mound/rows (melon beds), the water between the rows or mounds can reach the plants by capillary action but the roots will not be submersed in case of heavy rains or too much irrigation.

3. To protect the seed from insect attack, it should be treated with proven insecticide before planting.

\section{Further experimental tests:}

In addition to ongoing tests in Azakhel and Project Serve/ComDev's tree farm at Maskin near Peshawar, some experiments are underway in Balochistan. Dr. Safadar Kayan, Botany Department, University of Balochistan and Dr. Bakht Roldar Kahn of the Arid Zones Research Institute of Quetta were used as consultants for locating species and identifying ecosystems in Balochistan and southern Afghanistan that would have potential for rootfuel

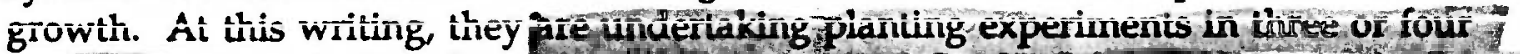
ecological niches in Balochistan and at the Botanical Garden of the University in Quetta.

\section{COOKING TRIALS}

In October 1990 cooking tests were carried out by Afghan cooks, one by a woman and one by a male cook, since in Islamic culture women cook in the home, but men do the cooking in public institutions - schools, restaurants, side-walk barbecue stalls, military posts, and hospitals. In both tests the cooks used their customary food ingredients, fireplaces, utensils, and cooking methods, substituting only the fuel. They were observed as they went about starting a fire with rootfuel (Cucurbita foetidissima) and throughout the whole cooking process. Observations were made of such factors as ignition time, time of cooking each food, and the fire/fireplace management. The cooks' observations were noted. The two cooking trial reports are attached in Appendix B. The cook, family, and observers all then tried the food. Generally, the responses were positive to rootfuel over wood, crop residues, or animaldung chips. The alternative fuel seemed to meet the cultural and technical acceptability standards of the two Afghan cooks and families, and in fact rootfuel seemed to impress them with its positive characteristics such as a lack of acridity in the smoke, the heat produced, and the coals (good for simmering foods). In one case, a videotape was made of the entire process.

\section{TRAINING AND DIFFUSION OF ROOTFUEL TECHNOLOGY}

In October of 1990, Wayne Bragg carried out an intensive training program at ADT, assisted by Betsy Amin-Arsala and Dr. Lester Bradford, for some key Afghan personnel of ADT, including Mr. Soor Gul and Mr. Mohammed Sofi. In turn, these men were to train other DAI/ADT agricultural officers in Afghanistan in the planting, harvesting, and use of rootfuel. In this training session, a handbook on rootfuel by Bragg and Shultz (Appendix E) was used as a text and modifications to meet Afghan culture and conditions were incorporated as a result. This handbook was later translated (see below) for use in extension and training activities by Soor Gul and Mohammed Sofi. Unfortunately for the project, both these men immigrated to Australic with their families before they could conduct a training program for agricultural agents involved in ADT programs inside Afghanistan. 
During the week of August 3-8, 1991, a second training program was held by Wayne Bragg and Nabi Aslamy at ADT in Peshawar for 20 Afghan agricultural officers who had come from Afghanistan for an ADT training program. By this time training within Afghanistan had become more problematic since USAID put all cross-border operations on hold due to unstable conditions. The revised draft copy of the rootfuel handbook was used as a basis for the training sessions, as well as a twenty-minute video of the Afghan Rootfuel Cooking Experiments carried out the year before. Discussions with the group included identification of local species, planting, cultivating, harvesting, drying and using rootfuel. Samples and photos of Cucurbita foetidissima and Citrullus colocynthis were used.

After the training session, these 20 hgricultural officers took cucurbitasseeds back with them with instructions on appropriate planting conditions and care. These men were from the provinces of Helmand, Zabul, Paktia, Nangarhar, Baghlan, Takhar, Wardak, Ghazni, Logar, and Paktika, but they also itinerate through other provinces and supervise other extension agents. They will look for other species with potential and will plant cucurbita in various ecosystems to see the results. If the seeds do not germinate in the winter, the seeds will typically lie dormant intïl the next raisis in Janiuary and February. These nuen with tronitor the planting trials and the eventual usage of rootfuel by farmers inside Afghanistan and report back to ADT/DAI in Pakistan.

A Farsi translation and adaptation of the rootfuel handbook that was developed in conjunction with this project was published for their use (see attached copy Appendix D).

\section{VIDEOTAPE RECORDING OF ROOTFUEL USE AND TESTS}

The team took a video camcorder Pakistan in order to record the search for local species and a cultural acceptability cooking test using rootfuel. A preliminary version of this footage was edited and taken back to Pakistan in August for training purposes. ADT/DAI has this draft video version.

A final version, which will also include footage of the process of harvesting and drying rootfuel as well as background shots from Pakistan and Afghanistan, is currently being edited for eventual use as needed both in Afghanistan and elsewhere. When the video tape editing is finished, it will also be sent to Winrock

\section{POTENTIAL REGIONS IN PAKISTAN WITH CONDITIONS FOR GROWING ROOTFUEL}

Discussions with Afghan agriculturalists gave some indications of potential growing sites in Afghanistan. Statistics based on FAO reports from Afghanistan were also used. Important growing factors include water, soil, and temperature. Rainfall data were not available, but Afghanistan receives monsoon rains (or snow) generally from February to April, depending on the region. The southwest also gets a late monsoon in October or November. Rainfall is obviously important but moisture can be substituted or supplemented as needed through irrigation. Soil type and temperature are the critical factors. In this report, temperature is measured by growing degree days (base 50 degrees F). Growing degree days range from $<2000$ to $>7000$ in Afghinistan. 
The recommended regions are delineated on the enclosed soil class map (Appendix C) with an overlay showing where temperature is judged to be too cold, based on growing degree days (GDDs). The inner line (red) represents unsuitable, very cold weather (less than $2000 \mathrm{GDDs}$ ), the next line (blue) represents cold (2000-3000 GDDs) that may be unsuitable. The rest of Afghanistan has a range of 3000 to $>7000 \mathrm{GDDs}$, indicating potentially favorable growing temperatures. Generally, the central Hindu Kush high mountain range appears too cold and is mostly clay soil, shown on the map overlay. However, this region has low population density (one person per square $\mathrm{km}$ ) as contrasted with the rest of the country (with 10-25 per square $\mathrm{km}$ in populated regions and $1-10$ per square $\mathrm{km}$ in deserts). It is these more populated regions which have potential for rootfuel, depending on the soil class and water conditions.

Much of central Afghanistan is clay soil. Rootfuel can grow in clay soil, as shown by some native colonies of colocynth near Peshawar and the cucurbit experiment in Project Serve's nursery (if not over-watered), so these species may grow in the clay soils in places where temperature is amenable. However, these species develop larger roots in sand or sanay ioam, so the regions with the best conditions combine good soiis isanay, sandy ioam, and loam) and a large number of GDDs (3000 to 7000). The regions with good growing conditions are those with loam and loamy clay soils with 3000 and above GDDs. On the map, the soil class marked "non-agricultural" (an unclear designation that could include marginal, heavily eroded or rocky soils, or areas too hot or dry for normal crops) but with good growing degree days (3000-7000) might be useable for rootfuel species. This would take experimentation.

It should be remembered that these calculations are based on macro statistics from FAO, and within any one region there will be wide fluctuations. Therefore, the map must not be considered as definitive without considering micro eco-systems with varying microclimates and soils.

\section{FOLLOW-ON PROGRAM}

A follow-on program is important if this project is to fulfill its potential for Afghan. The Afghan Rootfuel Project projected a possible second phase, to be written with TOR specifications by Enable International and Winrock International. Since the O/AID REP in Pakistan limited the second visit to one consultant rather than three, we have been unable to confer extensively to write the follow-on design. As an input to this process, the following criteria for such a proposal are submitted:

Background: The first phase, just finished, was very instructive and provides the basis for further application and study. However, several external circumstances affected the outcomes of this pilot project:

First, the plan was to return to Pakistan in March 1991 to be able to take advantage of the rainy season for planting the experimental trials, which would have been the appropriate season. Since the Gulf War had affected the general feelings in Pakistan as elsewhere against Americans, the O/AID REP in Islamabad advised that the trip should be postponed, and USAID gave Enable International and Winrock International an extension until August, 1991.

Second, Dr. Gene Shultz sent Cucurbita foetidissima seeds by DHL for planting, but 
in customs they were attacked by mice and almost totally eaten. Dr. Aslamy then sent $2 \mathrm{~kg}$ of seed from Arizona, while on home leave, but this shipment never arrived. Therefore, the out-of-season experimental planting in late October (just to see what would happen) and the Project Serve trial in clay soil became the only field trials, until the second planting in August of this year which is still underway in several sites, along with the experiments in Balochistan by Drs. Kayani and Kahn (see above). These are being irrigated or hand watered until germinated and established, since the main monsoon season is March/April in this region, with only a short, sporadic monsoon in August in the Peshawar region and in late November in Quetta. Dr. Beg and Dr. Aslamy are monitoring the Peshawar area trials and Dr. Kayani the Quetta planting sites.

Meanwhile the ADT agricultural officers who have been trained in Pakistan have taken seeds back to Afghanistan for the late winter monsoon planting season, so the results will be known next year, as will the results of further experimental plantings in the Peshawar and Quetta regions.

Facturs: The case cañ be miade for a second phase project based on the following summarized factors:

1. ADT extension officers have now received fresh seeds from us which they have taken to plant inside Afghanistan for the next growing season. Results are pending.

2. As a result of several training sessions on rootfuel potentials, the Afghan extension officers demonstrated high interest in this alternative fuel, given the critical shortage of fuel throughout Afghanistan. Their interest and involvement will help in disseminating the information as they return to their regions.

3. The August 1991 plantings of cucurbits in Azakhel, Pakistan, reveal that moisture is required for germination and establishment of the plants. Last year's germination failure is due to the lack of water, frost, and insect attack. When seeds were planted this August in ridges and mounds, watered, and subsequently received monsoon rainfall, germination occurred after 8 days and the seedlings will fully spread after 15 days. More seeds have been planted that were treated with insecticide to guard against potential ant damage.

4. The handbook prepared on species identification and on cucurbit cultivation, harvesting, and preparation as rootfuel is now translated into Dari (Farsi) and soon will be distributed to the extension officers. This will further increase the information on rootfuel, provide the technology needed at grass-roots level, and facilitate an ever-widening response.

5. A critical mass of information has been accumulated through the experimental tests, but more applied field study is needed on a region-specific basis. Further tests need to be conducted on other plants that have been identified with potential. Agronomic tests need to be conducted to determine productivity under cultivation, soil and water requirements, and potential problems as a cultivated crop, e.g., insects or other pests. The roots must be tested for heating value, rate of heat release, and specific fuel requirement (fuel weight needed per unit weight of food cooked), as well as cultural factors, for example, the time needed by Afghan cooks to complete a meal, their perceptions of the smoke (amount, odor), their evaluation of ease of initial ignitability, their judgment of the quality of the cooked food, etc. Because a number of promising native cucurbits have been found by Dr. $B: g$, all of these tests must be conducted for each species, to identify the best prospects for adoption. 
6. The real value of the work done and money expended thus far, will come in the follow-on. Without it the benefits will not be realized.

Follow-on Plan: Follow-on extension activities to expand the rootfuel concept and train people to seek species and grow them for fuel should include: training workshops for other agricultural agents and local leaders in villages where conditions favor the cultivation of rootfuel, the use of the handbook more extensively in these workshops, and the selection of some demonstration plots inside Afghanistan.

This follow-on program would begin January, 1992, so as to not lose another planting season. The first phase would include an evaluation of the planting experiments both in Pakistan (Peshawar and Quetta) and in Afghanistan. In December the agricultural officers will return to ADT from Afghanistan. They will bring any news of planting results thus far. On this occasion, they could be trained further, including the use of the final version of the videotape. Any modifications they may have to the Farsi handbook would be made.

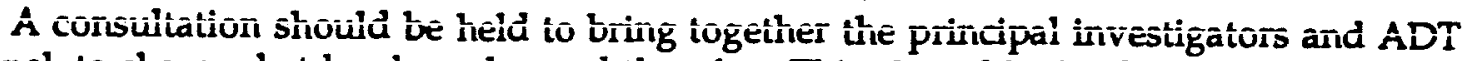
personnel, to share what has been learned thus far. This should be held in Quetta, since ADT will be moving its operation there, and since some of the research is being conducted there. All project principals should attend this meeting, which probably would be best held in August, 1992, to give ample time to evaluate the experimental tests and plantings in Afghanistan.

\section{APPENDICES}

A. Rootfuel: An Alternative to Scarce Woodfuel in Aridlands of the World

B. Experimental test layout

C. Cultural acceptability cooking tests

D. Map of potential regions for growing rootfuel in Afghanistan

E. Handbook on Rootfuel in Farsi

F. Rootfuel Handbook - English Draft

Respectfully submitted,

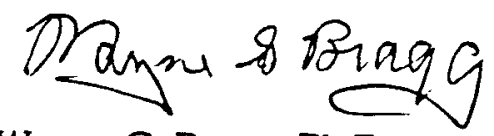

Wayne G. Bragg, Ph.D.,

President, Enable International

Assisted by Eugene B. Shultz, Jr., Ph.D. 


\title{
ROOTFUEL: AN ALTERNATIVE TO SCARCE WOODFUEL FOR RAPID DEPLOYMENT IN ARIDLANDS OF THE WORLD
}

\author{
Eugene B. Shultz, Jr., and Wayne G. Bragg \\ Bioresources Development Group \\ Department of Engineering and Policy \\ Campus Box 1106 \\ Washington University \\ St. Louis, MO 63130 USA
}

\begin{abstract}
A major world problem is the shortage of cooking fuelwood. More than half the world's women still use wood or some substitute for cooking. Firewood consumption far exceeds replacement rates. Deforestation and desertification are accelerating world-wide, affecting hundreds of millions of vulnerable people. The need is for an alternative cooking fuel that is cheap, accessible, quick-growing and similar to wood in performance. We propose "rootfuel" from aridland plants of the Cucurbitaceae (gourd) family that produce large, profligate, starchy roots rapidly with little water. This has been tested with good success in several countries for technological feasibility and cultural acceptability as cooking fuel in traditional three-stone fireplaces and in improved stoves. Rootfuel affords one immediate, ecologically sound alternative approach to the fuelwood crisis and related problems.
\end{abstract}

\section{THE PROBLEM OF FUELWOOD SCARCITY}

The world fuelwood crisis is serious and growing but only two solutions (reforestation and high-efficiency cookstoves) receive much attention. Neither has been a successful strategy. Trees are hard to establish in aridlands and reforestation is generally expensive, so planting lags far behind consumption in the major dry regions of the economically poorer world. Efficient cookstoves cost more than most people can afford and adoption rates are low. The greatest single demand for wood in aridlands is for fuel for the traditional three-stone fireplaces still predominantly used for cooking in poorer regions. Firewood supplies about 90 percent of fuel needs in these regions, and its consumption is about eight times greater than replacement rates [1]. People do not cut trees out of malice, but out of necessity for cooking. They lack money to buy the petroleum-based fuels and stoves available in the cities. In Africa, by the year 2000 nearly 100 million people will experience a severe shortage of fuelwood and 450 million will experience a firewood deficit; it takes 20,000 hectares of forest to supply Niamey its annual cooking fuel needs [2].

The heavy use of firewood by rural populations, while not the only factor, is one of the major causes of adverse ecological changes in semi-arid regions, with resulting social disruptions and migration, and the degradation of life-sustaining conditions. The destruction of dryland tree-cover is particularly critical since deforestation leads to less rainfall. Desertification is accelerating world-wide. The United Nations Environmental Programme estimates that it affects some 150 million people (up from 50 million just ten years ago) in an area of 35 million square kilometers, or 3.5 billion hectares, with each new year adding some 6 million hectares. Desertification in central Africa since 1980 has had a devastating effect: 35 million people in jeopardy of starvation, of which 1 million have died to this date (1987) [3]. 
Further, erosion accelerates as desertification increases. Sunkel reports that 72 percent of the soils of Mexico suffer high-level erosion [4]. Mexico has lost 50 percent of its forests in the last quarter century. This is typical of most Two-Thirds World countries. The soils have lost their ability to retain the few seasonal torrential rains and there is insufficient vegetation to soften the impact.

In dry deforested regions, the life situation of the dwellers becomes increasingly difficult, and much of the stress is placed upon the women. Women must now walk hours to cut wood, often bringing it home on their own backs. They supplement when they can with such materials as cornstalks and other crop residues, and animal-dung cakes. This extra burden on women is physically demanding, and carries with it a high opportunity cost - time from family responsibilities and opportunities to generate income. Thus, family and village life is adversely affected.

Biomass yields of native dryland trees are low. These trees typically grow slowly and tend to be thin, thomy, crooked and tough, requiring good tools to harvest. Since new forests cannot be established easily in drylands, fuel substitutes that are low-cost, accessible, easily-managed, and ecologically-sound are needed. An alternative fuel must require the use of only rudimentary tools, must grow readily in marginai soils and on siopes, witnout competing with cropland or for limited irrigation water.

\section{THE POTENTIAL OF THE ROOTFUEL APPROACH}

The solution to the fuelwood scarcity problem is not necessarily to grow more wood nor to burn it more efficiently. There are alternative bioresources that produce more biomass than trees. Certain members of the ubiquitous Cucurbitaceae meet the technical requirements for a satisfactory woodfuel replacement, and constitute an important partial solution to the many problems discussed above. Of special interest is Cucurbita foetidissima HBK, a feral gourd plant that is indigenous to the drylands of northern and central Mexico, and southwestern United States. Closely related plants of the same large world-wide family are also of interest for their biomass potential.

C. foetidissima is a fast-growing wild plant that produces an abundance of roots, even without irrigation, and it grows in all types of known aridland soils. DeVeaux and Shultz analyzed the Cucurbita foetidissima literature to mid-1984, referred to as "buffalo gourd," the common name used in the United States and in the English-language literature [5]. The review includes agronomy, genetics, ethnobotany, and uses other than for rootfuel (e.g., edible seedoil, fuel ethanol from the root starch). The use as direct rootfuel is a novel application, discovered by one of the authors (EBS) while working on ethanol uses.

The carrot-shaped taproots can be cut with a knife when fresh. The root pieces can then be sun-dried and used as "rootfuel" in traditional ways [6] [7]. The heating value of rootfuel is essentially the same as that of wood, but the combustion properties are different, falling between those of wood and charcoal [8]. Bragg, Duke and Shultz reported heating values (dry basis) from 7440 to $8000 \mathrm{Btu} / \mathrm{lb}$ for $\mathrm{C}$. foetidissima roots. In their tests, woodfuel burned about 2.6 times faster than rootfuel, and rootfuel burned about 3.7 times faster than charcoal. Because of the difference in heating values of rootfuel and charcoal, rootfuel was found to release energy about 1.6 times faster than charcoal. Further, in their water boiling tests the efficiency of capture of heat from a rootfuel fire was about 1.25 times greater than the efficiency of capture of heat from a charcoal fire. The ignitability of rootfuel was judged to be similar to that of charcoal. It should be understood that such quantitative comparisons are likely to vary with type of wood and charcoal, size of fuel pieces, density of packing the pieces, and many other variables such as air humidity. It produces coals that release heat slowly, and less rootfuel is needed than wood for comparable heating; Malkani found that it takes one-third less $\underline{C}$. foetidissima biomass to cook the same foods as typical woods [9].

Technological and cultural acceptability tests of this innovation have been carried out in rural Mexico, Senegal, and Niger with encouraging results. We found that these superior 
combustion characteristics were readily noted and appreciated. In Mexico, the tests of calabacilla loca (one of its indigenous names) as a rootfuel, were carried out with the assistance of a Mazahua woman, Claudia González de Moreno, who cooked a typical meal, substituting only the fuel [8]. The rootfuel was readily accepted for use in her three-stone fireplace, because it looked and felt like wood, only a bit denser and whiter. It took longer to ignite. She commented on the process as we watched and timed her cooking. She quickly discovered some differences such as the height of the flames, promptly adjusting the three stones to lower the pot. Claudia stated that the rootfuel was superior to wood, cornstalks, maguey cactus leaves, or animal-dung cakes, all of which burn rapidly and produce few coals. The rootfuel burned more slowly than these fuels, creating coals. Relatively slow-buming fuel is desirable for cooking foods that need long simmering, like the traditional rice and beans.

Claudia volunteered that there was no objectionable odor from the rootfuel, that there was less smoke than from her usual fuels, that the rootfuel smoke was less irritating, and that no objectionable flavor was imparted to the rice, tortillas and eggs that she cooked. We, along with her family, ate the food with gusto, and all indicated that it was excellent. Hugo, her four-year-old, probably too young to be anything but frank in his opinions, ate all

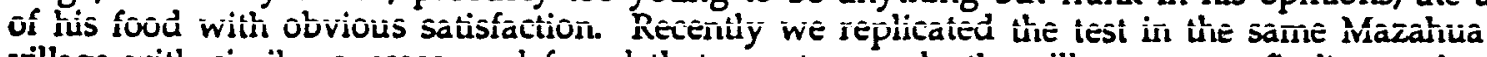
village with similar success, and found that spontaneously the villagers were finding and planting a local variety, san'coche, for fuel.

Similar cultural acceptability tests were carried out in Senegal and Niger by 15 women with Debra Duke, using both local roots from wild watermelon and $C$. foetidissima roots [10]. Duke found similar acceptance and performance of the rootfuel concept among all her rural participants.

\section{BIOMASS PRODUCTION}

C. foetidissima is adapted to the ecosystem, producing almost twice as much biomass in a summer as mesquite does annually, on the same area of land. McKell et al. (unpub.), cited in Cushman and Ranney [11], reported an unirrigated dry biomass yield of 6 tonnes of mesquite per hectare, annually, in New Mexico, under management. This is to be compared with Nelson who obtained up to 11 tonnes of dry C. foetidissima roots per hectare in one summer's growing season in Arizona, under management [12]. Few people are aware that it is possible to out-produce wood with an annual plant in drylands, as shown by this evidence. $C$. foetidissima is a perennial but intensive cultivation can be done from seeds.

More agronomic studies need to be done on cultivated plantations of $C$. foetidissima to see the potentials for increased pests and diseases. The literature is inconsistent on the resistance of $\underline{C}$. foetidissima to pests and pathogens, discussed in DeVeaux and Shultz [5]. Resistance to many species of insects appears to have been established, but certain viruses, root-rot fungus, and root-knot nematodes can cause problems. Difficulties can be minimized by planting in well-drained soils and avoiding riverine or wetland locations, as well as avoiding extensive or repeated monocropping. Clearly, this is an area that requires more research. Care should be taken to preserve primitive germ-plasm and propagate native varieties. Other Cucurbitaceae species that produce large, abundant roots need to be identified.

\section{CONCLUSIONS}

In summary, utilization of $\underline{C}$. foetidissima, and its relatives, promises a low cost, accessible, easily managed, and culturally acceptable woodfuel substitute with equal or better characteristics than current fuels. It needs no exogenous cultivation techniques, tools, fertilizers, or irrigation. It is simple and inexpensive to plant a crop in marginal soil along terraces or eroded hillsides, without displacing any food or money crops. Its use as a fuel would relieve pressure on the remaining aridland tree cover, deter desertification, and help 
avoid erosion. Rootfuel would release agricultural residues and animal dung for more useful service as fertilizers and soil conditioners. It would lessen the burden of women who gather wood at great physical and social cost. Rootfuel is indeed a viable approach to the fuelwood crisis and, alone or combined with other approaches such as more efficient cookstoves and reforestation, it holds an immediate solution for cooking fuel.

\section{REFERENCES}

1. Blackburn, Peter., Growing sahara imperils nomads. Chicago Tribune June, 1987, Sec. 8, p. 17.

2. Duke, Debra L., Non-woody fuel as an alternative to woodfuels in aridlands: Field experience in west Africa. M.Sc. thesis, Dept. of Engineering and Policy, Washington University, St. Louis, MO, 1988.

3. Coates, James, Environmentalists want Third World to turn over a new leaf. Chicago Tribune. May 31, 1987, Sec. 1, p. 6.

4. Sunkel, Osvaldo, Development styles and the environment: An interpretation of the Latin American case. In From Dependency to Development: Strategies to Overcome Underdevelopment and Inequality ed. Heraldo Munoz, Westview Press, Boulder, 1981.

5. DeVeaux, Jennie S., and Eugene B. Shultz, Jr., Development of buffalo gourd (Cucurbita foetidissima) as a semiaridland starch and oil crop. Econ. Botany 39 $1985,4,454-472$.

6. Shultz, Eugene B., Jr., and Ianto Evans, Dried roots as cookstove fuel: An innovation for drylands where trees grow with difficulty. Proc. 12th Annual.Third World Conf., Third World Conference Foundation, P.O. Box 53110, Chicago, IL 60653, 1986.

7. Bragg, Wayne G., and Eugene B. Shultz, Jr., A potential solution to the fuelwood crisis in Third World drylands: annual roots instead of wood as cooking fuel. Forum of the Assoc. of Arid Lands Studies Vol. 3, ICASLS, Texas Tech Univ., Lubbock, TX, 1987.

8. Bragg, Wayne G., Debra L. Duke, and Eugene B. Shultz, Jr., Rootfuel: annual roots as cookstove fuel in the arid Third World. Presented, 28th Annual Meeting, Society for Economic Botany, Chicago, IL, USA, June 22-25, 1987.

9. Malkani, Bharat H., Rootfuel as an alternative energy source in the Deccan plateau of India. Report of Master of Science Research, Dept. of Engineering and Policy, Washington University, St. Louis, MO, 1988.

10. Duke, Debra L., Wayne G. Bragg, and Eugene B. Shultz, Jr., Traditional uses and cultural acceptability of dried roots as altemative to woodfuel in drylands: Senegal, Niger, and Mexico. Presented at the 11th Annual Conference of the Society of Ethnobiology, Mexico City, March 9-13, 1988.

11. Cushman, J. H., and J. W. Ranney, Short rotation growth of hardwoods for energy applications across the United States: field results and economics. Proc. of IGT Symposium on Energy From Biomass and Wastes VI Institute of Gas Technology, Chicago, IL, Jan. 25-29, 1982.

12. Nelson, J.M., J.C. Scireerens, J.W. Berry, and W.P. Bemis. Effect of plant population and planting date on root and starch production of buffalo gourd grown as an annual. L. Amer. Soc. Hort. Sci. 108 1983, 2, 198-201. 
APPENDIX B

Rootfuel

Planting Diagram

$$
\text { A } A \text { AKHEL }
$$

4 mounds $/ m^{2}$

5 plants/mound

$B$

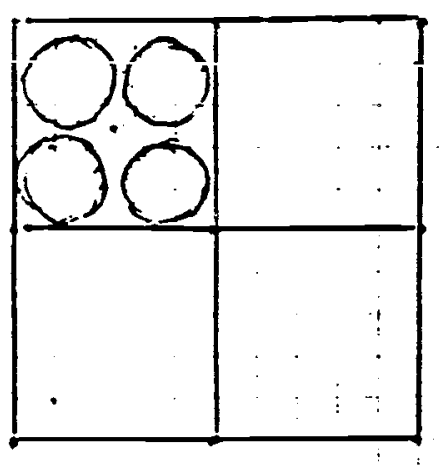

80 plants in $4 \mathrm{~m}^{2}$.

A
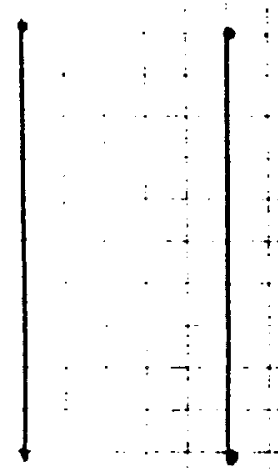

20 plants / Imear meter $5 \mathrm{~cm}$ apart 80 plants

$A=$ Citrullus colocynthis

$B=$ Cucurbita foetidissima 
COUNTRY: Afghanistan

(Conducted in Pakistan)

PROVINCE: Northwest Frontier

TOWN: Defence Colony, Peshawar

LINGOISTIC GROUP: Pukhtun

DATE: October 1, 1990

SEASON: Autumn, dry

COOK: Abdul Muqim

OBSERVERS: Mohammed Sof 1 and Soor Gul

4-AC Park Avenue Un1versity Town

Fesinawar, Fakistan

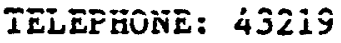

ROOT USED: Cucurb1ta foet1dissima

WEATHER: Dry and hot, no wind.

STOVE: S1x bricks open on one side, in open area of back yard. The smoke escaped freely.

FOOD: R1ce, o1l, salt, water.

DESCRIPTION:

We took dried roots which were placed in an open fireplace made of stacked bricks. The fuel was 750 grams. The pot was set on top. The flre started with pleces of wood and matches.

1:49 p.m. Abdul put 1.5 l1ters of water in an aluminum pot.

$2: 16 \mathrm{p} . \mathrm{m}$. the water bolled, and the cook put 500gm of rice in the pot of bolling water. He put salt and other necessary material with rice. The smoke was sweet.

2:44 p.m. The rice was cooked and the cook drained the water from the rice. After that he put $30 \mathrm{gm}$ of 011 in a separate small pot and put it on the stove and oll became hot. The cook pour the oll on the rice and then again put the pot of rice on the stove. The fire was very good. The smoke was more compared to the wood. If it was inside Afghanistan, the famlly can use 1t for cooking and $1 t^{\prime} s$ good thing. If the stove was made a little higher the fire will burn better.

Abdur said that if we cooked with local wood the same amount of rice will need about $3 \mathrm{~kg}$ of wood because the energy of th1s root 1s minre than wood.

$2: 50 \mathrm{p} . \mathrm{m}$. The coals were put on top of the pot at and after 10 minutes the cook takes out the fot from the stove and the food was ready at 3:00 p.m. 
COUNTRY: For Afghanistan

PROVINCE: Northwest Frontier conducted in Pakistan

TOWN: Peshawar

LINGUISTIC GROUP: Pukhtun

DATE: October 2, $1990 \quad$ SEASON: Dry, Early Fall

THE COOK: Parwin Popal

THE OBSERVER: Betsy Amin-Arsala

ADDRESS: Winrock International

1611 N. Kent Street

Arlington, VA 22209

TELEPHONE: (703) 525-9430

CUCURBIT USED: Cucurbita foetidissma from U.S.

WEATHER: Dry

STOVE: $\quad 4$ bricks, up against the wall

FOODS: Halwa, a boiled wheatena mixed and browned in oil. Sugar syrup flavored with cardamom is added. This is cooked on holidays and distributed among the poor and/or ones neighbors as a form of alms. Today is the birthday of The Prophet Mohammed as well as the day of his death.

SUPPLIES: Sujee (1 kilo), sugar (1 kilo), oil (1 kilo), cardamom.

\section{DESCRIPTION:}

3:15 p.m.

Parwin stacks two bricks on either side for the pot to rest upon. She starts the fire by crumbling a small piece of newspaper into a ball and lights it with one

$$
-1 / 3-
$$


match. She lays the pieces of rootfuel so that they come together at a point under the pot. She keep adding small pieces of newspaper in and around and under the root fuel. She adds more paper and a few pieces of wood-small leftover pieces. She asks me for some small pieces of broken rootfuel. She says again "This is very difficult to get started." The pot is empty waiting for the fire to get hot enough to sizzle the oil. She says this fuel is like "chob balut," some kind of wood used in Afghanistan that is also hard to start.

Parwin has now used 7-8 matches. She keeps adding paper and little match stick pieces of wood blowing and relighting. She thinks the smoke is bitter. It has made her eyes cry. She thinks the smoke is a lot but it does not give "lung tightness" like wood smoke. It has a slightly sweet personality. She is now fanning the fire.

3:30 p.m.

She adds the oil to the pot. She adds one more small lump of rootfuel. She keeps fanning. She says the wood is burning. Rootfuel now has coals. She has made the fire in the mouth of the stove and expects the flame to be sucked under the pot.

3:35 p.m.

Oil is still not sizzling. She thinks there is not enough rootfuel. She now tips, end to end, the burning pieces under the pot. The front end of the pot is completely black; oil is now "red" and hot. She adds the "Sujee" flour and sirs it into the oil.

She adds more fuel. The fire must be hotter to fry the flour. This dish in this size pot would normally take 2 kilos of wood. She claims we have not yet used 1 kilo of rootfuel.

\section{3:42 p.m.}

Parwin adds more oil. The sujee is bubbling. The smoke coming now is not mixed with the wood smoke. She says this smoke is much better than from the wood in Afghanistan. She says if this rootfuel makes good coals, it would be wonderful for use in the Sandali (a means for heating using coals covered with sand in a brazier under a table covered with cotton blankets.)

3:53 p.m.

Still stirring sujee. It is not brown enough yet. 
4:10 p.m.

Parwin is adding more rootfuel - 1 long and 1 short piece. The sujee is now taking color. She fans the fire to keep flames leaping.

[Observation: Afghan cooks in general seem to feel that flames should be high and leaping up the sides of the pot or that nothing will cook. Unfortunately, when one fans coals the net effect is to burn them up too quickly.]

4:20 p.m.

Now not enough coals to bake the sujee. Parwin adds a few sticks of wood. She relights with a match. She adds another piece of rootfuel.

4:25 p.m.

Parwin adds the sugar and stirs it all in.

4:35 p.m.

Lots of stirring. Now we add the powdered cardamom. The lid of the pot is added with a padded cloth between lid and pan. The "deg" will now sit on the fire and bake approximately 30 minutes.

5:15 p.m.

Fire is out. We will eat the Halwa. Guests have arrived who are served after the Halwa is blessed. All proclaim it very tasty. There are children present ages $11 / 2$ to 12 and 16 . There are guests in their 20's, 30's, 50's and 70's. All eat heartily. 

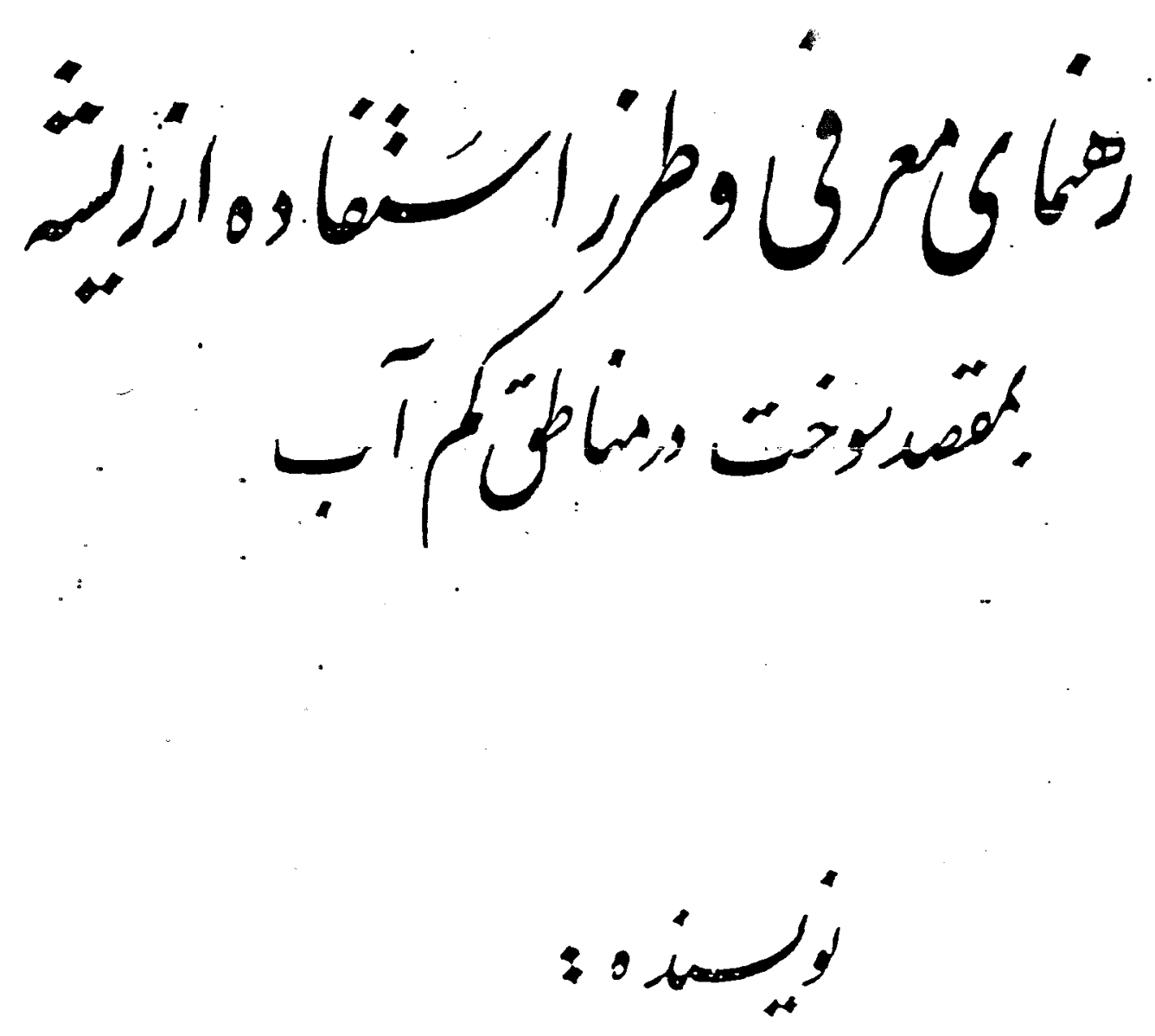

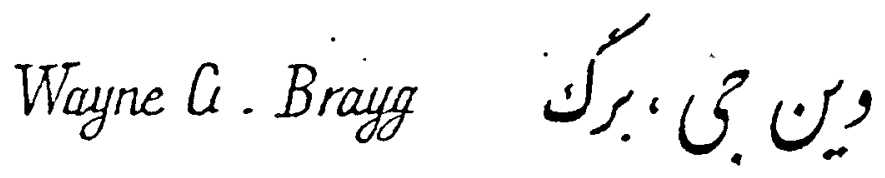

Eugene B. Shultz.Jr.

Dr.M. Nabiaslamy

Mhunmad Hamayour. OStrin

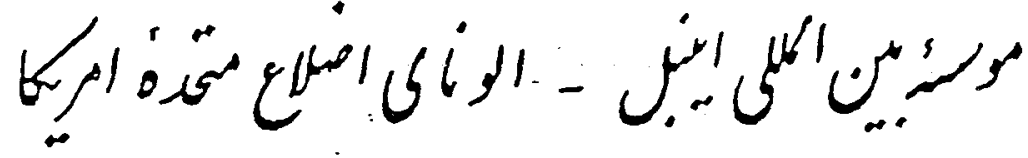

$$
\begin{aligned}
& \text { Enable Interntional } \\
& \text { G08 N President Street. } \\
& \text { Wheaton IL } 60187 \text { US A } \\
& \text { Aug.. } 1991 \\
& \text { آن }
\end{aligned}
$$




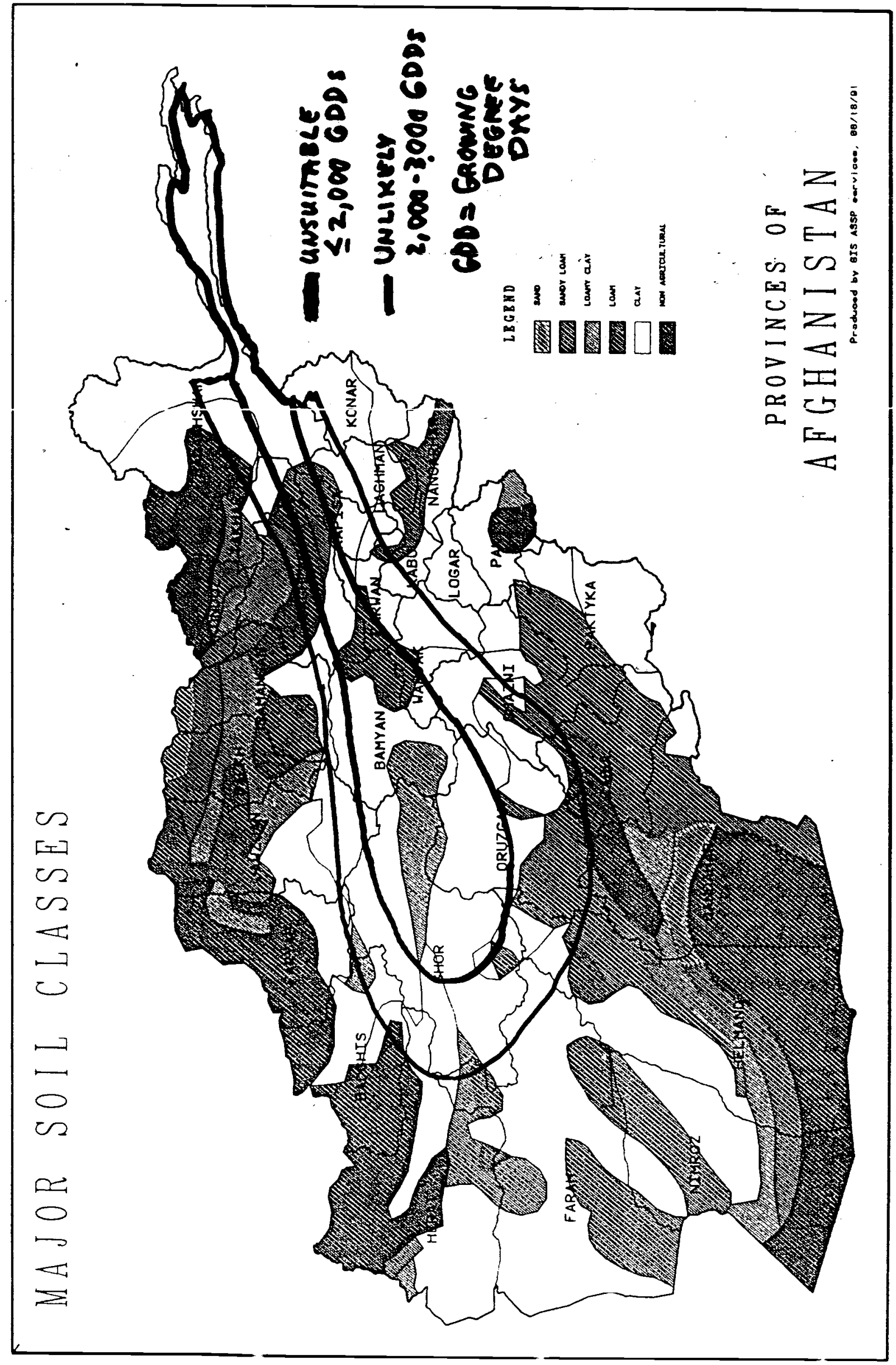



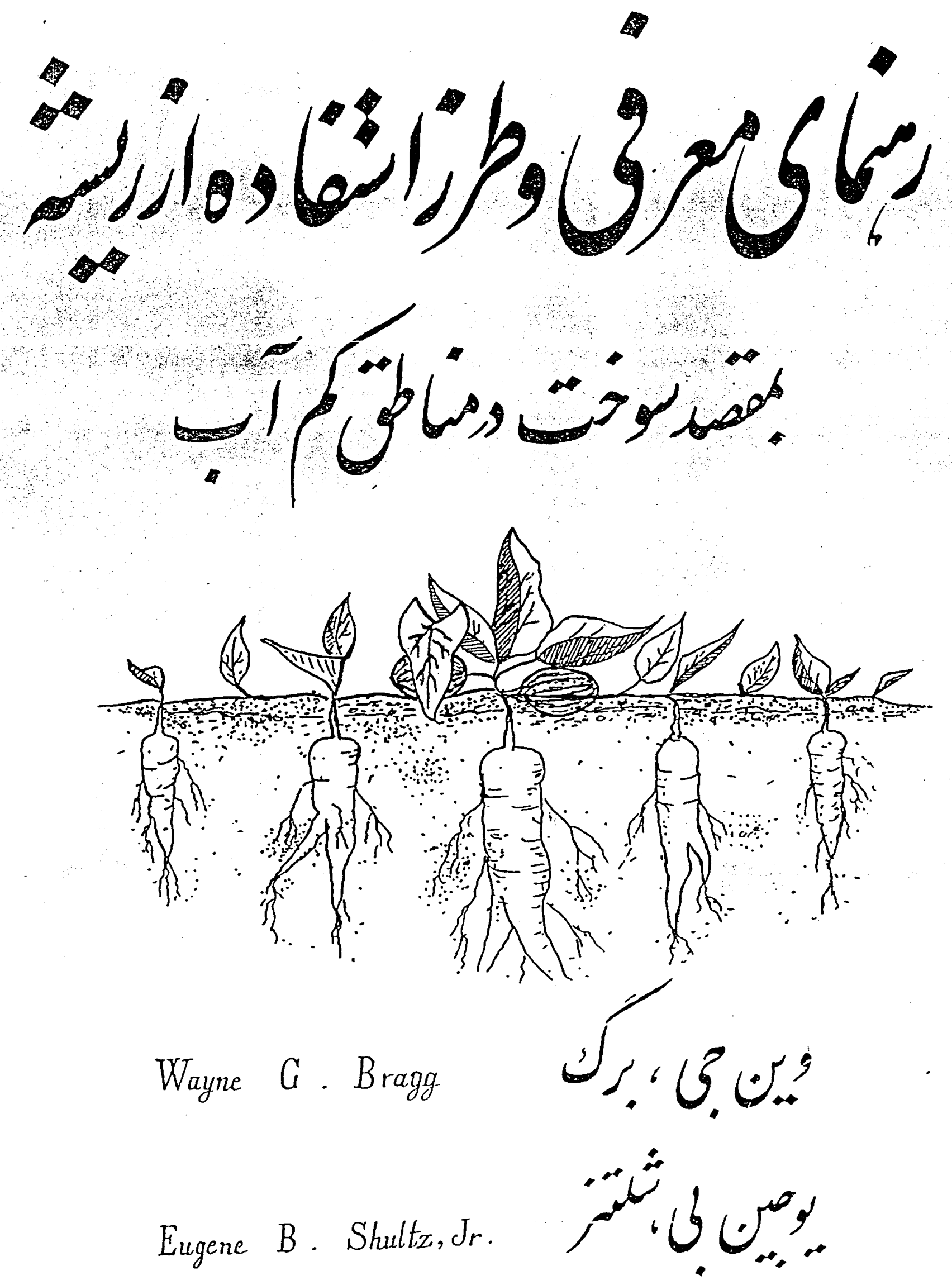


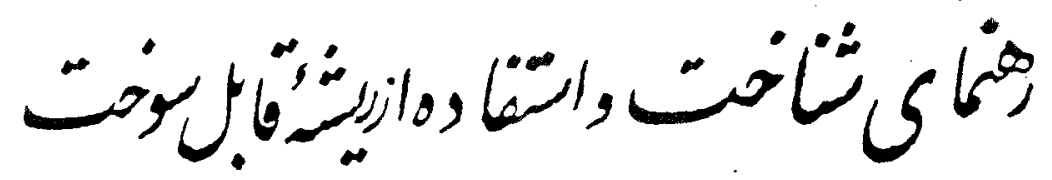

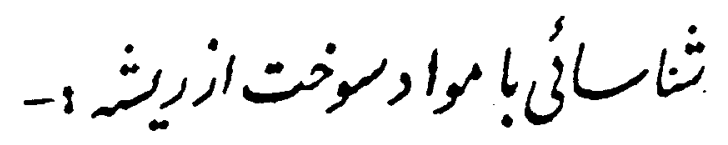

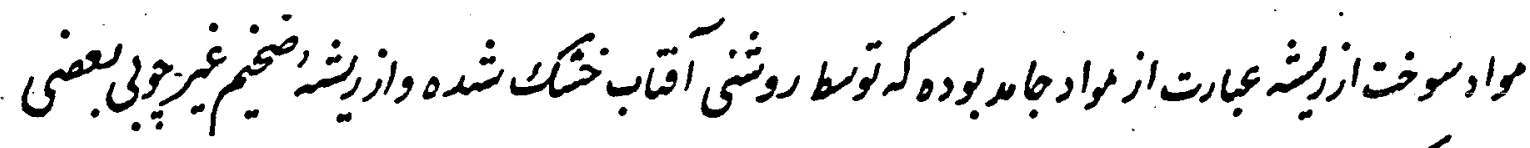

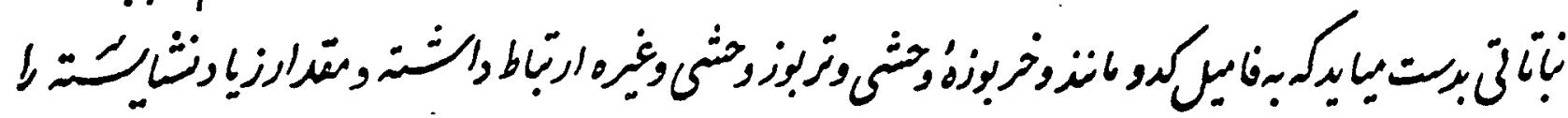

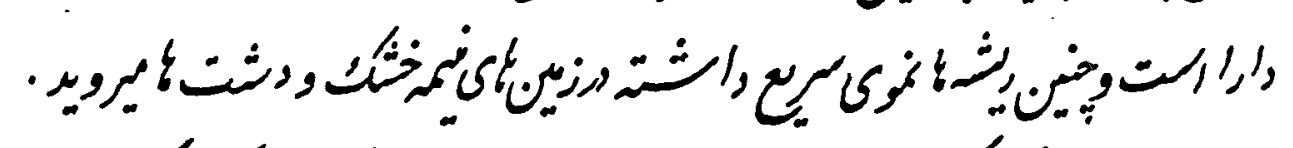

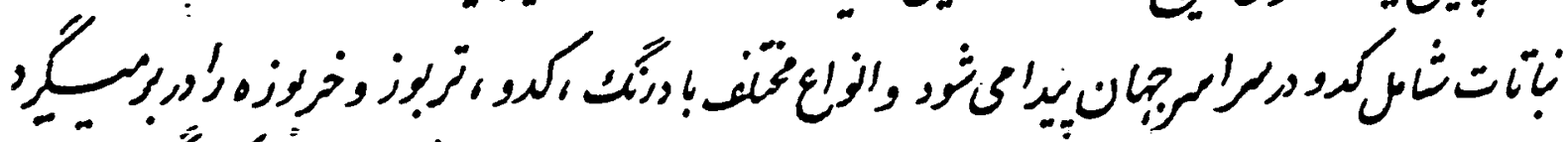

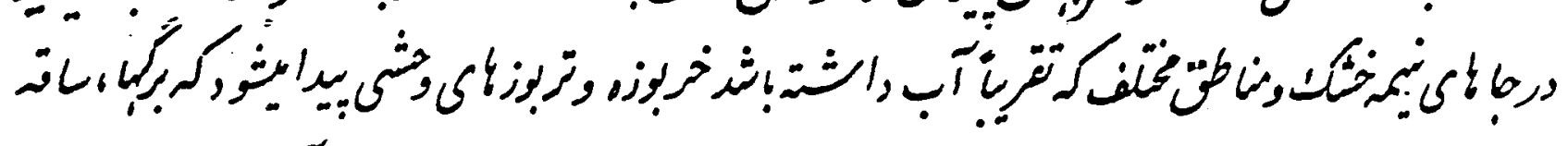

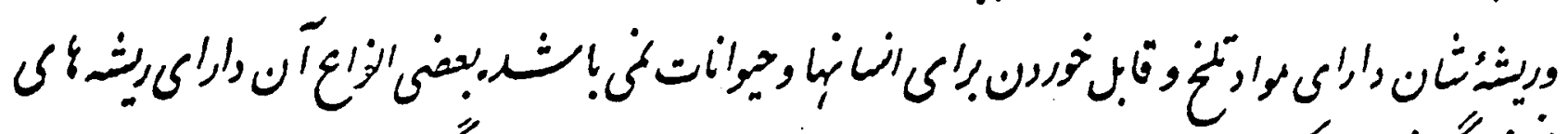

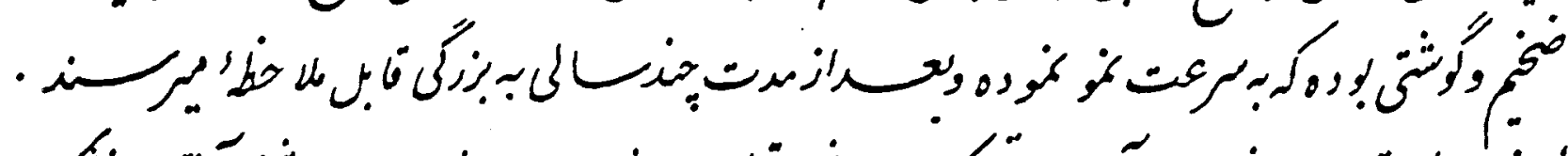

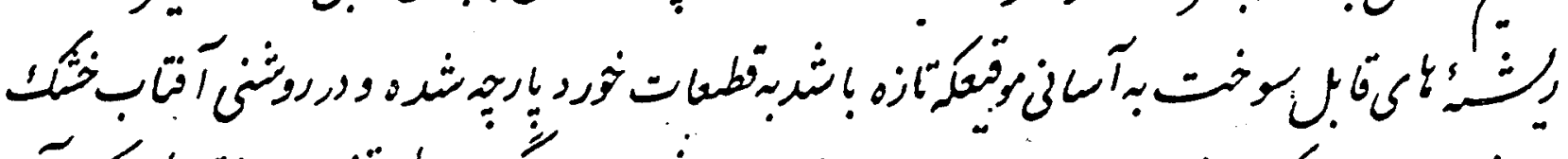

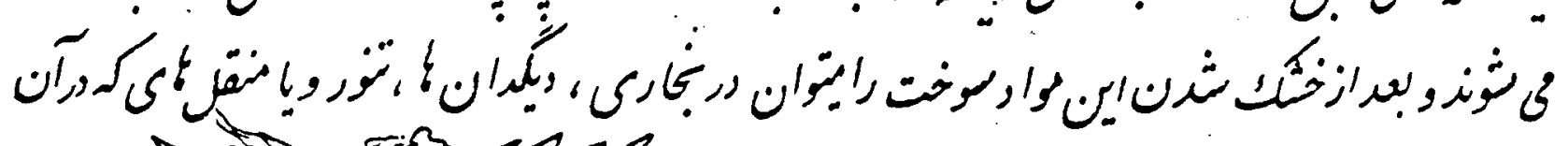

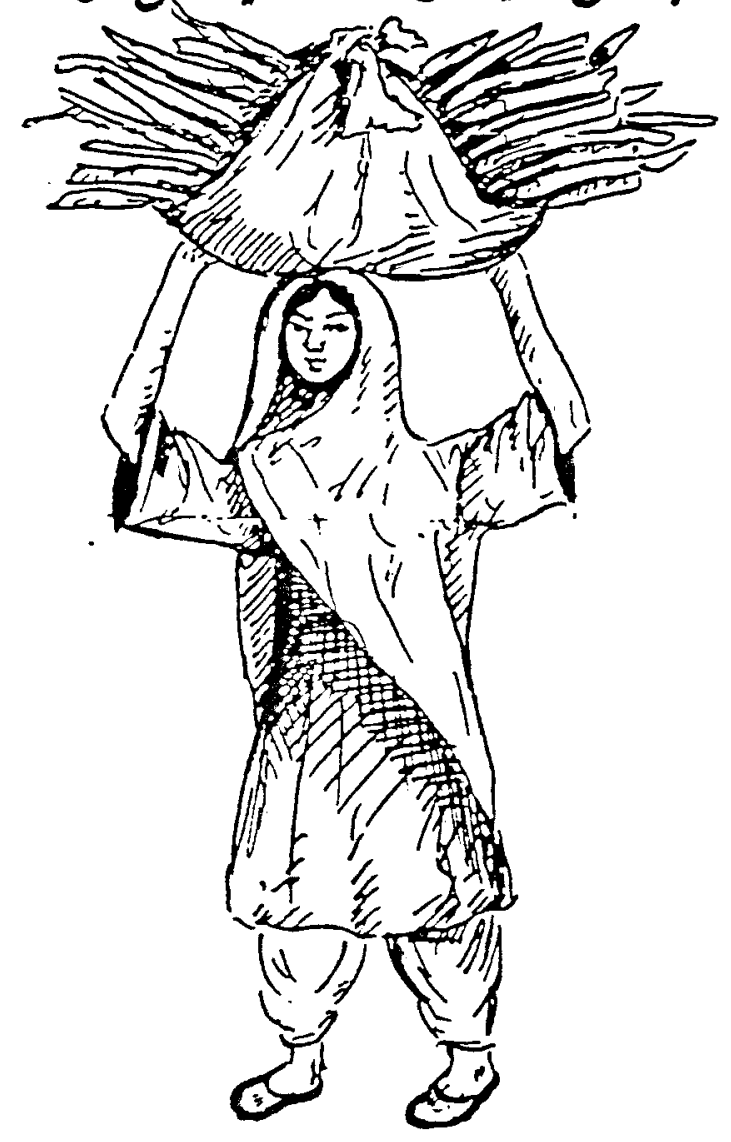

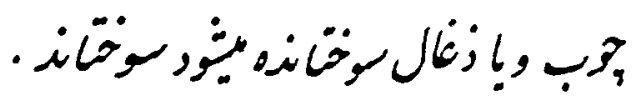

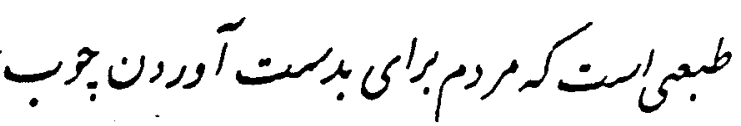

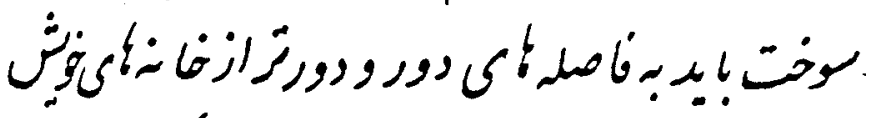

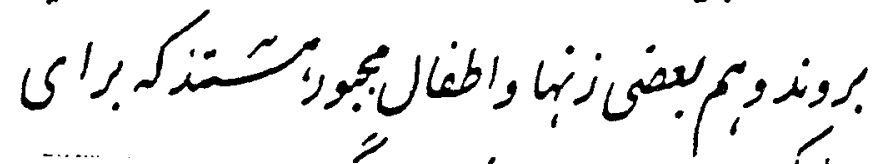

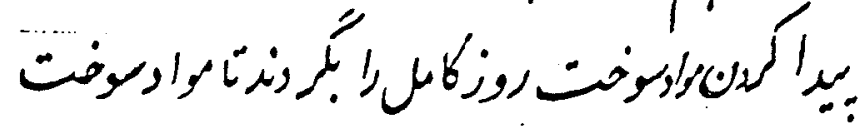

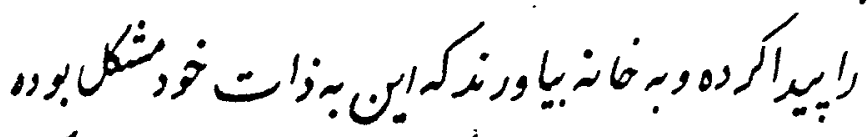

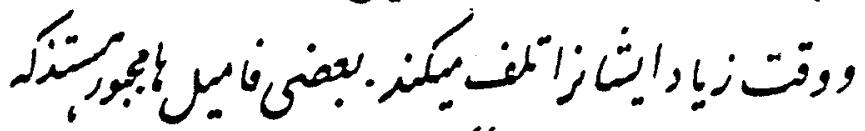

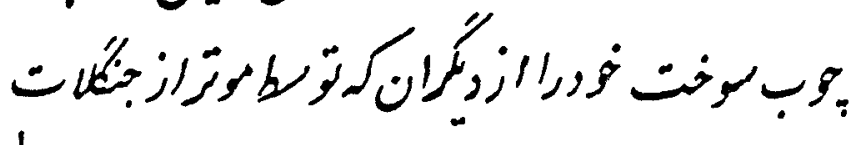

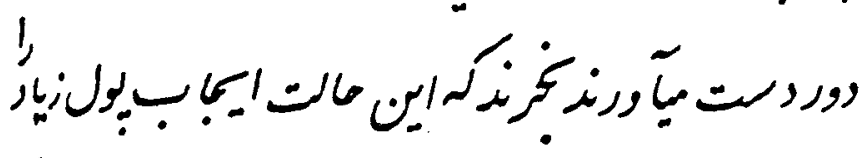




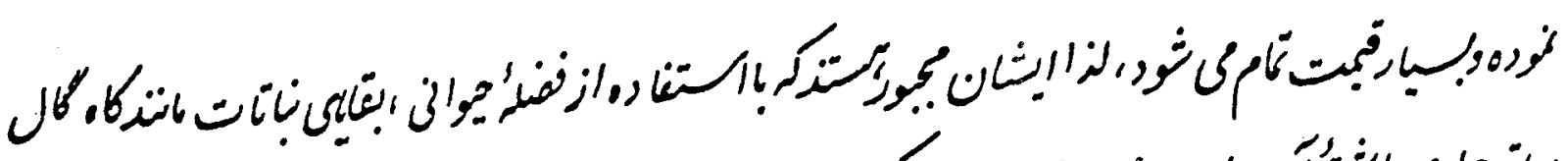

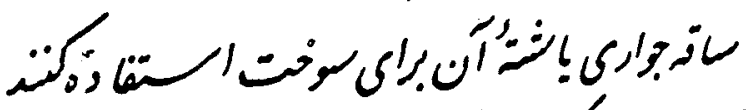

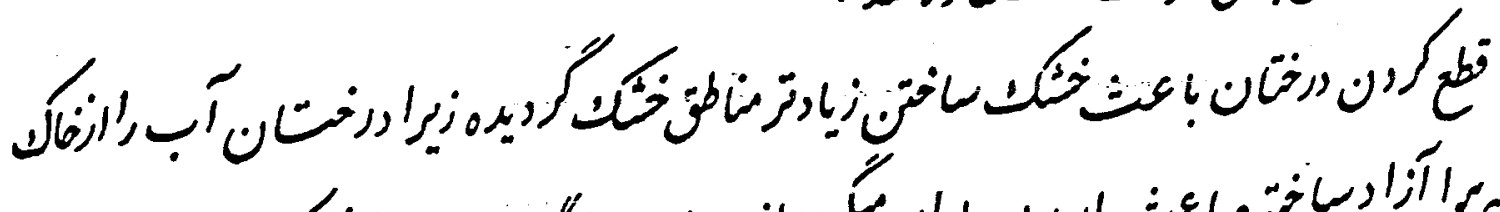

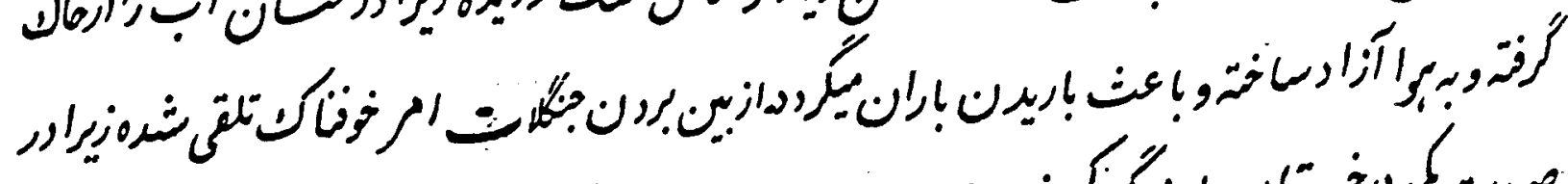

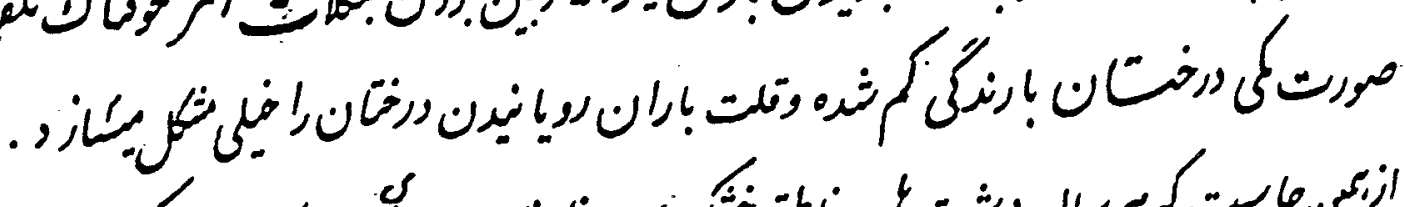

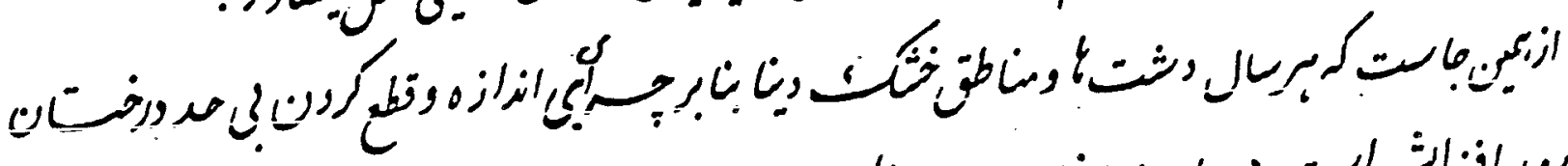

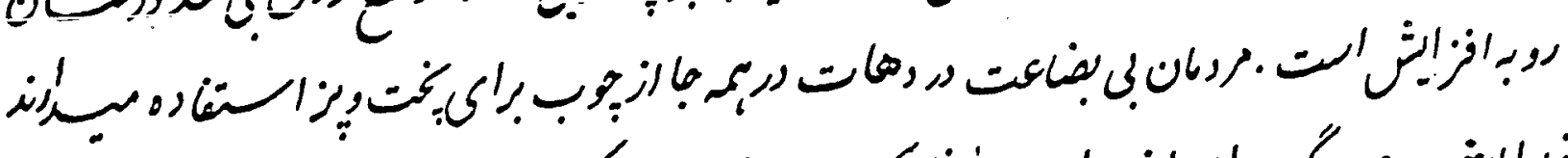

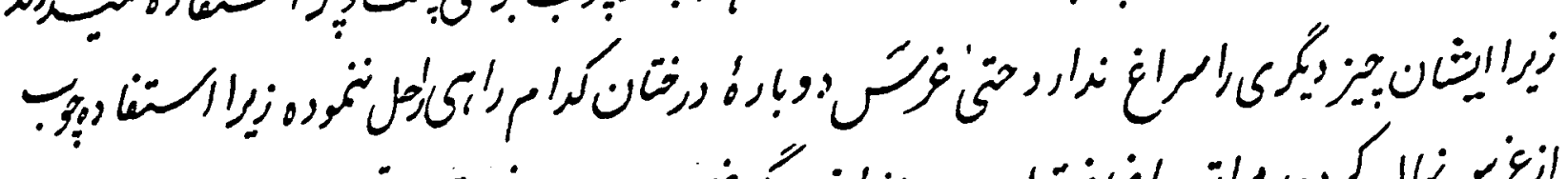

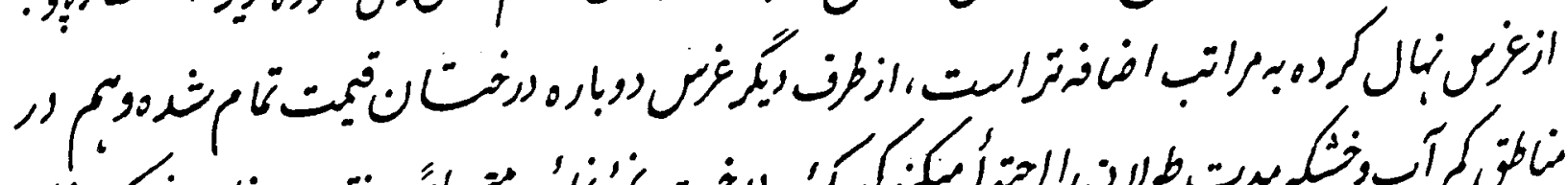

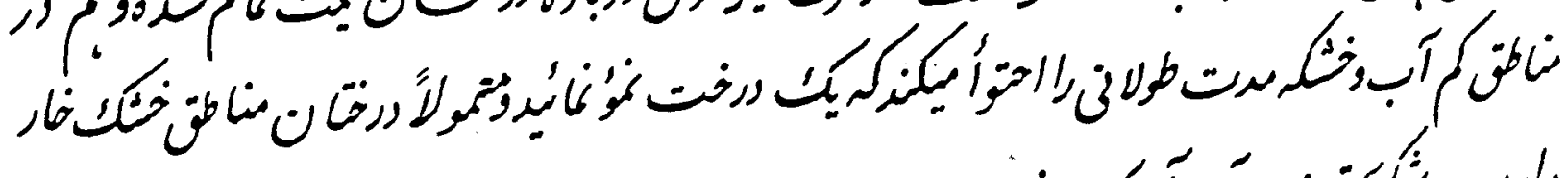

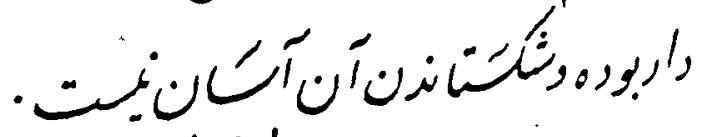

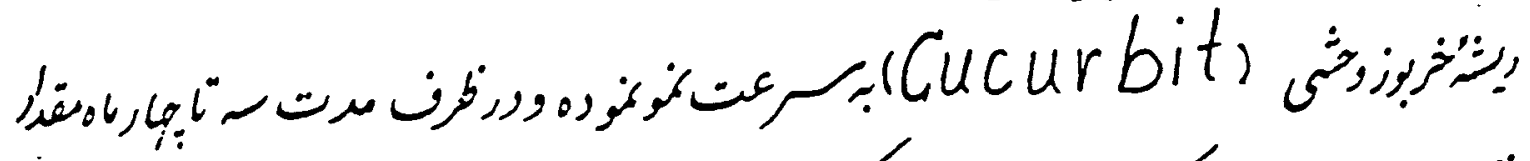

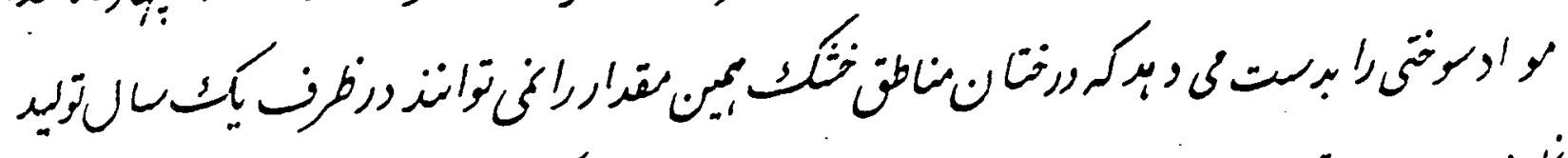

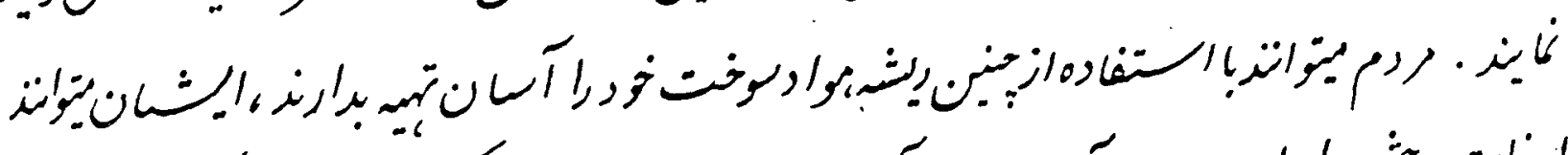

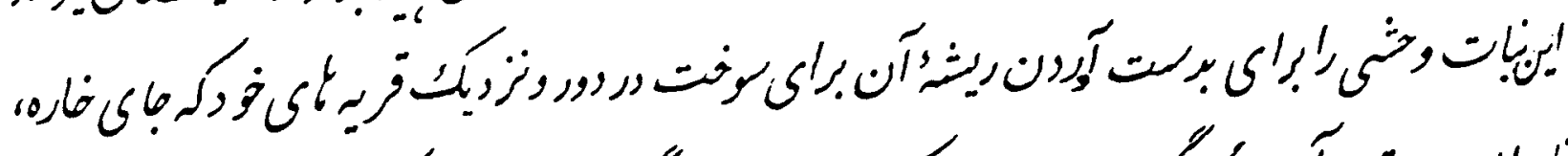

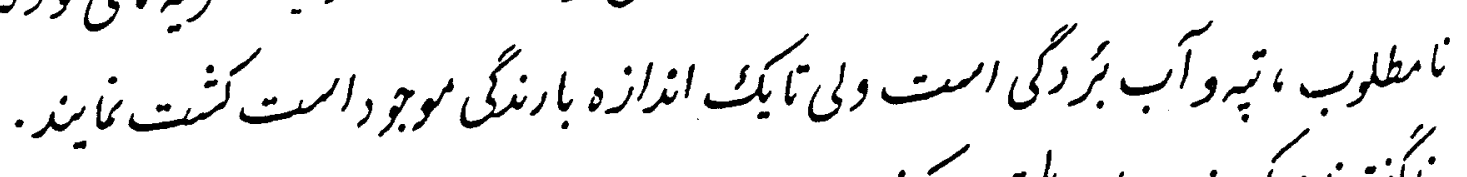

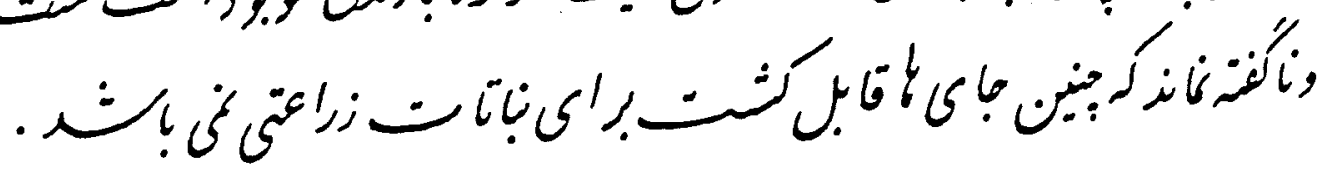

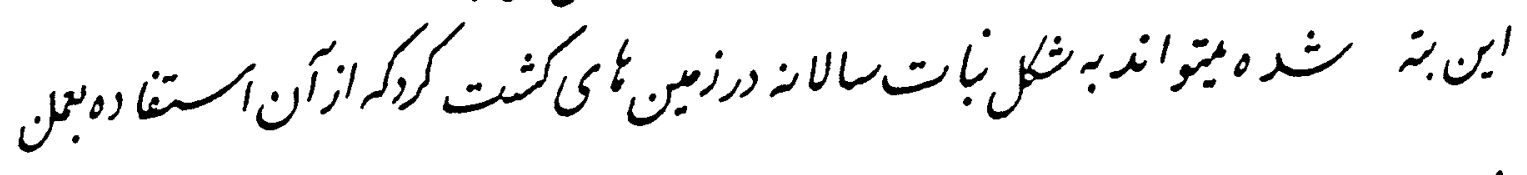




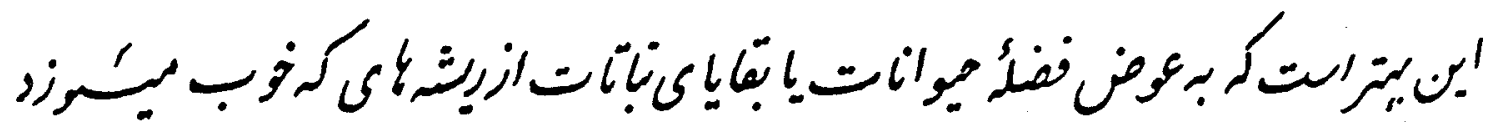

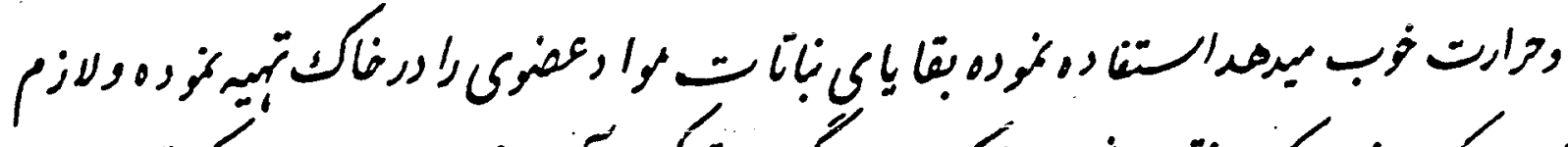

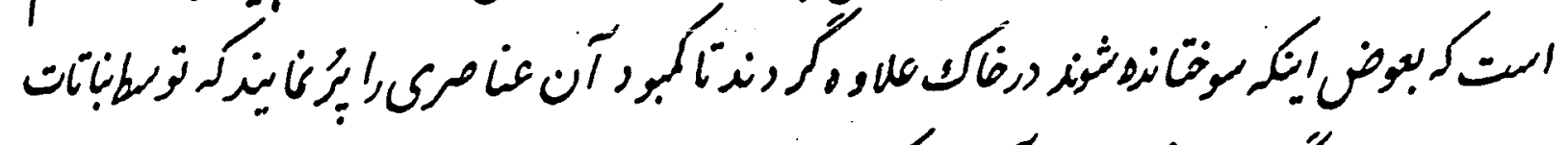

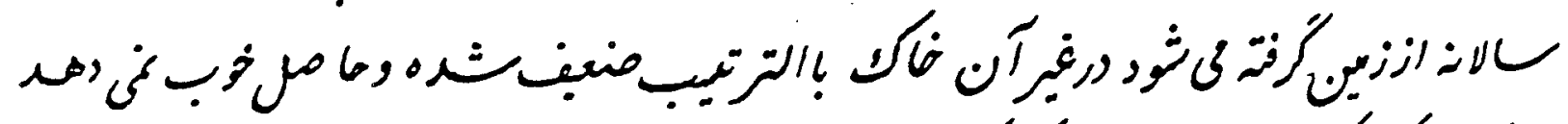

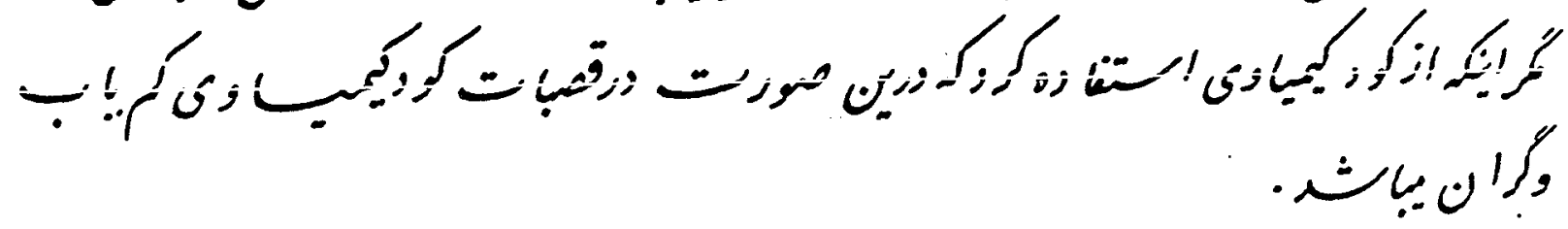

$$
\begin{aligned}
& \text { هار مرارونت أريثن } \\
& \text { موار مونحت ازريثـ راراى }
\end{aligned}
$$

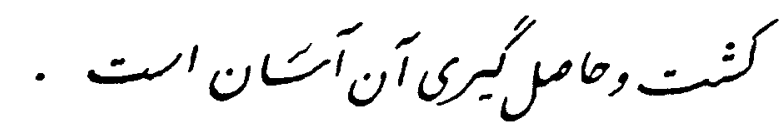

$$
\begin{aligned}
& \text {,وبر. }
\end{aligned}
$$

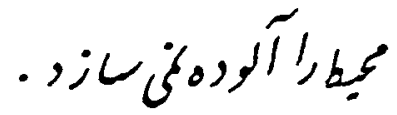

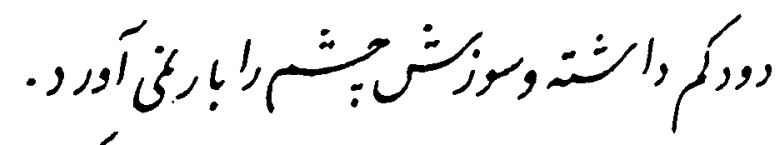

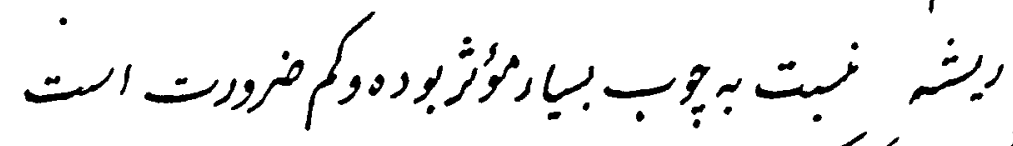

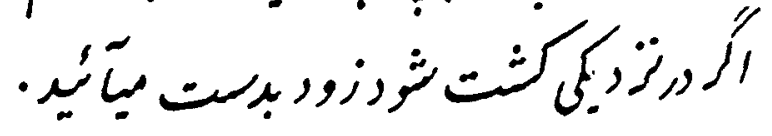




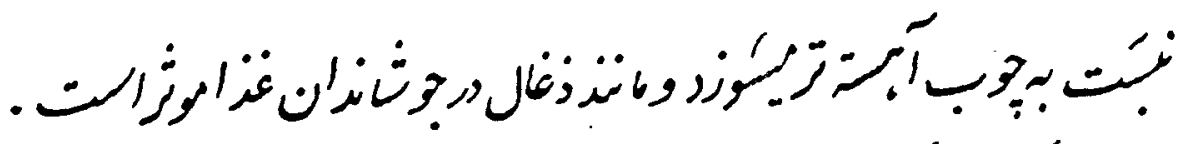

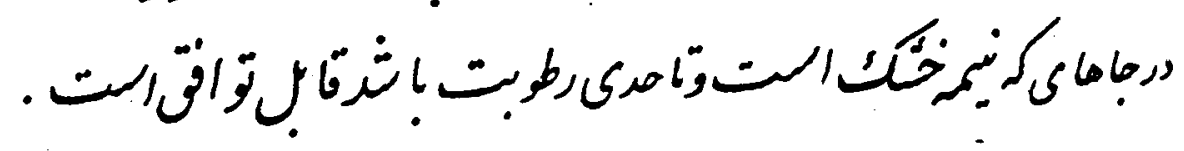

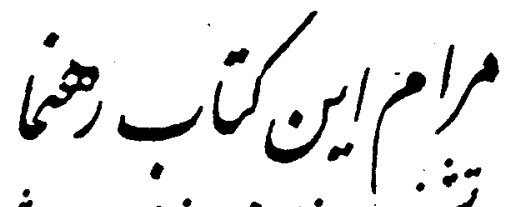

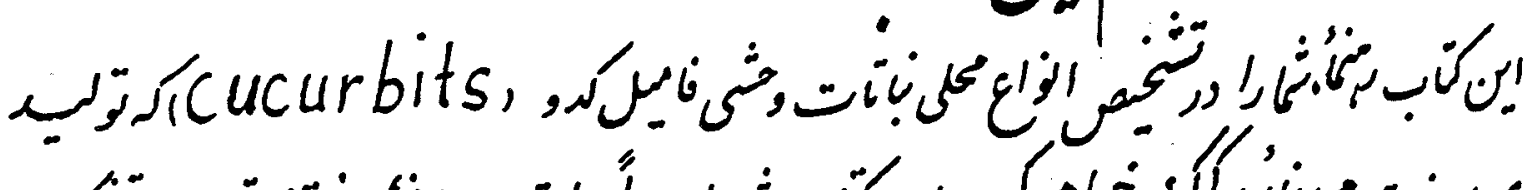

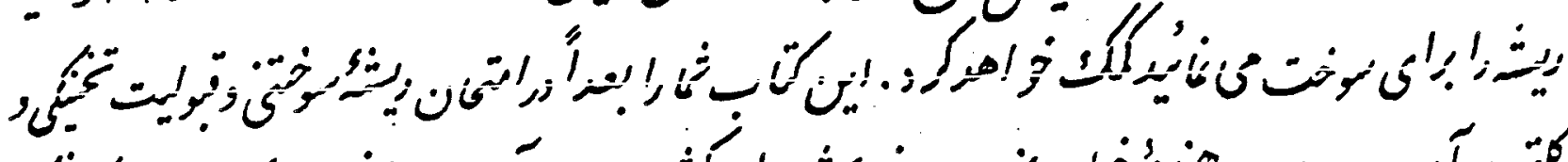

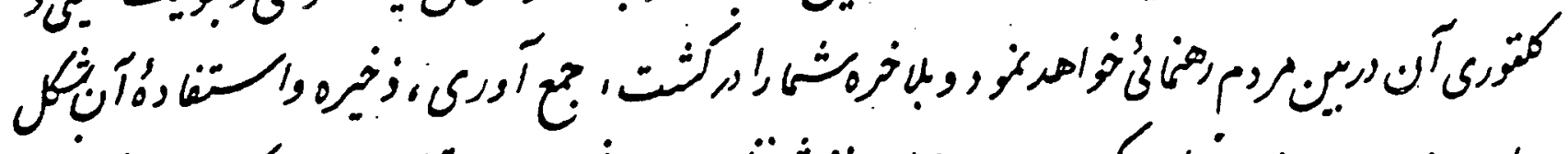

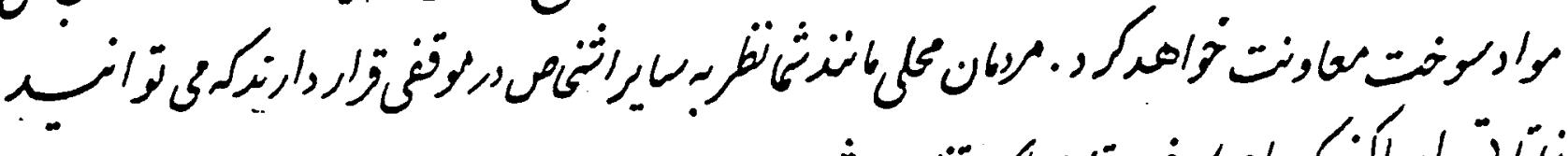

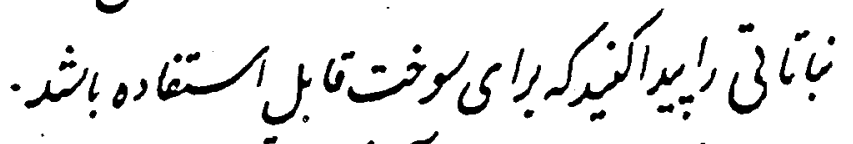

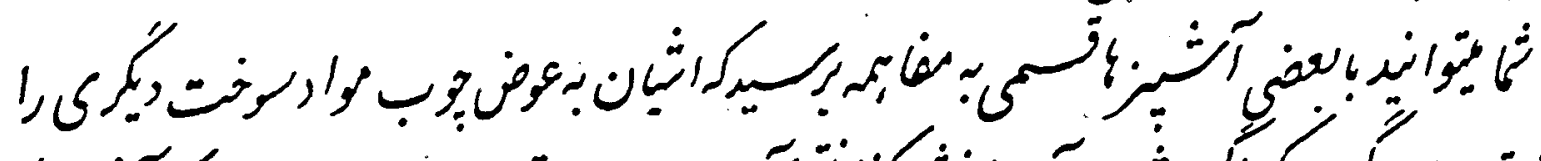

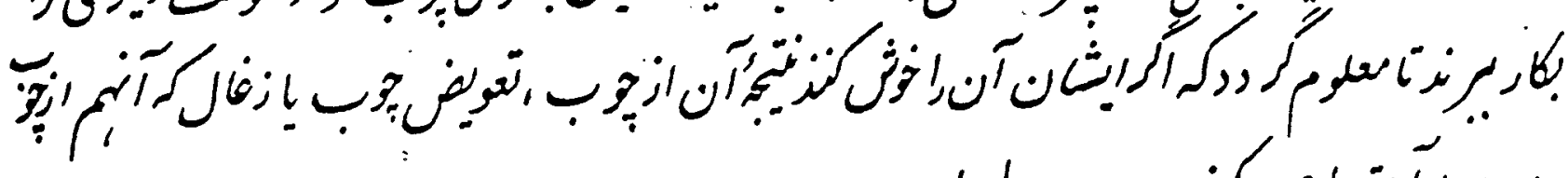

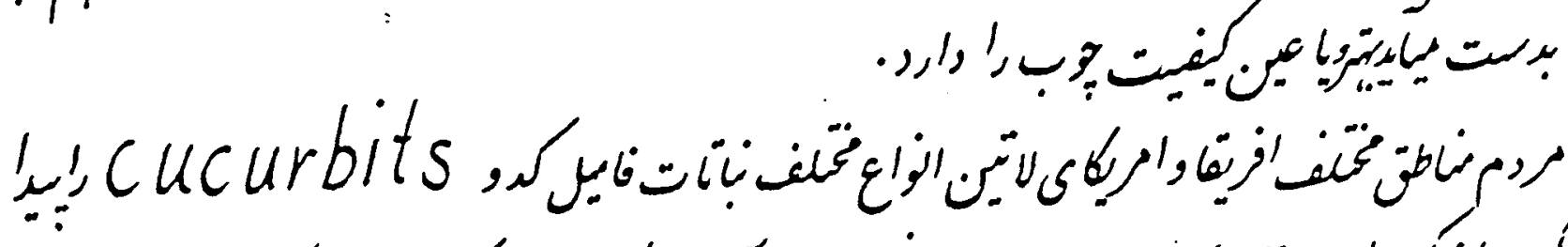

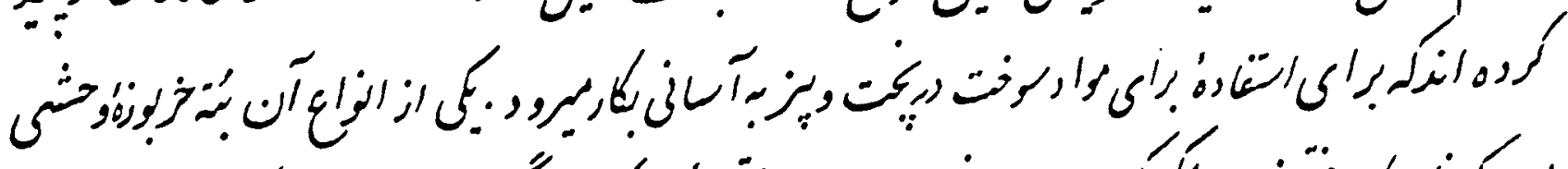

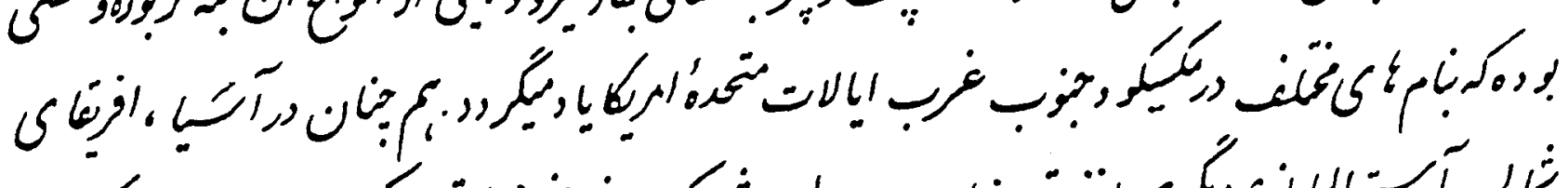

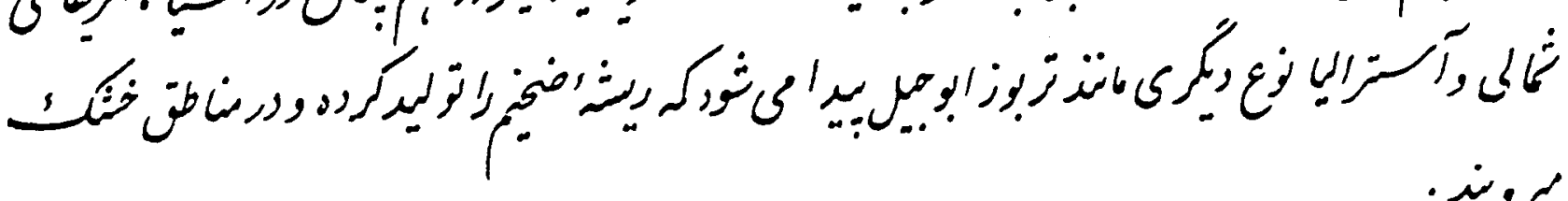
يمرني.

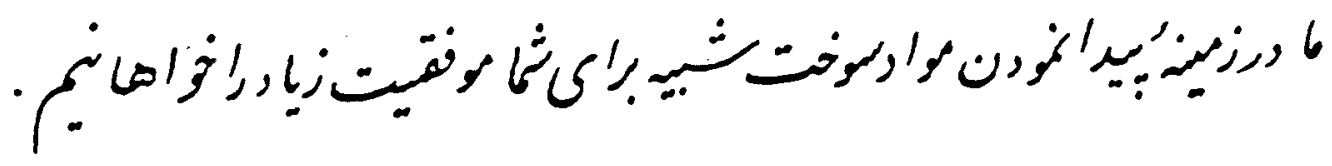




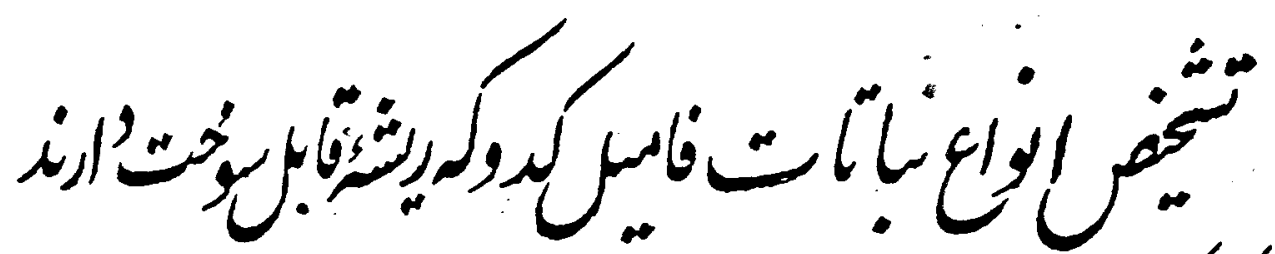

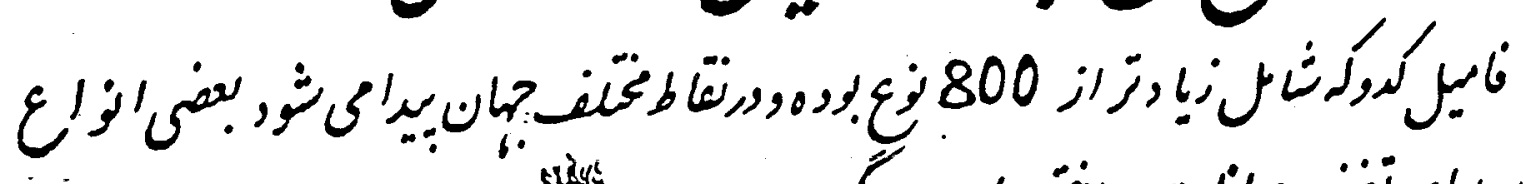

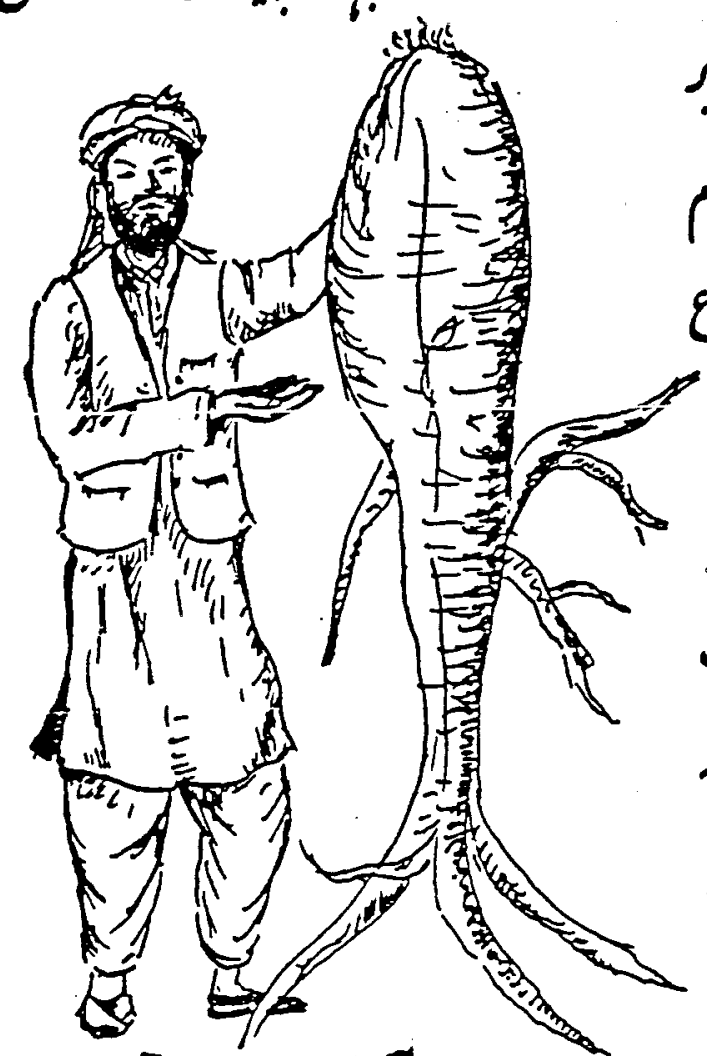

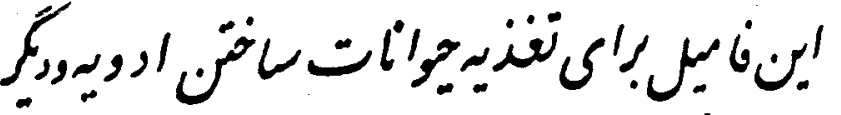

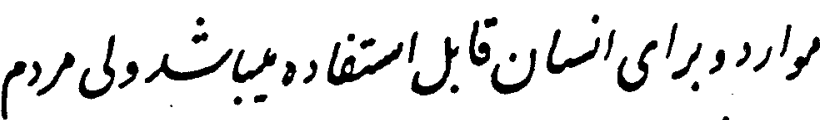

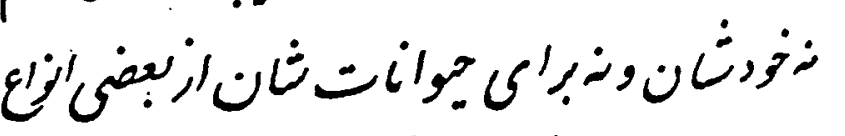

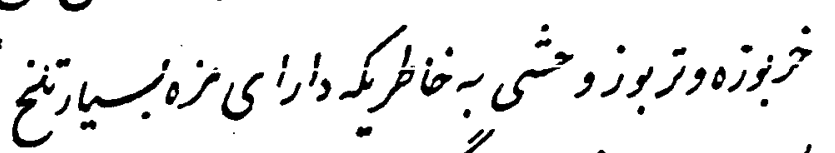

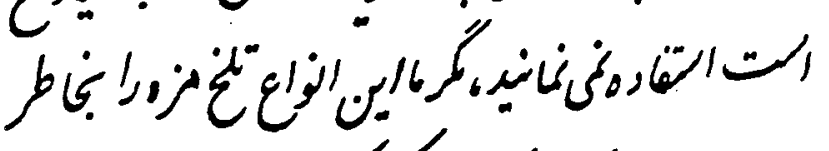

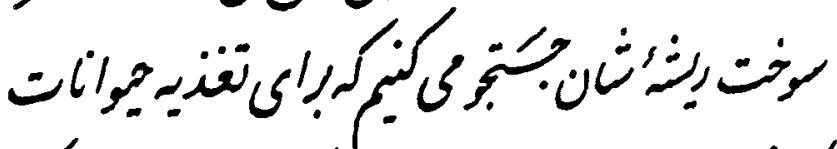

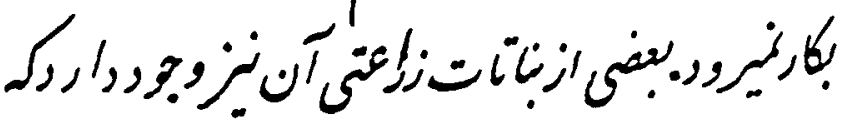

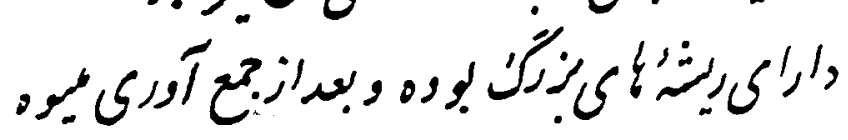

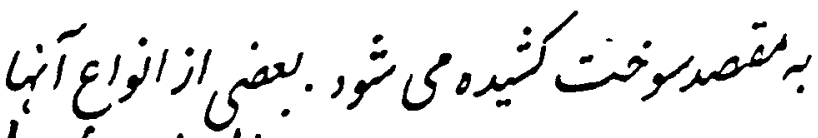

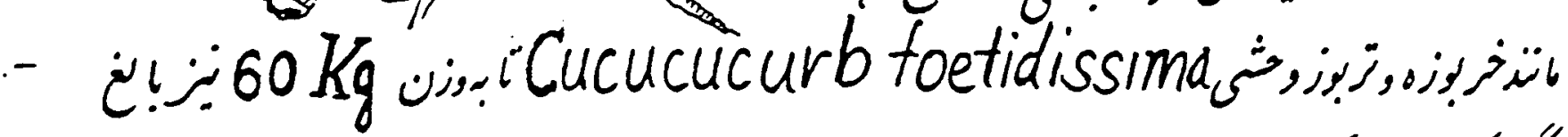

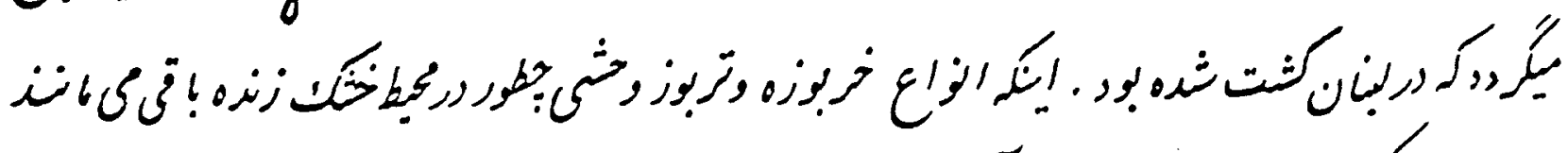

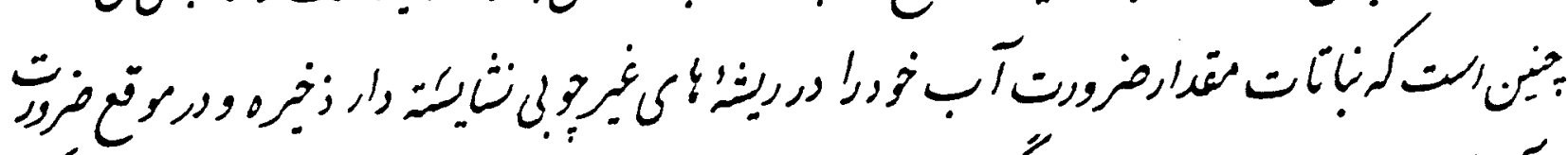

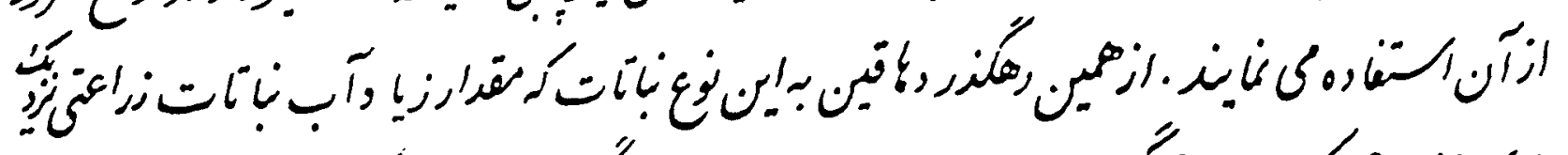

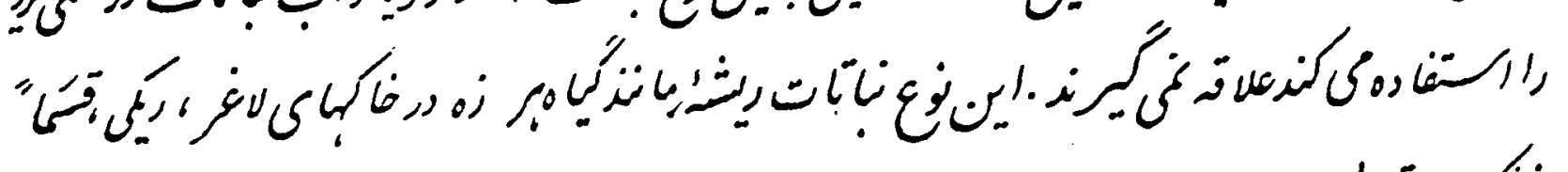

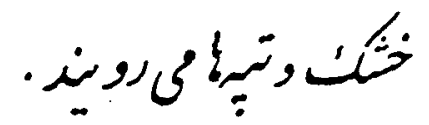

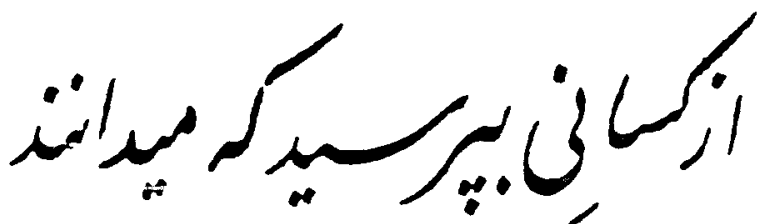

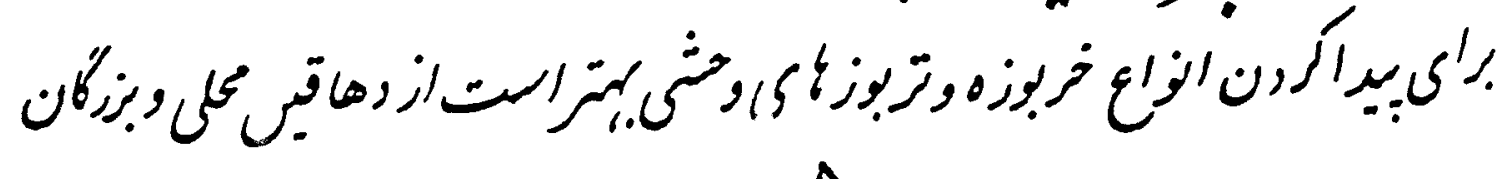




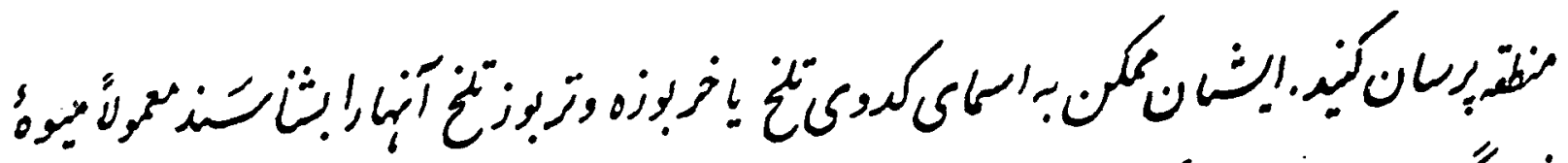

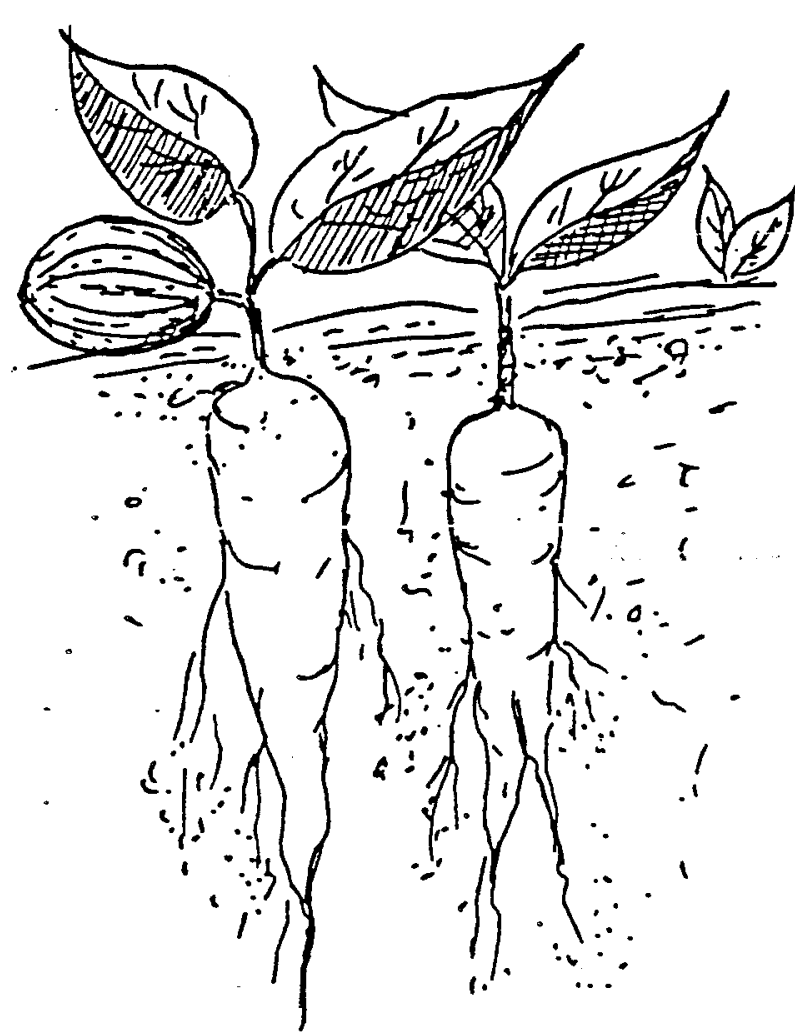

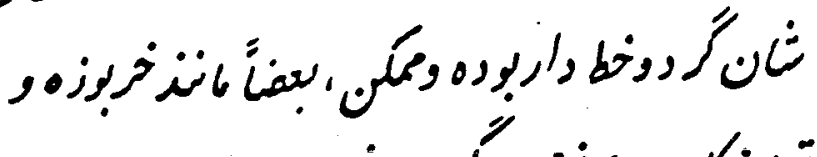

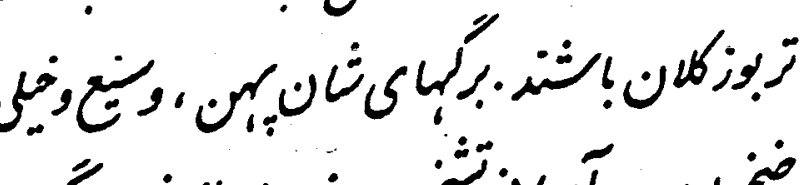

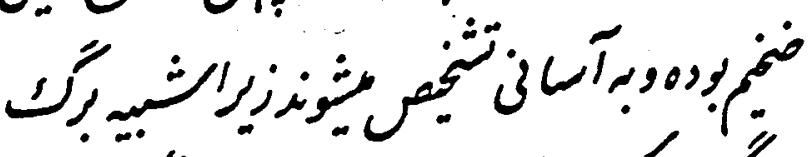

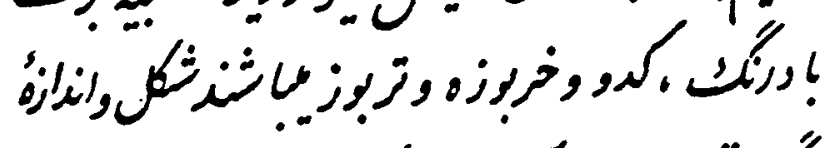

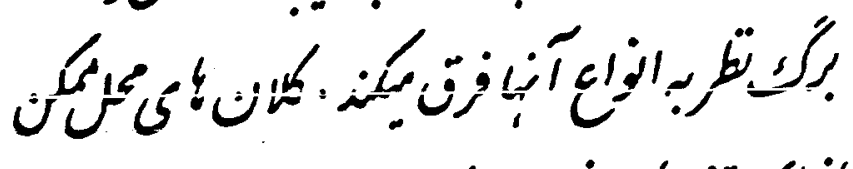

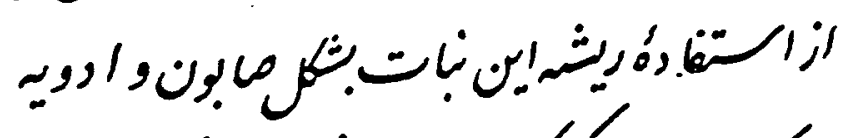

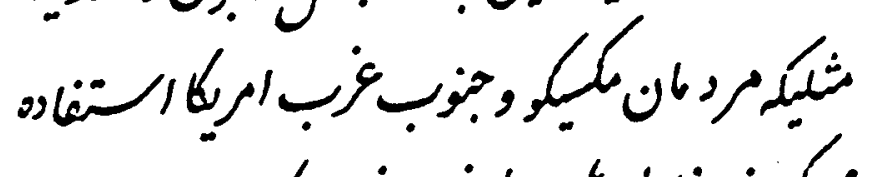

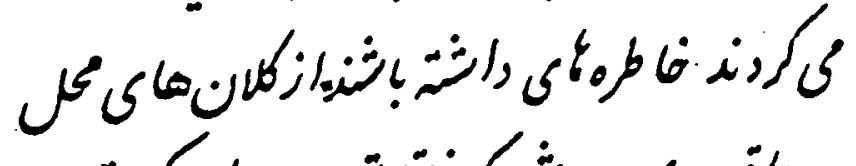

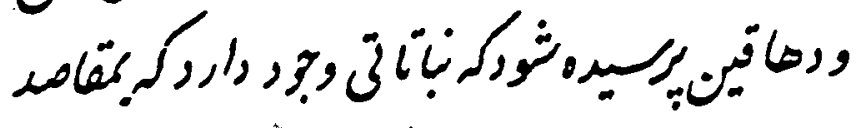

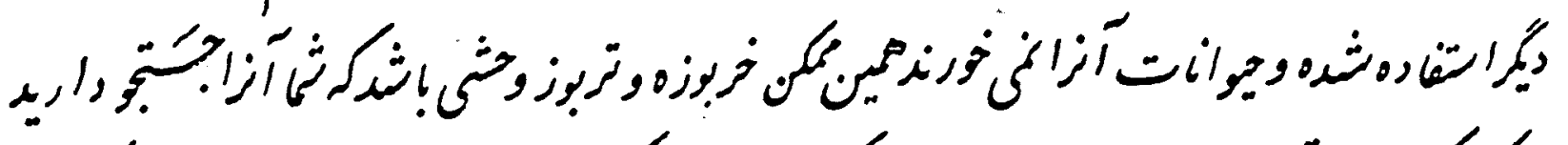

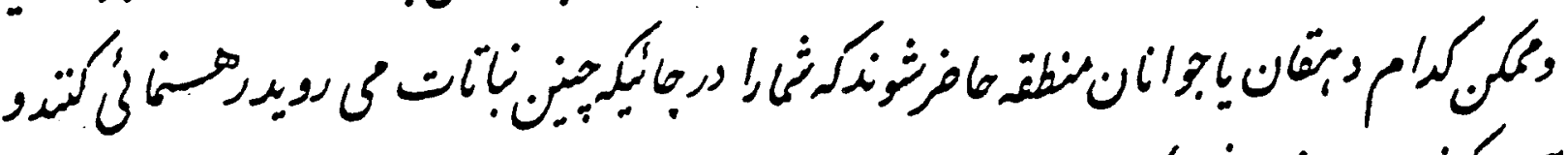

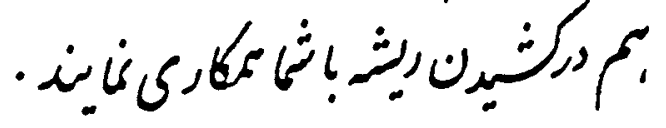

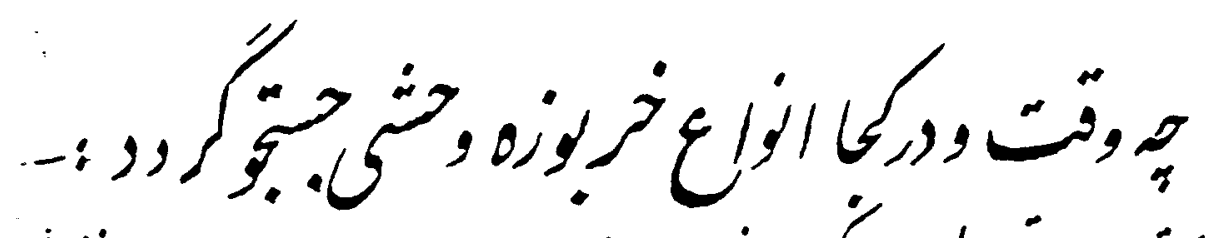

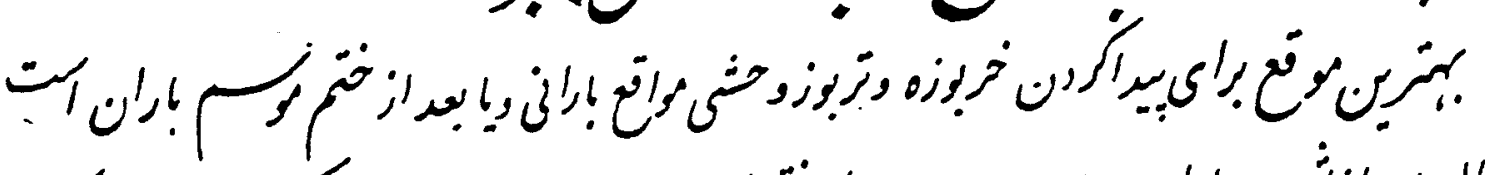

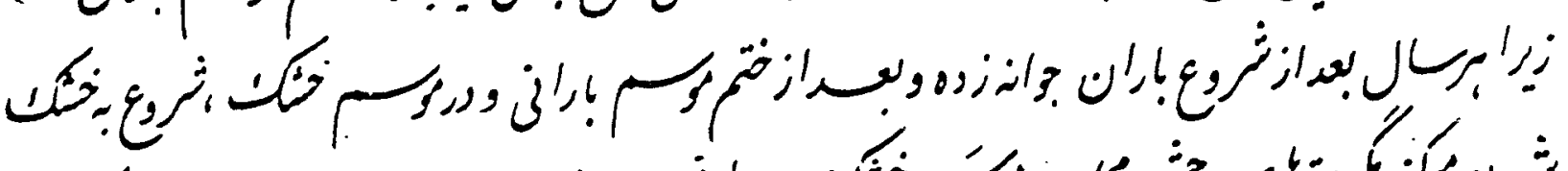

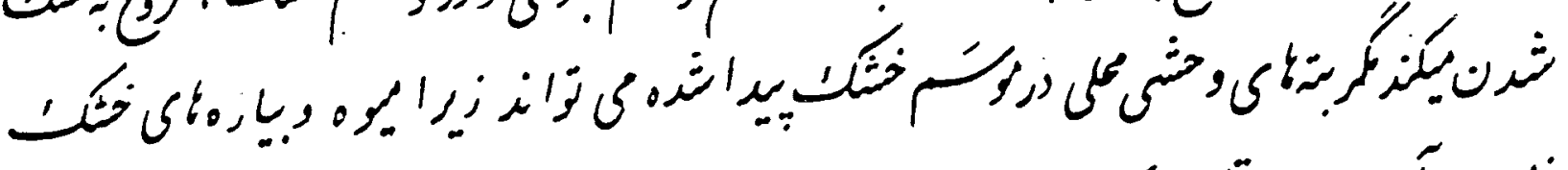

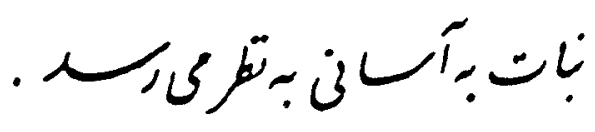




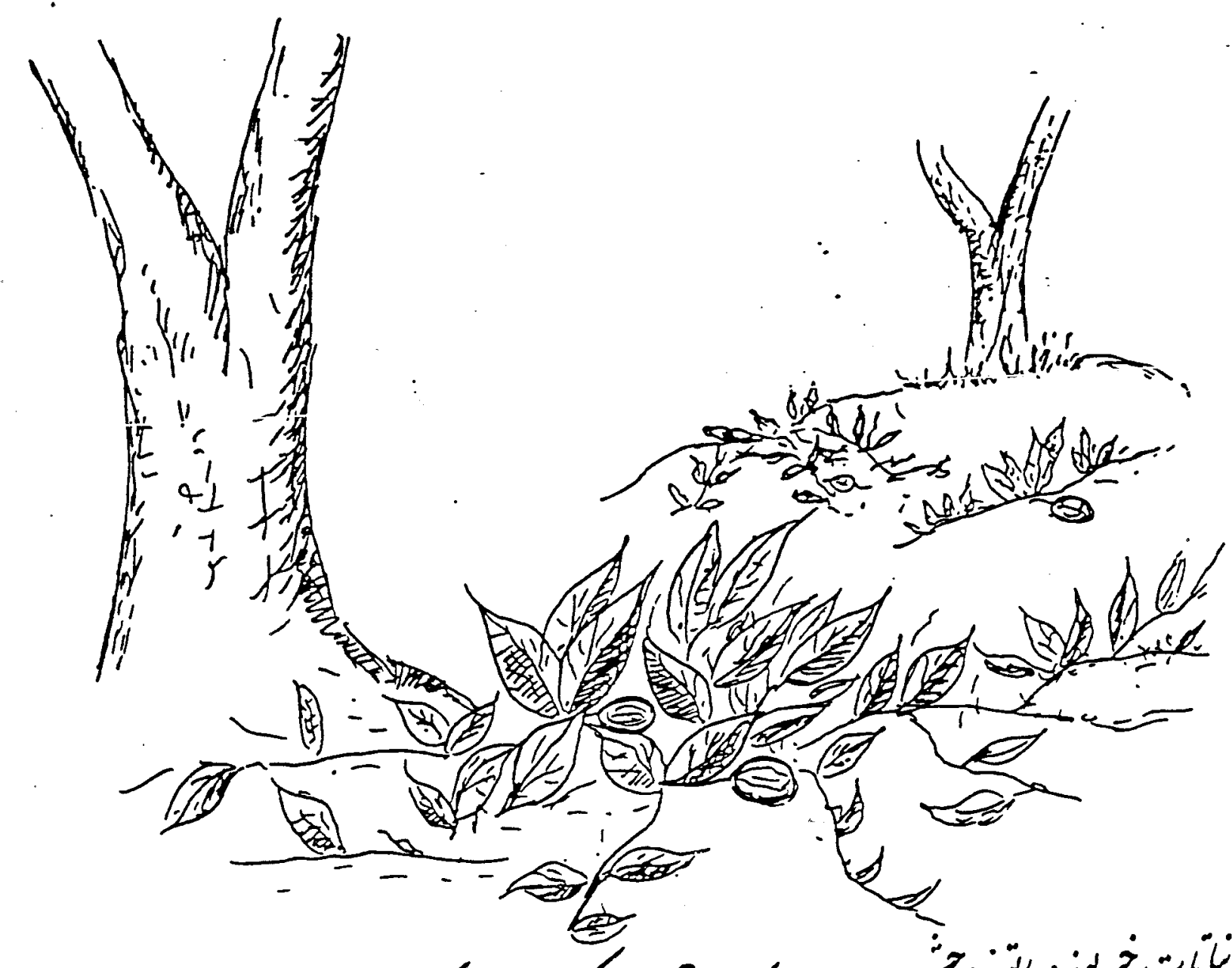

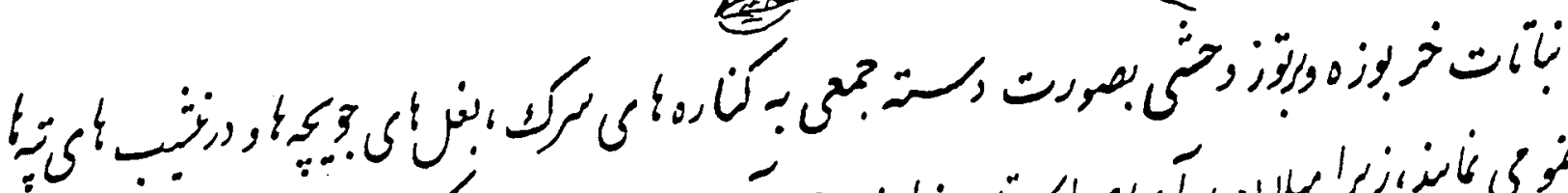

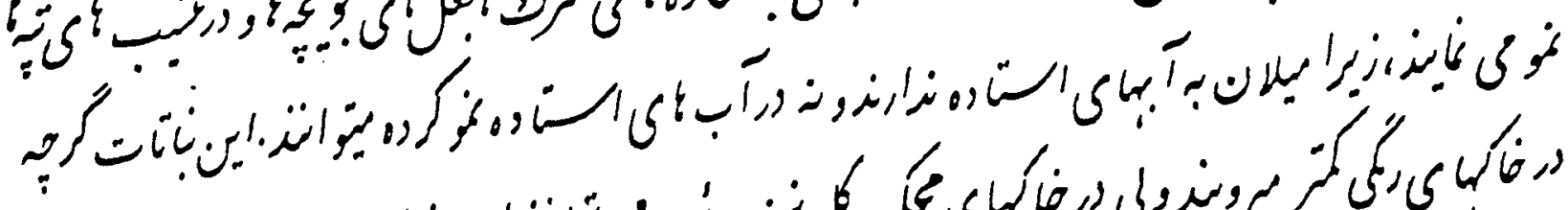

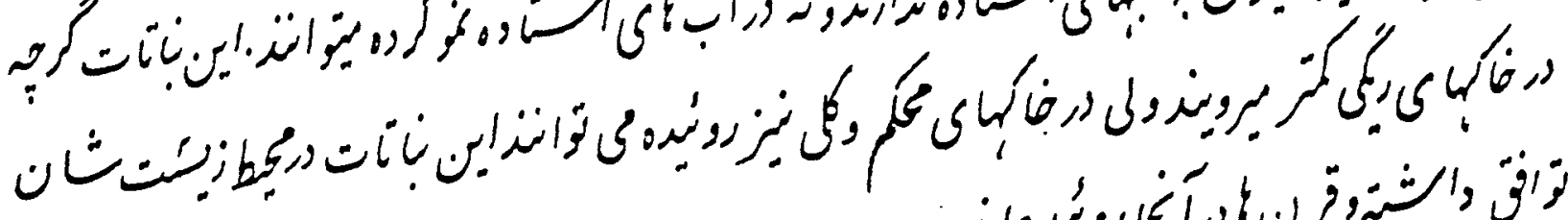

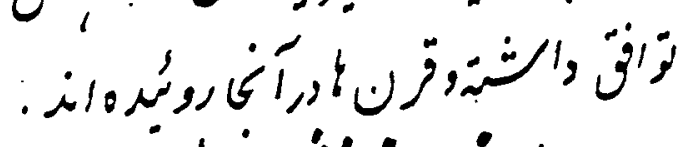

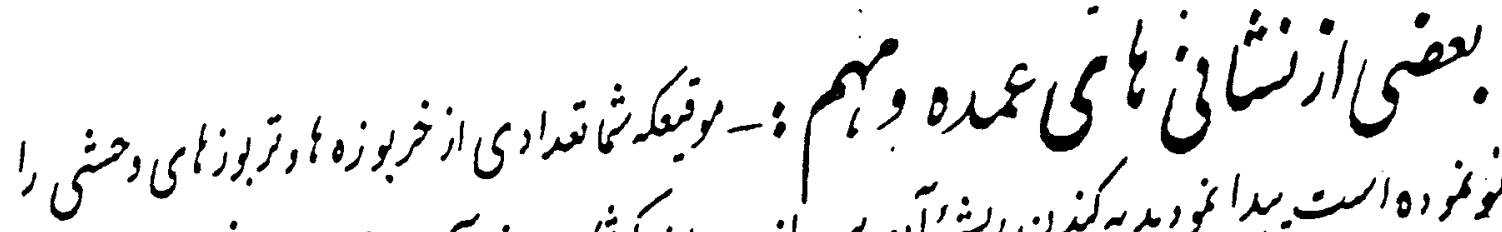

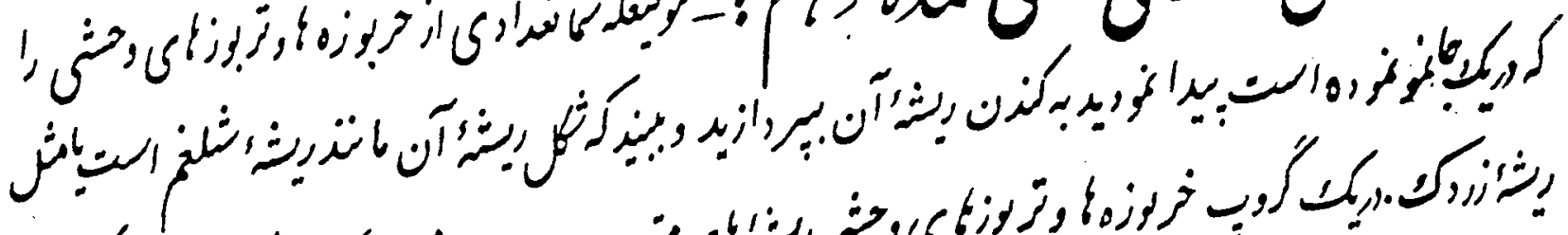

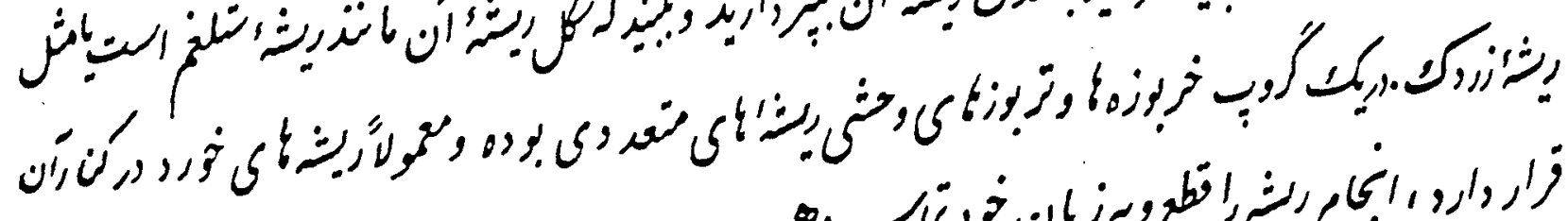

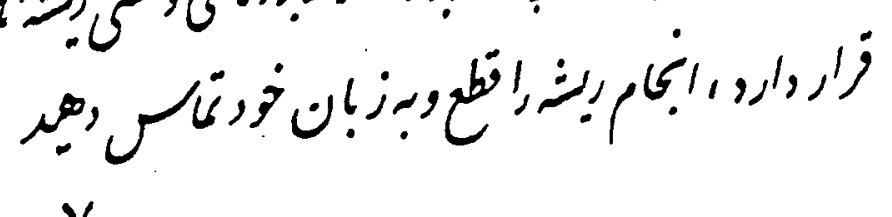




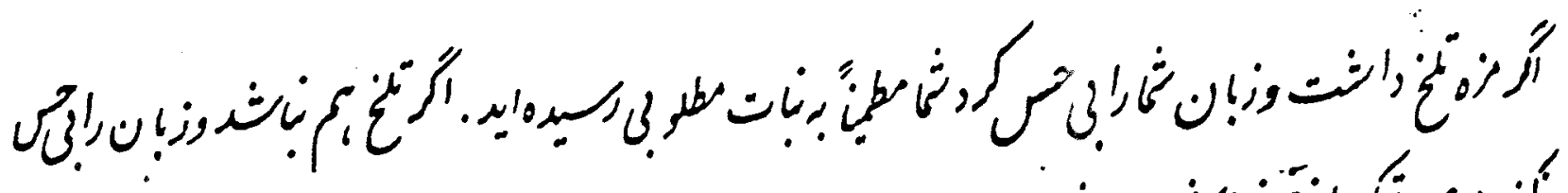

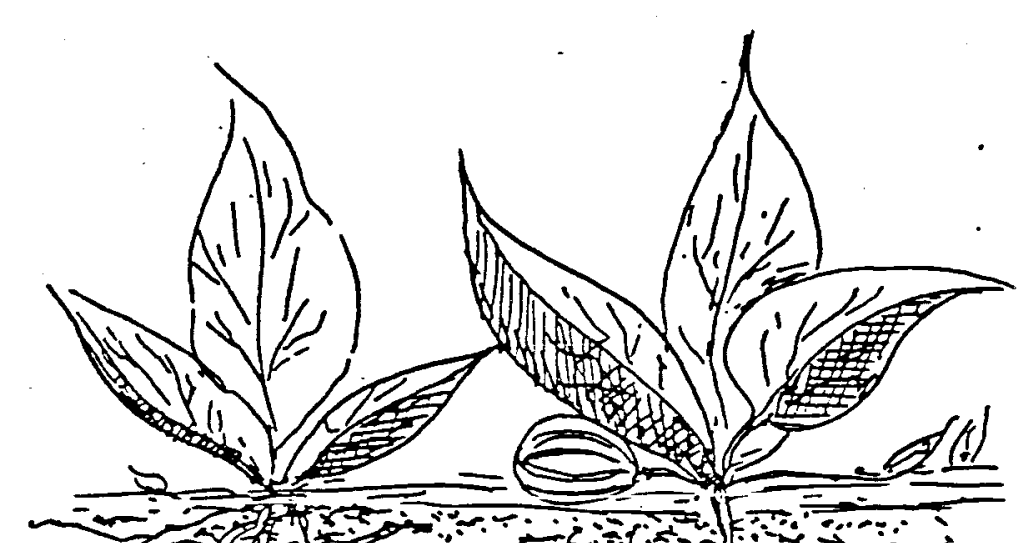

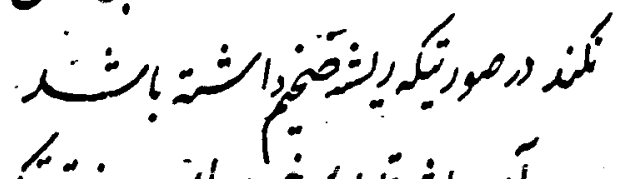

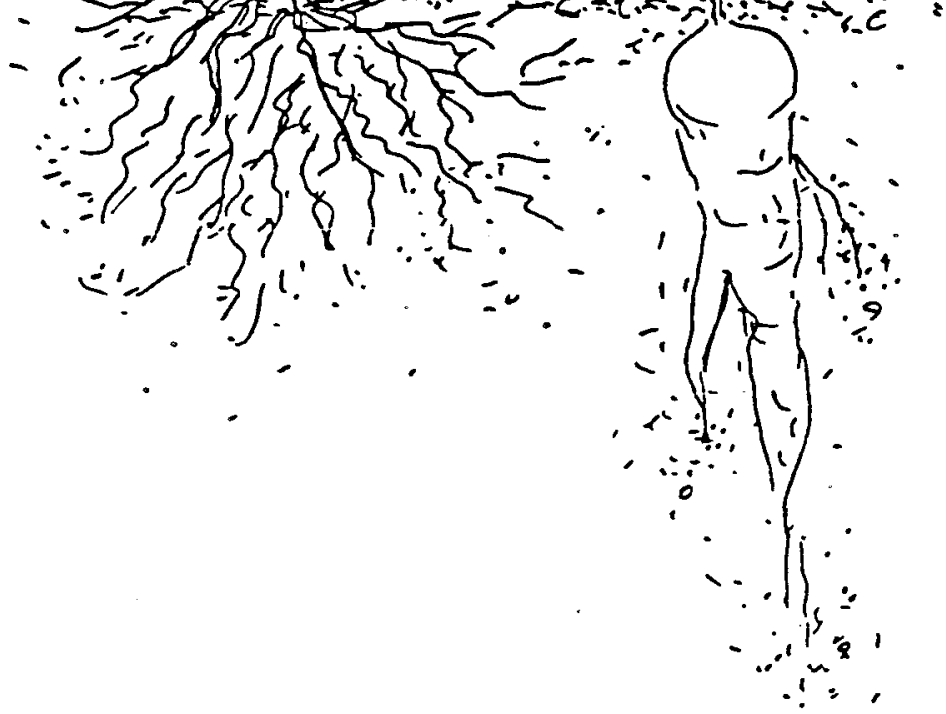

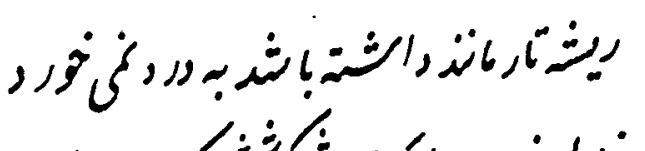

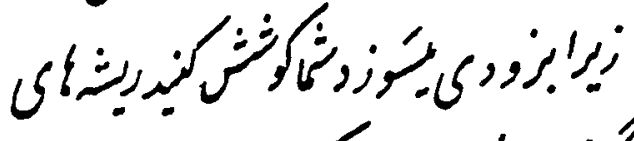

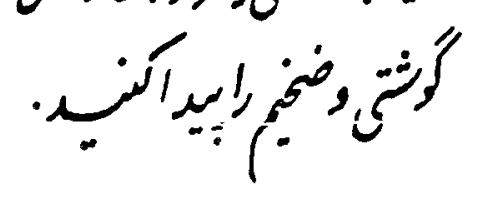

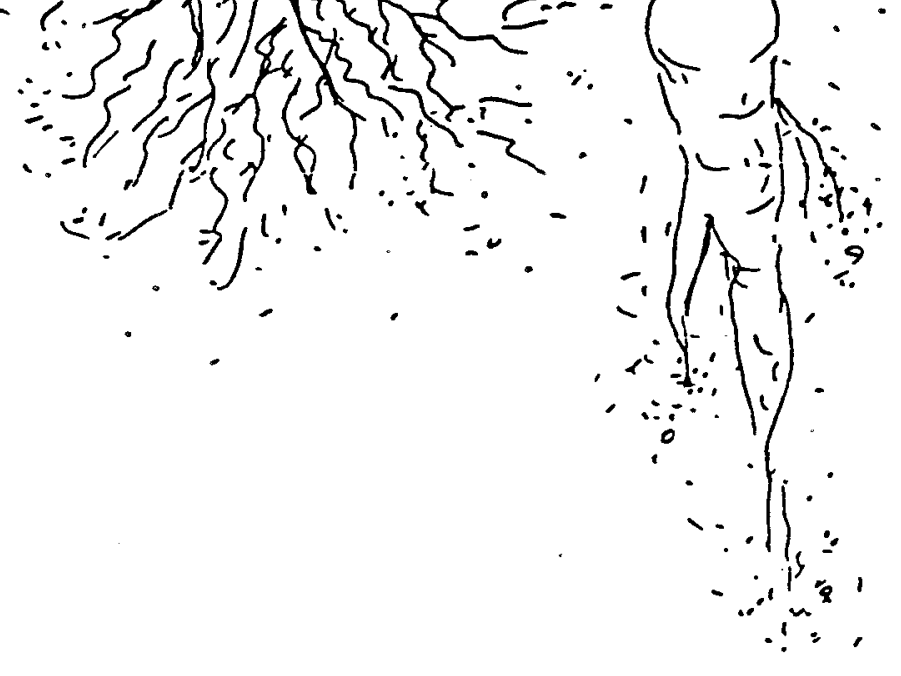

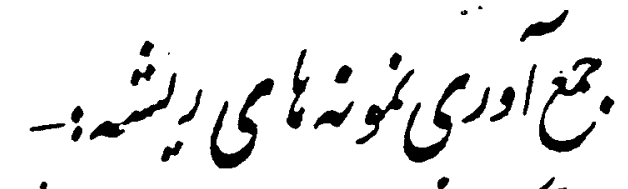

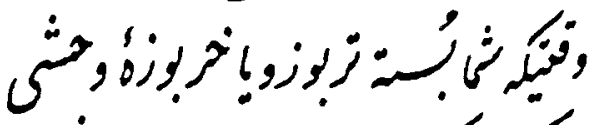
إِ

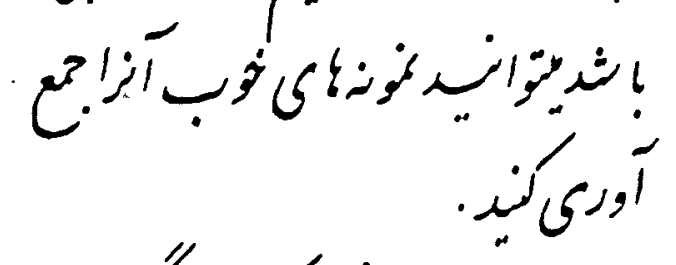

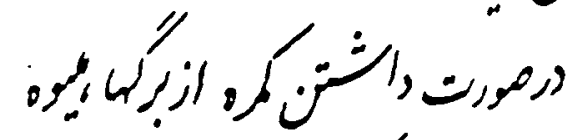

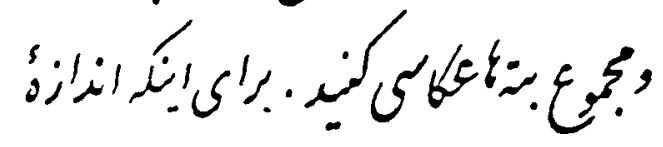

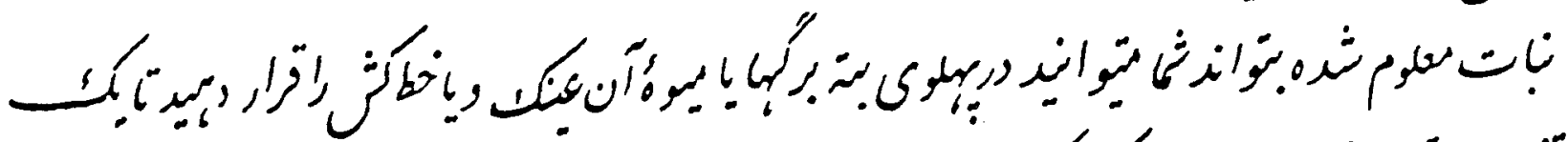

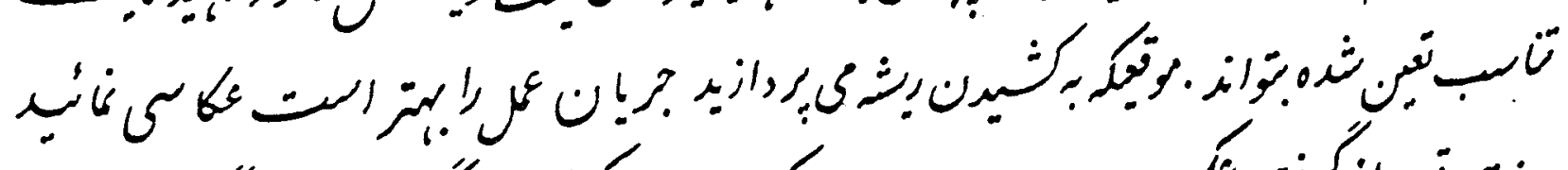

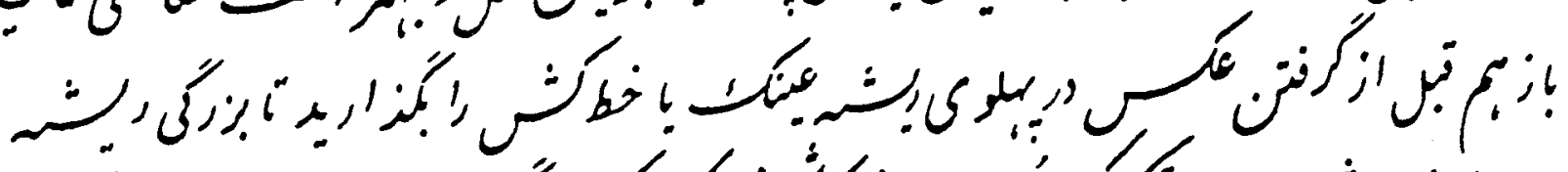

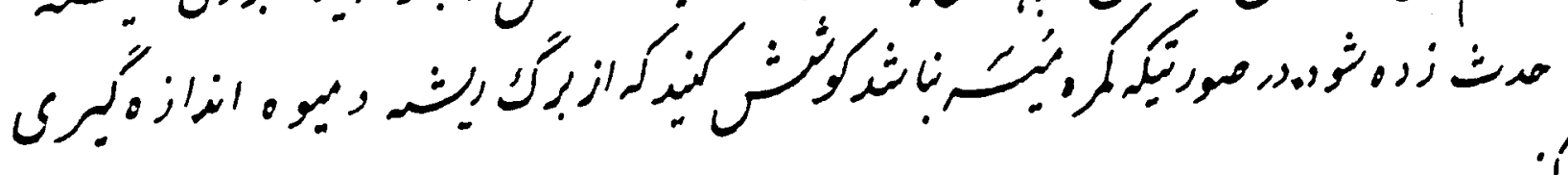

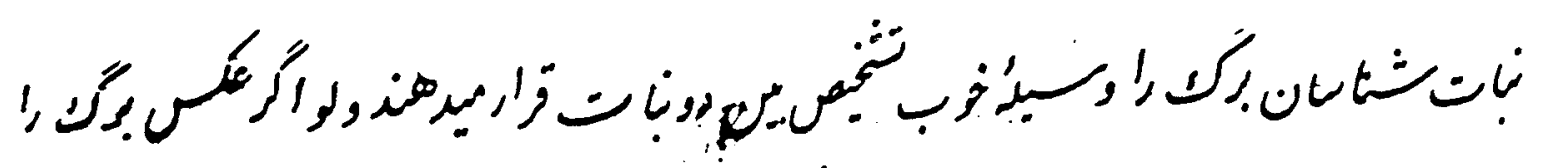




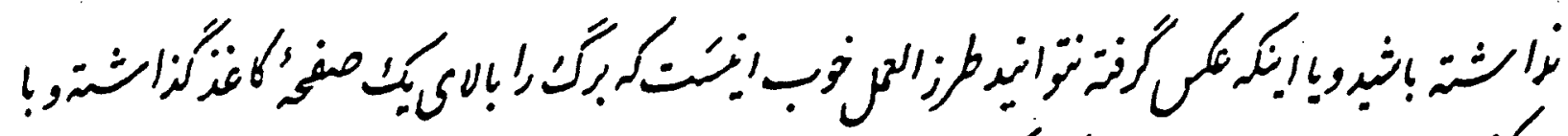

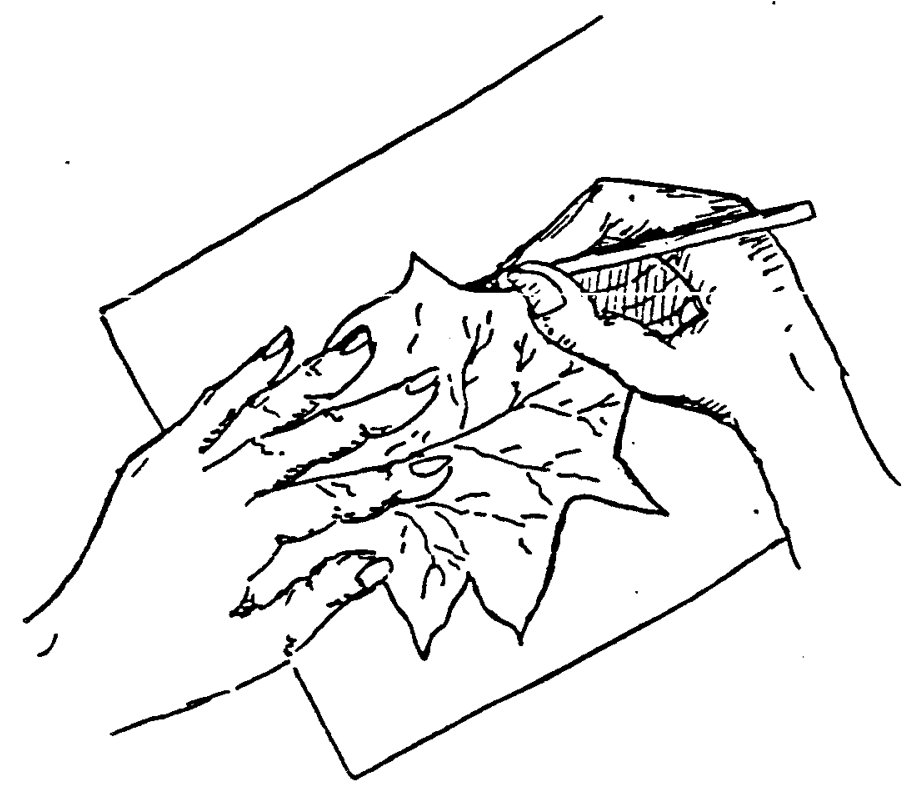

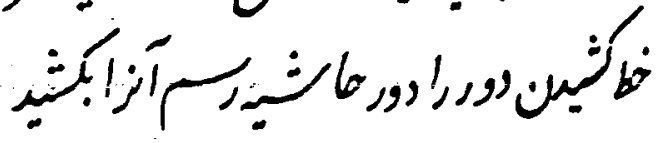

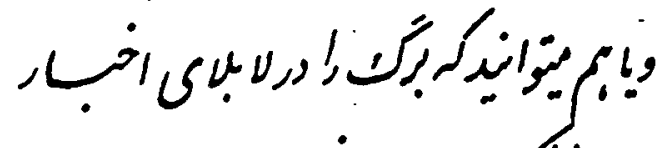

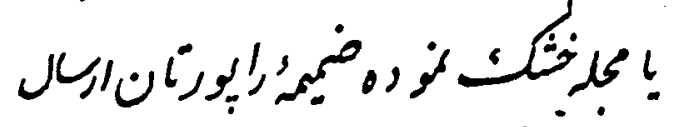

بارئ.

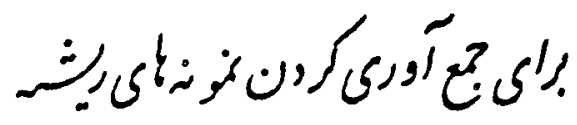

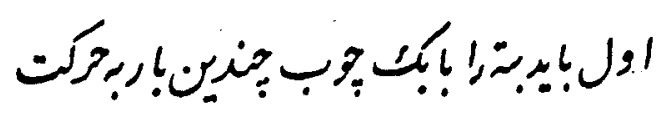

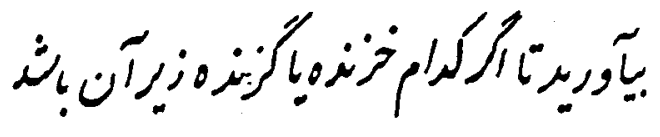

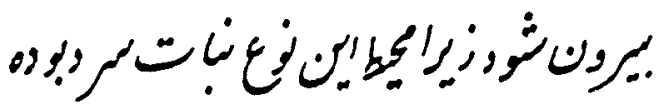

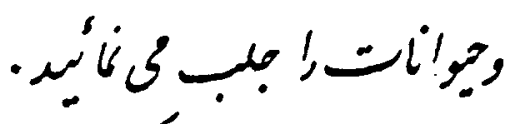

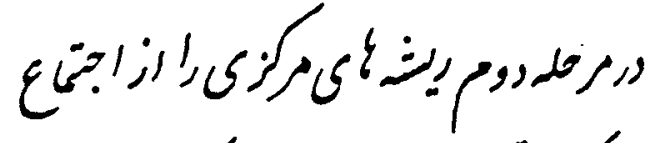

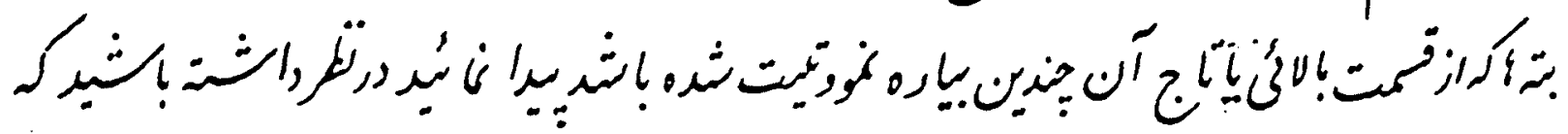

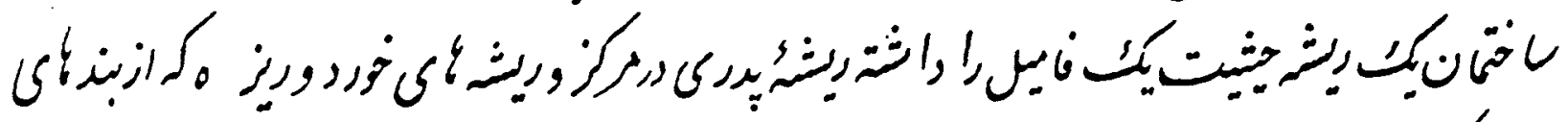

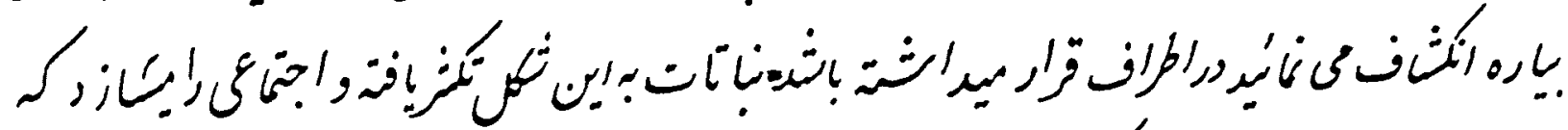

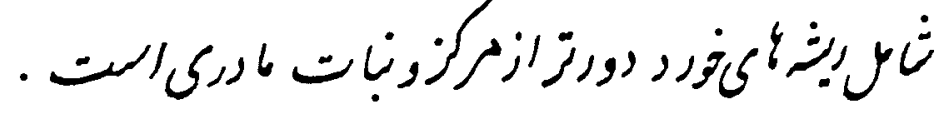

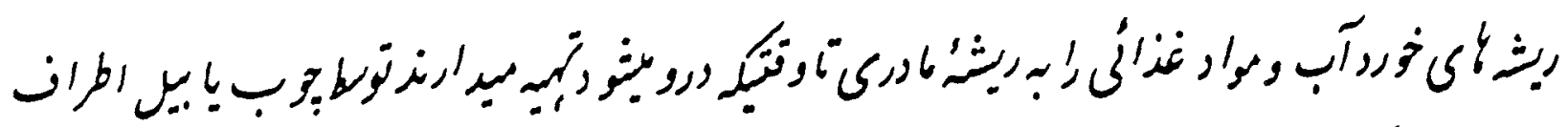

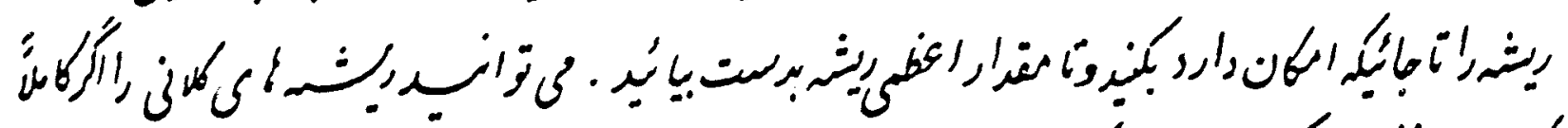

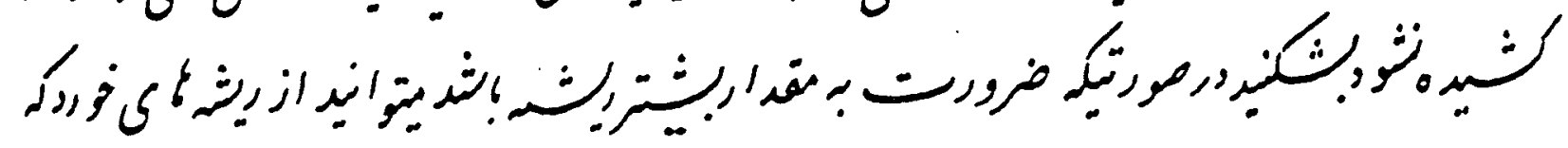

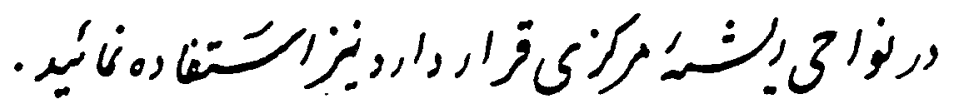




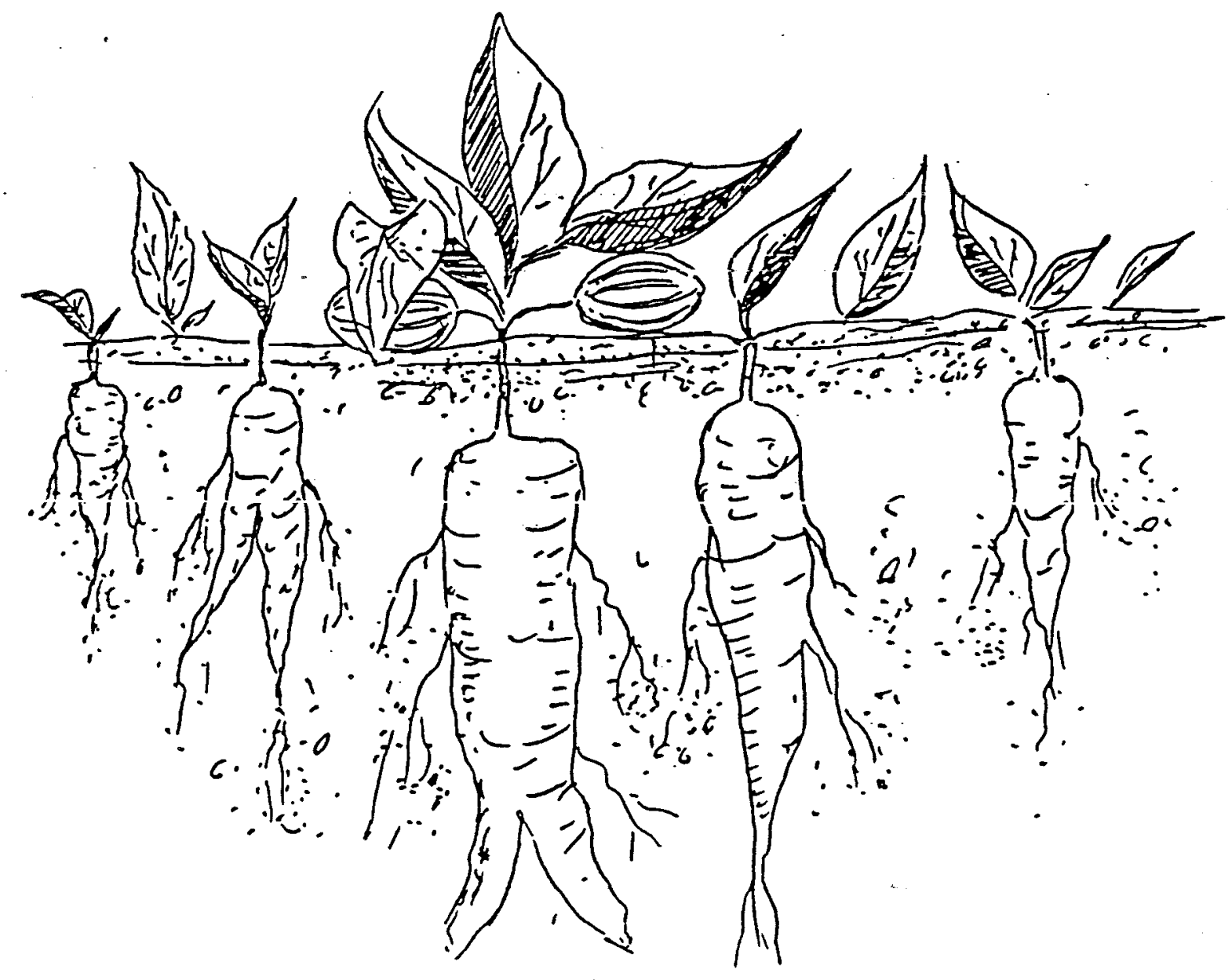

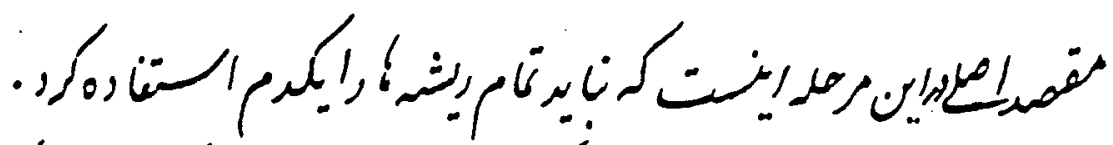

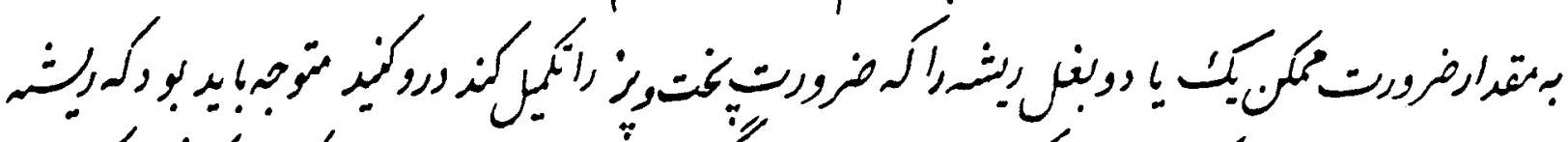

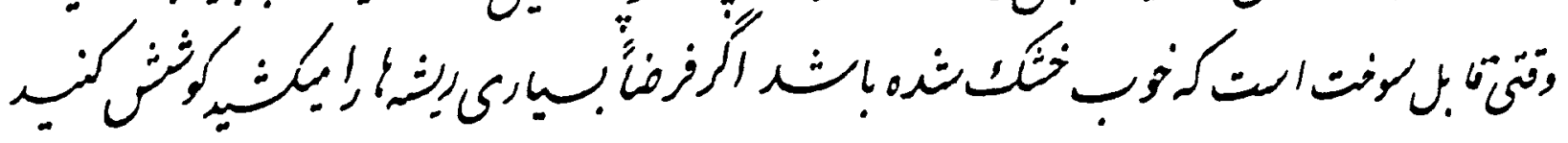

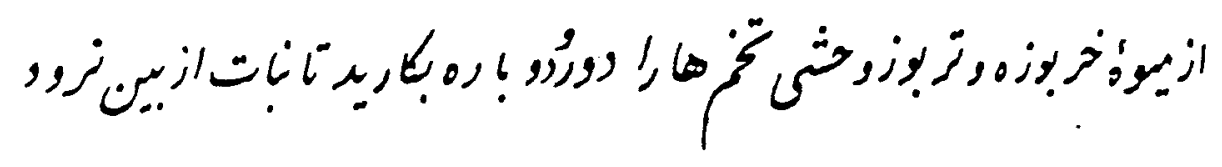

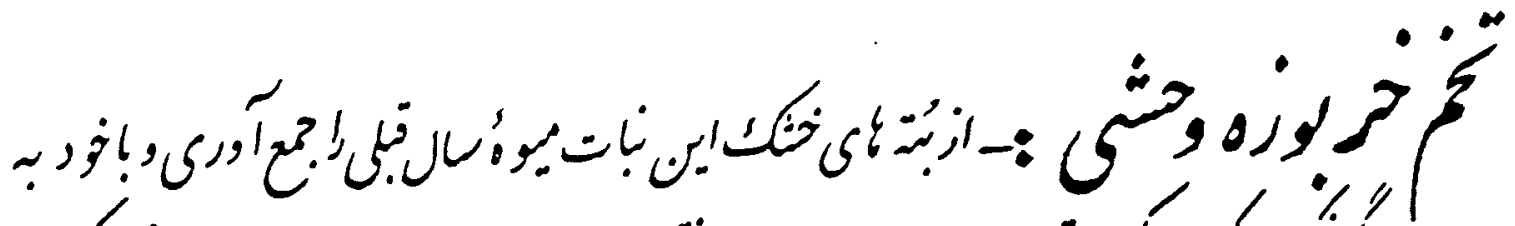

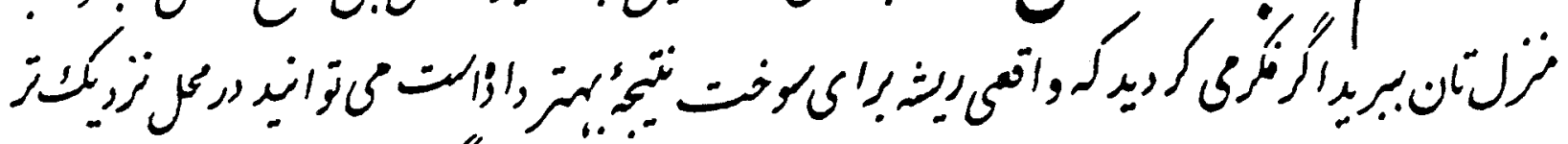

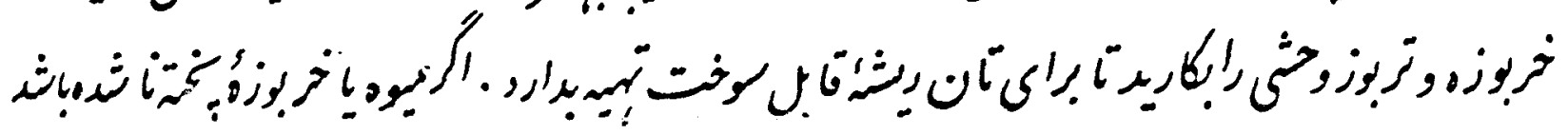

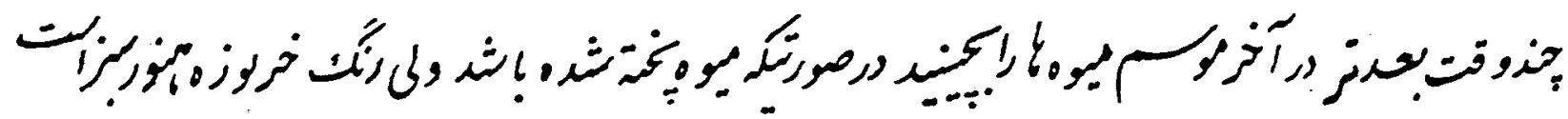




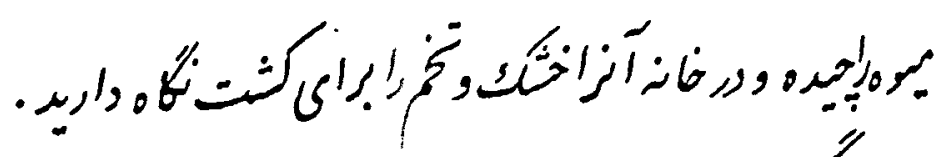

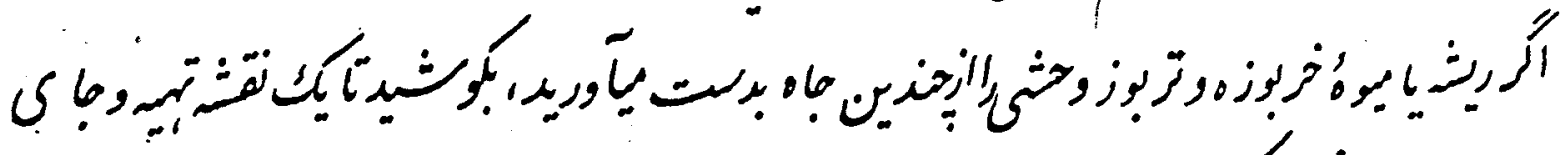

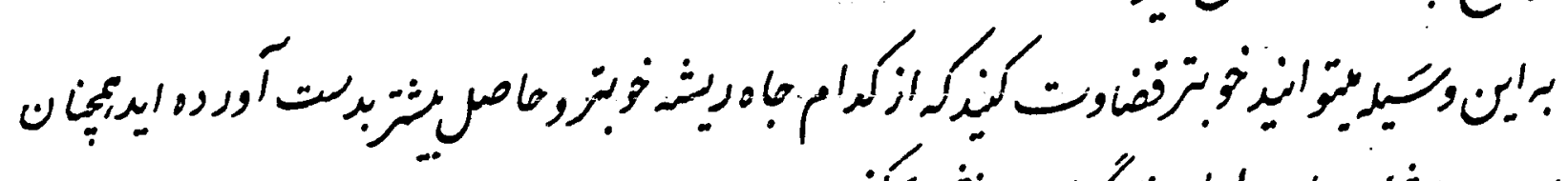

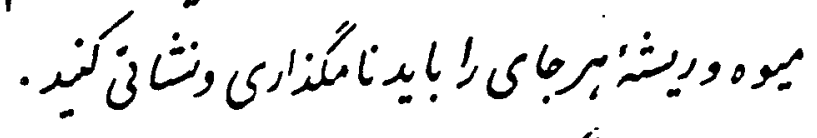

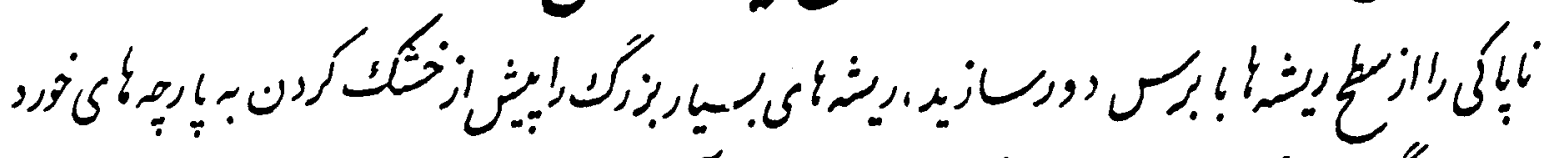

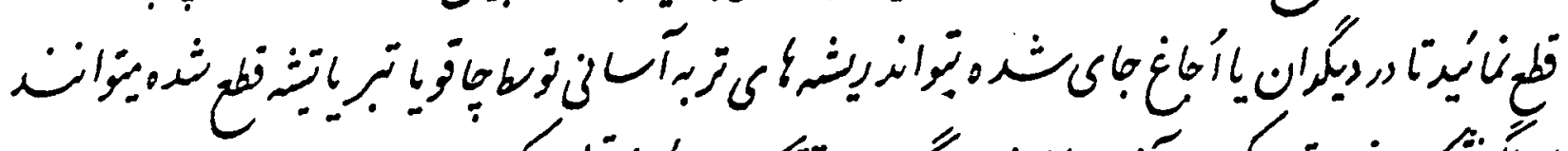

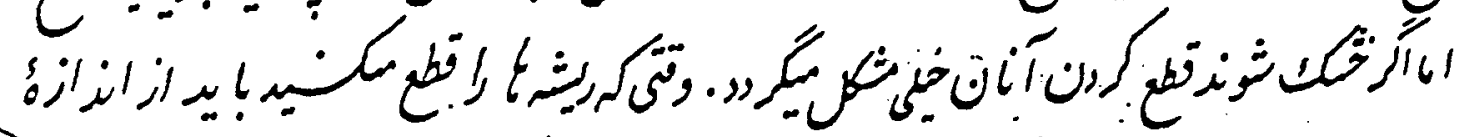

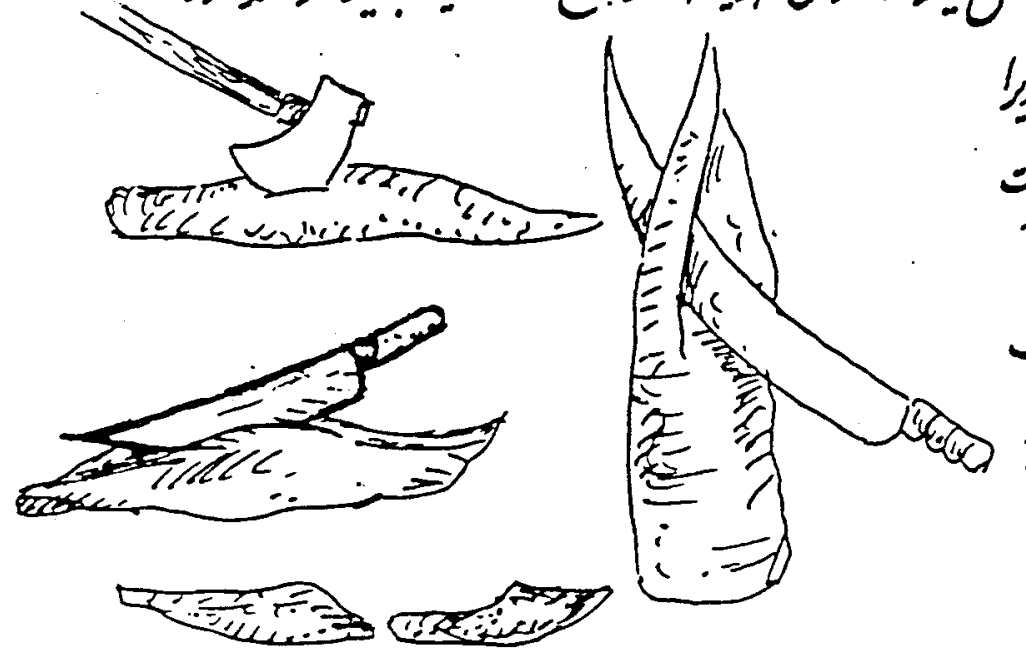

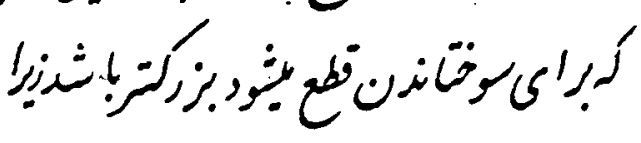

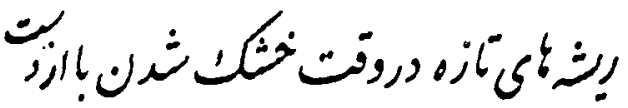

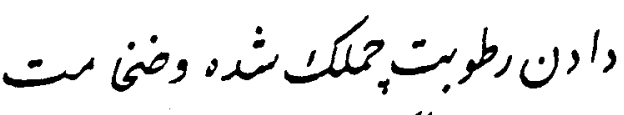

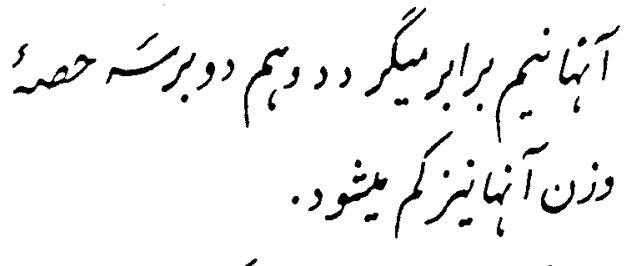

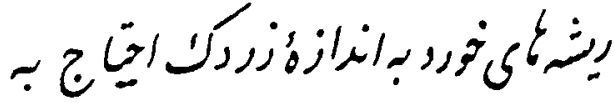

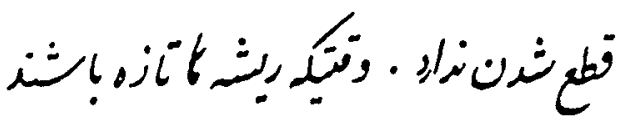

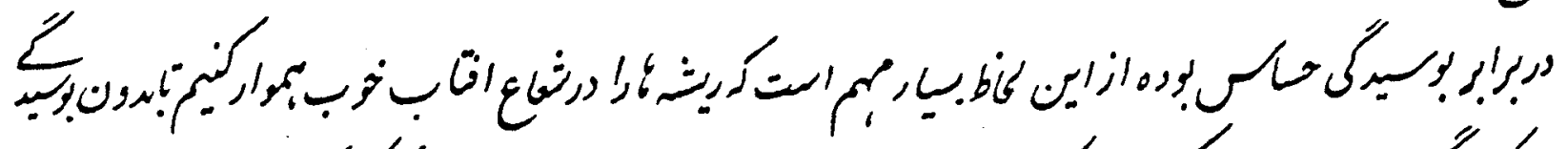

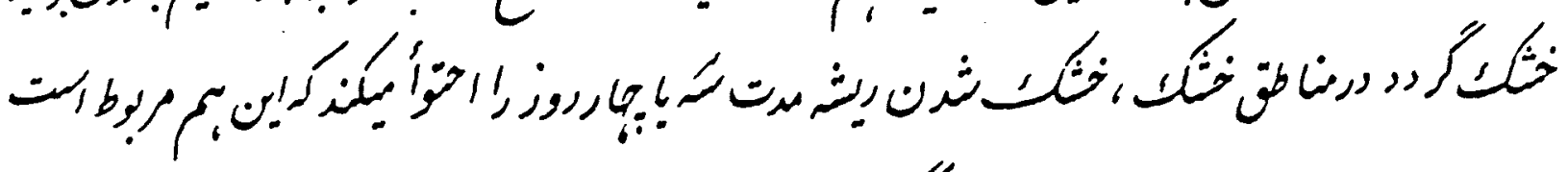

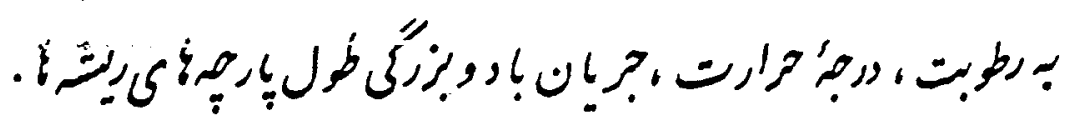




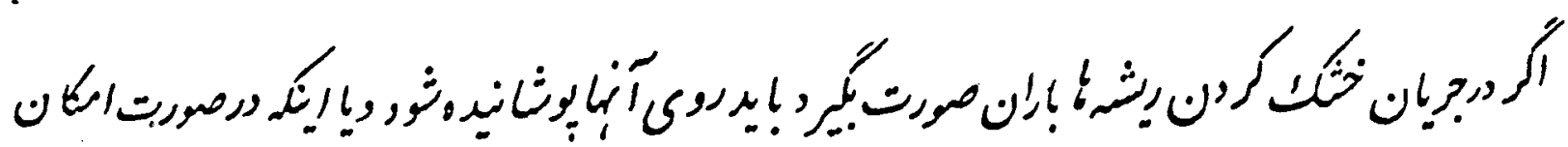

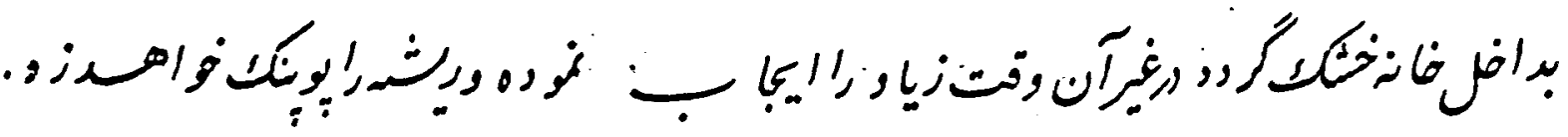

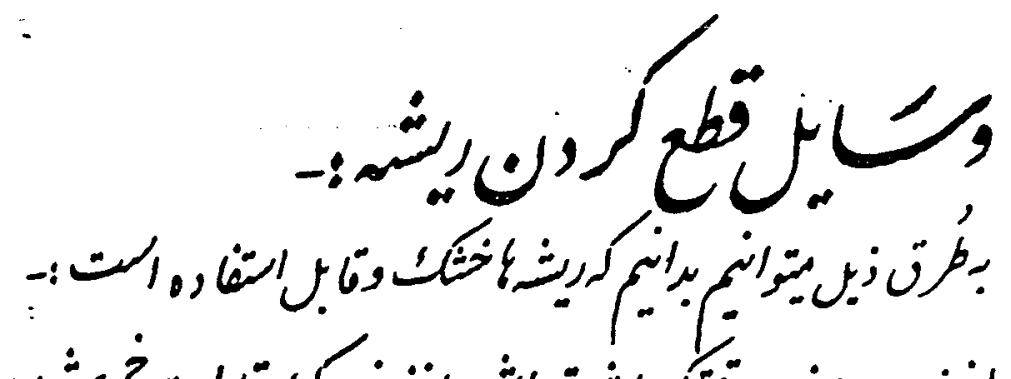

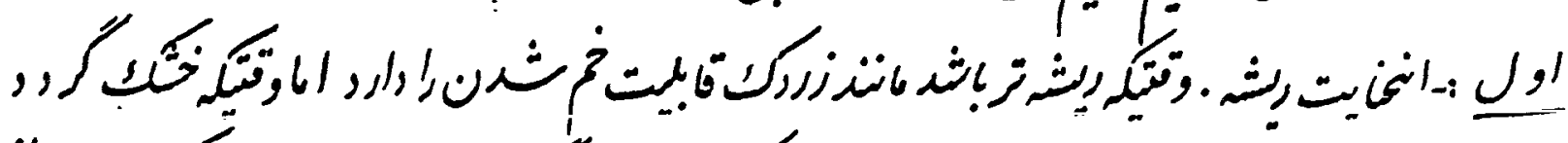

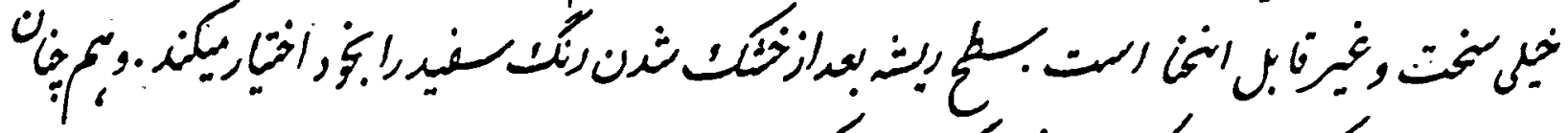

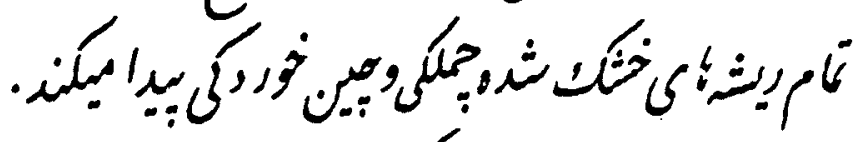

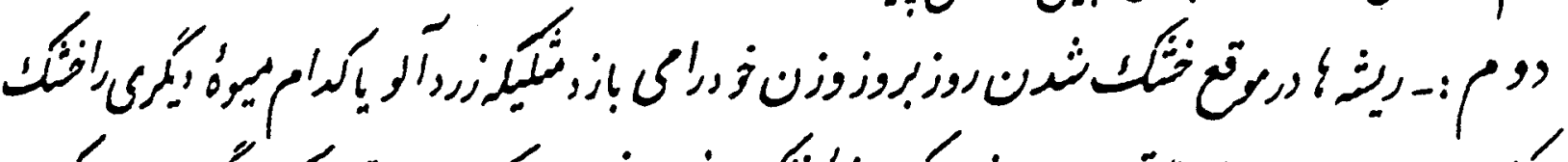

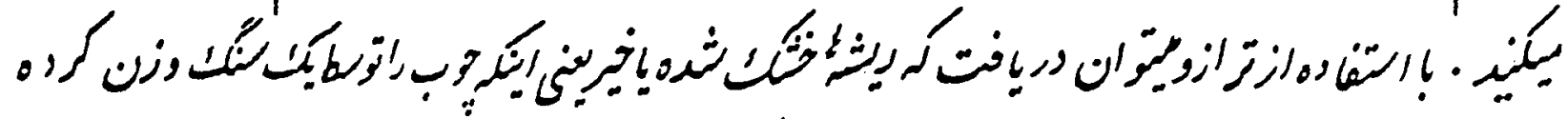

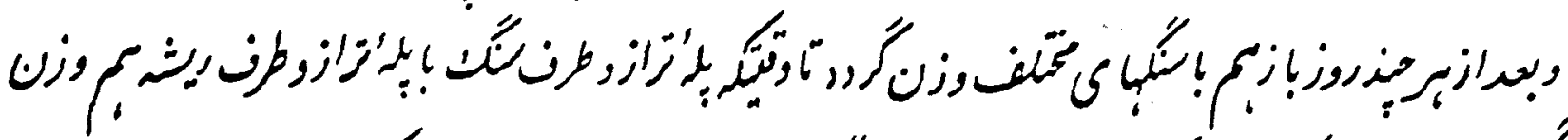

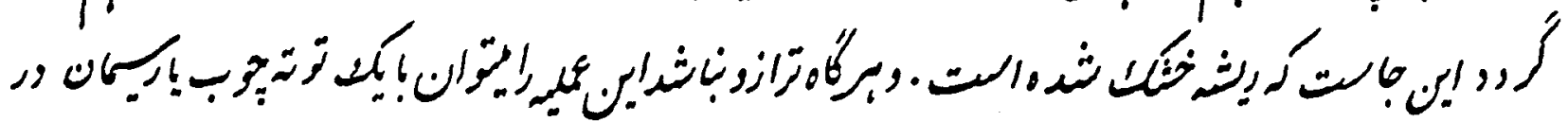

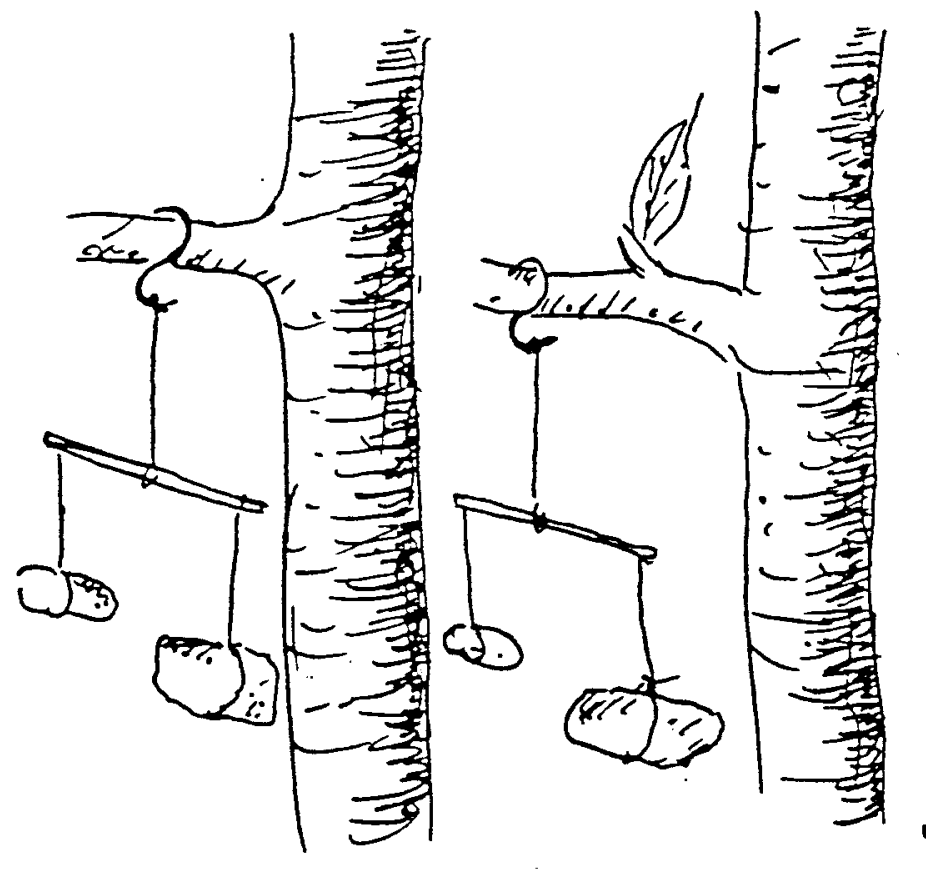

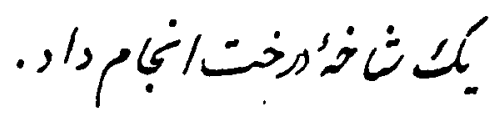

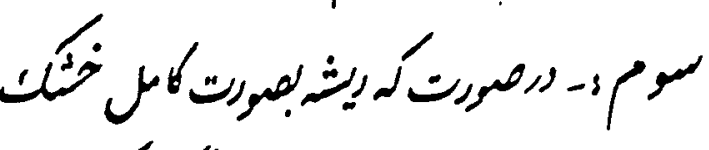

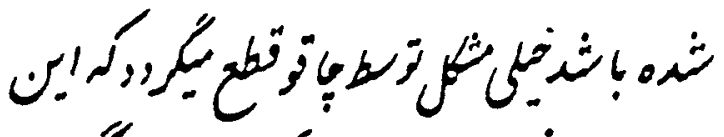

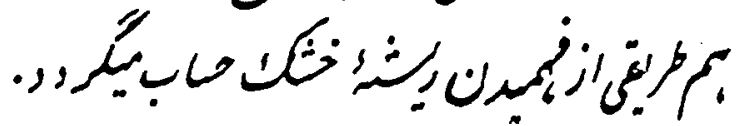

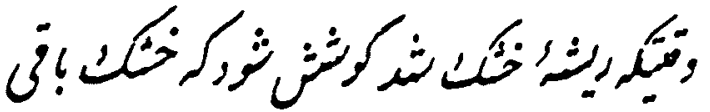

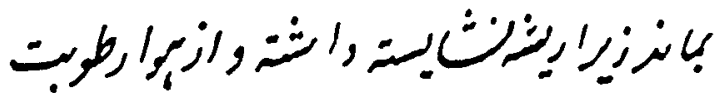
راجزبكن.

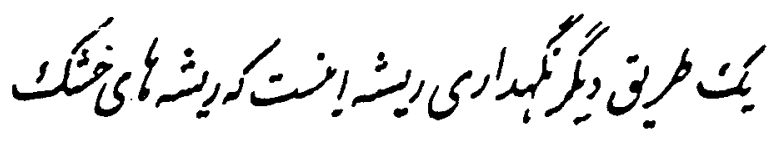




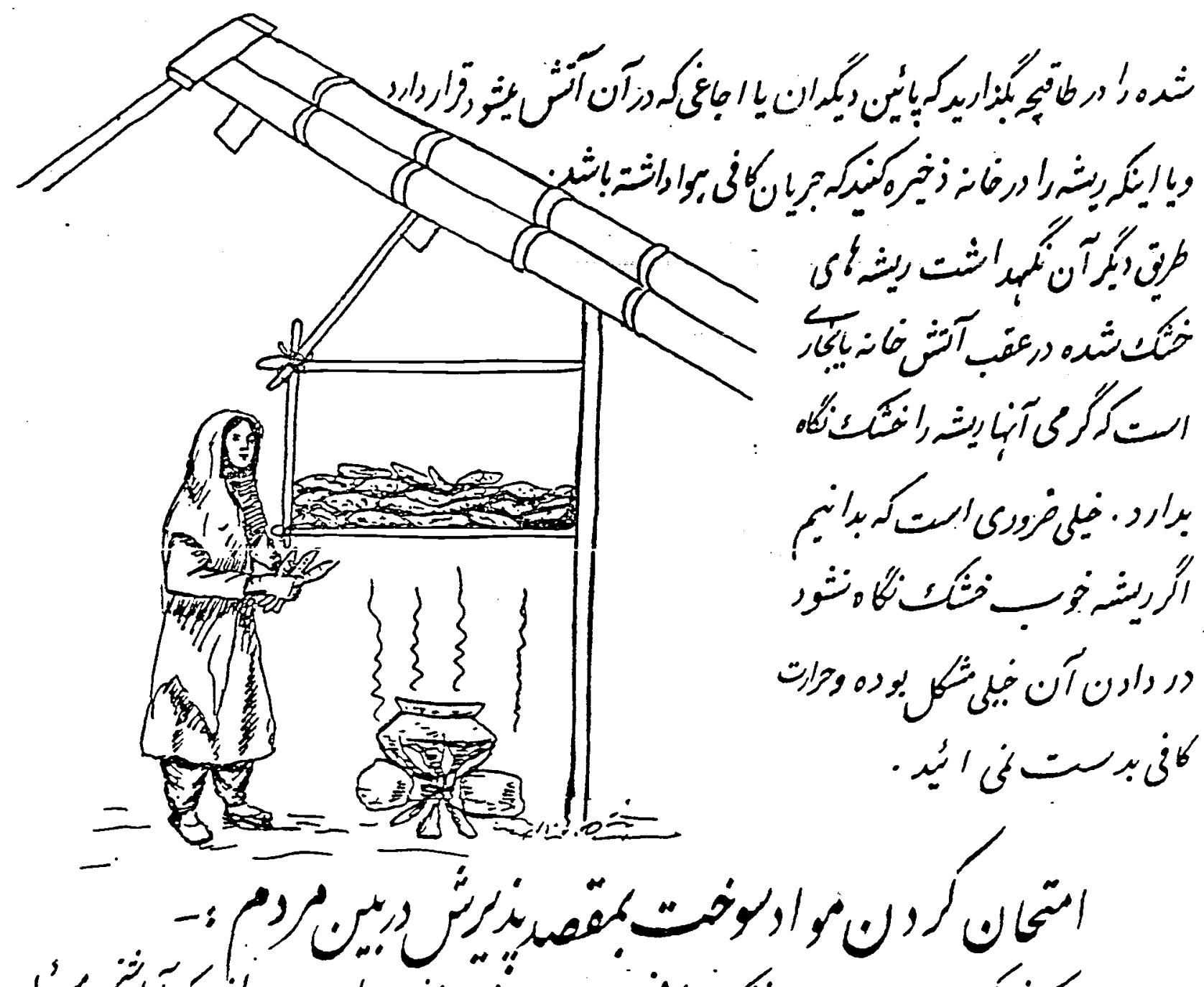

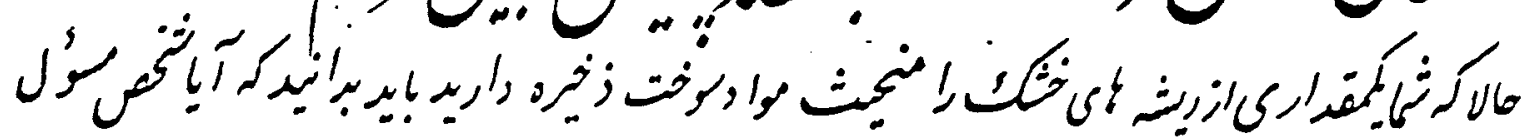

$$
\text { : }
$$

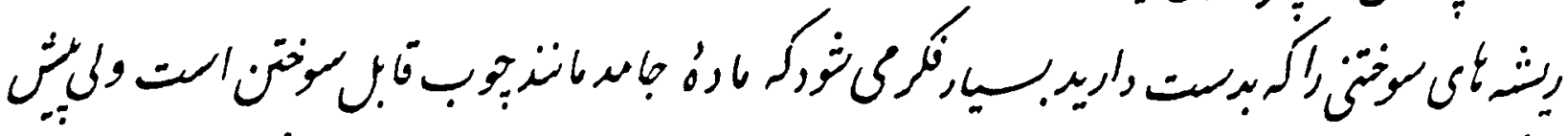

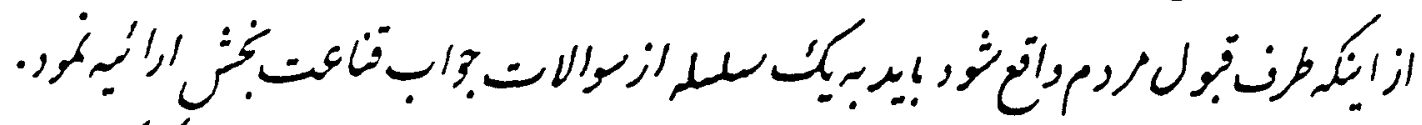

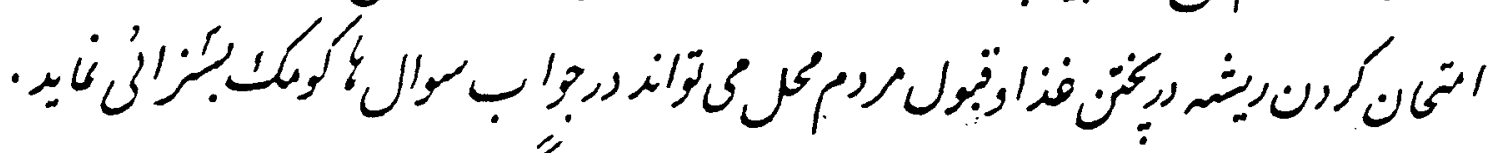

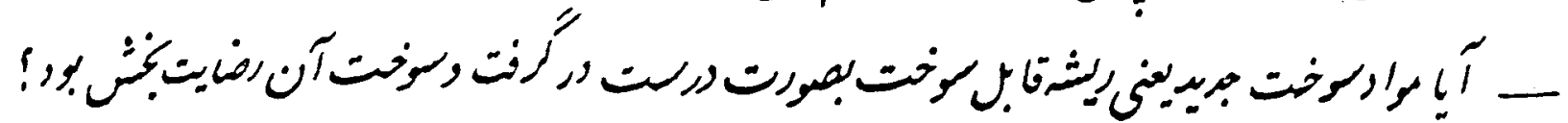

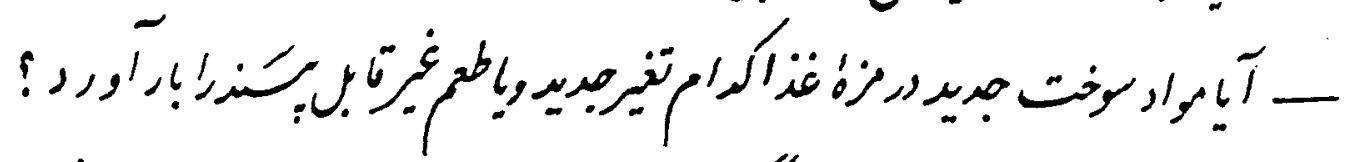

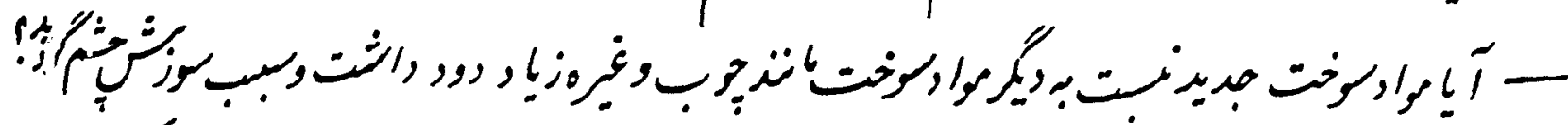

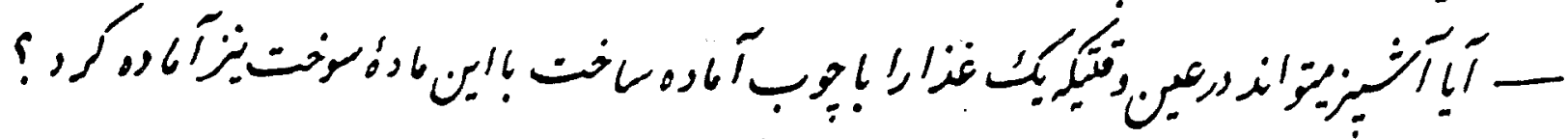
$\pi$ 


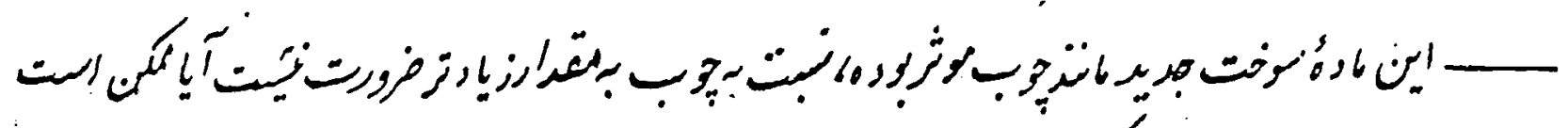

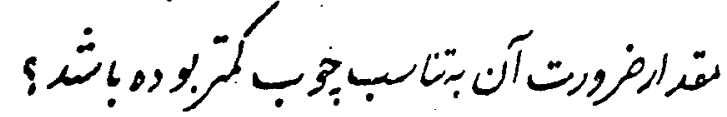

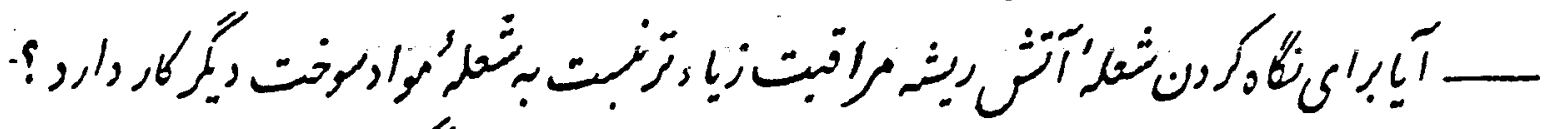

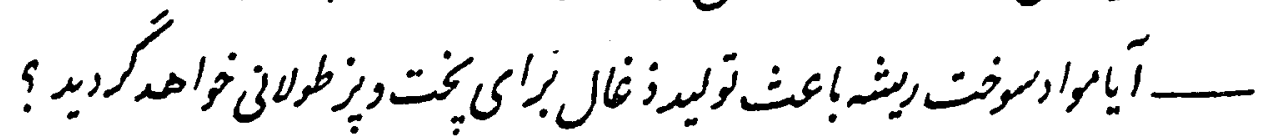

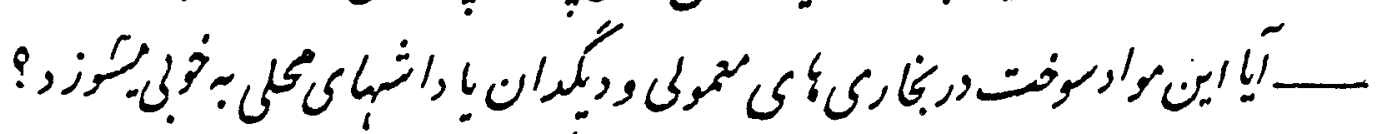

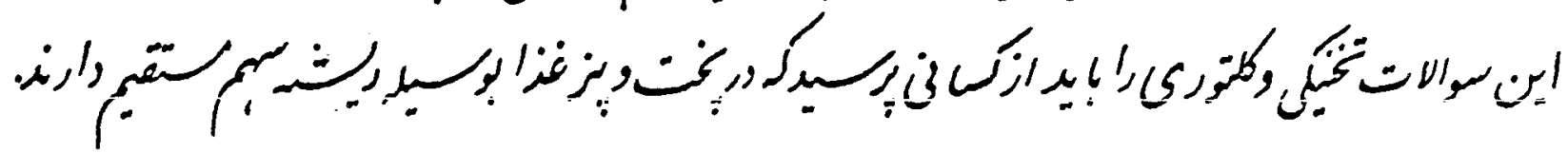

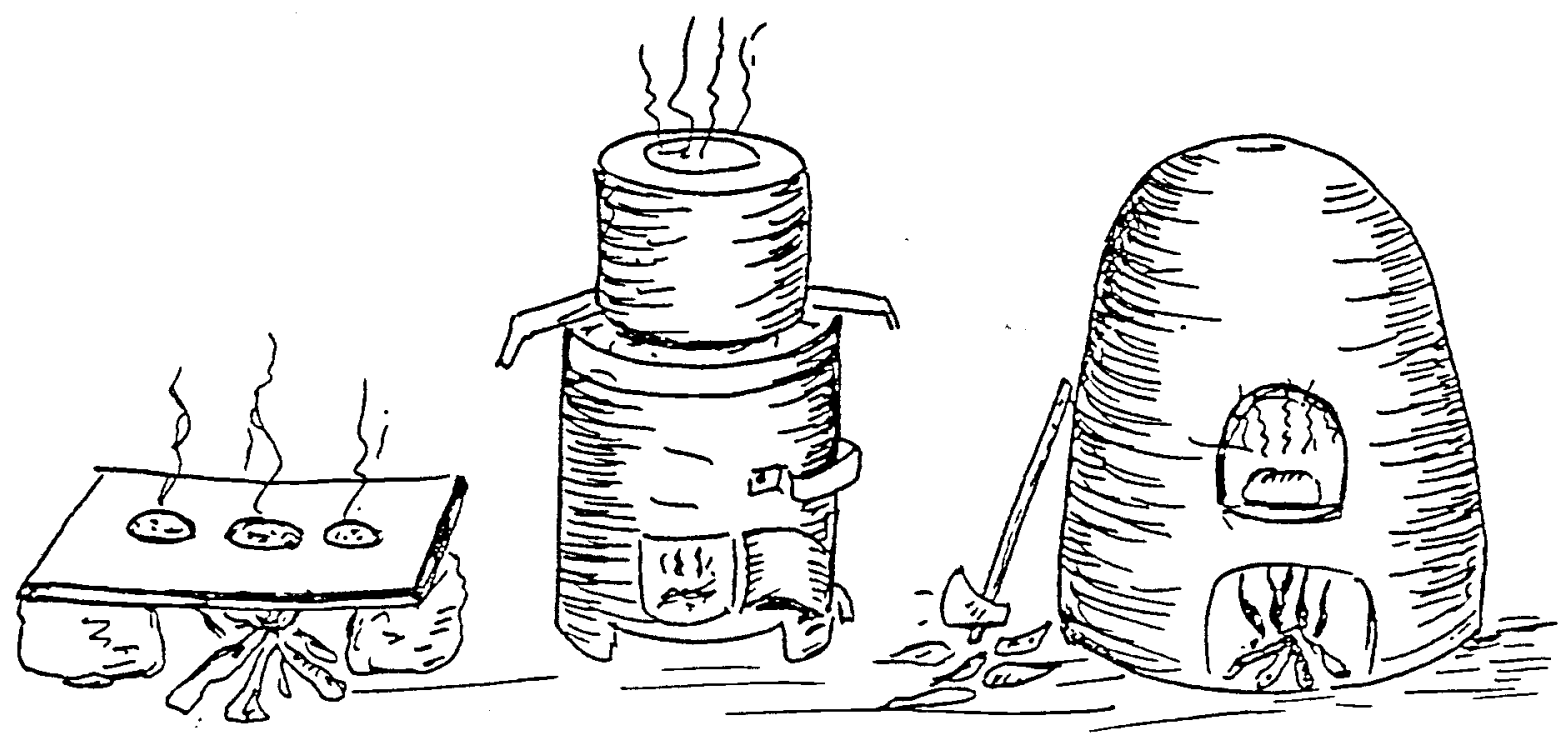

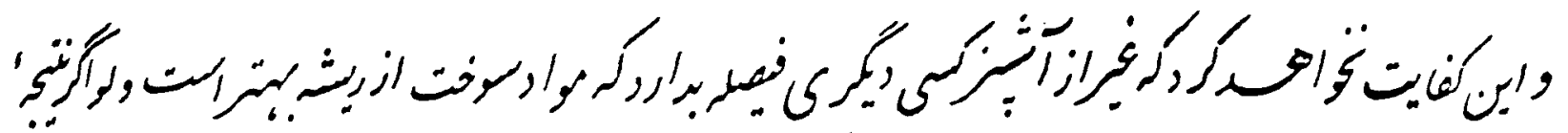

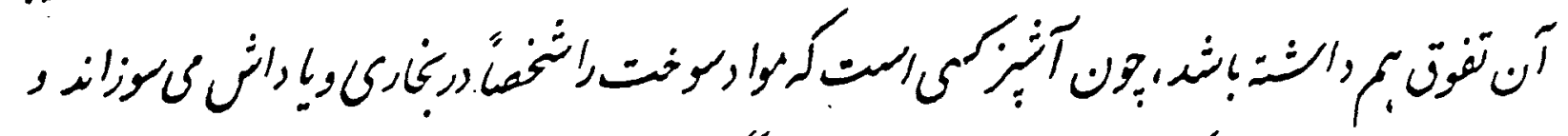

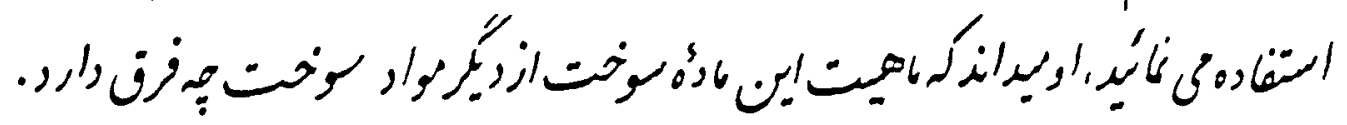

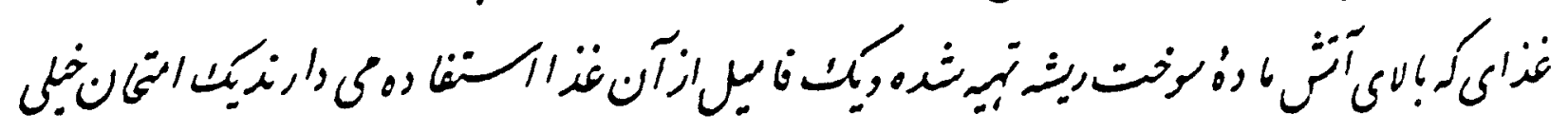

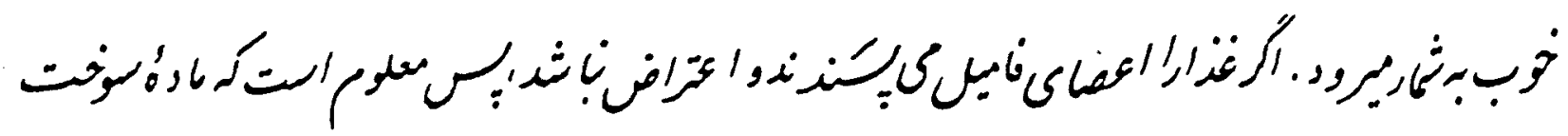
if

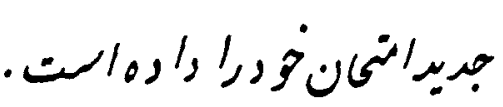




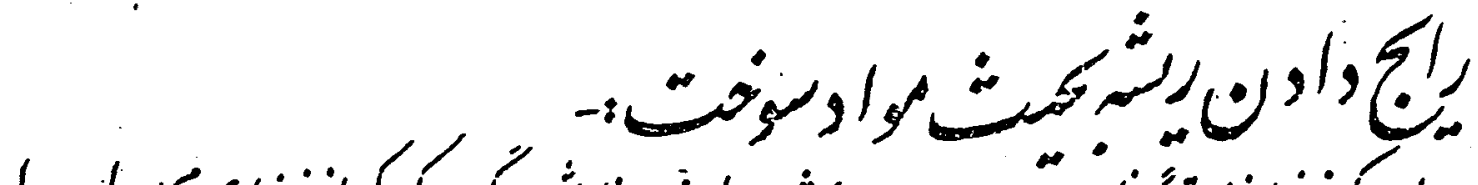

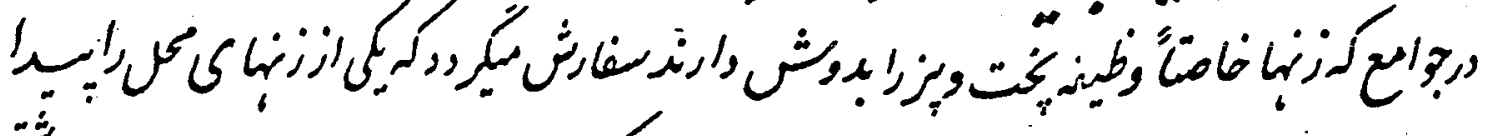

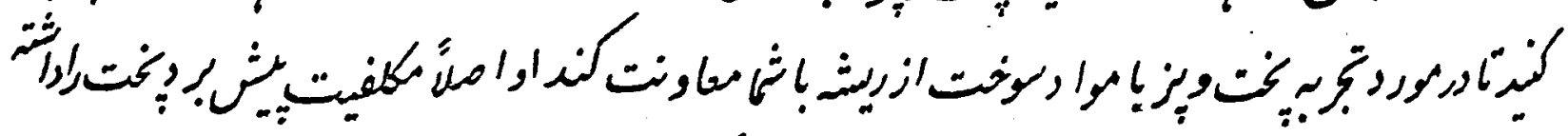

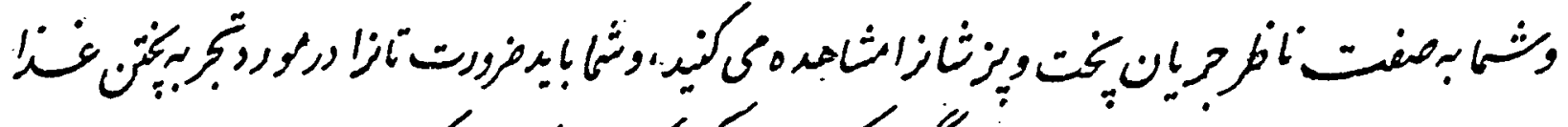

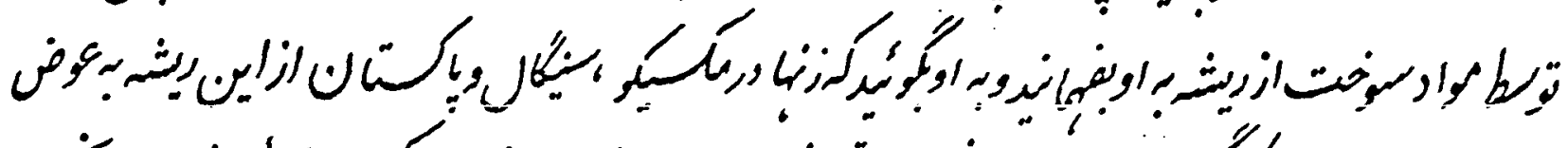

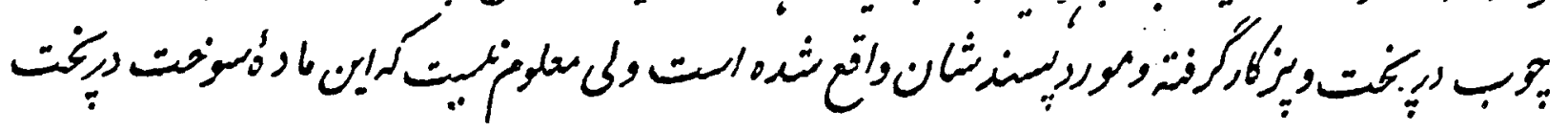

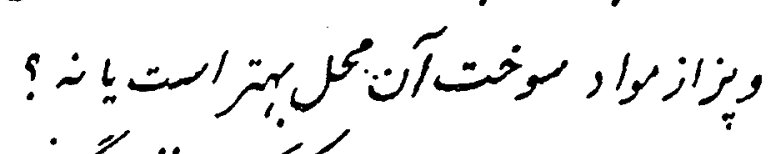

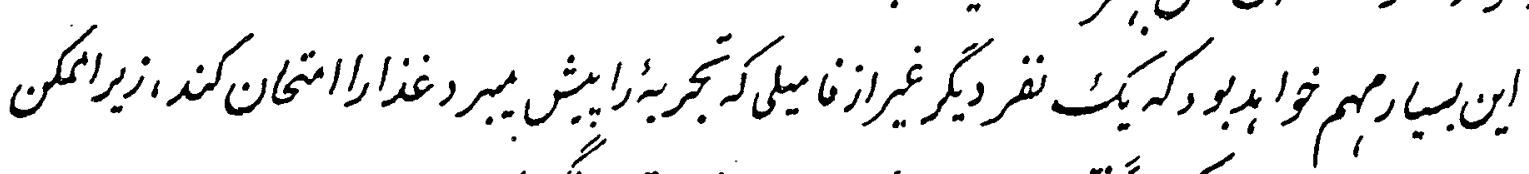

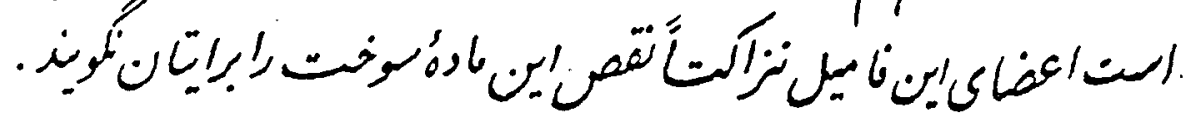

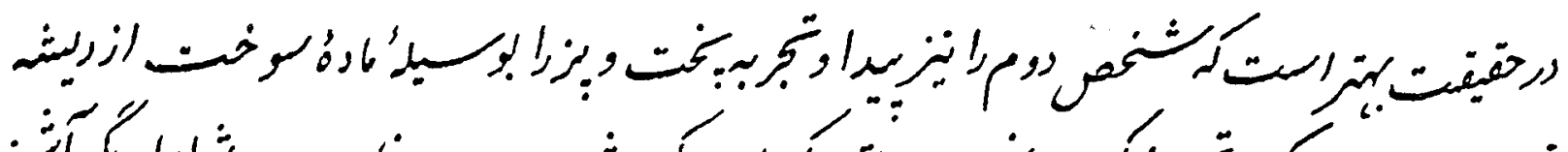

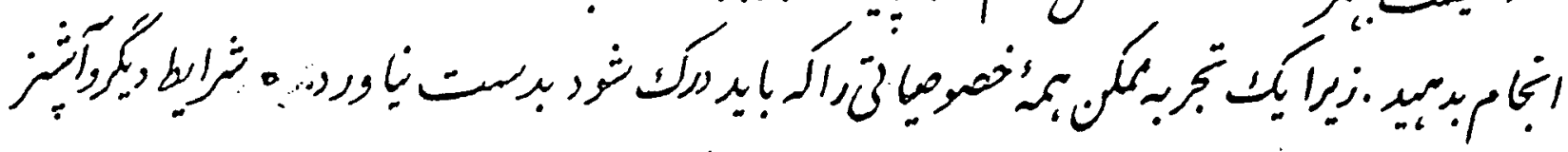

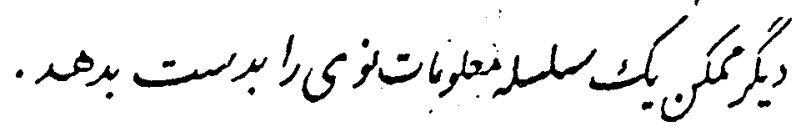




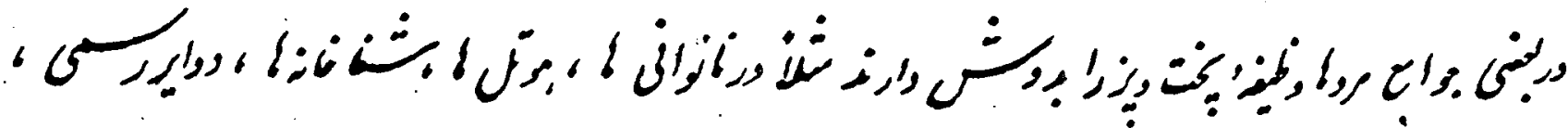

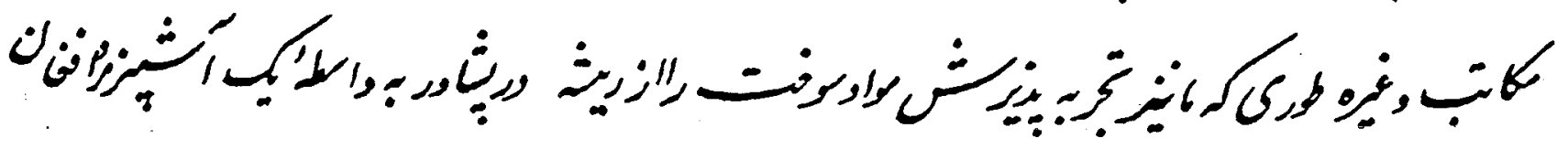

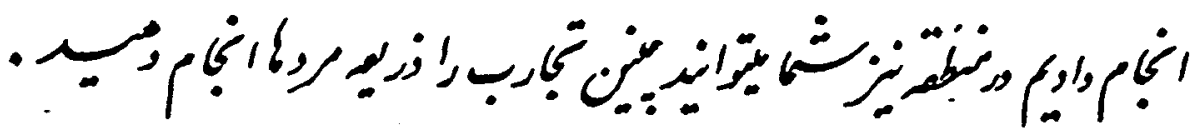

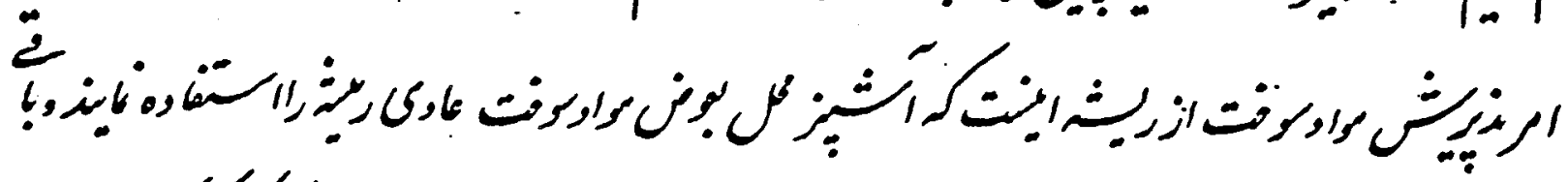

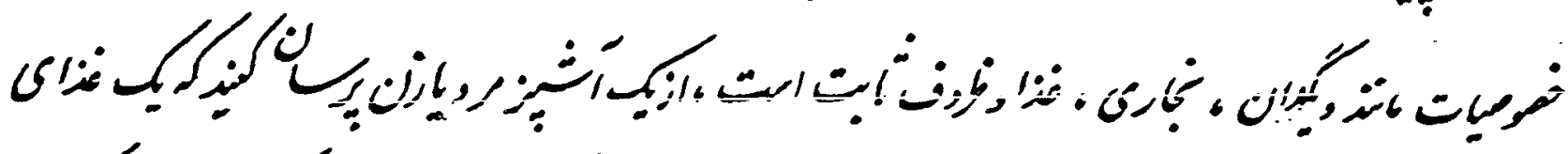

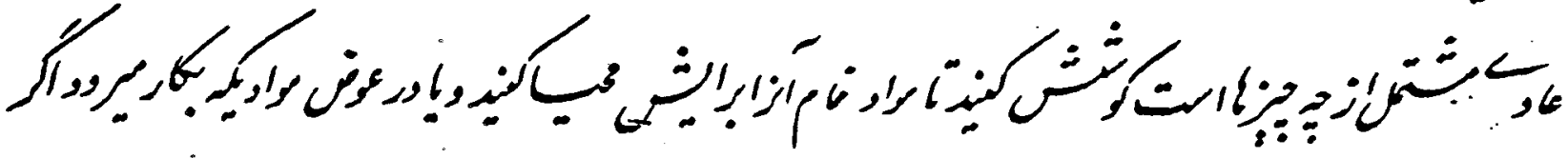

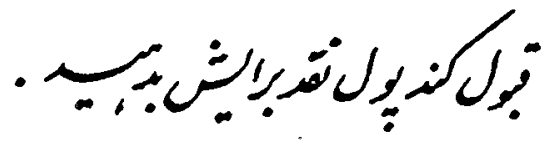

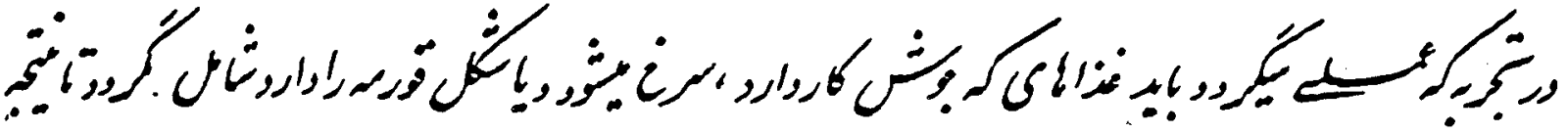

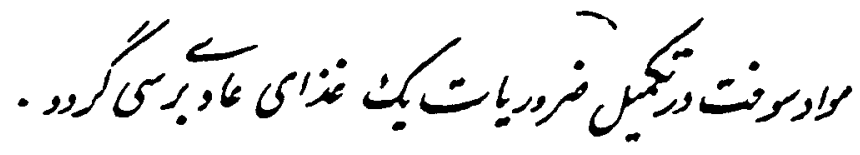

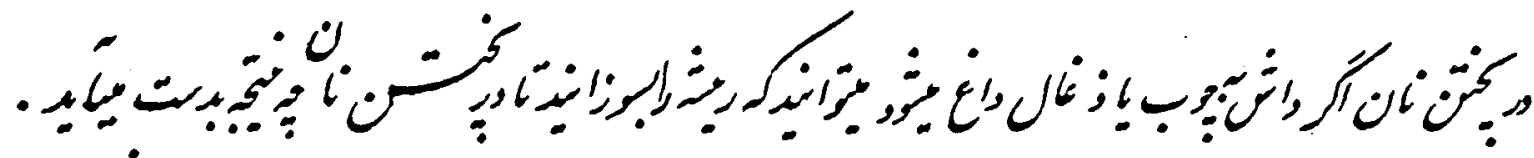

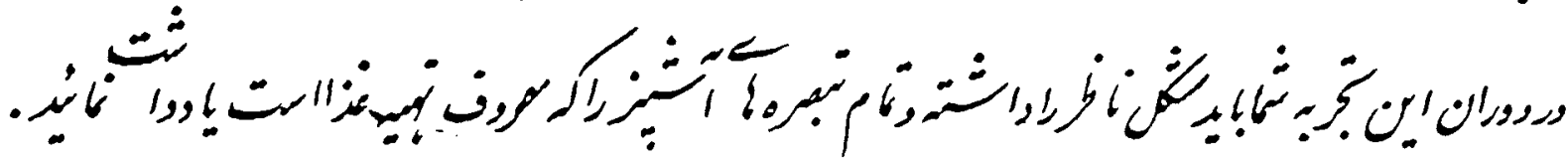

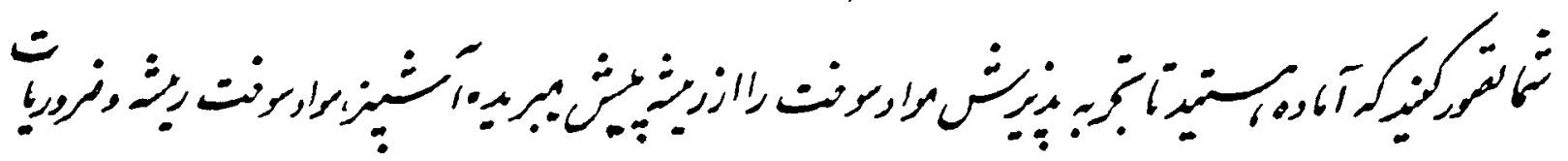

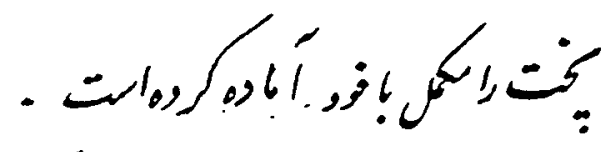
وربن

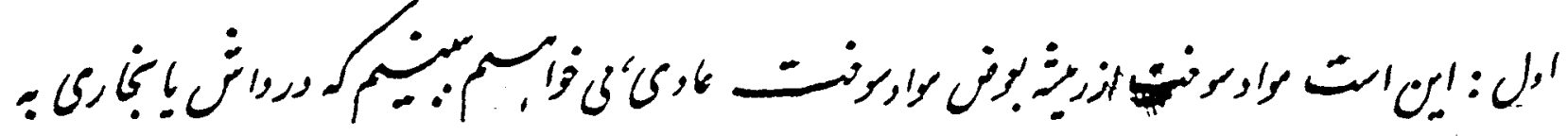
? 


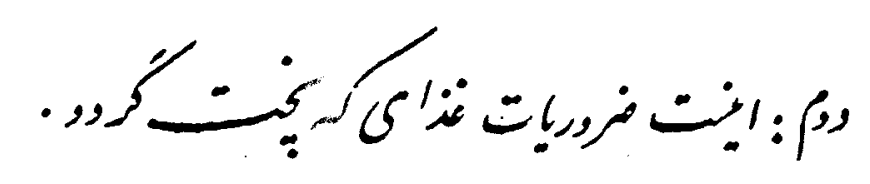

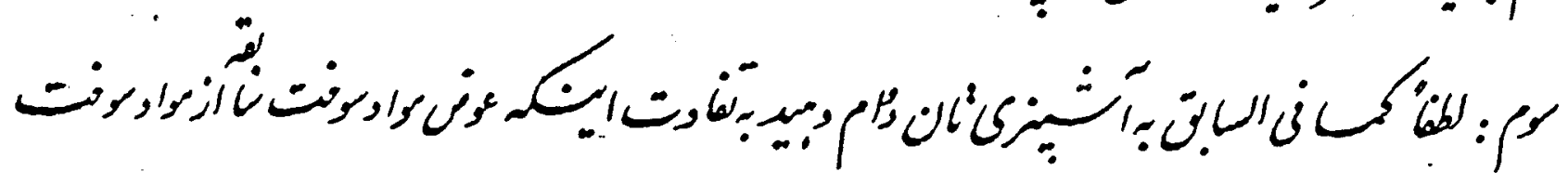

$$
\text { . }
$$

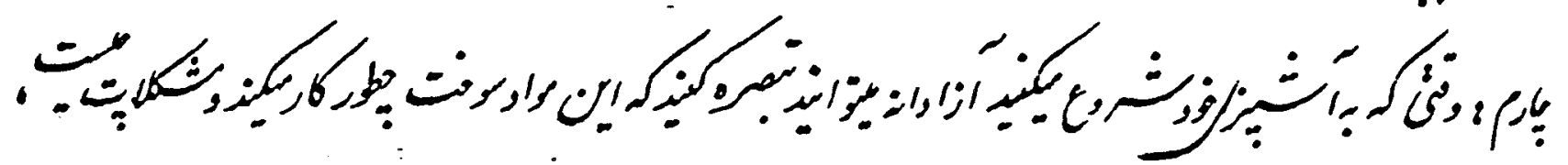

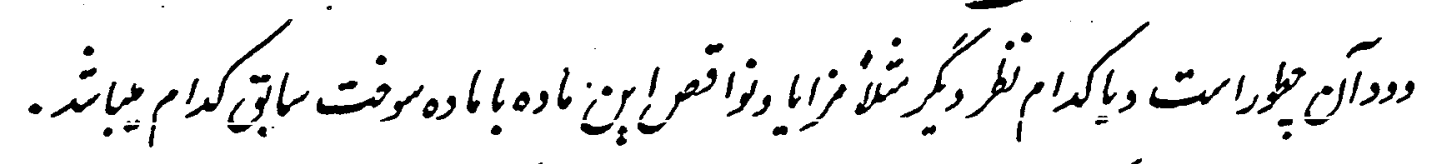

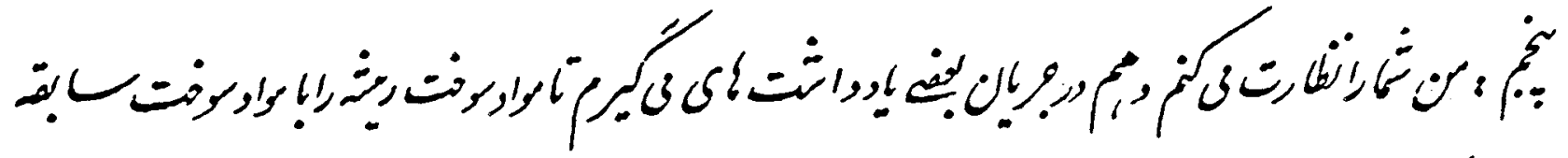
:

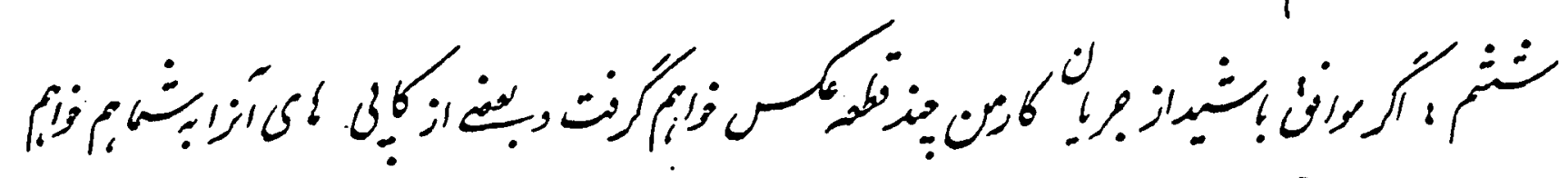
;

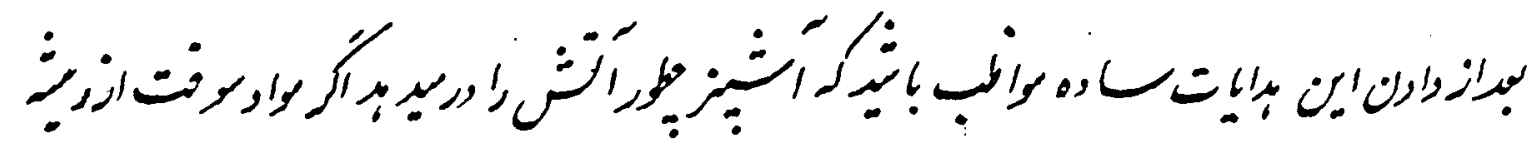

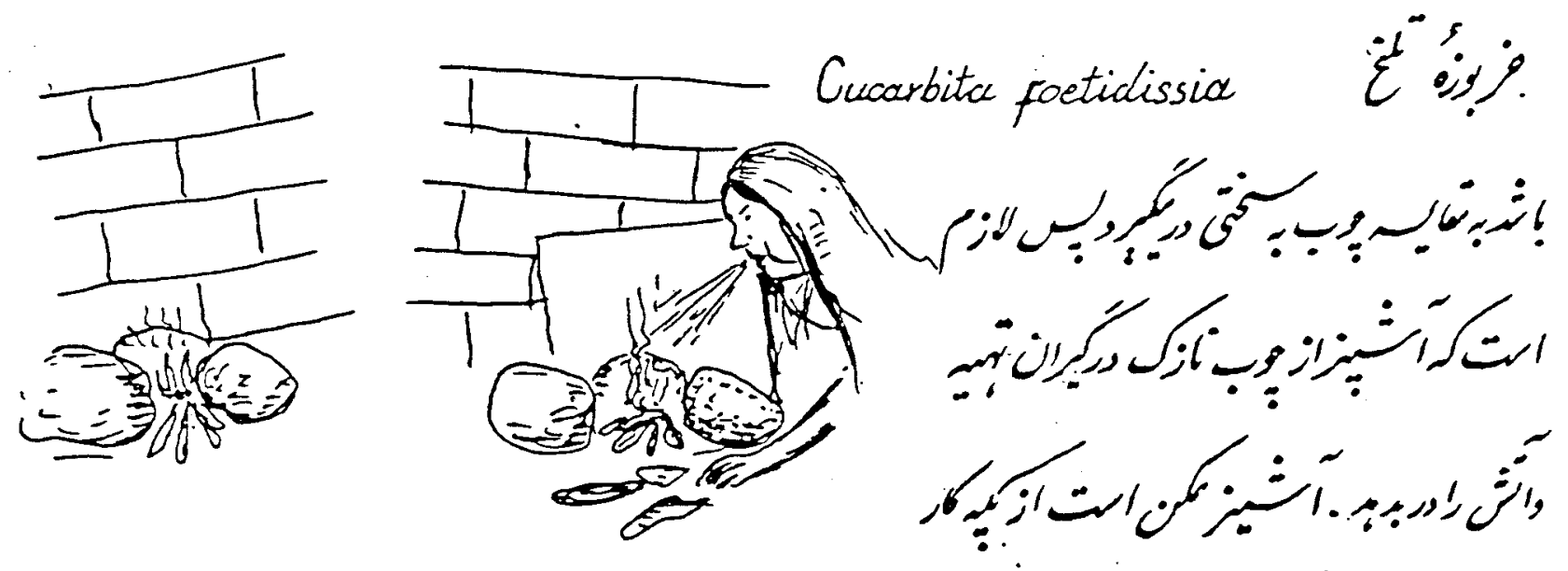

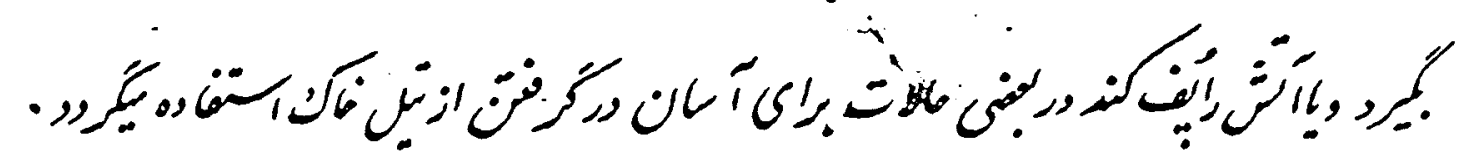

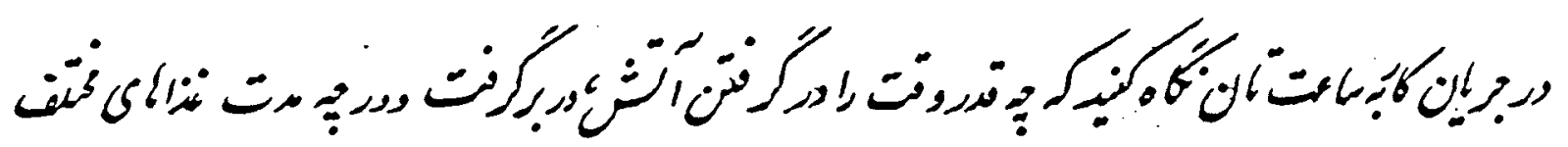


:

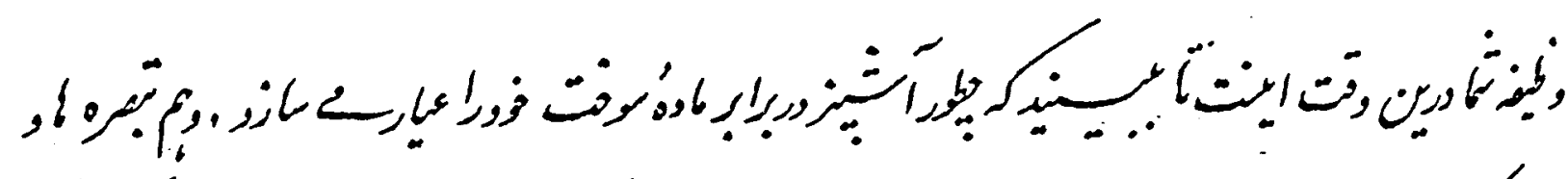

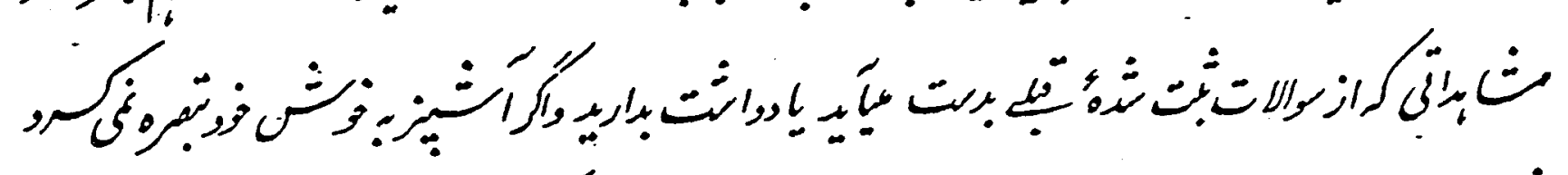

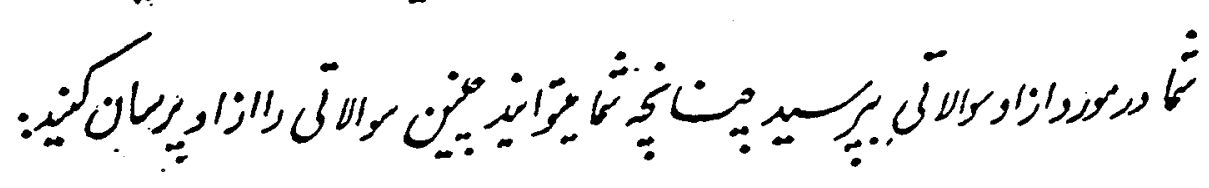

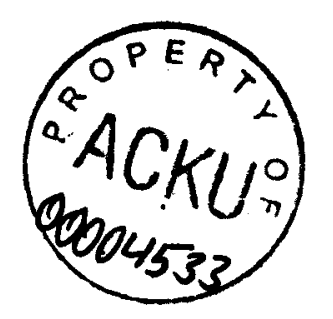

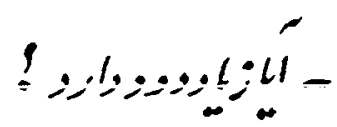

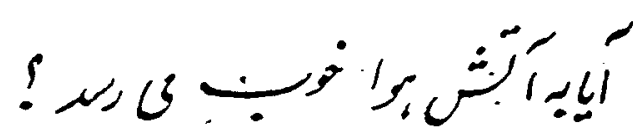

-

ـ -

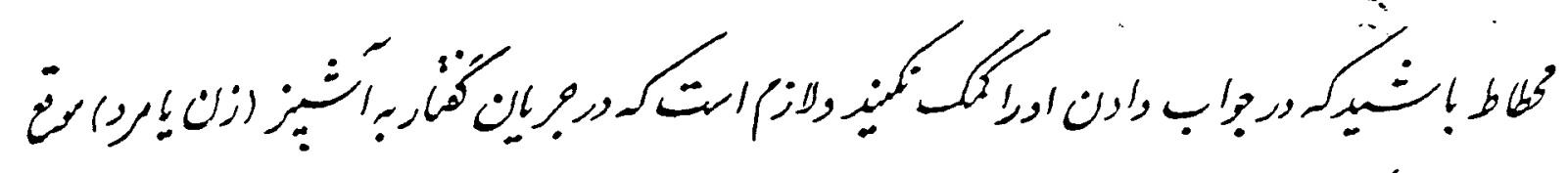

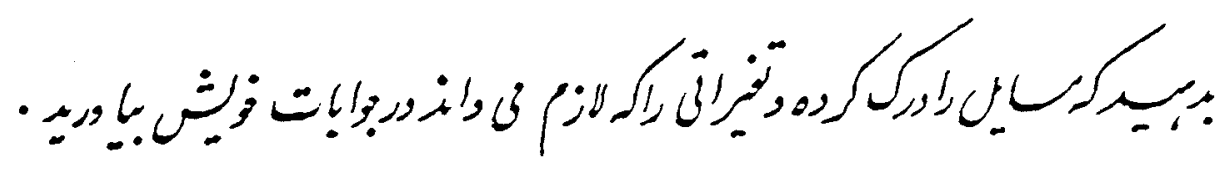

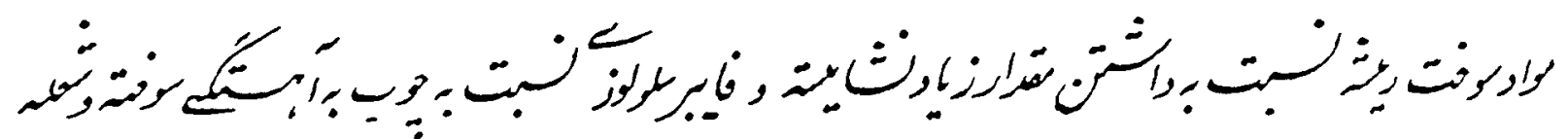

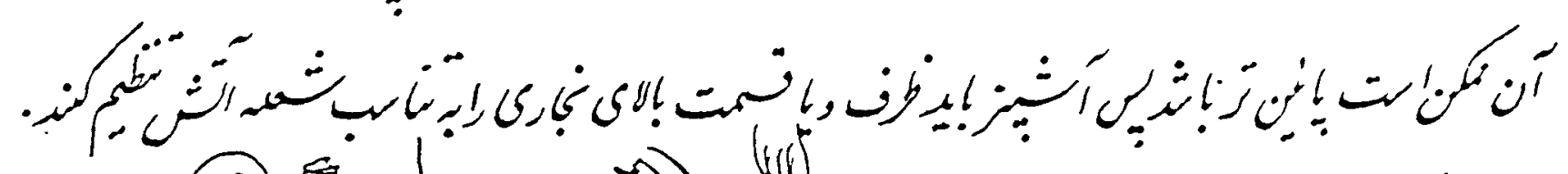

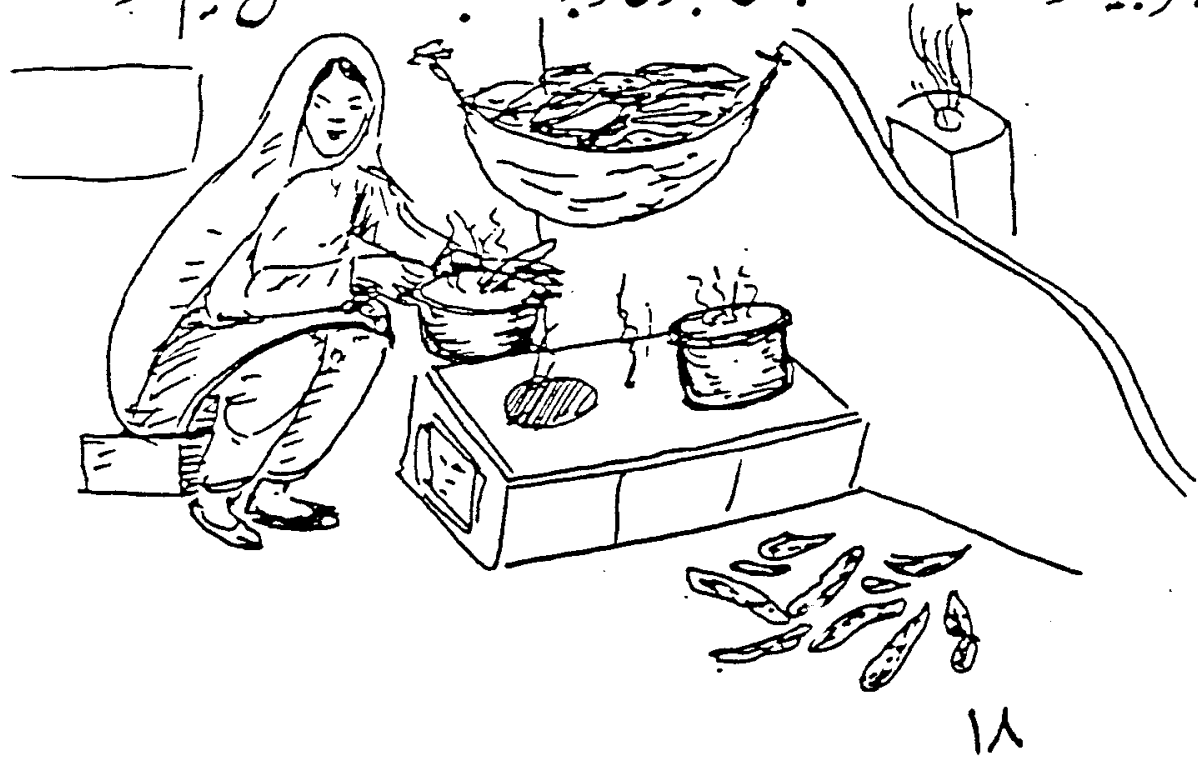

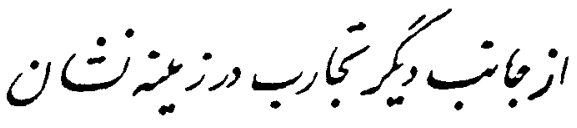

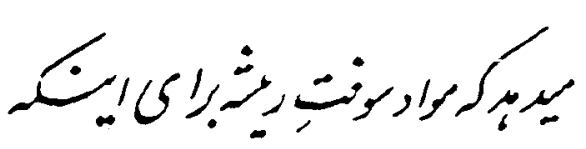

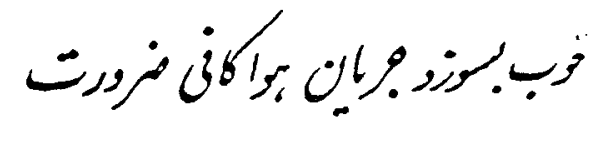

وارو. 


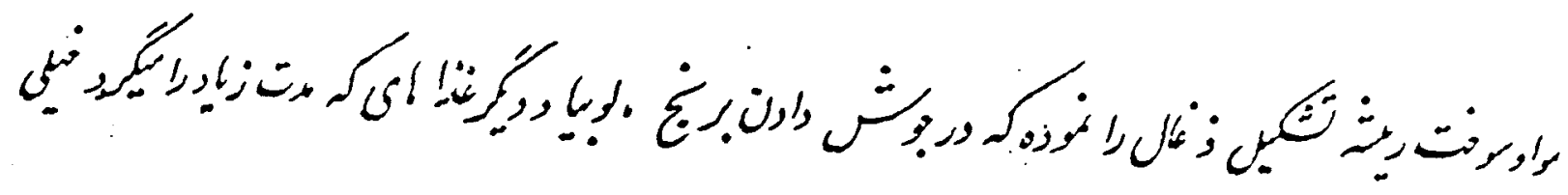

زب/ات .

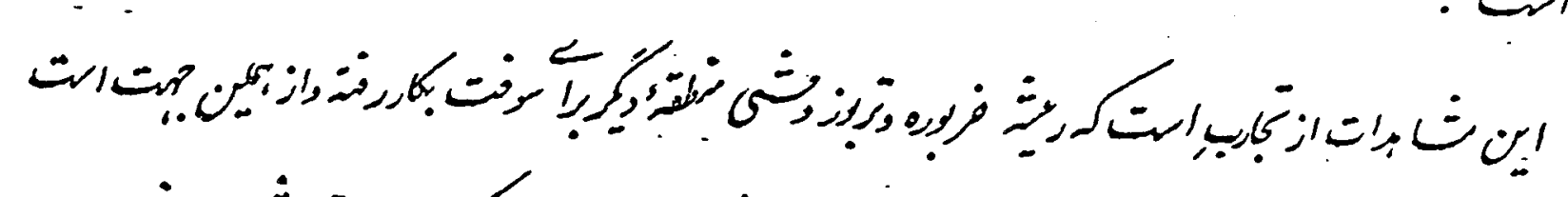

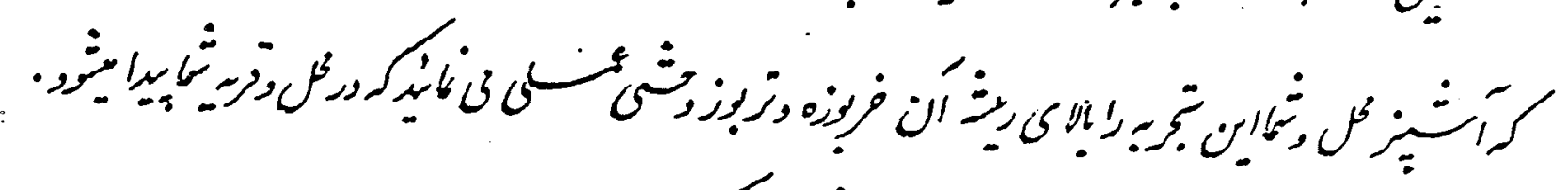

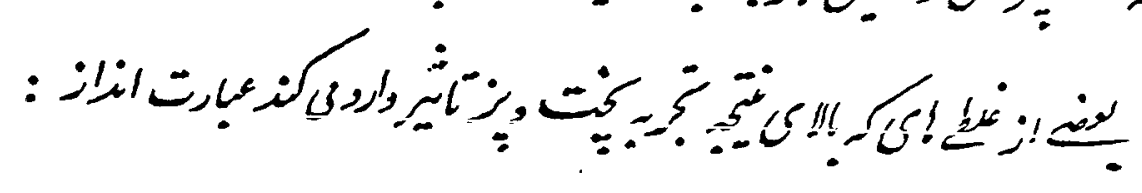

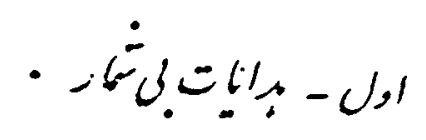

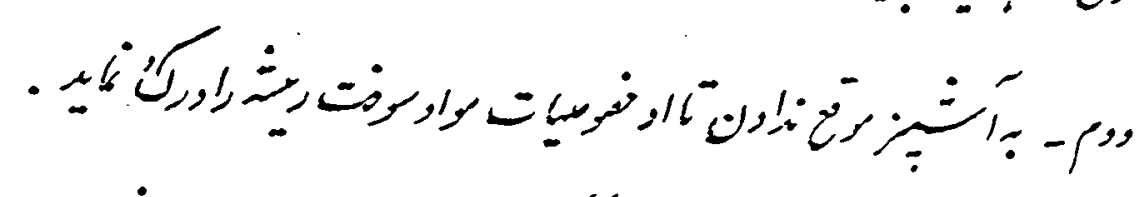

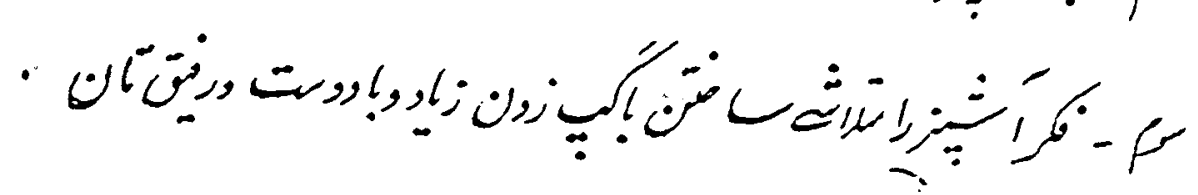

-

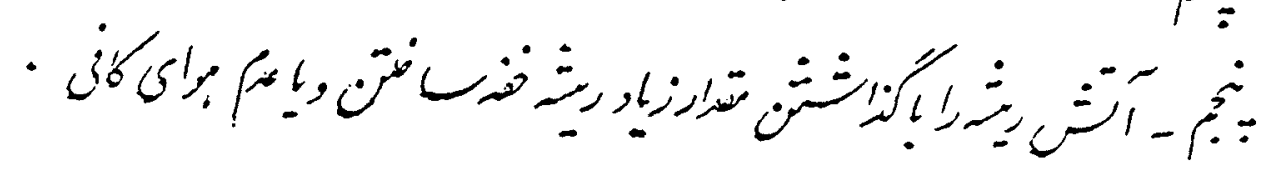

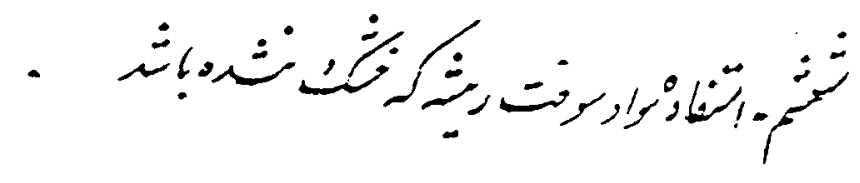

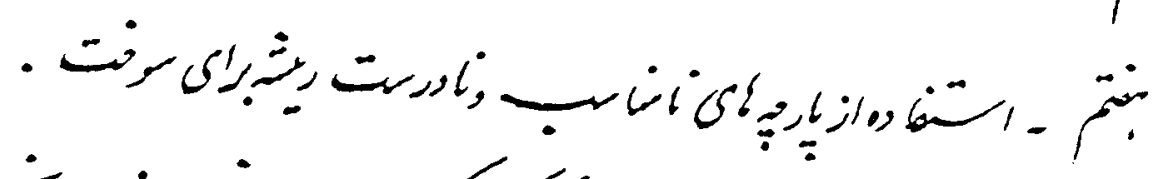

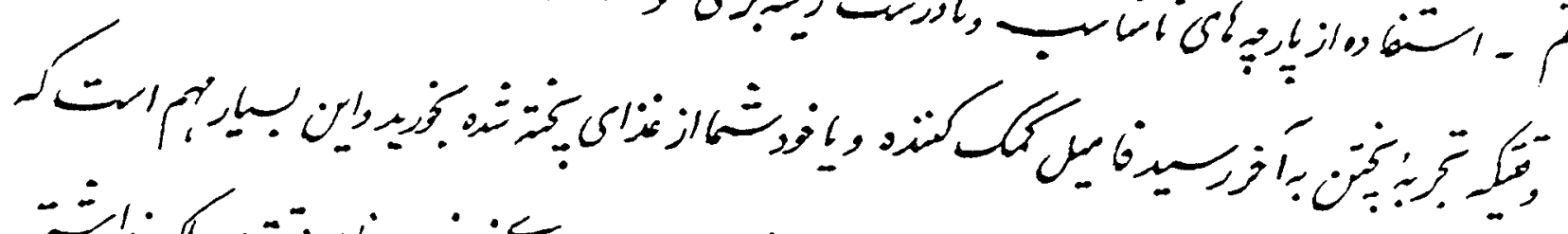

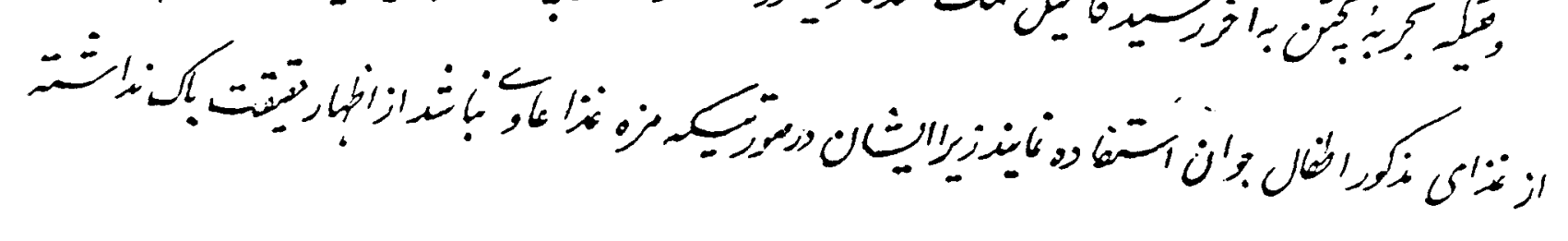

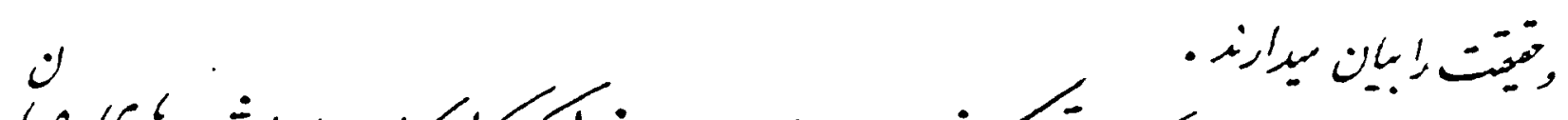

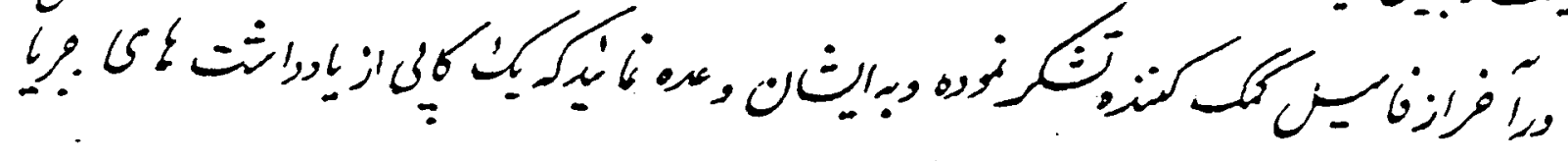

19 


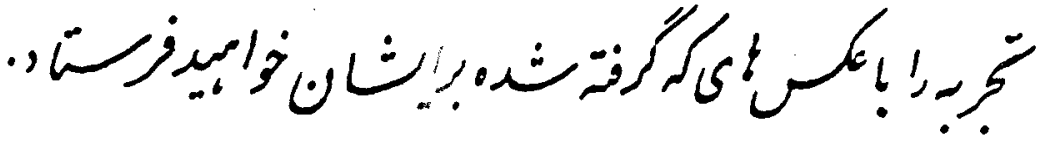

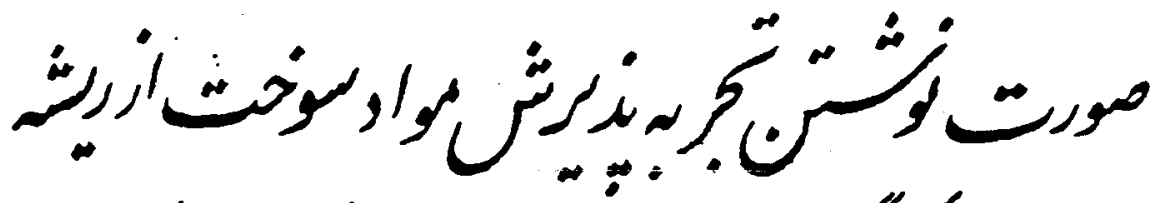

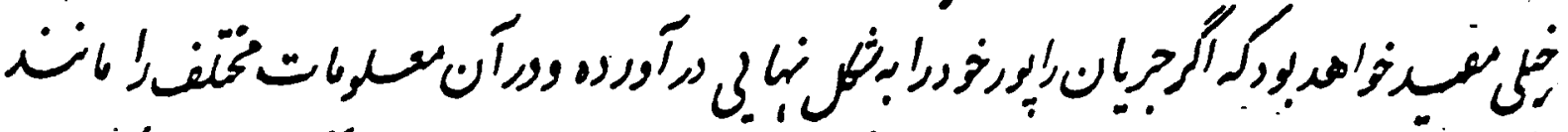

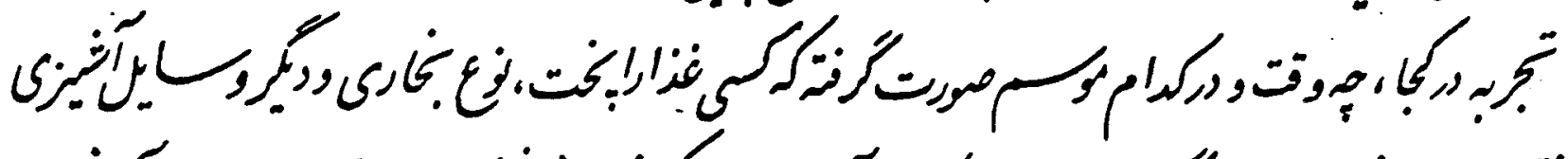

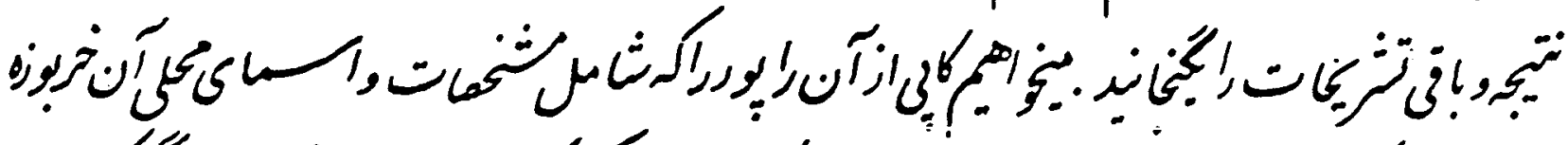

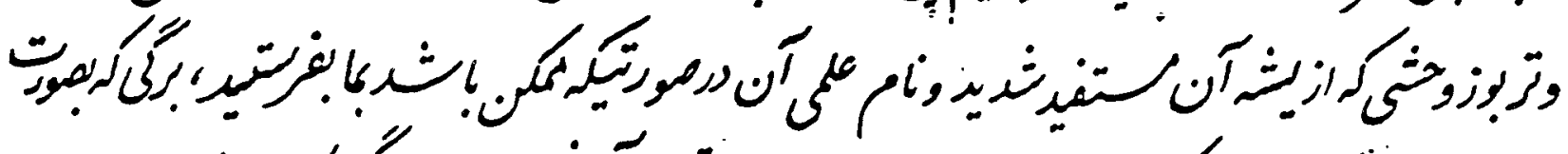

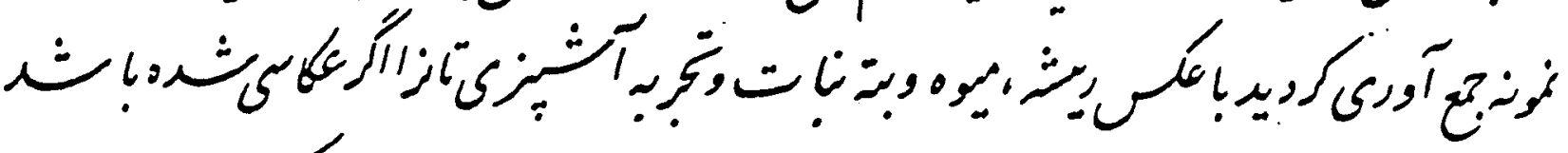

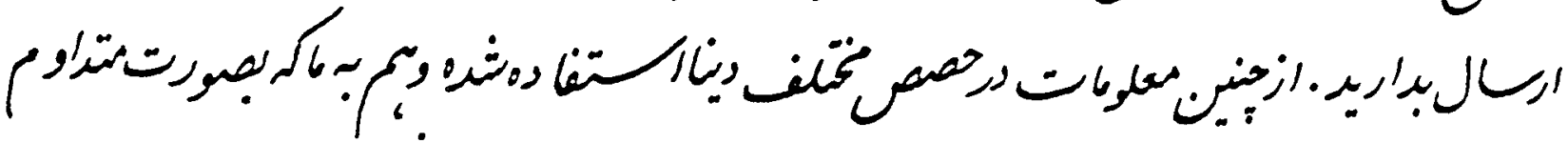

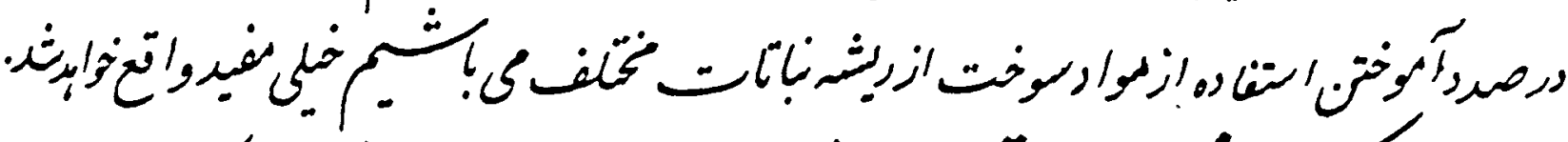

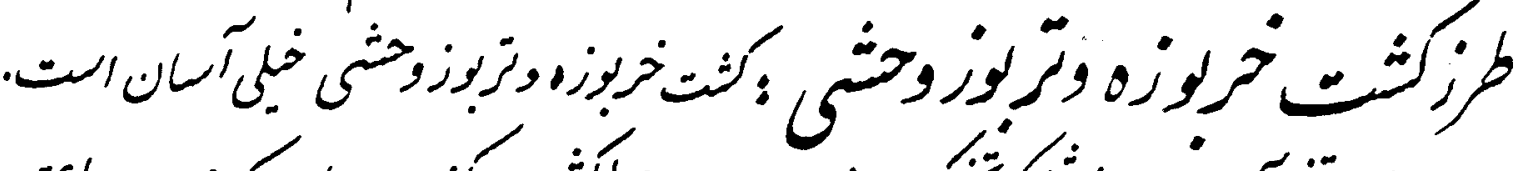

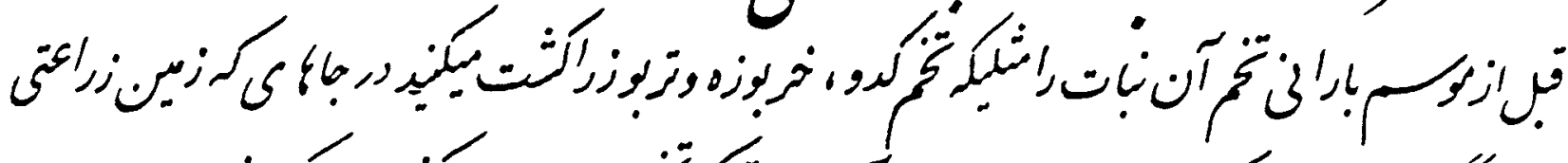

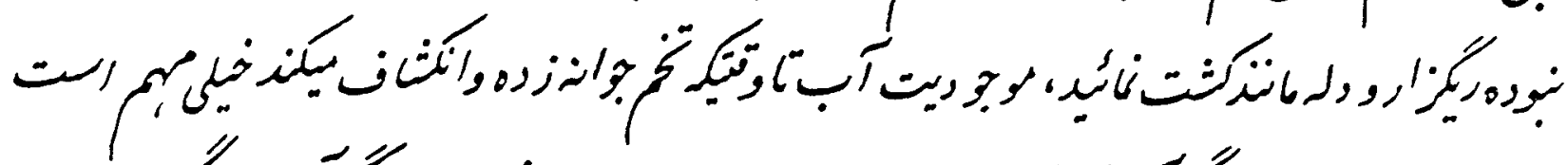

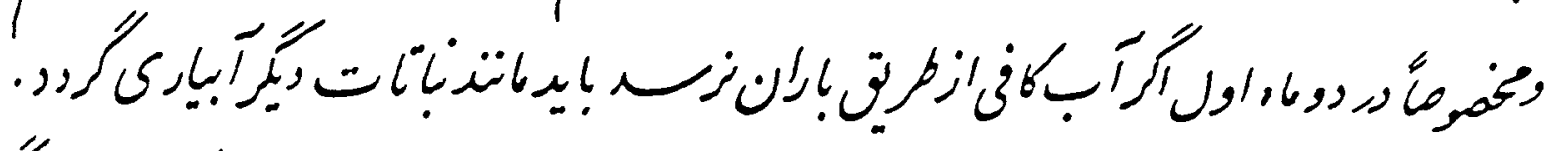

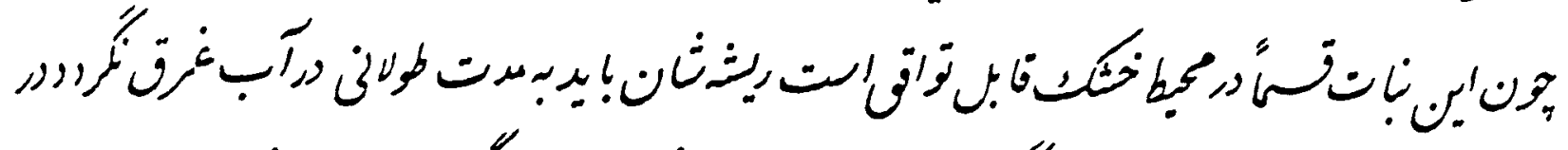

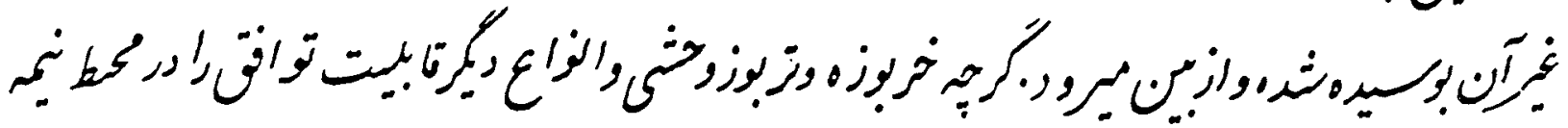

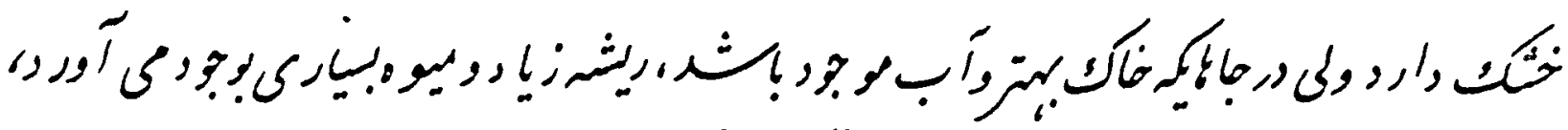

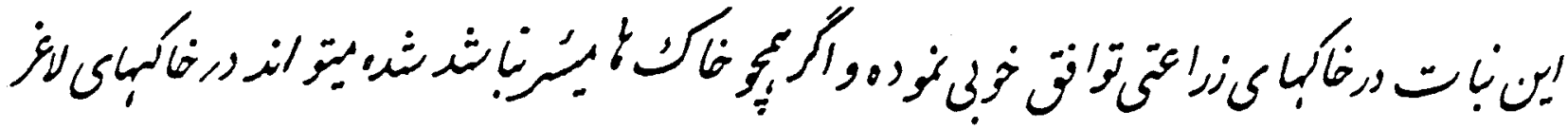

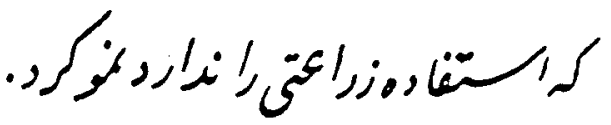




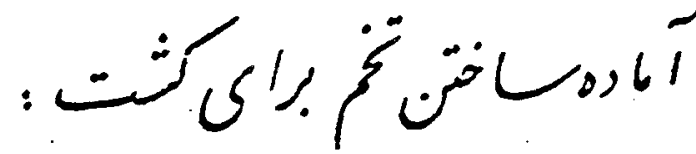

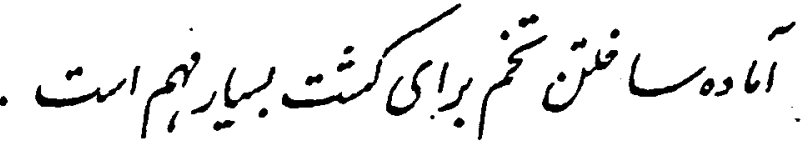

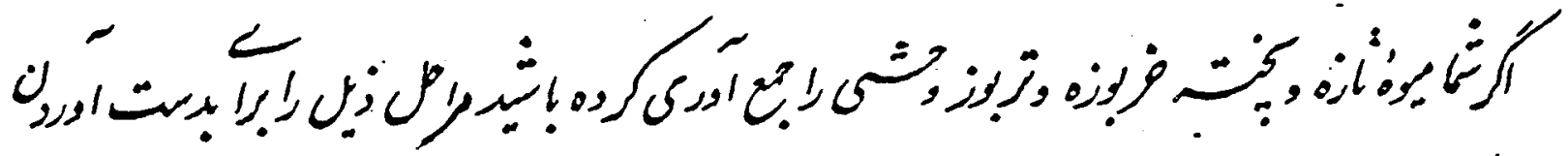

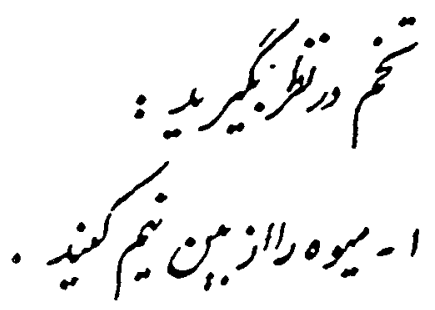

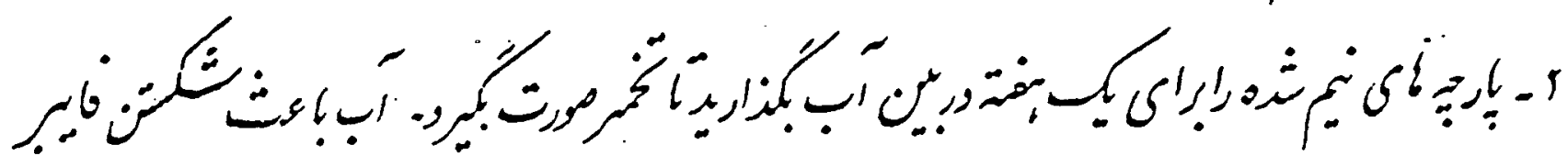

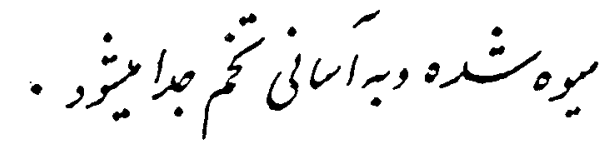
1

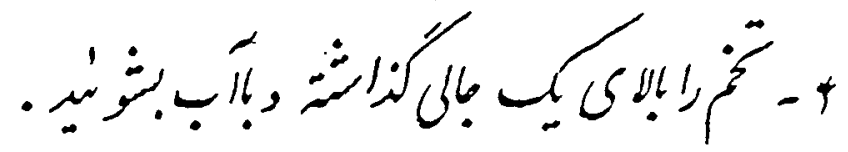

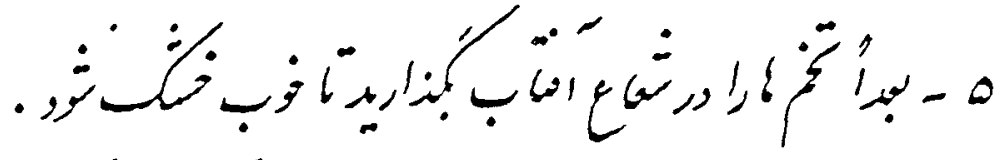

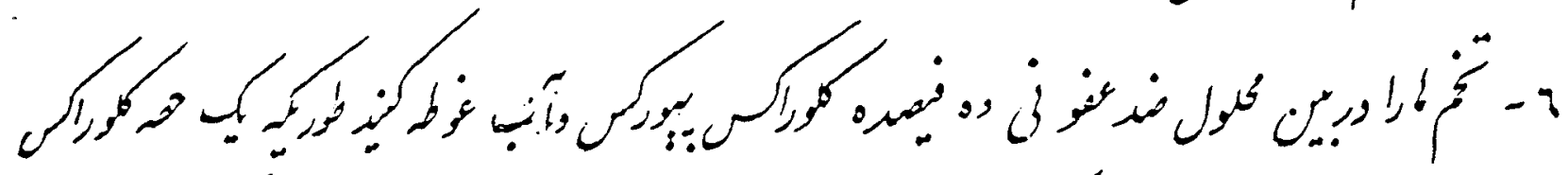

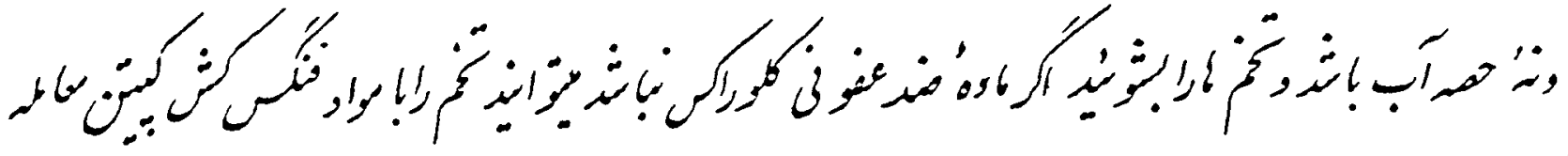
.

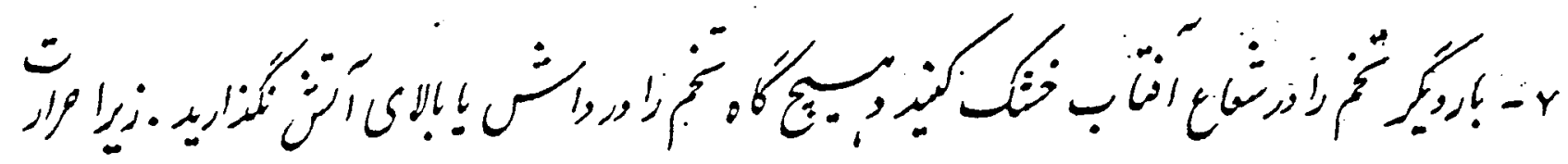

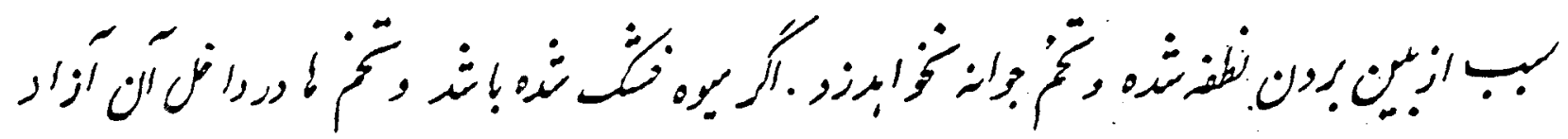

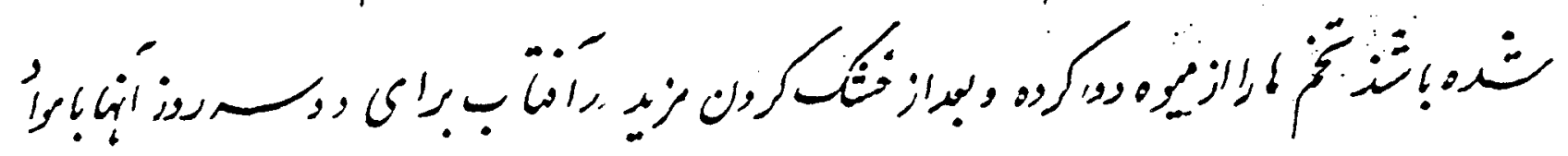




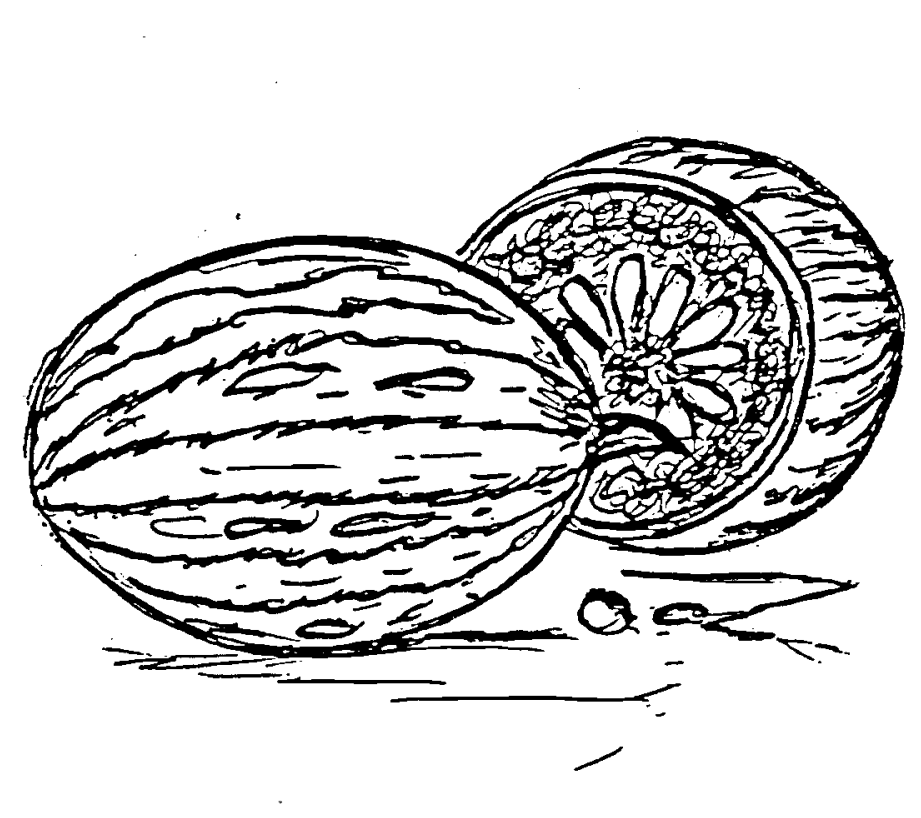

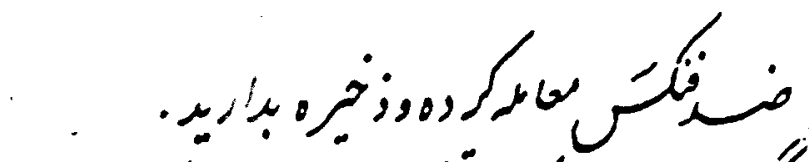

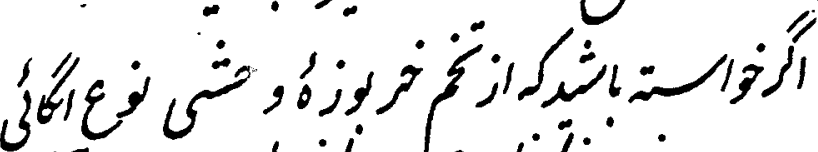
¿Cucurbita foetidissima)

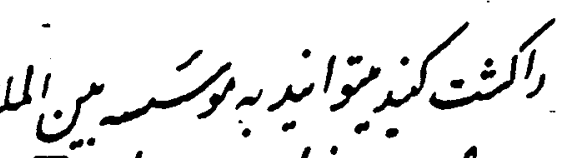
Enable International)

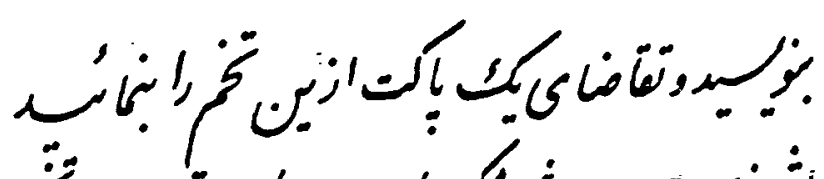

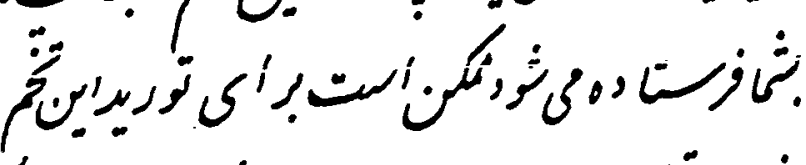

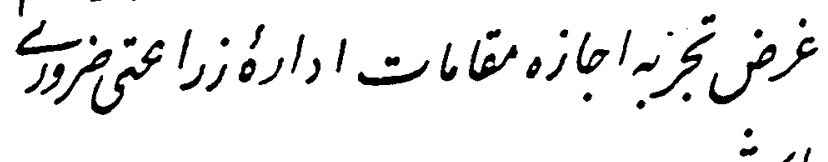


$\therefore$

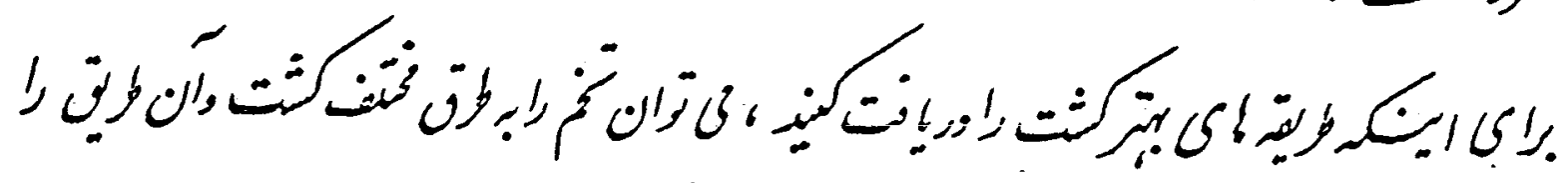

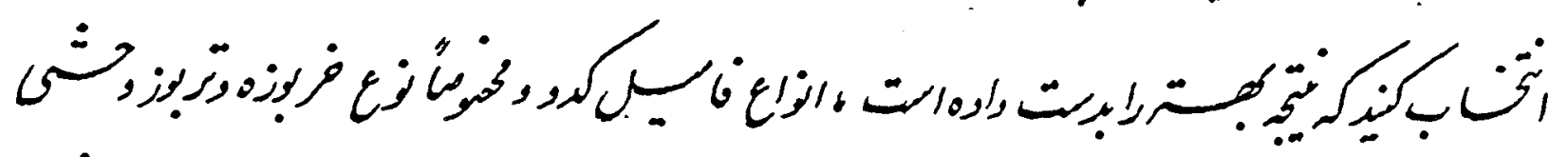
(Cucurbite Foetidissiona)

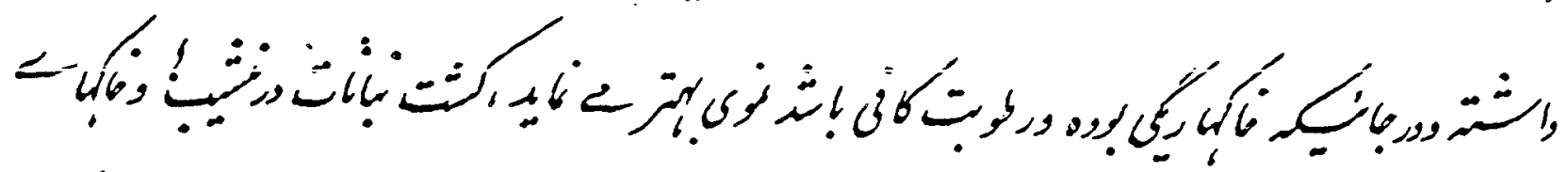

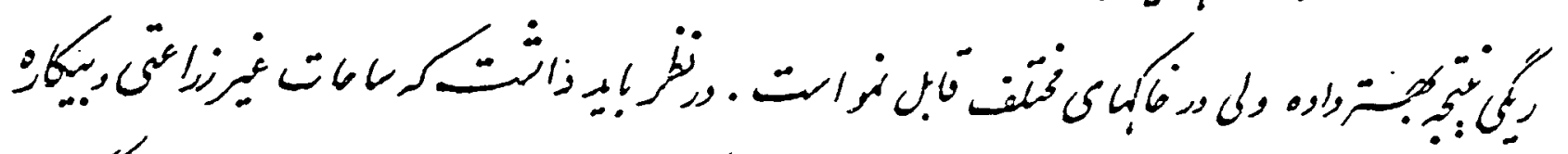

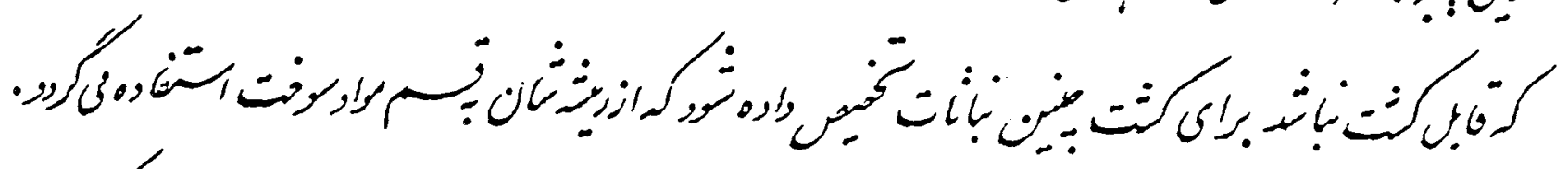

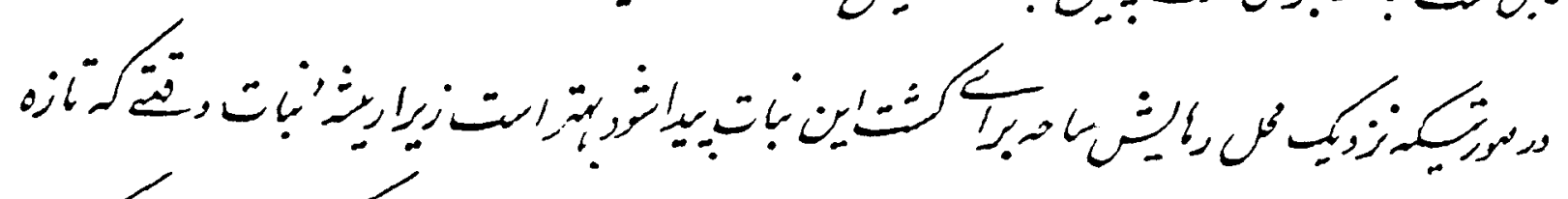

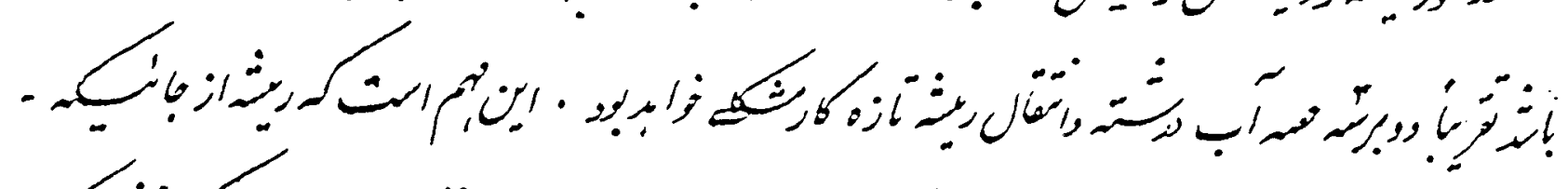

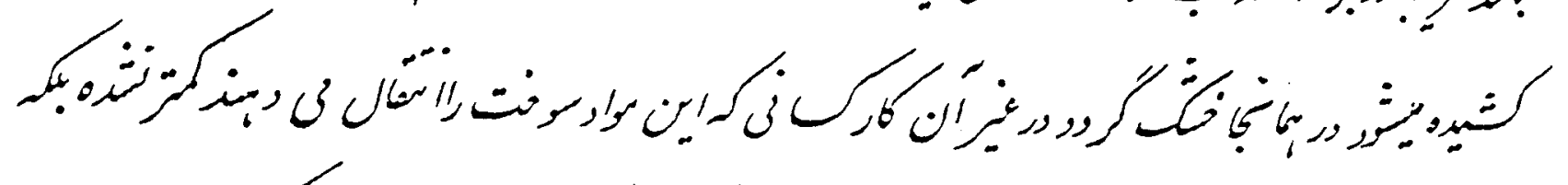

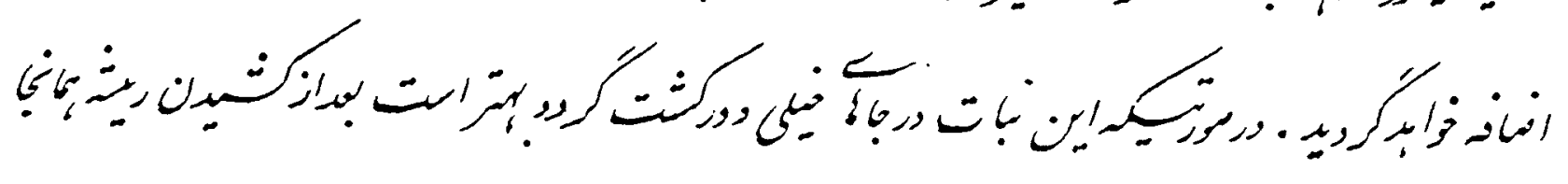
ن

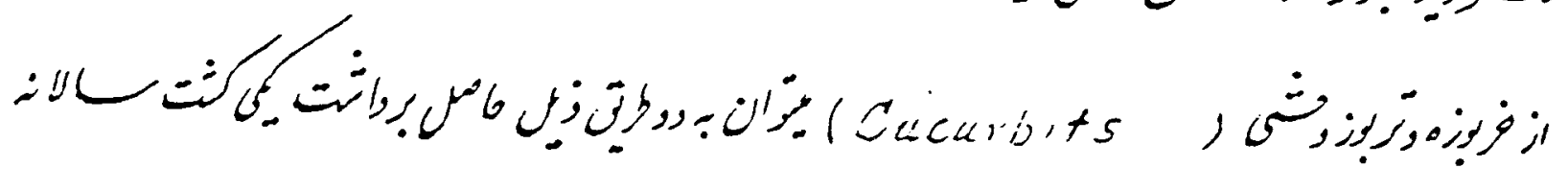
- 'ل

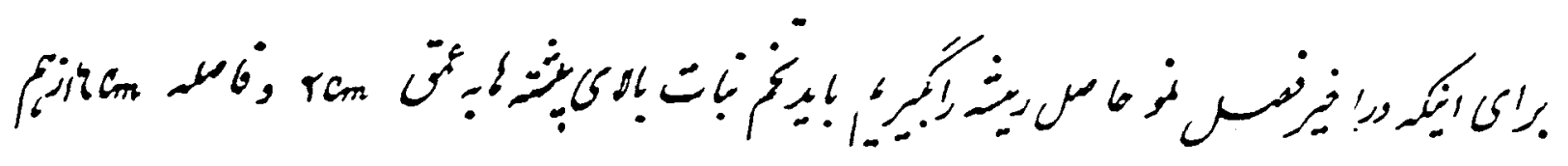




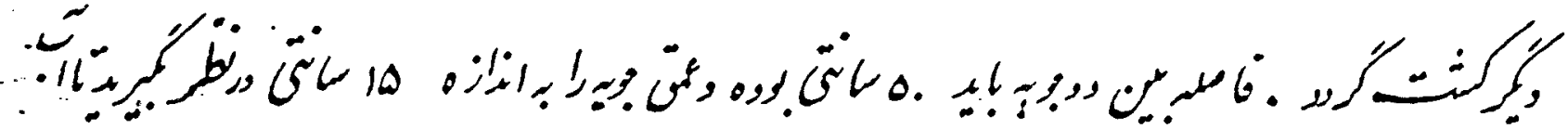

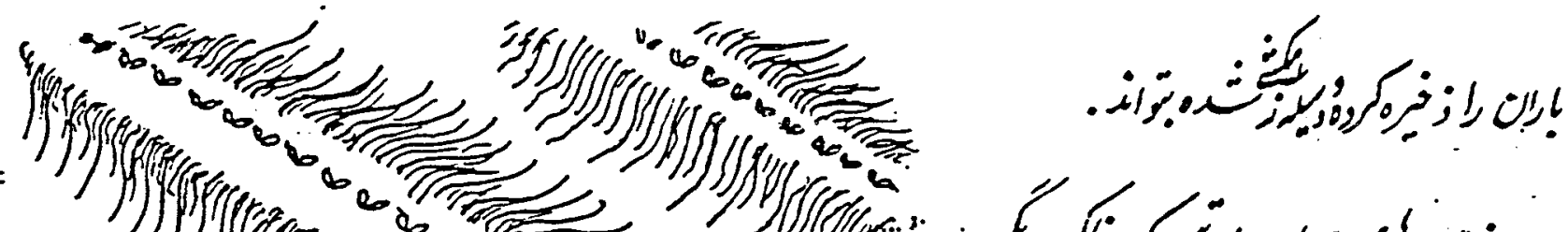

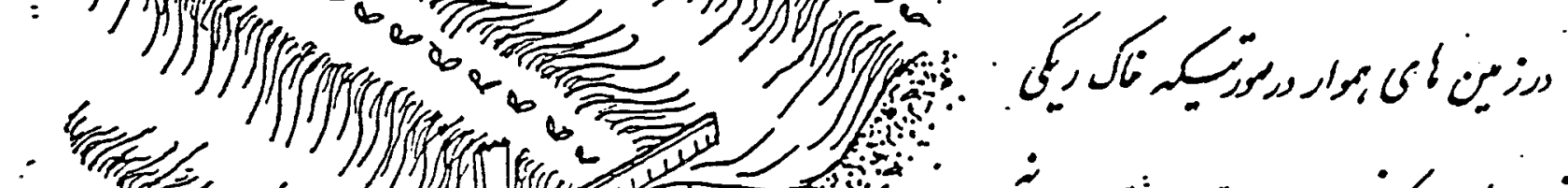
! 栣红

1)

$$
\int \sqrt{100}
$$

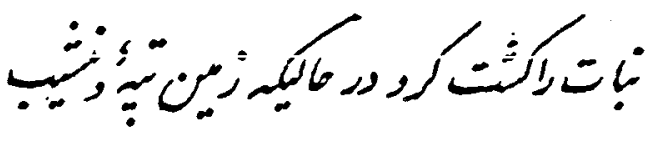

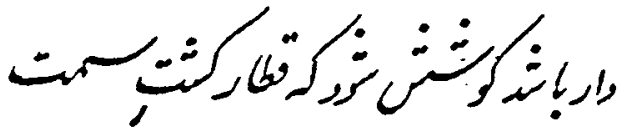

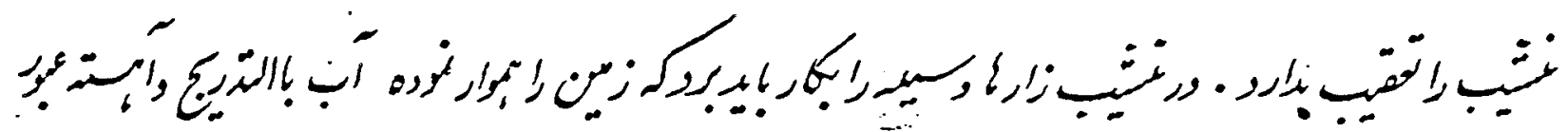

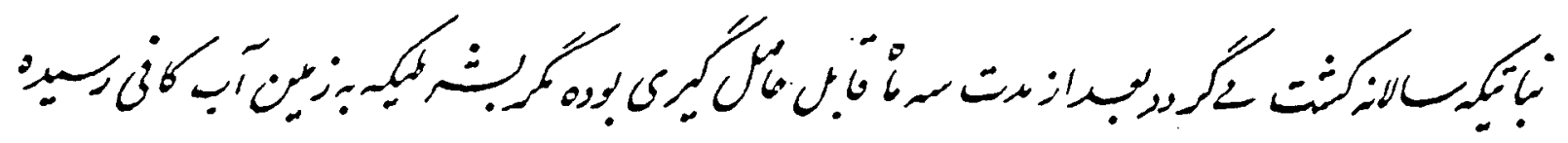

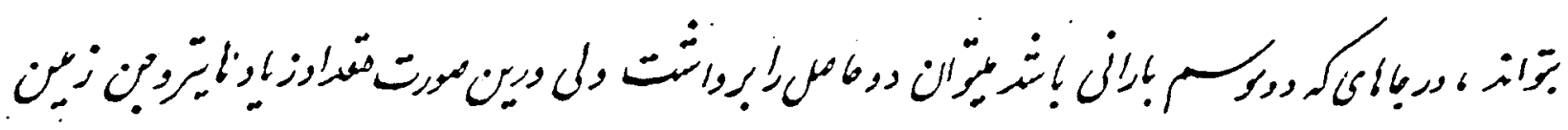

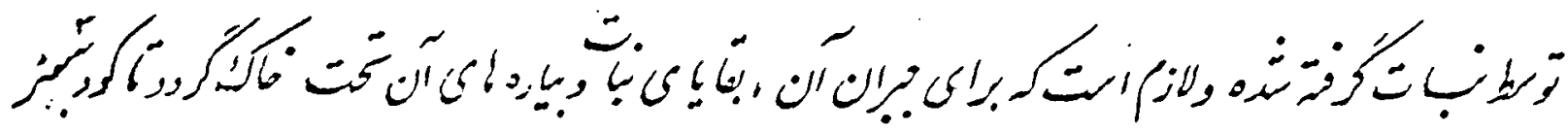

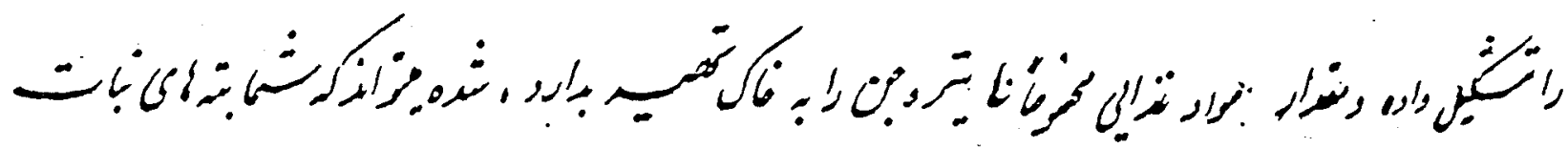

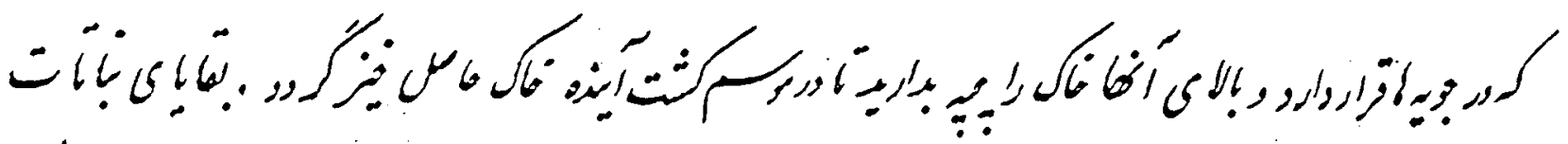

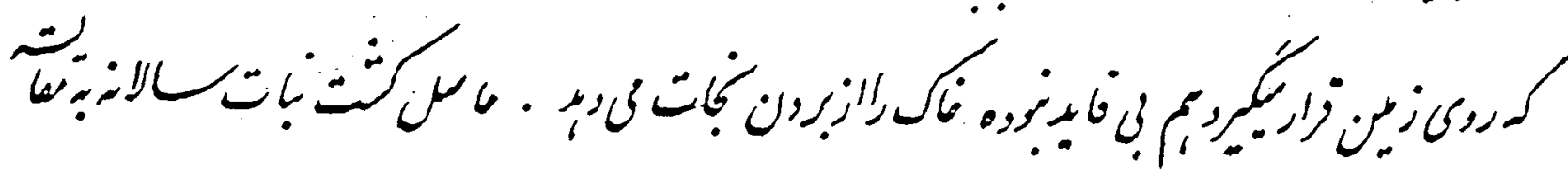

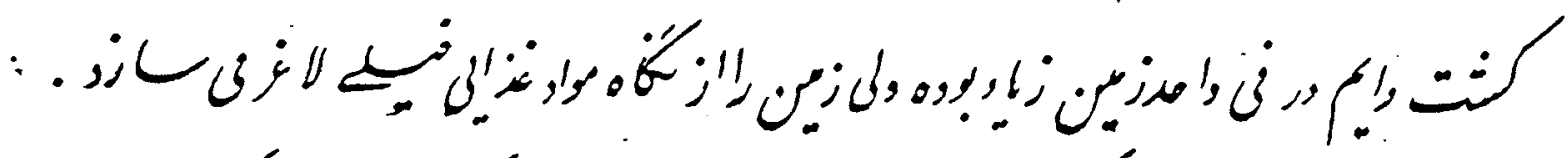

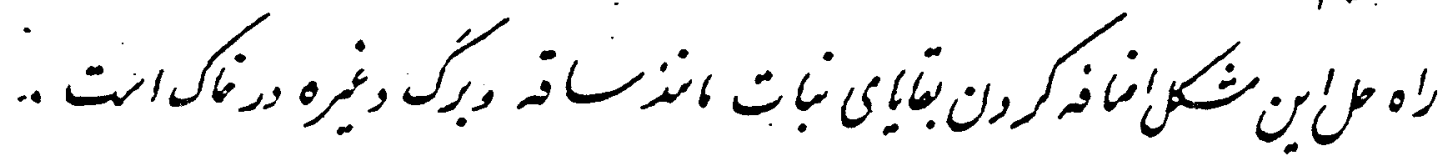



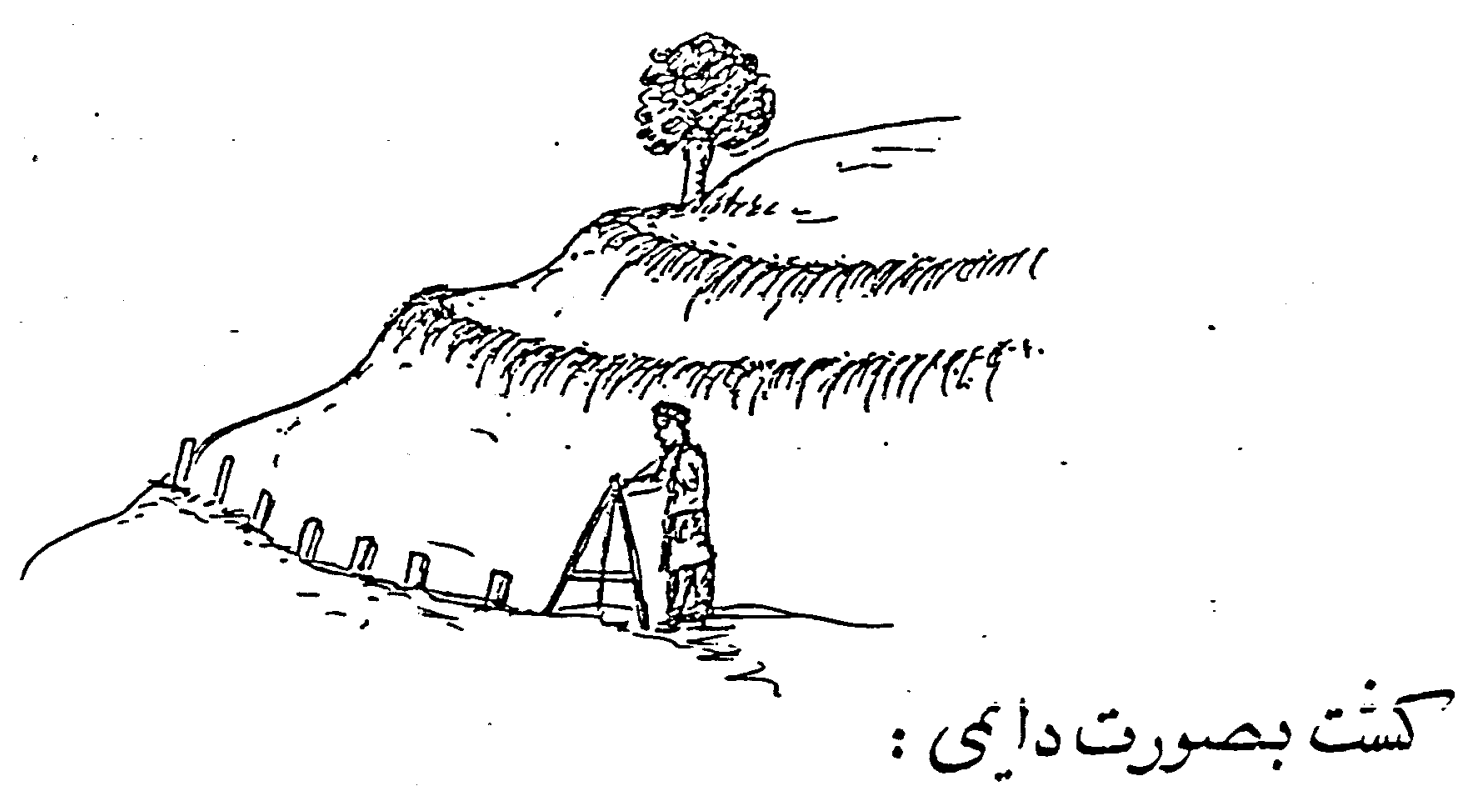

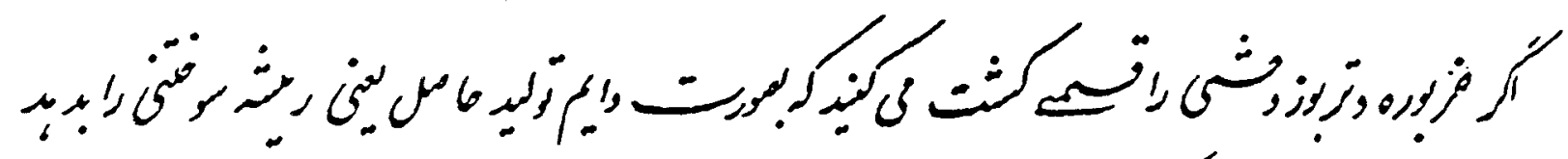

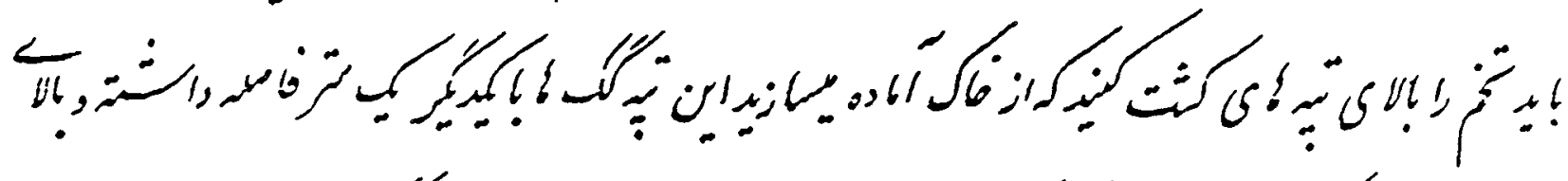

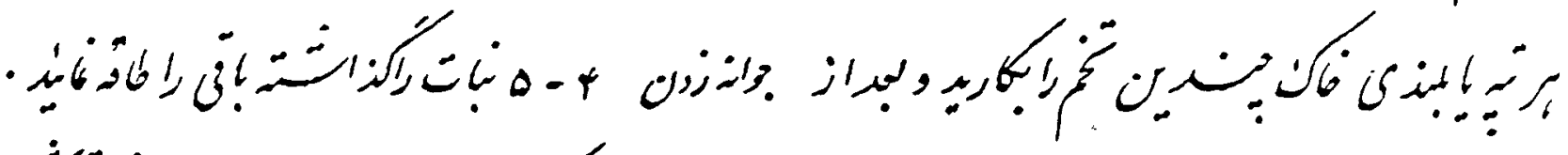

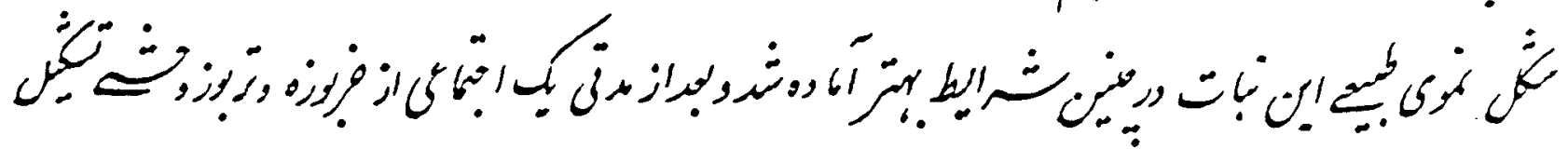

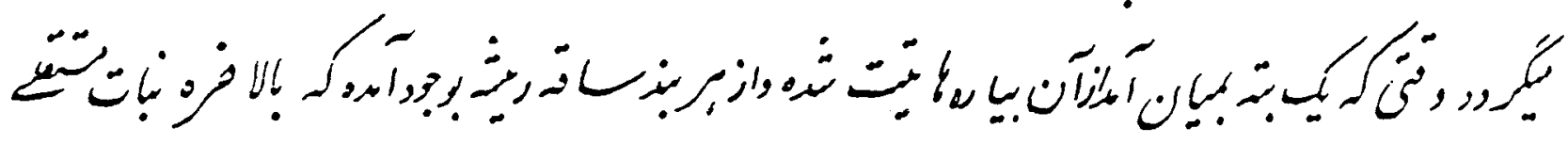

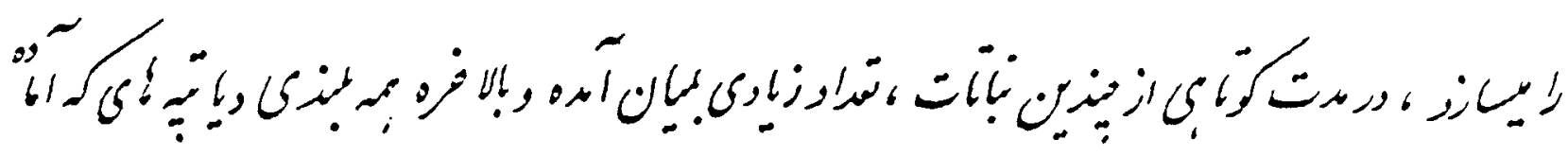

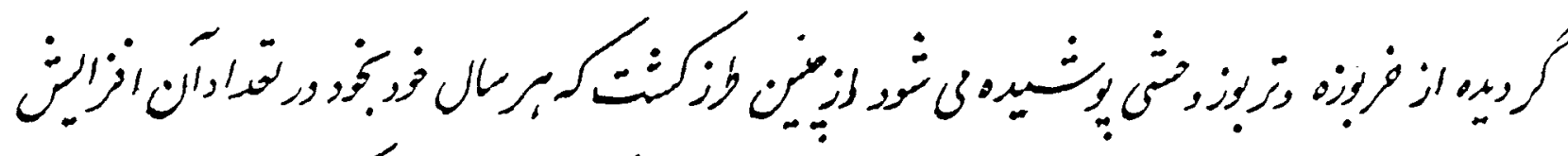

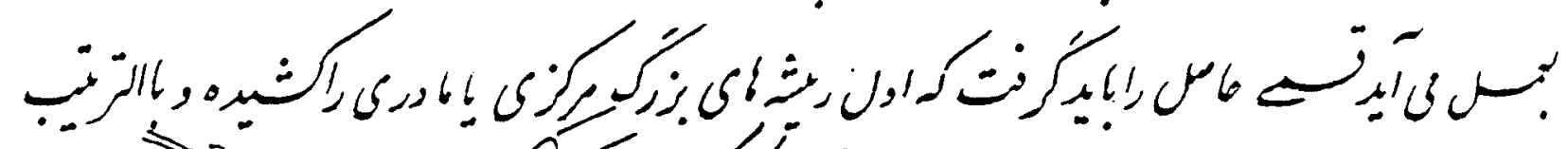

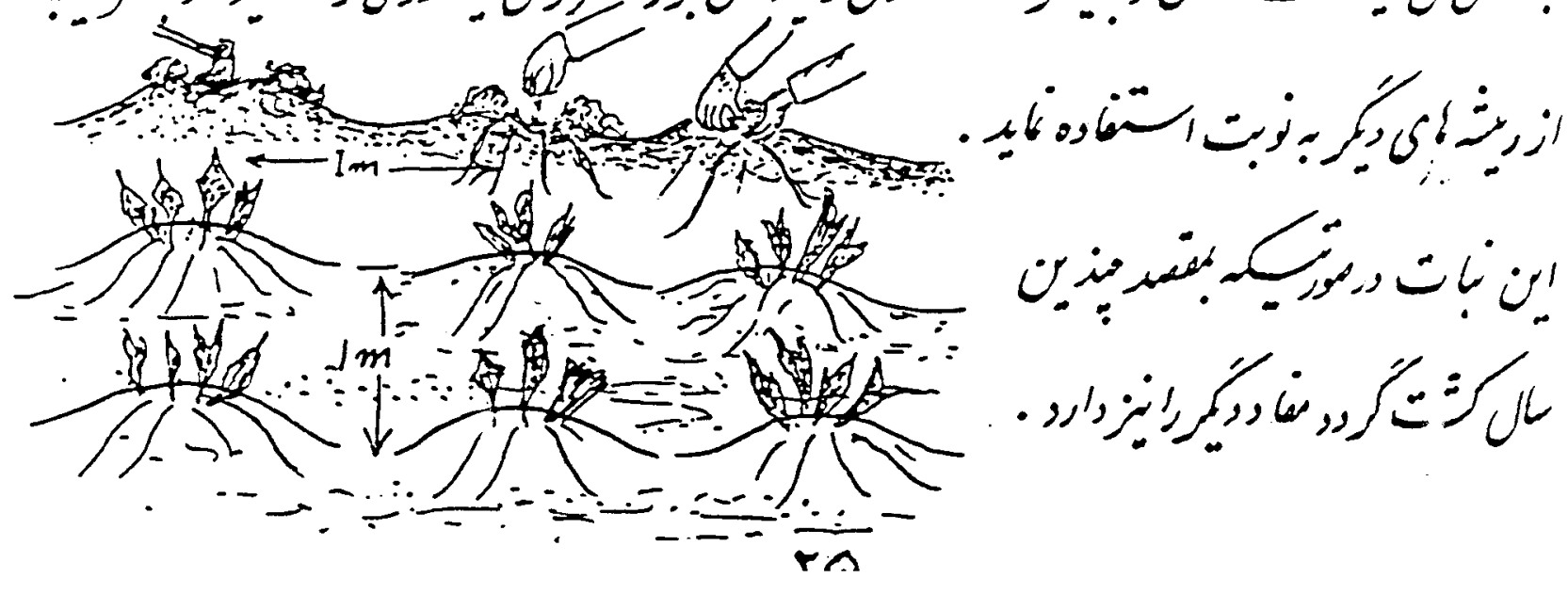




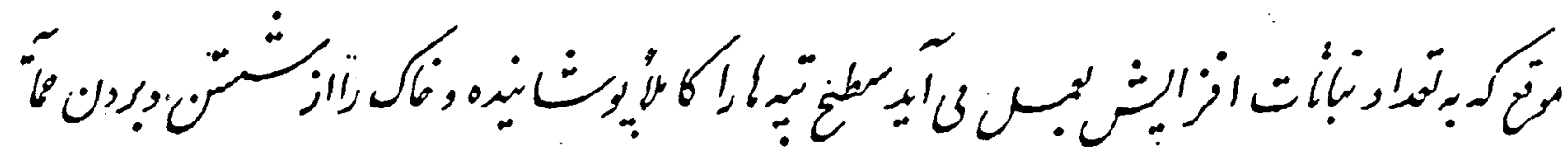

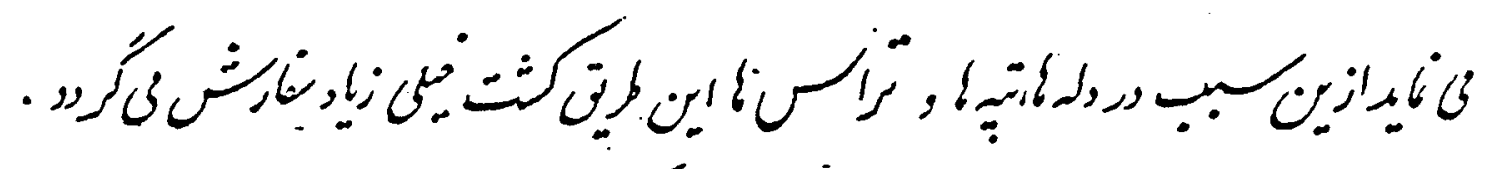

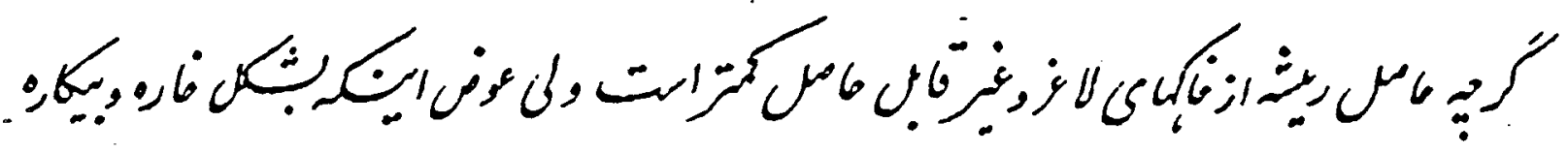

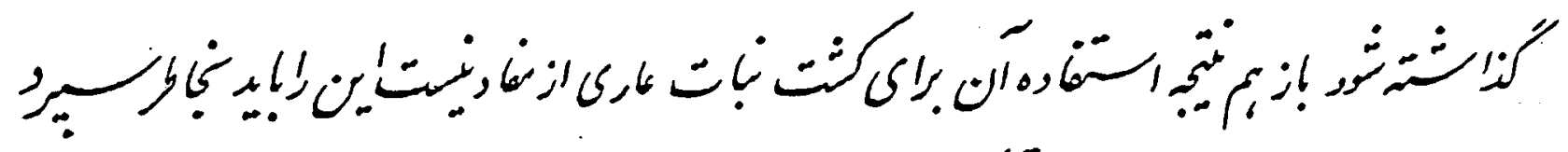

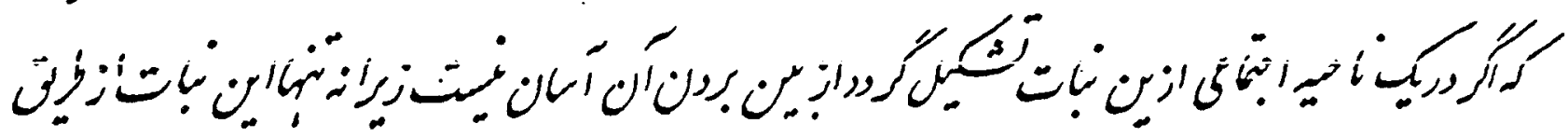

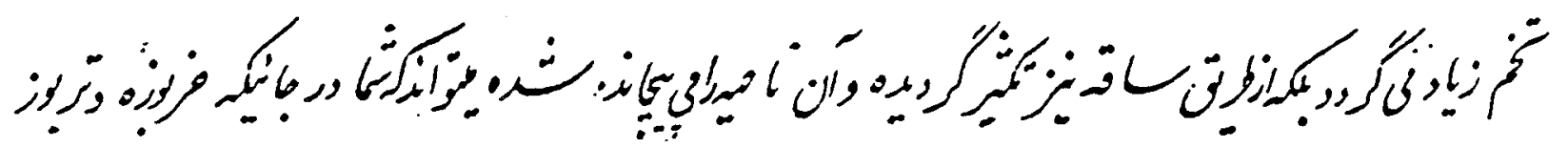
,

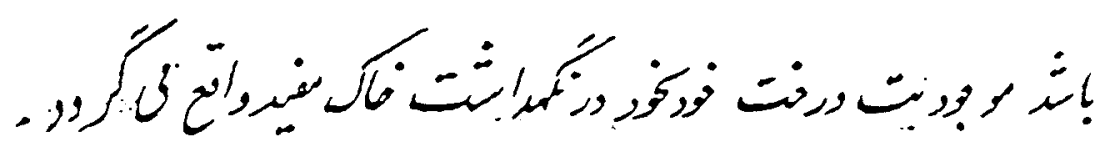

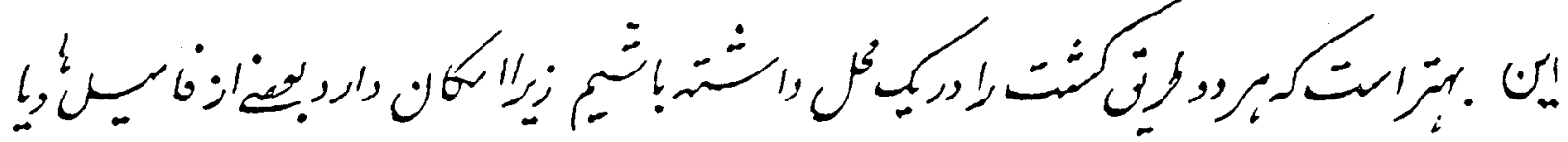

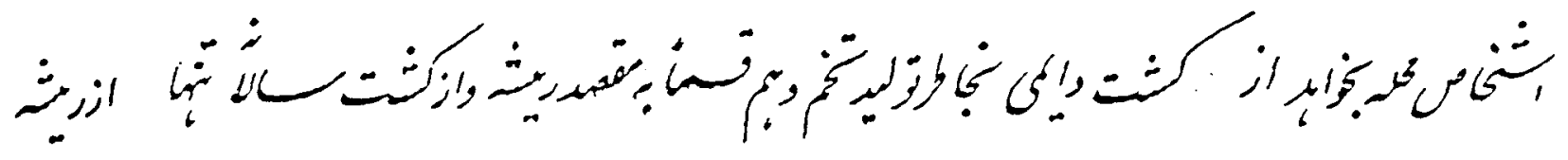

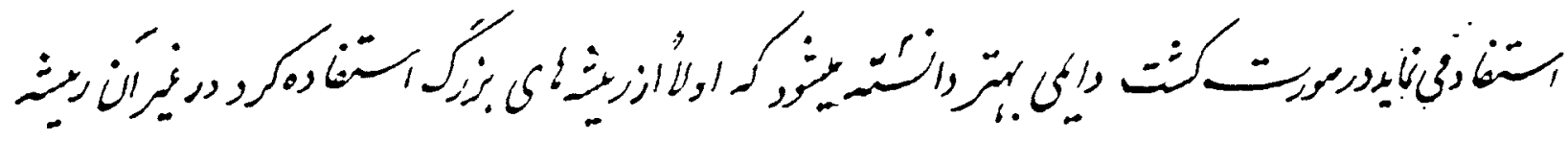

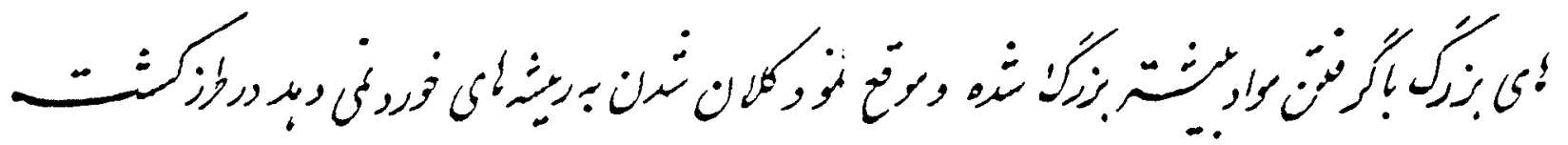

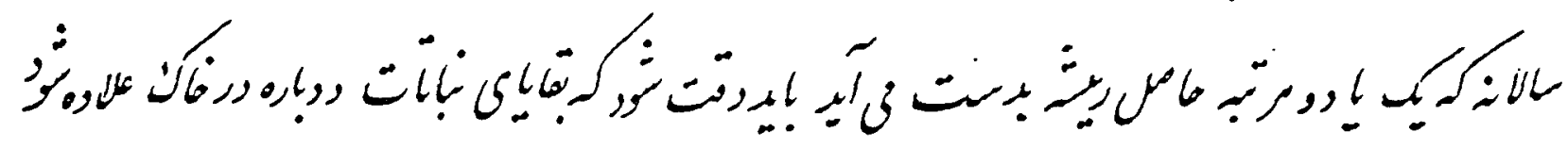

$$
\text { . }
$$




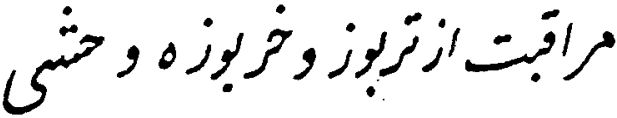

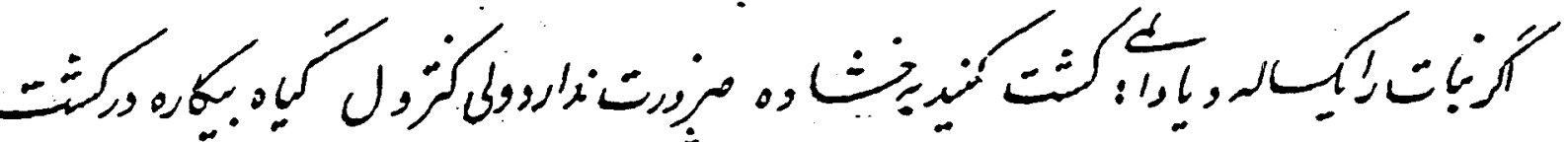

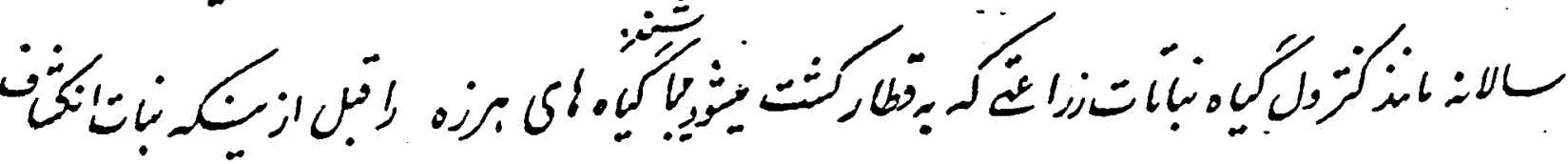

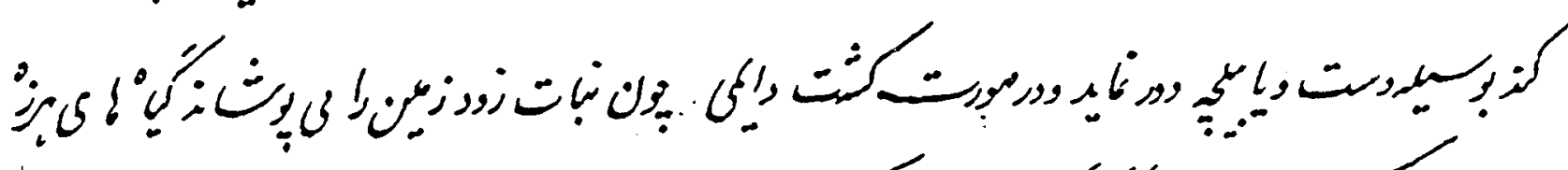

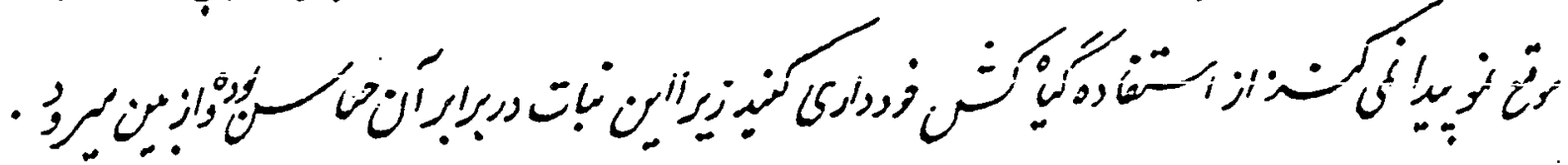

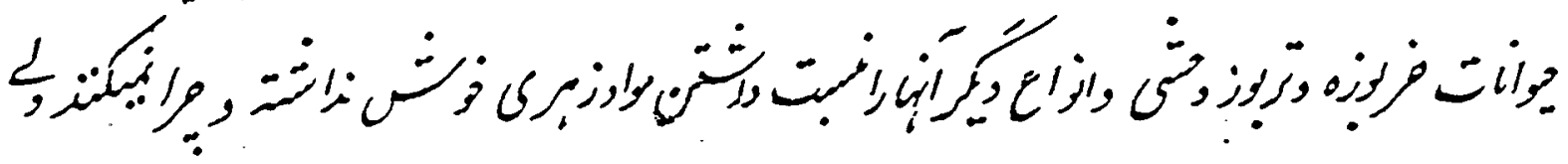

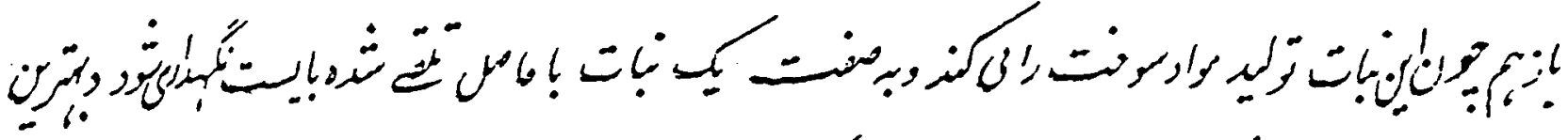

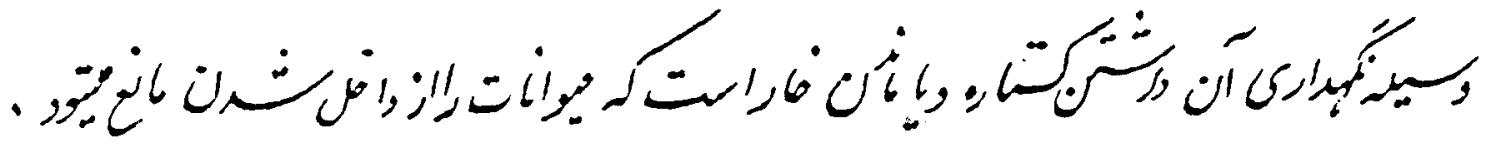

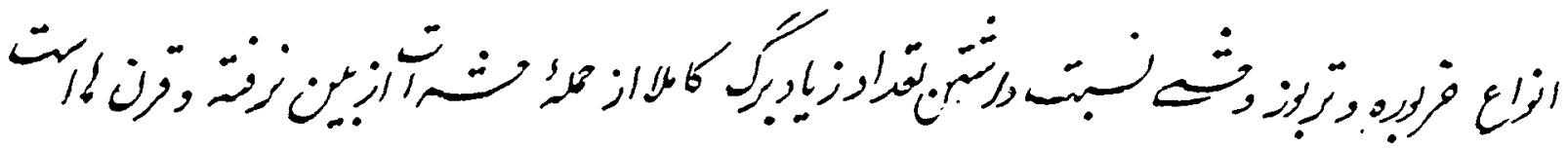

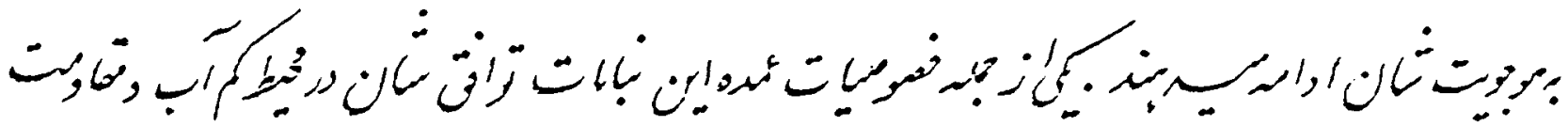

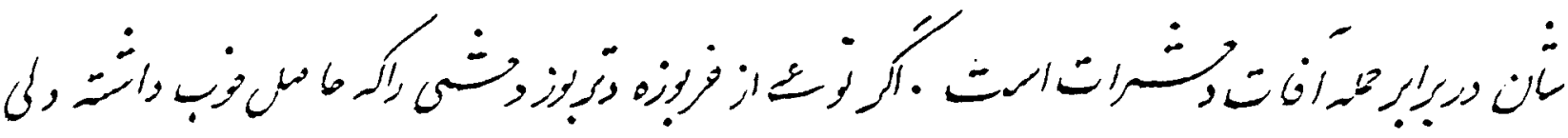

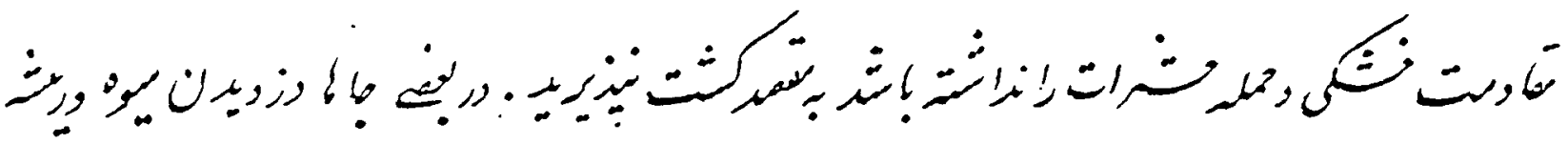

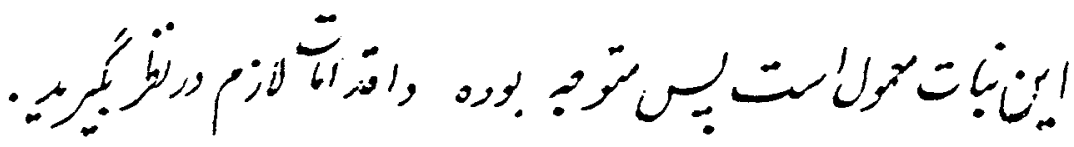

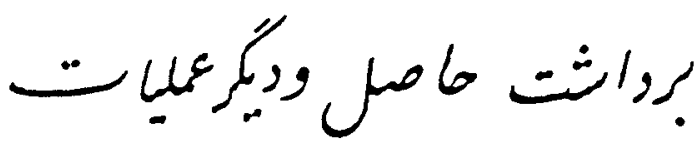

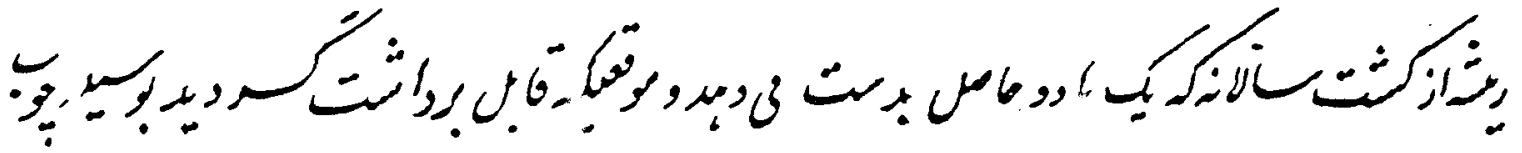




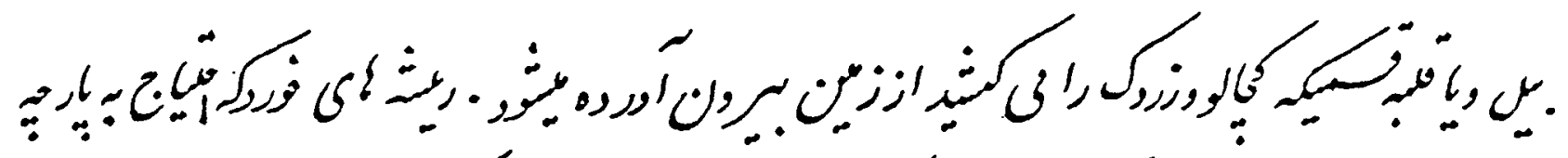

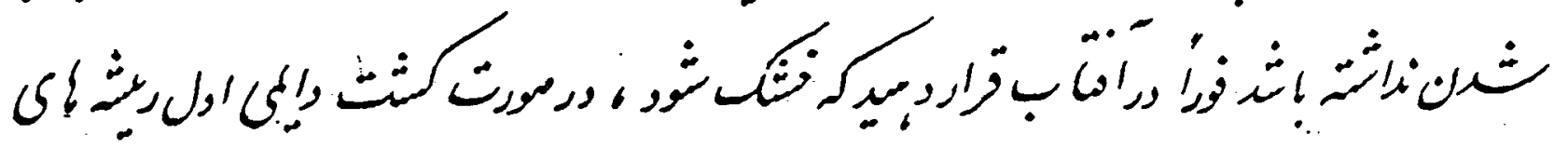

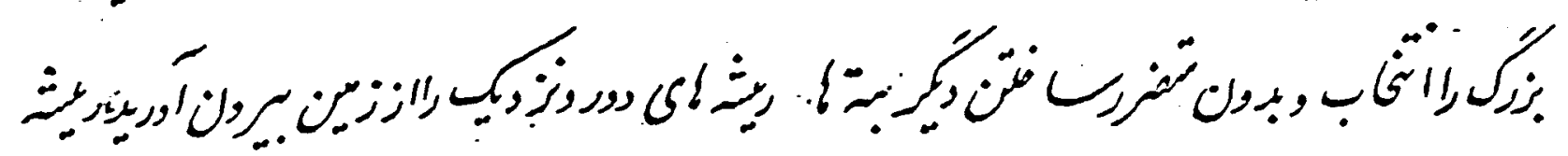

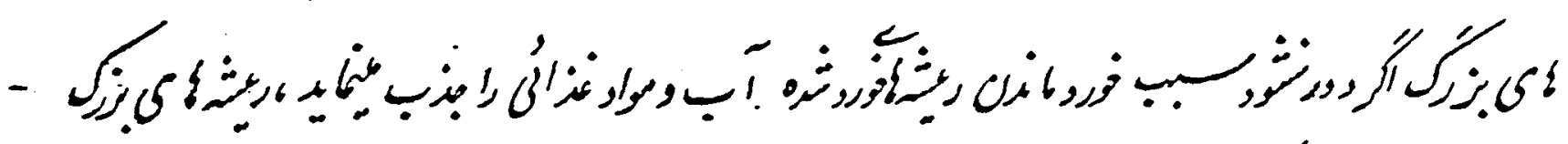

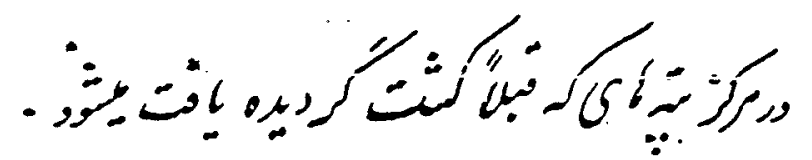

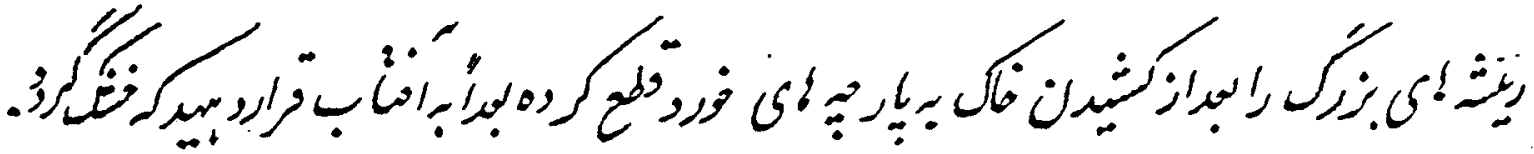

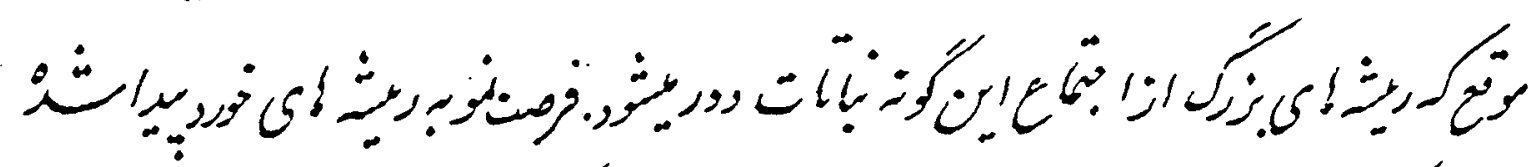

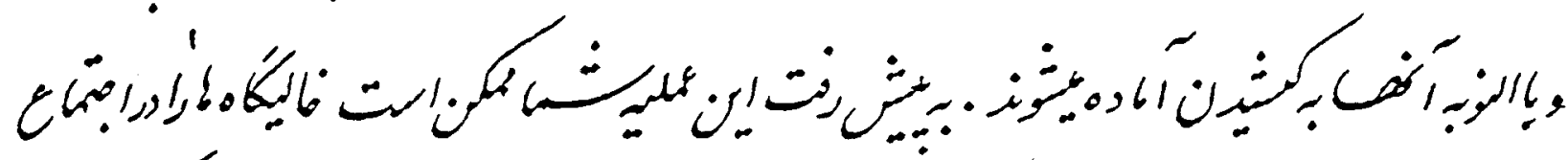

i

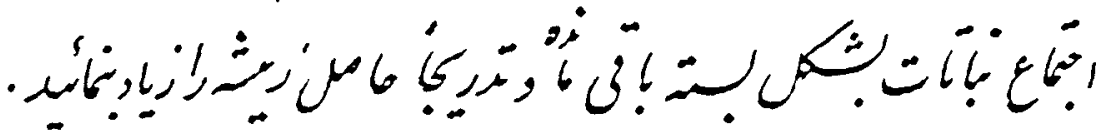

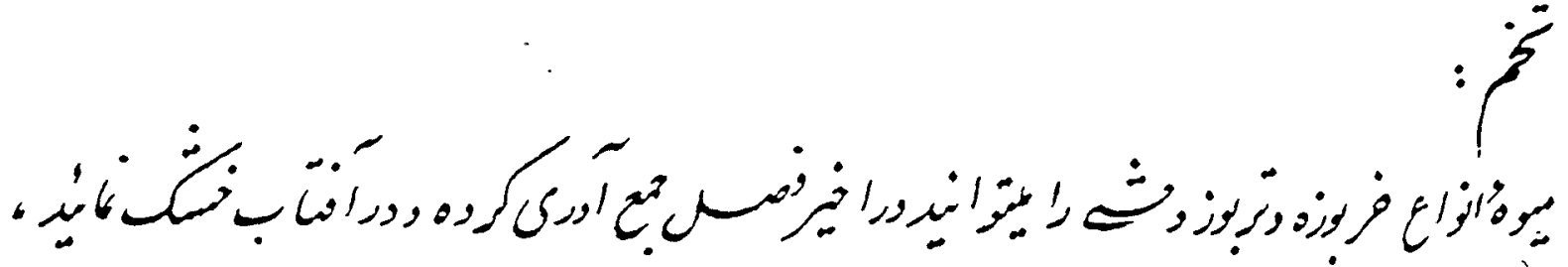

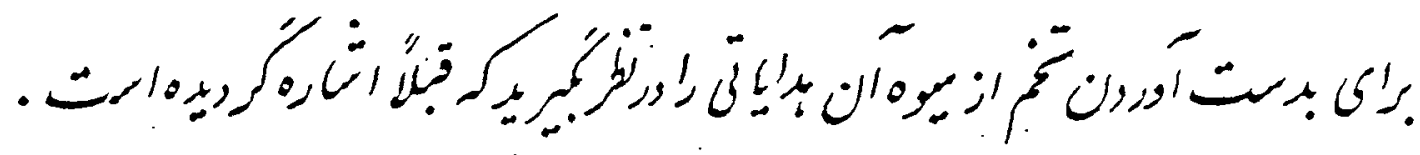

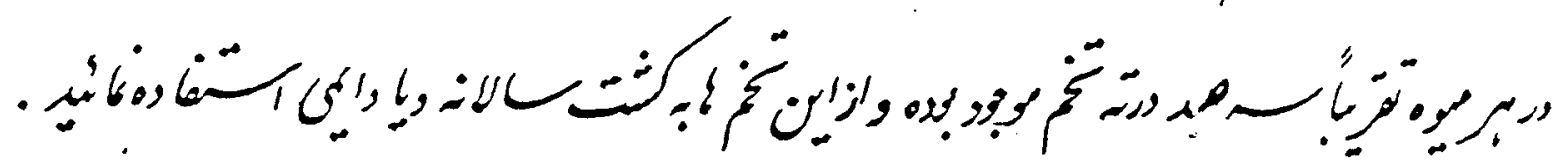

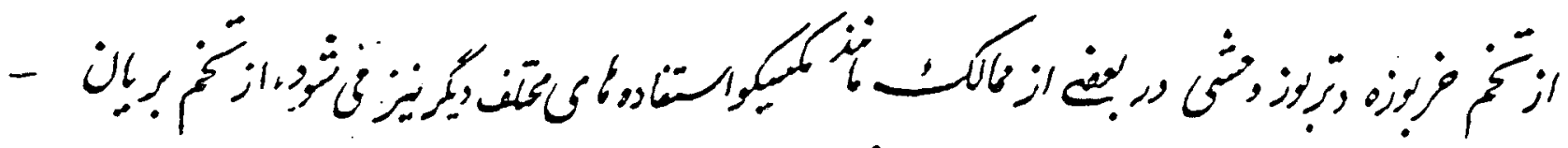

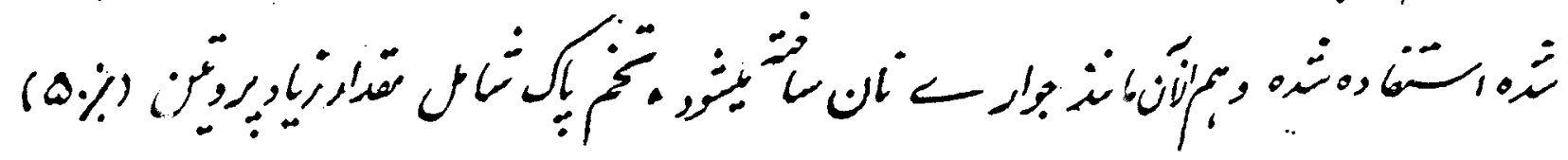

$\Gamma \wedge$ 


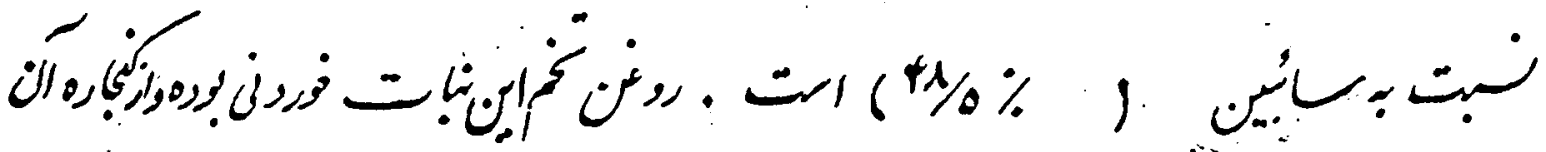

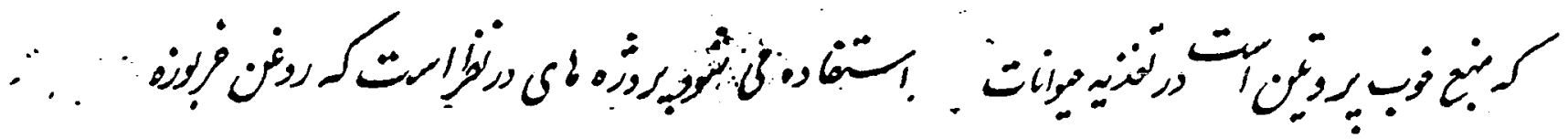

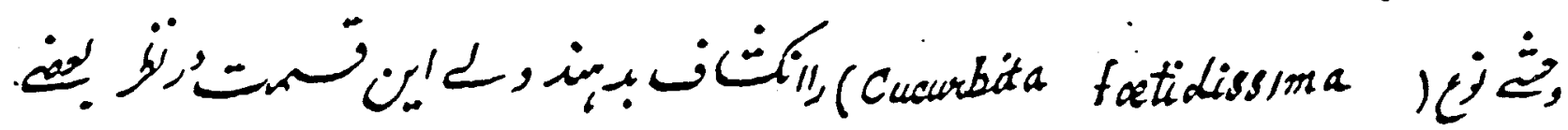

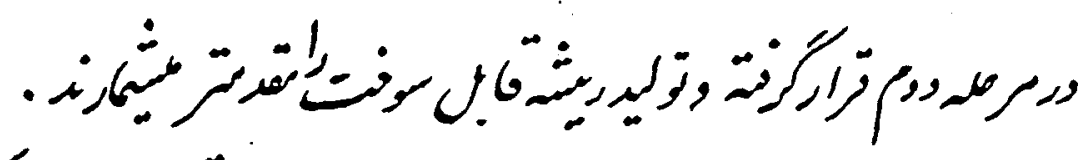

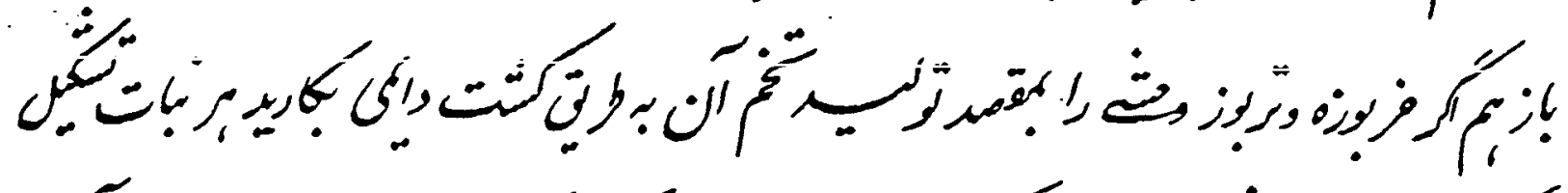

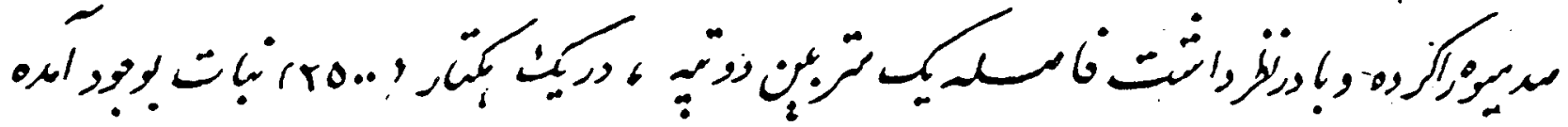

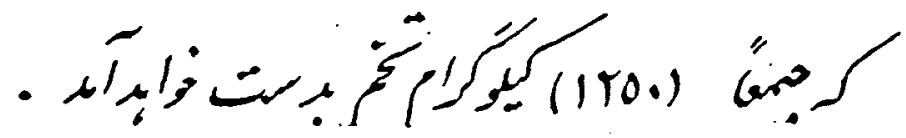

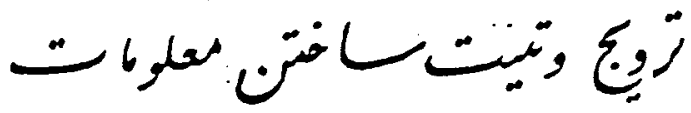

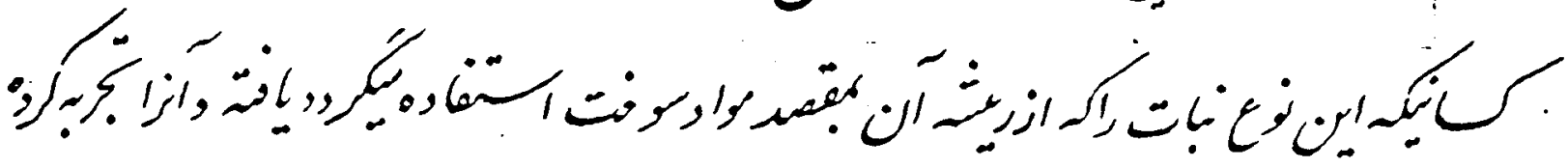

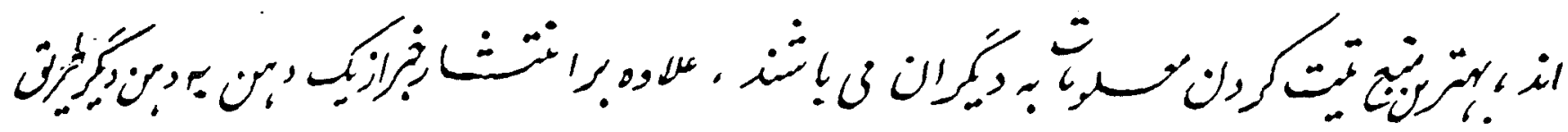

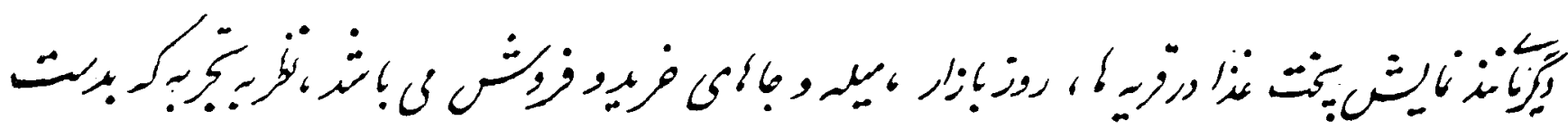

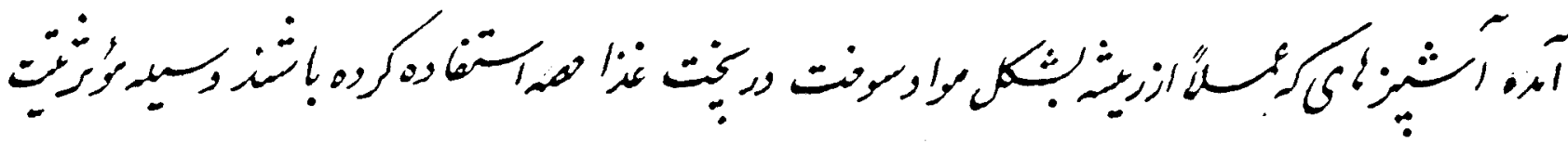

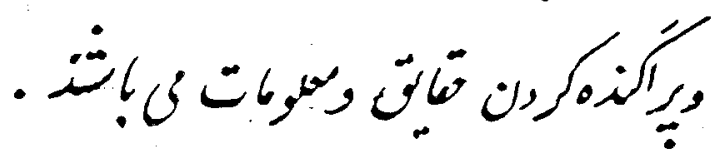

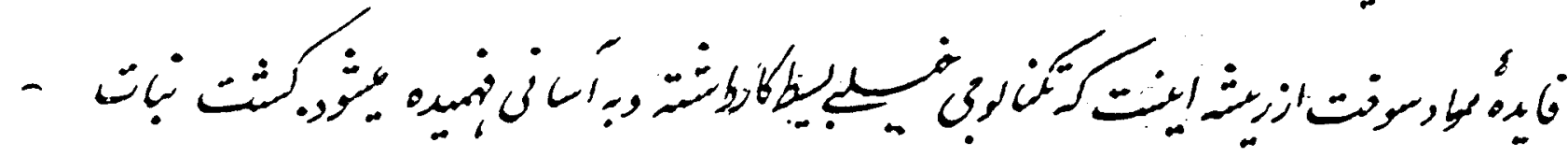

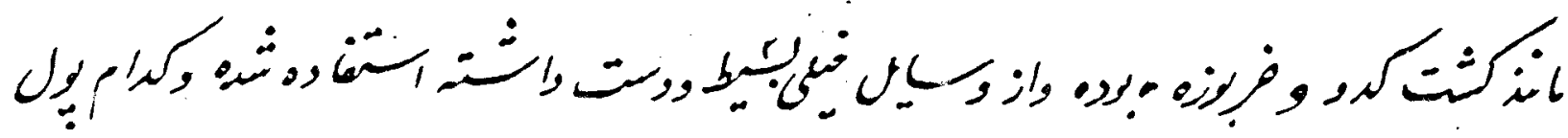

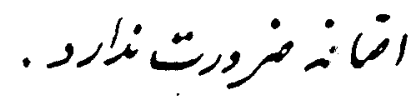




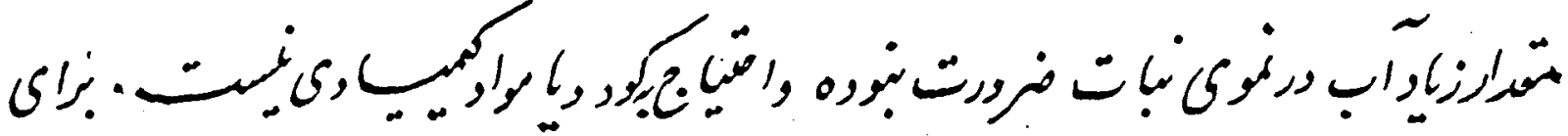

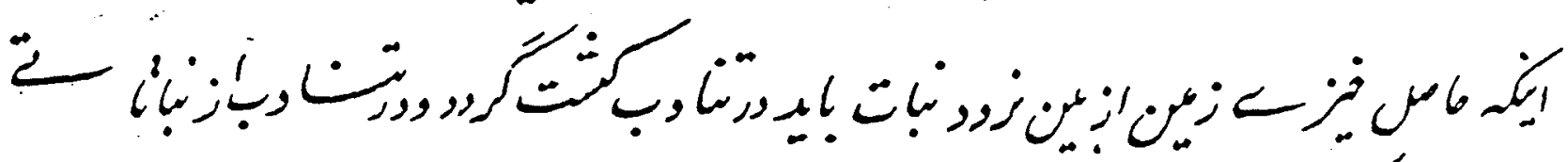

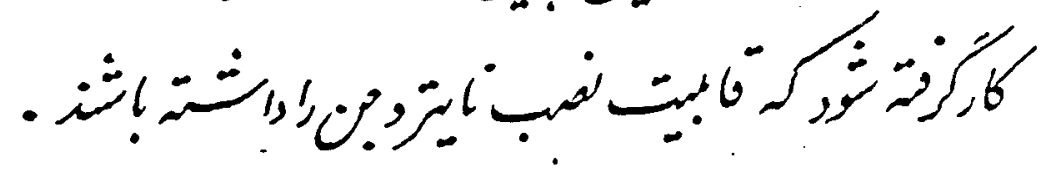

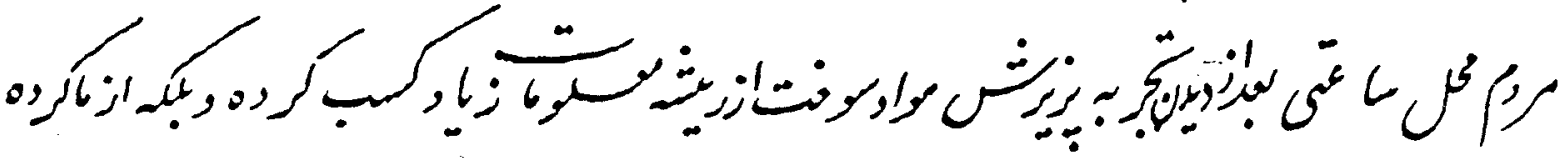

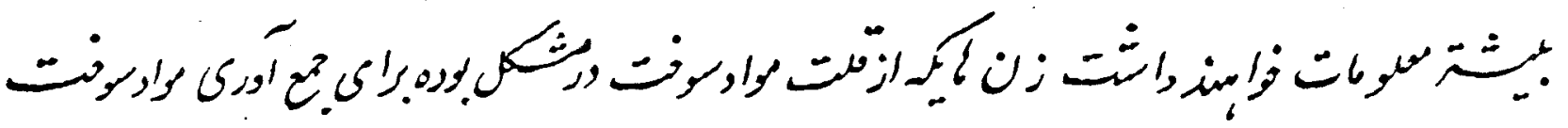

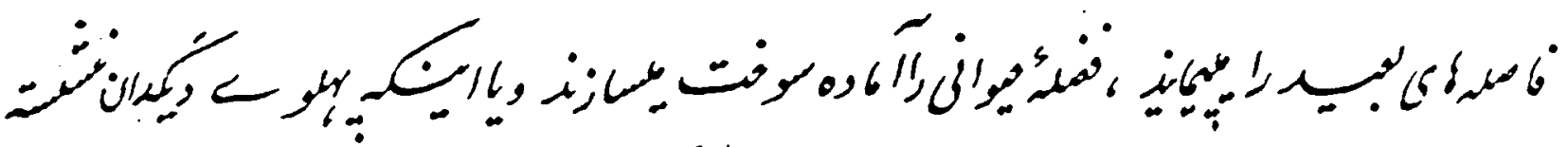

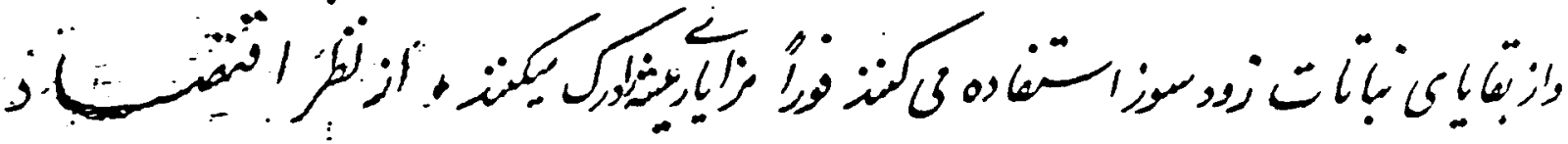

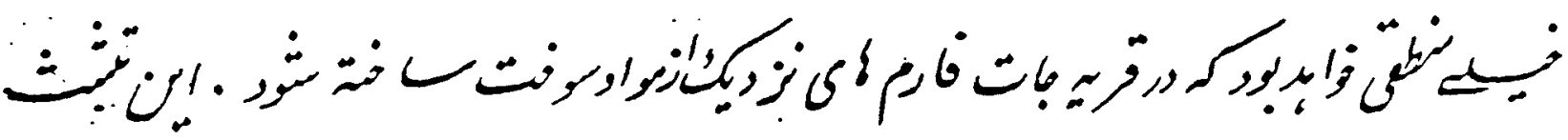

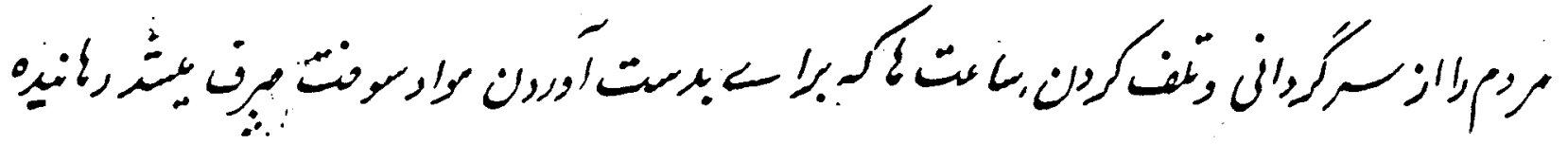

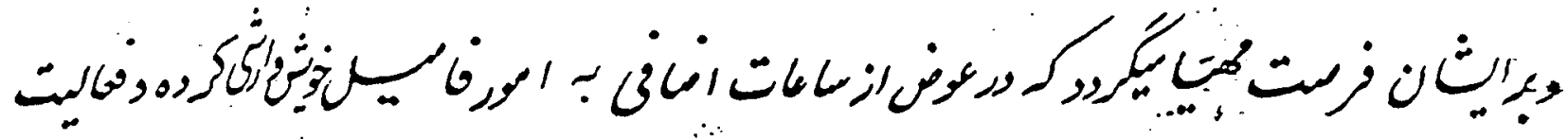

. 


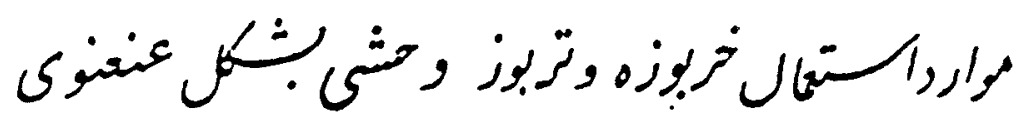

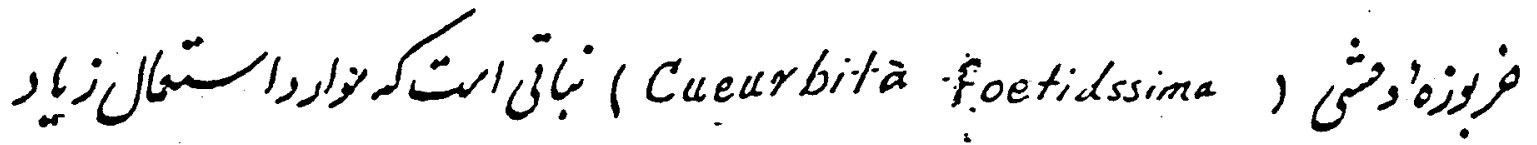

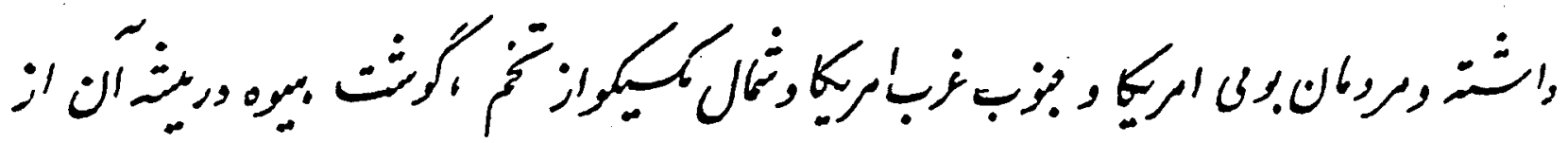

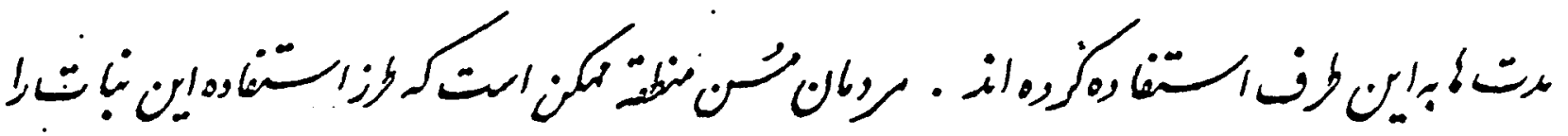

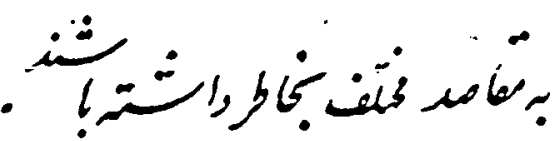

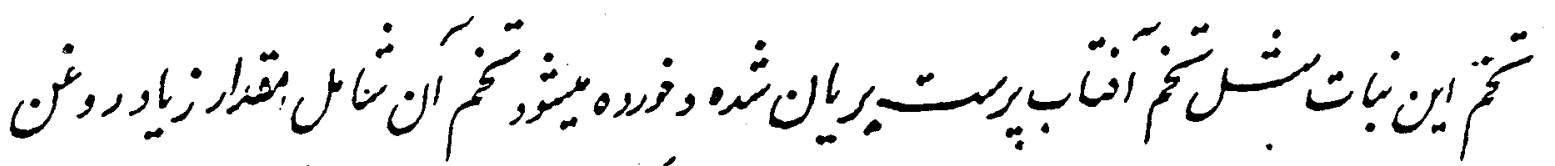

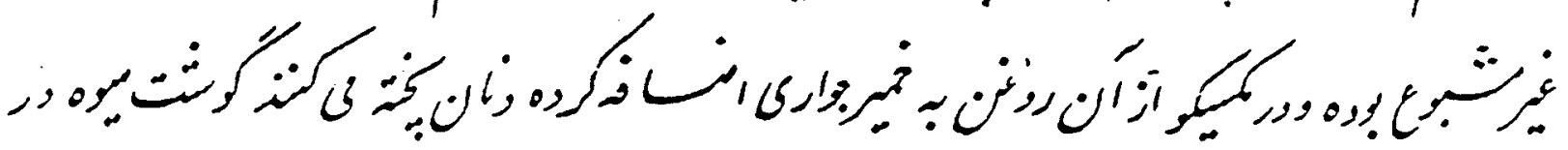

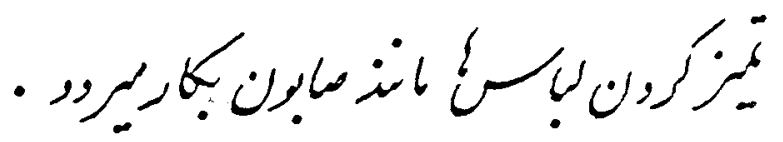

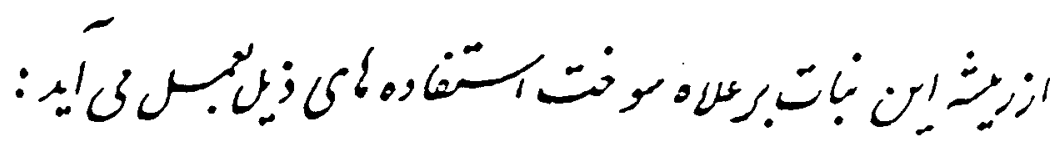

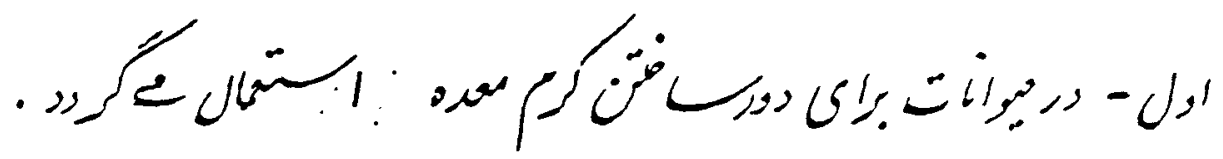

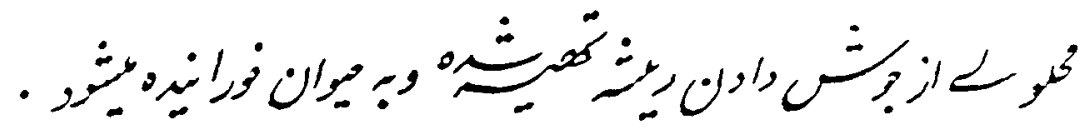

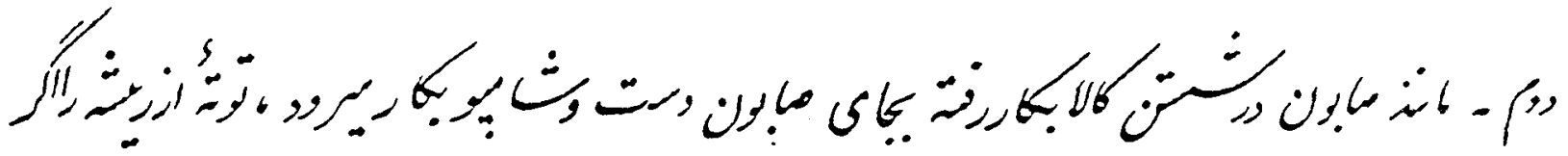

بدت بلي

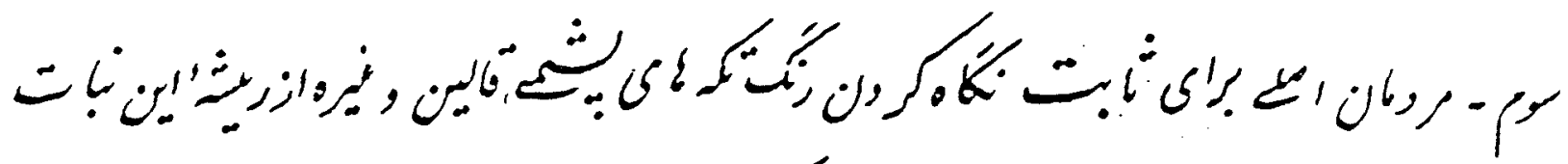

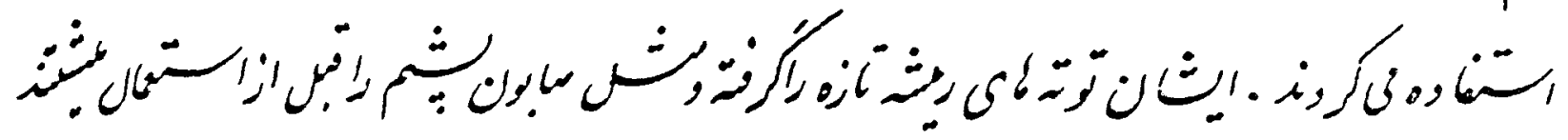

i

$r_{1}$ 


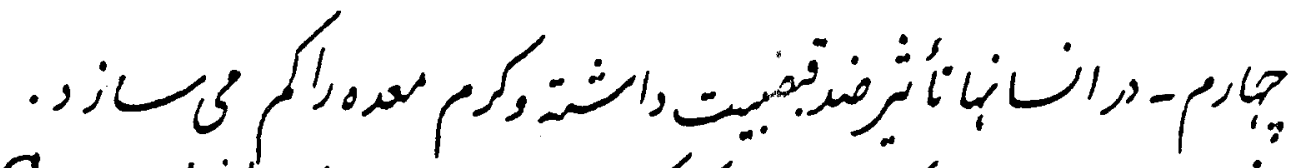

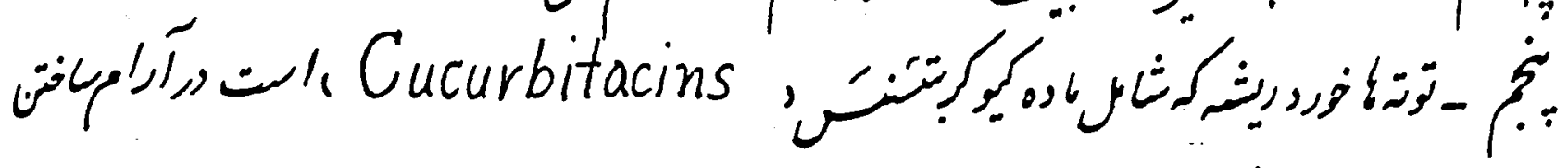

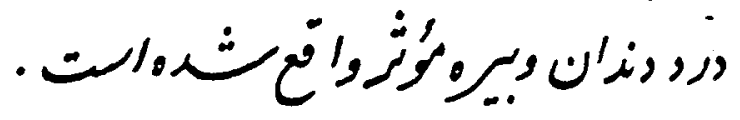

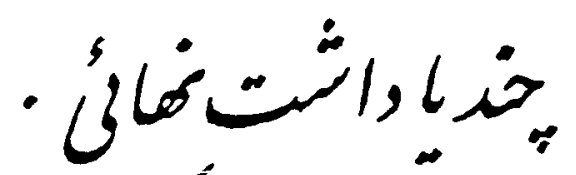

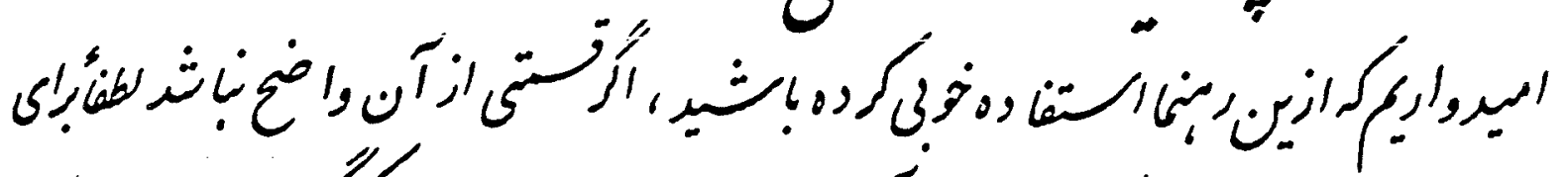

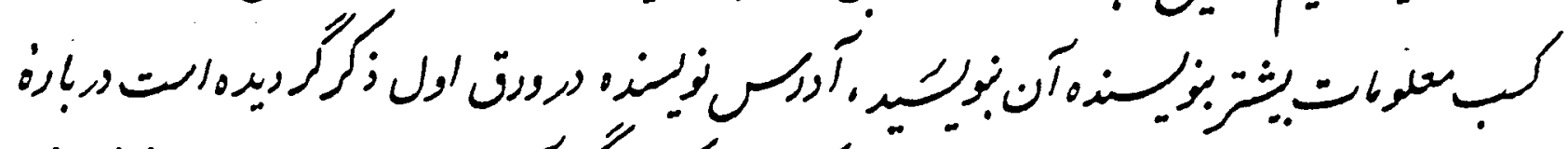

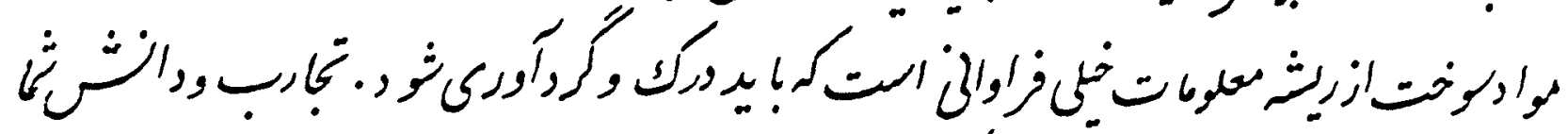

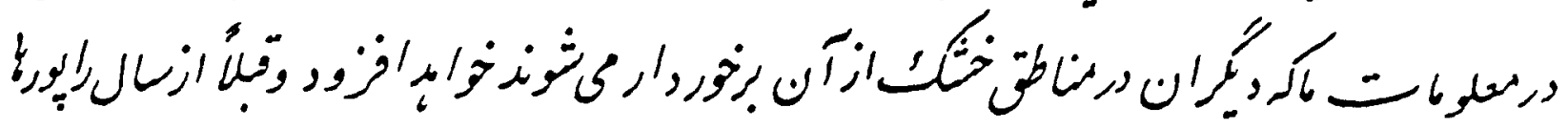

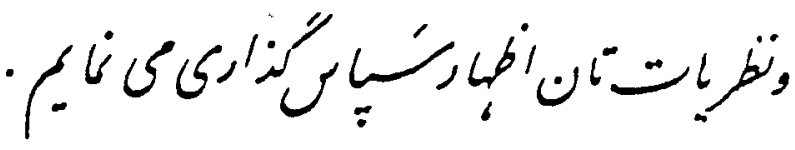

$\pi$ 


\section{USING ROOTS}

FOR COOKING IN

ARID LANDS:

A HANDBOOK ON

\section{ROOTFUEL}

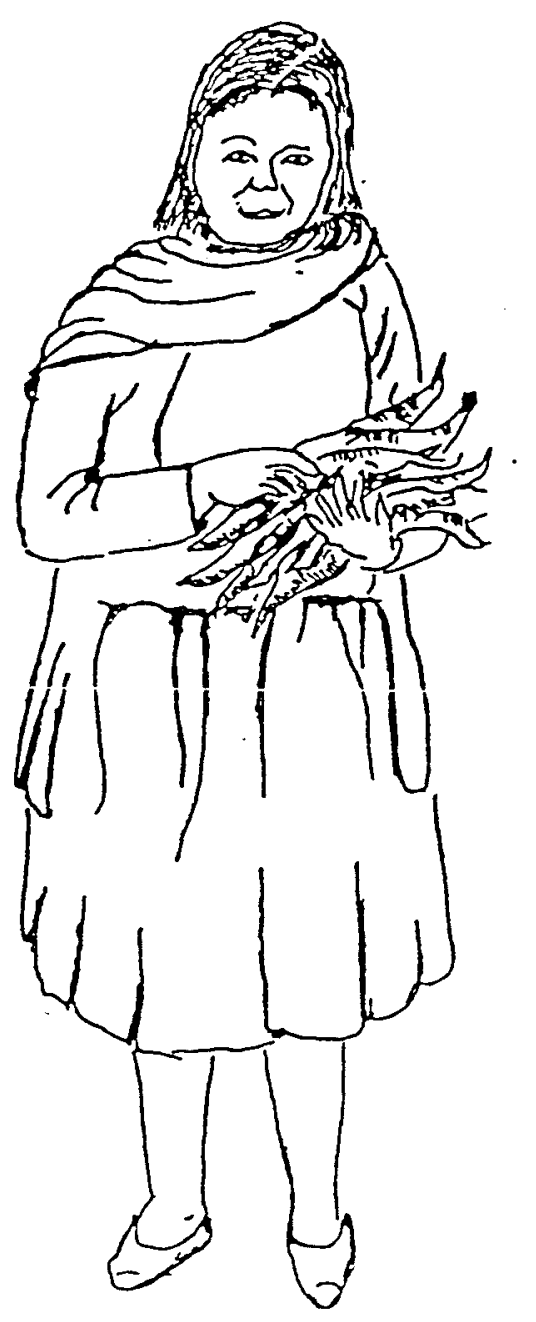

Wayne G. Bragg

and

Eugene B. Shultz, Jr.

Illustrated by

Sandra Gilderson

Enable International 
Copyright $\odot 1901$ by Wayme G. Büagg and Eugene D. Shuitz, jr. Published by Enable International, Inc.

608 N. President St.

Wheaton, IL 60187 USA 


\section{Foreword}

This handbook is written to help people in the arid lands of the world meet some critical problems they face - the growing scarcity of woodfuel for cooking and the effects of excessive tree-cutting on fragile dryland environments. One potential solution is to find altematives to woodfuel that do not depend on high technology, petroleum, or other expensive substitutes. One substitute is dried roots, or "rootfuel," a source of biomass energy normally overlooked as a traditional fuel. Rootfuel is proposed as only one alternative; there are many others that could be used, such as solar cookers, efficient cookstoves, and other biomass plant resources, or "bioresources.". Other bioresource fuel materials might include hybrid cotton stalks and bolls, rice hulls, camel thorn, Artemesia sp. saltwood (Haloxylon) Onobrachius comuta Sesbania sp. and even grasses like Saccharum voluntaria and Cymbopogon jwarancusa. Rootfuel, however, has already been tested for technical performance and cultural acceptability.

The authors, Wayne G. Bragg, Ph.D. and Eugene B. Shultz, Jr., Ph.D., are investigating underutilized biological resources to meet human needs in a sustainable, culturally acceptable way. Their multi-disciplinary Bioresources Development Group in the School of Engineering and Applied Science at Washington University in St. Louis has for some years done applied research on numerous promising plant species for food, cooking, feed, insect repellent and other basic needs in the Two-Thirds World. This research is implemented through a non-profit organization, Enable International, with the participation of local people and groups around the world.

Eugene Shultz discovered the potential of one cucurbit species, Cucurbita foetidissima, as a cooking fuel while doing research in New Mexico on alcohol fuel from its fast-growing, massive roots. Since then the authors, their research assistants, and friends have tested this amazing plant for technical and cultural acceptability in Senegal, Niger, Mexico, and Pakistan. Economic feasibility studies in India compared rootfuel with agroforestry fuelwood. These rootfuel tests are described in another publication by the same authors, The Rootfuel Alternative to Scarce Woodfuel in Drylands: A Case Study. For definitions to new terms that you might find in this handbook, look in the Glossary at the end.

This handbook is written for all who are interested in identifying alternative cooking fuels in the drylands. It will help the reader to visualize and understand the process of identifying, testing, growing, and using similar cucurbit roots or other biomass as alternative fuels. We trust this rather unorthodox approach to an alternative cooking fuel at the village level will stimulate research and utilization of rootfuel and other bioresources that can take the pressure off the rapidly disappearing forests and make life easier for many.

We dedicate this book to all who have the burdensome chore of collecting, cutting, and carrying wood for distances in order to be able to cook for their families.

Thanks go to the dozens of friends in many lands who contributed to this handbook through their participation in finding, identifying, and testing rootfuel. 


\section{INTRODUCTION}

We define "rootfuel" as a solid fuel made by sun-drying the non-woody starchy taproots of certain members of the Cucurbitaceae family ("cucurbits"), such as fast-growing wild dryland gourds and melons. Cucurbits are found world-wide, and include species like cucumber, squash, melon, chayote, and gourd. In arid lands, there are wild cucurbits that neither people nor animals eat because they contain a bitter essence in the leaves, stems, and roots. Some of these species produce large, fleshy taproots that grow rapidly, reaching astounding size if left to grow several years.

These roots can be dug, cut easily into pieces while fresh, and dried in the sun in a few days. Then they can be burned in any fireplace or stove just like wood or charcoal, but without some of the problems of these traditional cooking fuels. In drylands, cooking fuel is scarce and is getting scarcer as populations grow. People have to go looking for woodfuel farther and farther from their homes. Some women and children have to walk a full day to find wood and bring it home on their backs. This is a hard, physical chore and takes time that they could use better for other duties with their families. Some families are having to buy wood fuel from people who bring it in trucks from distant forests. This is an expense that many cannot afford, so they turn to using alternatives like dung-cakes or crop residues like millet straw, comstalks, and corn-cobs.

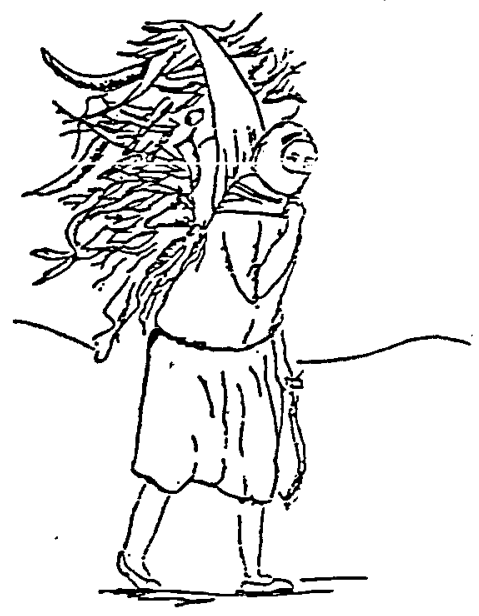

Cutting trees causes the arid lands to dry out even more, because trees pump water from the subsoil into the atmosphere which is then returned in rain. Deforestation is a vicious circle: the fewer trees, the less rain; the less rain, the harder to grow trees. So every year the world's deserts and drylands grow larger because of over-cutting for woodfuel and over-grazing by animals. Rural people everywhere in the poorer areas of the world cook with wood because they have nothing else. Even reforestation programs do not break the cycle because people cut down more trees than are replanted. It is also expensive to replant trees. In the drylands, trees take a long time to grow, and are usually thorny and tough to cut.

Cucurbit roots grow fast, and in three or four months produce more potential fuel than most dryland trees will produce on the same area of land in a year. People can grow their own cooking fuel by using these roots. They can plant cucurbits for fuel around their villages on poor, eroded, or hilly land that is not good for crops. And they can cultivate cucurbits as an annual crop on plots of land they can spare.

It is better to use roots for fuel than to use animal dung-cakes or crop residues for fuel. These organic materials should be recycled into the soil to replenish the nutrients taken out, as farmers have traditionally done. Otherwise the soil produces less and less unless chemical fertilizers are used which are usually too expensive or difficult to get for most small rural farms. 


\section{ADVANTAGES OF ROOTFUEL}

Rootfuel is:

- Easy to cultivate and harvest

- A renewable, fast-growing resource

- Non-polluting

- Less smoky and irritating

- Easier to cut than wood

- More efficient than wood (less fuel is needed)

- More accessible if planted nearby

- Slower burning than wood

- Good as coals for simmering food

- Adapted to the drylands

\section{THE PURPOSE OF THIS HANDBOOK}

This handbook will help you find and identify local cucurbit species that might produce roots for fuel. It will help you then test these roots for technical and cultural acceptability as cooking fuel. Then it will guide you to plant, harvest, store, and use rootfuel.

Local people, like yourself, are in a better position to find useful plants in your region than anyone else. You can also work with some cooks to try out the alternative fuel to see if they like it and if it performs as well as or better than wood, wood substitutes, or charcoal
(which is made from wood).

People in other places in Africa and Latin America have found species of cucurbits with roots that have been useful as a cooking fuel. One such cucurbit is Cucurbita foetidissima, called "calabacilla loca" in Mexico and "buffalo gourd" in southwestern United States. Wild watermelon roots in Senegal have potential use. Another possibility in Asia, Northern Africa, and Australia is Citrullus colocynthis, which produces taproots and grows widely in arid lands (see Appendix $A$ in the back of this handbook). We wish you good success as you look for similar useful plants.

This handbook is not so much a manual of techniques as it is a guide. We want it to guide people living in arid lands to identify, grow, and use native cucurbits as rootfuel. Because plants adapt to their surroundings differently, this handbook will raise questions that will help 
you find local root plants that may have found a home in your particular region. Furthermore, since each society and culture is distinctive, we want to help you find out if people will accept and use rootfuel.

As you proceed in the discovery and use of alternative fuel, we would like to ask you to send us a description of the plants that you discover and the results of your experience with testing rootfuel, so that we may share these with people in other arid lands of the world. For this purpose, this handbook includes a report form and an example of a cooking test to give an idea of how to describe a cultural acceptability test of rootfuel (see Appendix B).

\section{IDENTIFYING CUCURBITS WITH POTENTIAL AS ROOTFUEL}

The cucurbitaceae family is extensive, with some 800 species found around the world, including species that are usefil for humans as food, feed for their animals, medicine, and other uses. But people and animals do not eat some cucurbits because they have a very bitter taste. These bitter kinds are the ones we usually seek out for rootfuel because they are not good to eat or to feed animals. There may also be some cultivated plants that have large roots also which could be harvested after the fruit is gathered. Some varieties have taproots that look like carrots and grow fast. Some cucurbit roots reach $60 \mathrm{~kg}$ in weight, like the Cucurbita foetidissima shown here that was grown in Lebanon.

The way these cucurbits survive in harsh arid climates is to store water in the form of starchy, non-woody roots. For this reason farmers tend to dislike them because they tend to take water away from nearby food crops. Farmers often treat wild

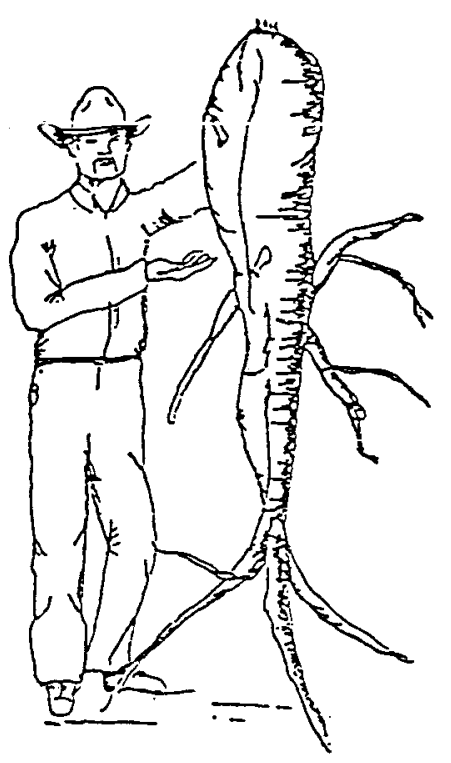
cucurbits like pests or weeds. Like weeds, they grow in disturbed soil, in poor sandy so:ls, and on inclines or hills. We now turn to how to find and identify them.

\section{Ask People Who Know}

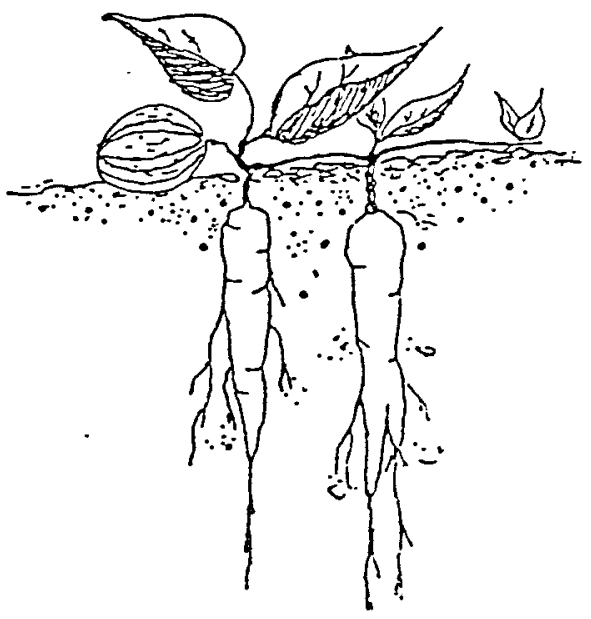

To find these wild rooty cucurbits, ask local farmers or elders in the community. They may know them as a bitter gourd or melon. Often the fruit is a small, round gourd with stripes on it, but it may also be a larger melon-like fruit. Their leaves are very broad and tough which you can easily identify because they look like cucumber, squash, or melon leaves. Leaf shapes and sizes vary depending on the species. Elders in the community may remember making soap or medicines out of the roots, as people used to do from the Cucurbita foetidissima in Mexico and in southwestern USA (its many traditional uses are listed in Appendix C). Ask elders and farmers about inedible plants that have been used for other purposes or that animals do not graze upon These may be the cucurbits you seek. Perhaps a local farmer or some young people can go with you to locate plants, and even help you dig them. 


\section{When and Where to Look}

The best time to find cucurbits is during or after the rainy season, since they tend to sprout each year after the rains begin and dry up in the dry season. But native wild plants can still be found in the dry season since the gourds and dry vines often may still be seen.

The plants tend to grow in colonies along road sides, sides of ditches, or on hiiisides because they do not like standing water. They like sandy soil particularly, but will grow in other soils, even very hard clayey soils. They have

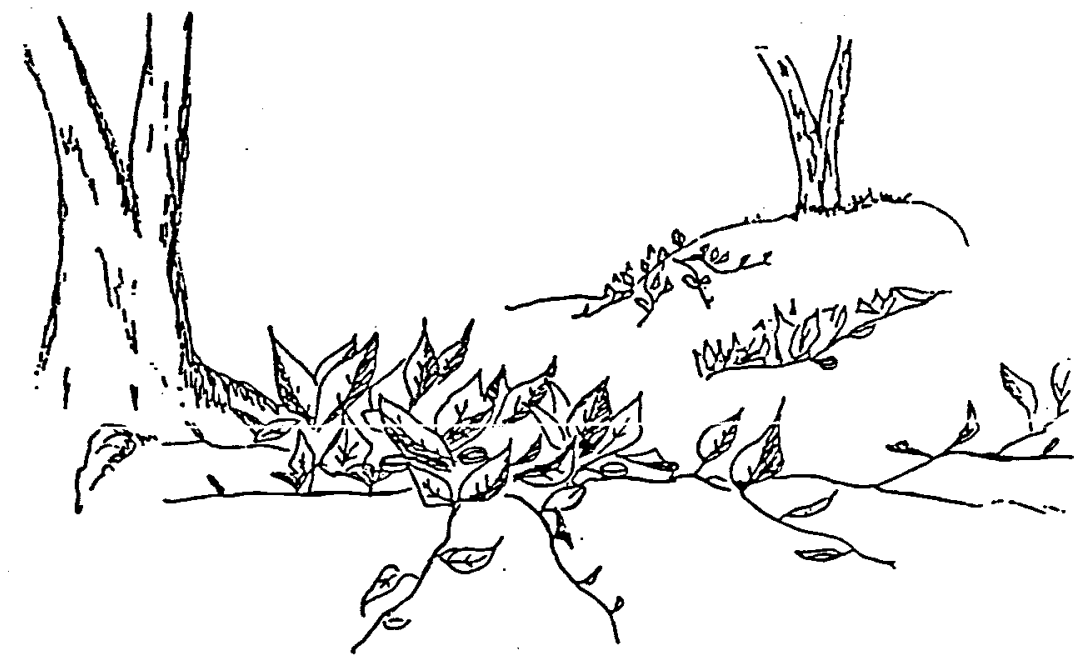
adapted to their ecological home for many centuries.

\section{Some Good Indicators}

Once you find a colony, try digging up a root to see if it has a shape similar to a carrot or turnip. There are many roots in a wild cucurbit colony, the smaller ones being located at the edge. Cut the end off a root and touch it carefully to the tip of your tongue. If it is bitter or makes your tongue feel numb, you may have a good candidate. Even if it is not bitter or numbing, if the root is dense and heavy, it may be good for rootfuel. Plants with only thin fibrous roots will not serve since they will burn too fast. Seek out plants with thick tap-roots.

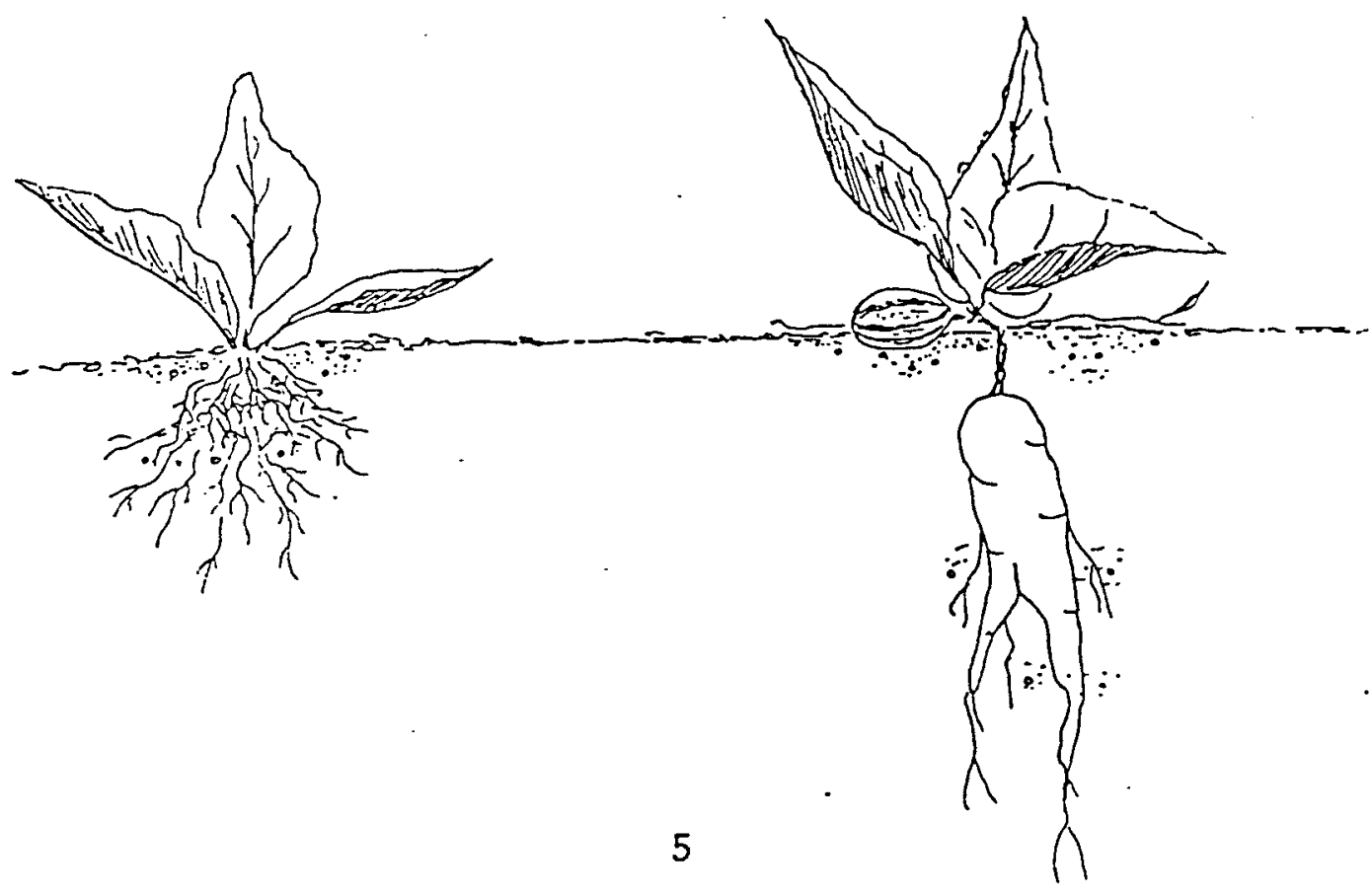




\section{COLLECTING ROOT SPECIMENS}

When you have found indigenous wild cucurbits with taproots, and have determined that they are potential rootfuel candidates, you can collect a good sample of them.

Before digging further take some pictures of the colony, the leaves, and the fruit, if you have a camera. Place a ruler or a familiar object like a pair of eye glasses by the side of the leaves and gourd or melon before taking a picture, to give an idea of size. As you proceed to dig the roots, take pictures of the process and the roots. Again, place a ruler or glasses by the root before snapping the picture. If you cannot take pictures, measure the fruit, a leaf, and the root.

The leaf is one of the best ways botanists use to identify a plant family or species. Even if you take pictures (and especially if you don't), take a sheet of paper and lay a leaf on it to trace its outline on the paper. You may also dry a leaf between some newspaper pages and send it with the report.

To gather root samples, you should first take a long stick and thrash the foliage so that any animals (like rodents or snakes) living in the plant colony will leave. In the hot drylands, animals may like the cool atmosphere under these shady plants.

Next, seek out the central roots of the plant.

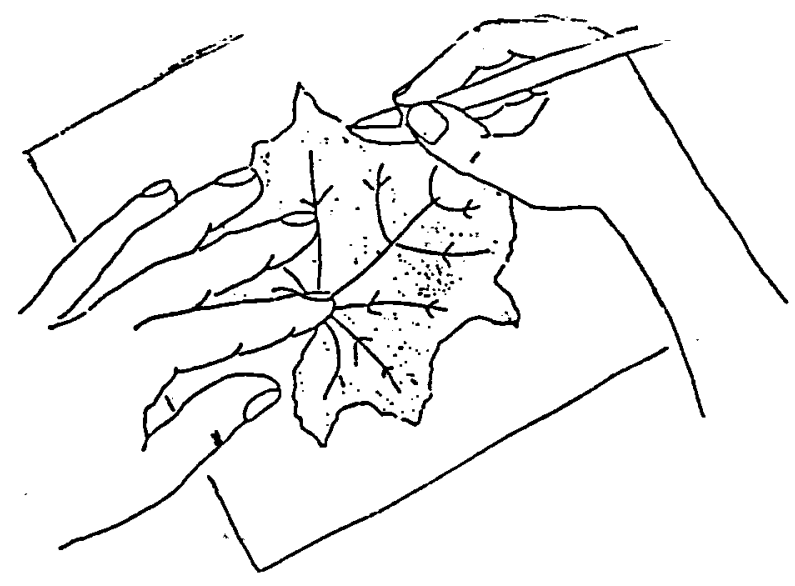
They will usually be found by the numerous vines coming out of a central place in the colony. Remember that the root structure is a "family" comprised of the big "grandfather" root, surrounded by many, many smaller roots that grow from the joints (called "nodes") of the vines. The plant spreads or "colonizes" by this method. These younger roots ("children") will be smaller the farther away they are from the central old parent root. The small roots help feed the larger root with water and nutrients (until the big root is removed).

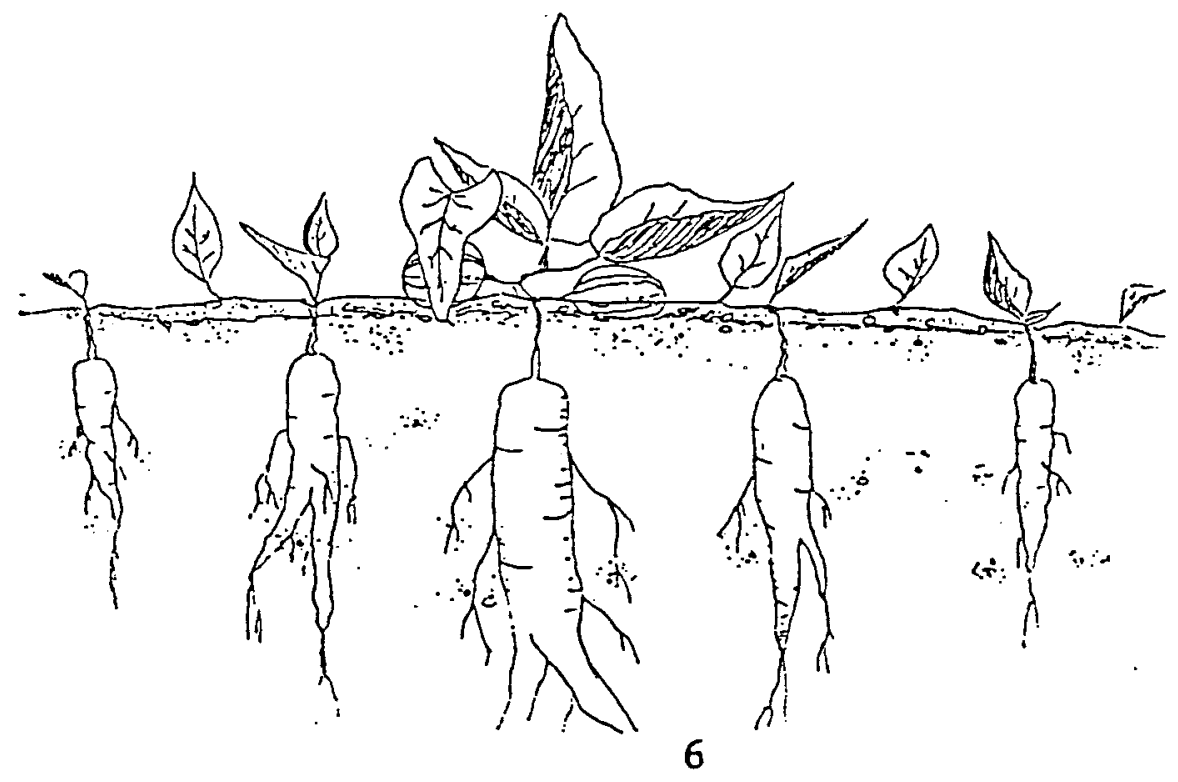


With a digging stick, hoe, or mattock, dig around the bigger roots and extract as much of them as you can. You may have to break off the big ones. Collect also some of the smaller roots around the central one if you need to.

The purpose, at this stage, is not to dig all the roots up which would destroy the plant. Dig only enough for cooking one or two meals (when dried). Remember that they will shrink as they dry, so collect enough - about two armfuls. If you dig up most of the roots, try to plant back some seeds from the gourds.

\section{Seeds}

At the same time, if there are mature gourds or dried melons from last year on the vines, collect the gourds and take them home also. If the roots prove to be useful, then you will have the seeds to plant closer to home.

If the gourds or melons are not ripe, come back at the end of the growing season and collect them. If the gourds are mature but still green, you may collect them and take them home to dry and prepare for planting later. More about that later.

If you collect seeds or roots from several locations, make a map of the region and mark where you found each cucurbit colony. Mark your seeds and roots accordingly. This will help you identify the sites for the future and to know which sites produce the best roots.

\section{CUTTING AND DRYING ROOTFUEL}

Remove most of the dirt from the roots by brushing it off. The roots that are too large to use in an ordinary three-stone fire or stove must be cut before drying. When cucurbit roots are "fresh" they can be easily cut with a strong knife, machete, or hatchet but after drying a day or so they become hard and almost impossible to cut. Cut the fresh pieces so that they are larger than normal firewood pieces, because fresh roots will shrink upon drying by about half their thickness and some of their length, in addition to losing nearly two-thirds the weight. Small, carrot-like roots can be dried without cutting.

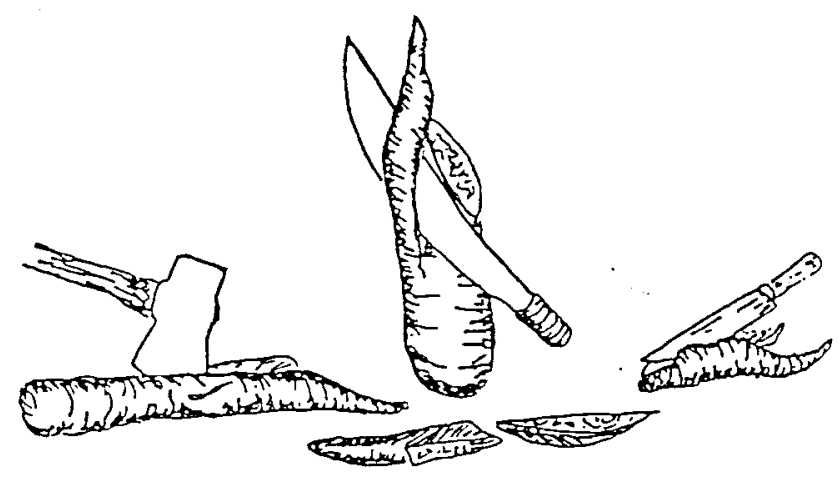

While fresh, the roots are susceptible to rot. It is very important to spread them out completely in the sun to dry. Within three or four days in arid lands they will be dry, depending on the size of the pieces, humidity, temperature, and breeze. If it rains while they are drying, the roots must be covered during the rain or taken inside just as you do when drying millet or fruit in the sun. You can also dry them inside if you have to, but it is much slower and the pieces may become moldy. 
You can tell if the roots and pieces are dry enough in several ways. First, by flexibility. Fresh roots bend (like carrots), but when dry, they become stiff and hard. The surfaces that are cut will become whitish almost like a bone. The whole roots will shrivel and wrinkle. Second, the weight-loss will stop when roots are finished drying. Roots lose weight from day to day when drying, just as apricots or any dried fruit. You can put one on a scale, if you have one, and watch it lose weight until it stabilizes. If you don't have a scale, you can make a simple balance-beam scale with a stick, a rock on one end and a fresh root on the other. When the balance beam stabilizes or stops moving, the root is dry.
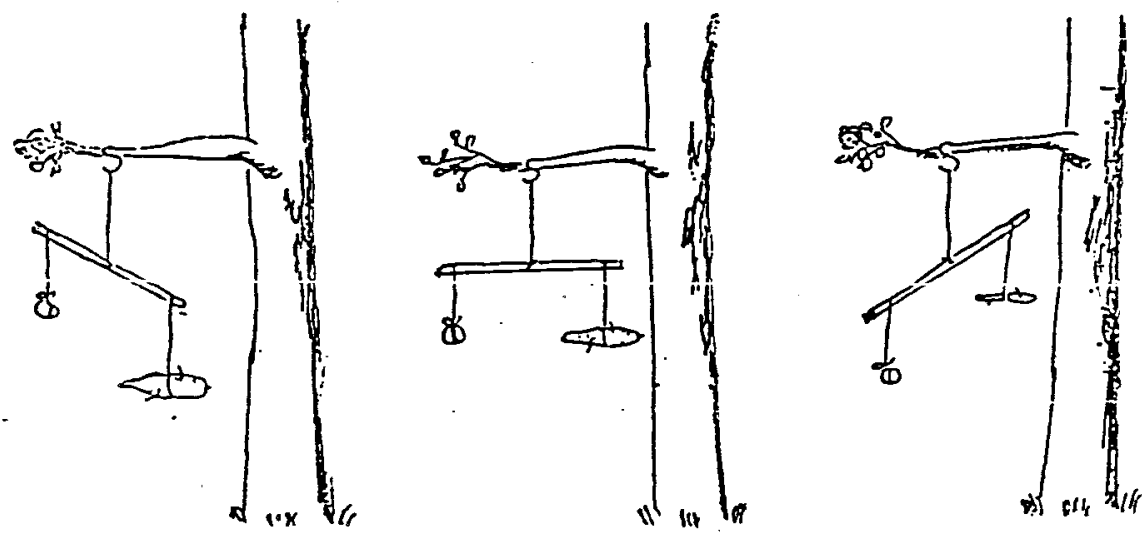

A third way to test for dryness, is to try to cut a root with a knife. If it is hard to chop or cut, it is probably dry enough to burn.

Once the roots are dry it is important to keep them .dry, since roots are starchy and tend to absorb moisture from the air. One way is to store them in a rack up above the fire or in the rafters of the house until ready to use. Another way is to store rootfuel behind the stove or fireplace so the warmth of the fire keeps it dry. It is important to keep the rootfuel dry to be able to start fires more easily, and to get the most heating value out of the fuel since wet fuel will take energy to dry it out enough to burn.

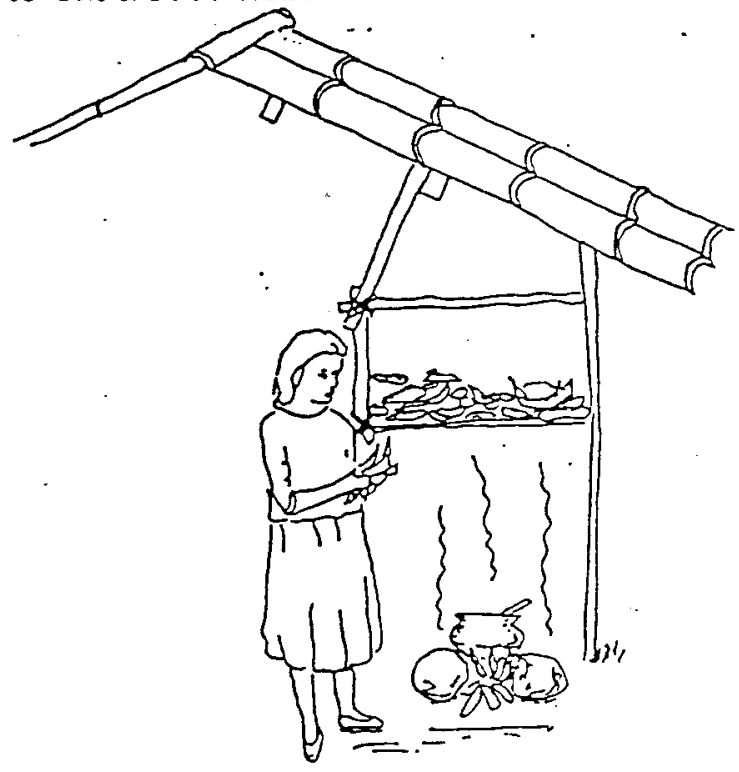

\section{TESTING ROOTFUEL FOR ACCEPTABILITY}

Now that you have a supply of dried rootfuel, it must be put to the test to see if cooks will use it or not. It has the look and feel of a good solid fuel, almost like wood, but there are questions that need to be answered before you can feel sure that people will accept it. A cultural acceptability cooking test will help answer these questions: 
- Will the "new" rootfuel ignite acceptably and burn in a satisfactory way?

- Will the new fuel impart a strange or unacceptable flavor to food?

- Will rootfuel smoke more than other fuels or irritate the cook's eyes?

- Can the cook prepare a meal in about the same time as with wood or other traditional fuels?

- is rootfuel as efficient as wood, requiring no more fuel than wood, or perhaps even less?

- Does the fire have to be tended, or replenished, more frequently than when other fuels are used?

- Will rootfuel create coals for simmering longer-cooking foods?

- Will rootfuel burn well in a traditional fireplace, stove, and oven?

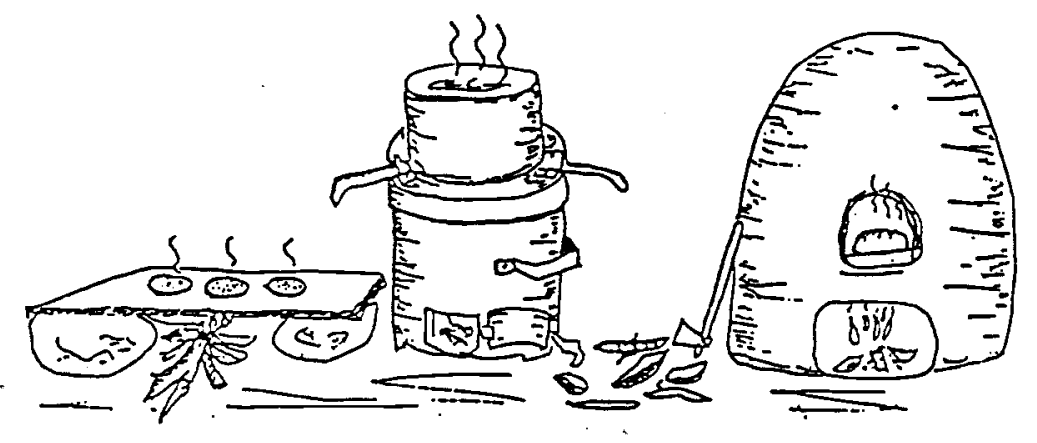

These technical and cultural questions must be answered by trying rootfuel with those who actually do cooking. Cooks are the ones who can determine best whether this "new" fuel is acceptable. It is not enough for others to decide that rootfuel is good, no matter if it performs better than the traditional fuels. Cooks can tell by using it how it behaves in their stoves, fireplaces, or ovens and with their usual cooking utensils. If the family will eat the food cooked over rootfuel, that is the final test.

Trying the Rootfuel

In societies where women are the ones who do the cooking, we propose that you get a local woman to assist you in an experiment of cooking with rootfuel. She will be the primary experimenter and you are the observer of the cooking process. You should explain your need for help in carrying out the cooking test. Tell her that women like her in Mexico and Senegal and Pakistan have tried cooking with this alternative fuel and have liked it, but that you don't know if this fuel from a local plant is good for cooking.

It is important that someone other than a family member to test it, who might not want to offend you. In fact, if possible, get another person to do a second cooking test afterward. The second test will give a more balanced perspective on the results, because one test may not 
indicate all there is to find out. And trying it again under other conditions with another cook may reveal some new factors.

In some societies men do much of the cooking, especially in public institutions, hotels, schools, restaurants, barracks. In these, the testing for acceptability should be done by men as well, as we did in Pakistan with an Afghan man.

The secret of an acceptability test is to get the local cook to use rootfuel instead of the normal fuels. Everything else must remain the same: the same stove or three-stone fire, the customary foods, and the cooking utensils that the cook is accustomed to. Ask him or her what the normal meal consists of and, if possible, supply the ingredients for the meal. If not, offer to pay for the supplies used, if this is acceptable.

The meal should include the usual variety of foods, involving boiling, frying, and stewing. This will test rootfuel for normal meal requirements. If bread is baked with a wood or charcoal-fired oven, try the rootfuel to heat the oven as well.

As the test is carried out, your role is to observe and make notes on what you see and on the comments made by the cook as the meal proceeds. To help you, we have included a brief write-up of the rootfuel acceptability test by Claudia Gonzallez de Moreno in Mexico in Appendix $B$ at the end of this handbook. Read it for ideas before you start.

Now you are ready to start the acceptability test. The cook has the rootfuel and the food stuff. Give only minimal instructions, such as the following:

- "Here's an alternative cooking fuel to use instead of your normal fuels. I would like to observe how it works in your stove (or fireplace) as you cook."

- "Here are the ingredients for the meal" (if this applies).

- "Please cook in your usual way, exchanging only this new fuel for your old. You may have to make some adjustments to this fuel, which is not wood."

- "As you cook, feel free to comment on how the fuel is working or not, what the problems are, how the smoke is, how cooking with it compares to cooking from your old fuel, and anything else that you notice that is better or worse than your old fuel."

- "I will watch you and make some notes on the process, so we can compare this fuel with your normal cooking fuels.

- [If you are able to take pictures, add:] "I would like to take some pictures as you cook, if that is all right. I will send you some copies of the pictures."

After giving these simple instructions, observe how the cook starts the fire. If it is like Cucurbita foetidissima, it will ignite more slowly than wood, something like charcoal, so the cook may have to use some small pieces of wood or other easy-to-light material to start the 
rootfuel. The cook may fan the fire or blow on it. He or she may even use something like kerosene to help it start.

Look at your watch and time the process. Time how long it takes to get the fire going, and then how much time it takes for each kind of food to cook or bake. Your task is to watch how the cook adjusts to the fuel, noting down comments as well as your observations about the questions listed at the beginning of this section. If the cook does not volunteer comments, you might ask for
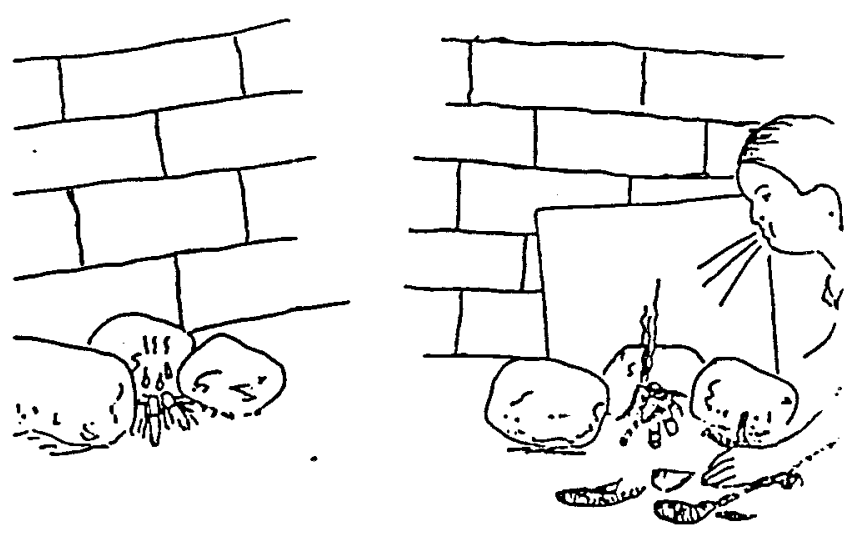
impressions on how the cooking is going.

Allow the cook to make mistakes, and watch for any adjustments made to allow for them. If not, you might ask such questions as: "Is it smoking too much?" "Does the fire have enough air?" "Is the pot too far away from the flame?" "Is the flame lower than usual?" Be careful, however, of putting words into the cook's mouth. Allow time to discover the problems for herself or himself, and to make the necessary changes.

Rootfuel will probably burn more slowly than wood fuel, due the high content of starch with cellulose fibers. The flame will possibly be lower, so the cook may have to adjust the pot or stove-top closer to the flame or coals. Our tests also showed that rootfuel needs good ventilation because of its dense nature.

Rootfuel should create some coals, if it is like our other tests, which are good for simmering the typical rice and beans or other long-cooking foods. But all this is based on our tests with a New World cucurbit that may not apply in your region. That is why a local cook and you are doing this test on local cucurbits.

Common mistakes that can affect the results of the cooking test include such things as:

- Too many instructions.

- Not allowing the cook time to discover the peculiar qualities of rootfuel.

- Distractions due to socializing with friends or with you.

+ Using unfamiliar foods.

- Smothering the fire with too much rootfuel or not enough air.

- Humid rootfuel.

- Using the wrong size of rootfuel pieces (large chunks ignite slowly and small pieces burn too quickly). 
When finished, the family and you can eat the meal. It is important to have young children eat the meal just prepared, if possible, because they are too innocent to be polite about strange tastes. Thank the cook and the family. Promise to send a copy of anything you might write up about the experiment, and photos if you took any (including a portrait the cook and the family if you can take one).

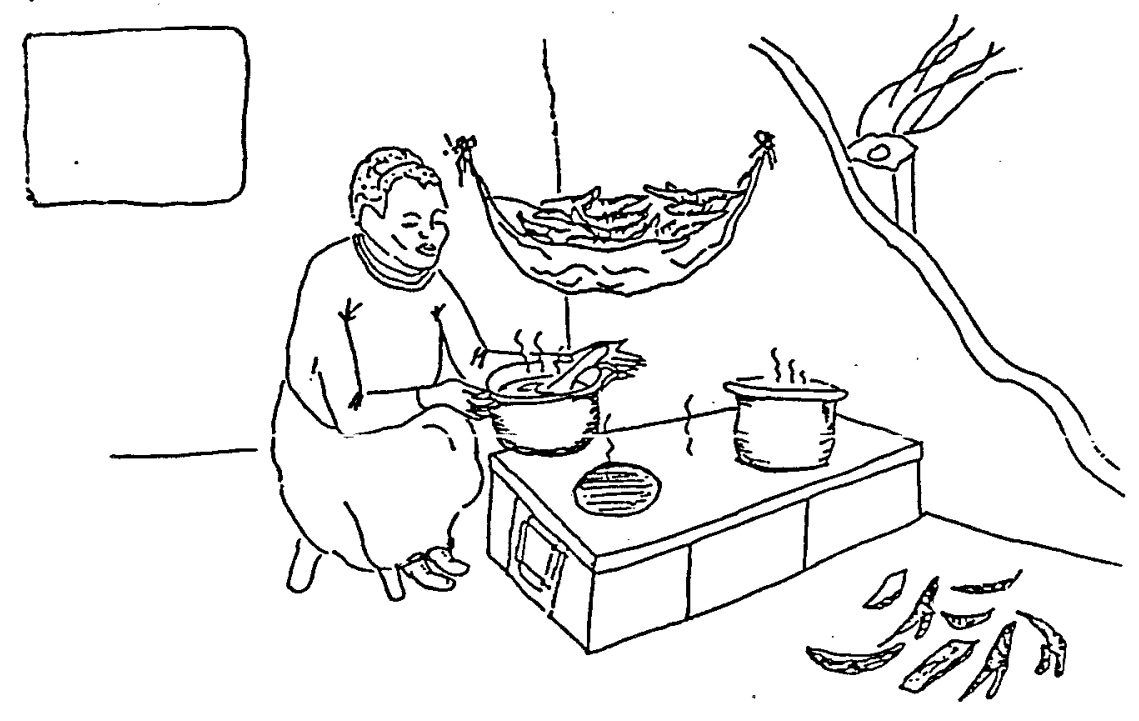

\section{Writing up the Test}

It would be helpful if you could write up the notes you took in a final form, putting at the beginning the circumstances of the test - where, when, the weather at the time, who cooked, the type of stove and cooking equipment, the results, and any other details. Use the sample report form in Appendix B as a guide. We would like to receive a copy of the report, including a description and local names of the cucurbits used (and the scientific name if you can find it). The leaf that you traced on paper should be included, along with any photos of the plant, the roots, fruit, and the cooking experience, if you took pictures. This information will be useful to people in other parts of the world, and helpful to us as we continue to learn about the use of rootfuel.

\section{GROWING CUCURBITS FOR ROOTFUEL}

Wild cucurbits are easily cultivated. Before the rainy season, the seeds can be planted like squash or melon seeds. Rain is important during the first month so the plants can establish themselves. If the rains stop before the little plants are established, you may need to water them as you would any other crop. But since they are dryland plants, their roots cannot be submersed in standing water for long without drowning. Remember that cucurbits like sloping inclines and well drained soils, and that they can prosper in relatively marginal and poor soils.

While cucurbits or other dryland species can survive harsh conditions, they will do better and produce more roots and fruit under better soil and water. If there is plenty of cultivable land, cucurbits can be grown like any crop. If not, they can be planted on under-utilized or waste lands. 


\section{Seed Preparation}

Preparation of the seed for planting is important. If you have collected fresh, mature wild cucurbit gourds you will need to take the following steps to get seed to plant:

1. Cut the gourds in half.

2. Put the halves into water to allow them to ferment for a week. This breaks down the fibers and makes it easier to extract the seeds.

3. Scoop out the seeds with a spoon and separate from the pulp.

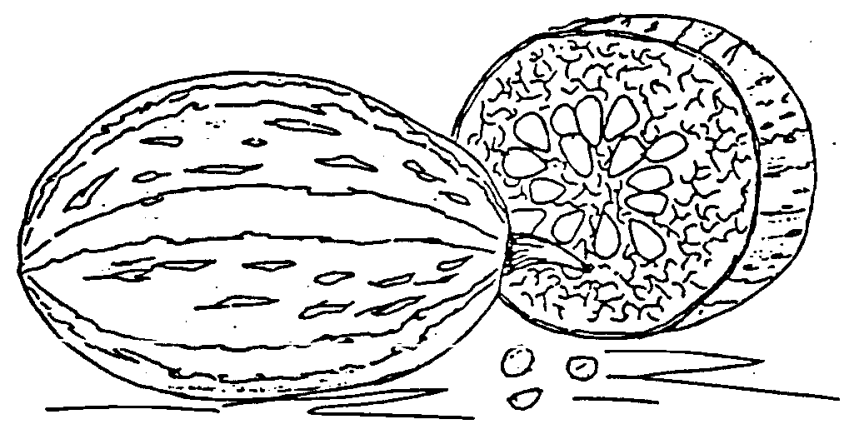

4. Put the seeds on a screen wire or porous cloth and rinse them with water.

5. Dry the seeds in the sun until they are good and dry, a few days in the tropical sun.

6. Take up the seed and dip them into a solution of $10 \%$ Clorox or Purex and water, that is, one part Clorox to nine parts of water. Do not rinse. (You may just dust the seeds with a fungicide like Captan instead of dipping in clorox water.)

7. Dry the seed again in the sun. Never put them in an oven or on a fire; this will kill the germination.

If the gourds are already dry and the seeds are loose inside, you only have to take the seeds out and dry them in the sun a few days and then treat them for fungi either by dipping them in the solution or dusting them with a fungicide before storing (see step 6 above).

If you would like to also try planting some seeds from Cucurbita foetidissima from the New World, write Enable International for a packet of seeds ready to plant. You may need to get permission from your department of agriculture to import these seeds for purposes of experimentation.

Planting Methods

You might try different methods of planting to see which is best. Most arid land cucurbits, like Cucurbita foetidissima, do well in all dryland soils without fertilizer. They have survived in a hostile environment through centuries of adaptation, so if you observe where they are growing in the wild and try to copy these conditions, you will succeed. Since dryland cucurbits do better in well-drained soil, you should plant them on a slope if possible, or if not, then plant on the top of raised mounds of earth. Sandy loam is the most desirable soil, 
wherever available. Remember that the ideal is to plant rootfuel crops where other plants do not grow well, on eroded hillsides or otherwise wastelands.

There is good reason to plant the crop near the house or village if soil conditions and area permit. Since fresh roots contain two-thirds water, you would not want to transport them for long distances. It is important to harvest and dry them in the same locality. Otherwise the work of those who carry fuel would be increased, not lessened. If the cucurbits are cultivated in some remote field, they should be dried there or carted home on animals or carts to dry.

There are two methods of cultivating rootfuel cucurbits, as a seasonal crop (annuals) or as a permanent crop (perennials).

\section{Annuals}

To cultivate as an annual crop for harvesting at the end of the growing season, cucurbit seeds should be planted about $6 \mathrm{~cm}$. apart in rows, with about 0.5 meters between rows. About the width of three fingers is equal to $6 \mathrm{~cm}$. Plant the seeds $2 \mathrm{~cm}$. deep on top of each row, with furrows between the rows about $15 \mathrm{~cm}$. deep, to catch the rain and provide drainage.

Annuals can be planted on fairly level land if it is sandy enough.

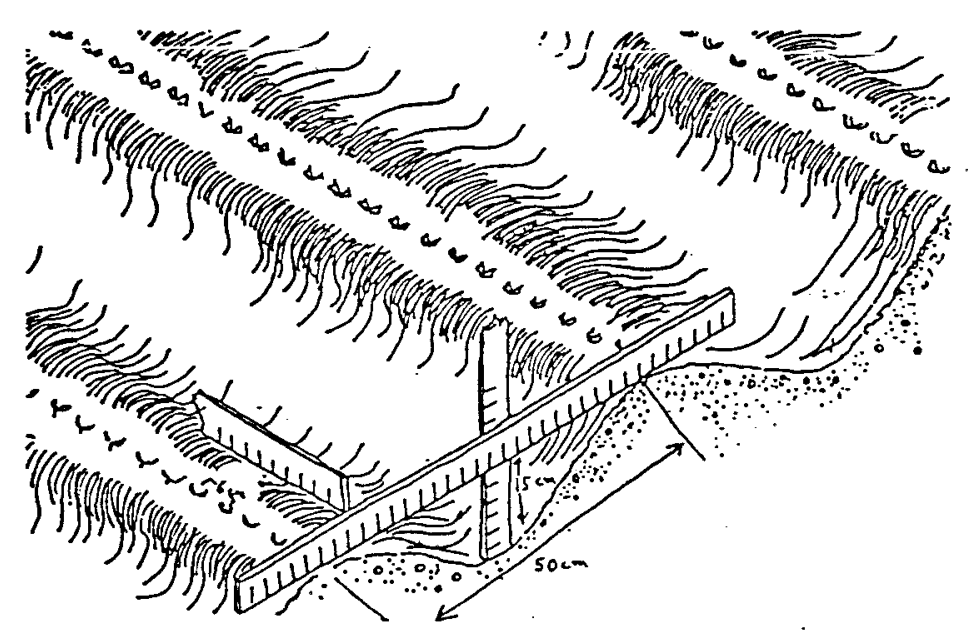
If planted on sloping land, make sure the rows follow the contours of the land. Use a leveling device, if necessary, so the rows follow the hillside and channel the water off gradually. One leveling method is to use a triangle with

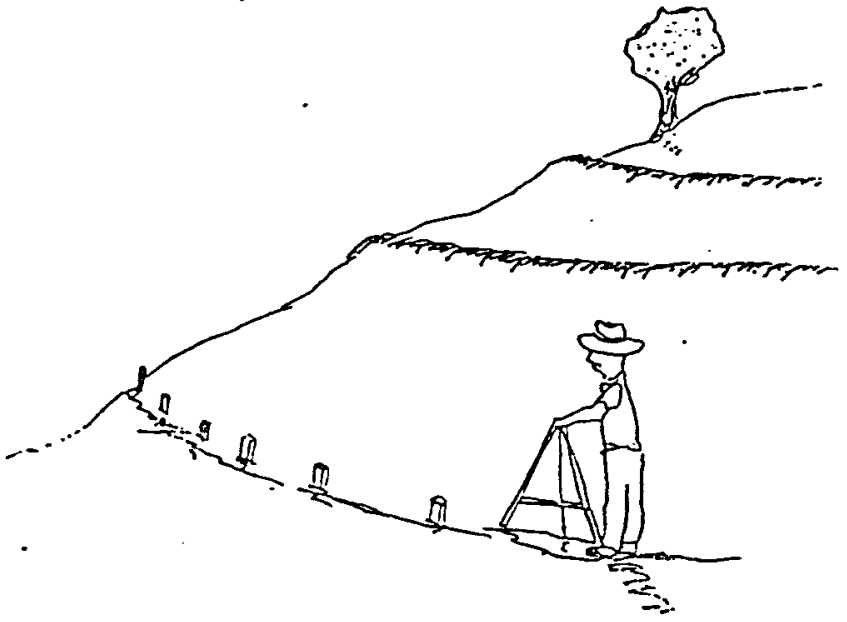
a plumb-bob on a line and a mark in the center of the cross-bar. By moving the legs of the triangle around the slope with the plumb-bob slightly off center, a gradual drainage terrace can be made that will run the water off gradually at the lower end. This is important to lessen erosion on constantly cultivated plots of sloping land.

Annual cucurbits will be ready to harvest in about three months. If there are two rainy seasons, you could have two harvests. But by such intensive use of the land, the nitrogen in the soil could be soon used up. Nitrogen is very important for

healthy plants. Therefore, the vines and leaves should be chopped and put back into - 
the soil as "green fertilizer" by turning it under, or folding it into the soil. One way is to put the green vines and leaves into the furrows and cover them with soil until the next planting season. The use of mulch will also help prevent soil erosion.

Annual plots will produce more rootfuel per hectare of land than perennial plants will, but it is harder on the soil and will require the recycling of vines and leaves mentioned above, or some other source of nutrients. If rootfuel eventually substitutes the use of animal dungpatties for fuel, then the dung should be put back into the soil. Remember that fertilizers need water to release the nitrogen, so there is no need to fertilize in the dry season.

\section{Perennials}

To cultivate cucurbits as a permanent crop, doing selective harvesting of some of the bigger roots each year, plant cucurbit seeds in mounds or "hills" about a meter apart. Plant more seeds than you expect to sprout to allow for infertile seeds. If the plants come up too thickly, you can thin out the weaker plants later to about 4 or 5 to a hill. This spacing is more like the way

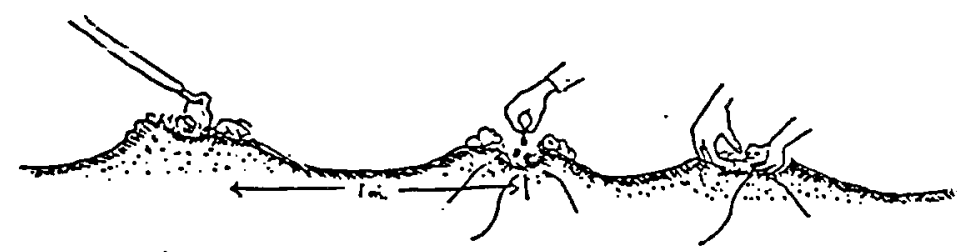
cucurbits grow naturally and will produce runners. The plants will send down new roots at the joints of the vines to spread into a colony. The colony will soon cover the mound.

Perennials serve another function, stabilizing the soil from wind and rain erosion because of the thick leaf cover and the root structure. So the best place for perennials is on eroded hillsides, terraces, or other non-useful land.

The yield of roots will be somewhat less in poorer soils, but in the long run the benefits for this otherwise waste land make this an attractive option. Besides, you need a perennial crop to produce seeds for planting and possibly for food - edible oil and meal (explained below). Just remember that once firmly established as a permanent colony, cucurbits are hard to get rid of because they tend to sprout back from the roots or broken bits of roots (like a potato) as well as from gourd seeds. Choose land not used for your food crops. Furthermore, you might want to plant trees among the cucurbits if you are trying to recuperate an eroded hillside or gully. If you do, remember to water the tree seedlings or make sure they get enough water since cucurbits are thirsty.

\section{Agricultural Management}

Ideally, there should be both perennial and annual plots. A family or community would thus use the perennial plot to produce seed and scme roots for fuel (during and after the second year). It would use the annual plot for harvesting roots once a year (or twice if two rainy seasons permit double cropping). In the perennial plantation, the older roots must be harvested 
every year or they will grow too large and stunt the growth of the younger roots in the colony. As we noted above, in the annual or bi-annual plantation, care must be taken to not exhaust the nutrients in the soil. Replace the nutrients by putting the vines and leaves back under the soil. This is good agricultural practice, whatever the crop.

\section{CARING FOR THE CUCURBITS}

Neither annual nor perennial plots need cultivation or hoeing. Weed control in the cultivated annuals is the same as with other row crops, by hoeing or pulling weeds until the cucurbits are established. In the permanent plots, weeding soon becomes unnecessary, since the thick vegetation chokes out most weeds. Do not use herbicides because they may kill the cucurbits.

Animals typically will not graze on bitter cucurbits except in dire necessity. In the case of Cucurbita foetidissima, only the javelina (wild tusked pig) will eat it. However some lessbitter species of cucurbits may need some protection from grazing animals. The traditional ways of keeping animals out of neighbor's croplands or gardens - by herding, or fencing - will work as well with cucurbit crops. People may have to be taught to think of these wild gourd or melon plants as a valuable crop and not just a weedy pest, so that the animals will be kept out.

Some insects do attack cucurbits, but since they are locally adapted, cucurbits have survived insect infestations for centuries. Because there are so many leaves, some can be sacrificed to insects without much loss of plant vigor. It is most important for the plant to survive drought and the attacks of the usual insects in your region. High yield is secondary in importance to survivability. If you happen to find an interesting cucurbit but you notice that it is imperiled by insects or drought, avoid this species.

Normal care should be taken against thievery of roots and seeds in the field if stealing is a problem in your area. Most rural villages in traditional cultures have less of a problem with crop stealing than more urban areas. Since the roots are harder to harvest than fruits or vegetables, the problem may not be great. In some societies a person sleeps in a tiny house near the crops as harvest time approaches.

\section{HARVEST AND PROCESSING}

Roots

We have already suggested that annual root crops will be harvested after maturing (some three to four months). A hoe, digging stick, mattock, or even a plow can turn the roots up, as people have traditionally harvested potatoes and carrots. These small roots must be quickly spread out to dry. They will probably not need to be cut into smaller pieces.

Again, the perennial colonies need selective harvesting of the larger roots without disturbing the colony or the smaller lateral vines and roots. Harvesting large roots keeps them from growing too deep and from monopolizing water. Large roots can be found in the center 
of the colony, on the mounds where they were planted initially. Large harvested roots, then, must be cut immediately into pieces of appropriate size for sun-drying.

When the larger roots are removed, the smaller roots will start growing faster, eventually becoming candidates for harvesting. Thus the colonies will gradually shift as they grow outward. If large areas are harvested from the colony, they can be re-seeded to keep the colony producing.

\section{Seeds}

We haven't said much about seeds. The mature gourds can be collected at the end of the season and dried in the sun. For either fresh or dry gourds, follow the step-by-step process described above to remove the seeds and prepare seed for future use. There are about three hundreds of seeds in a gourd. Use seeds to start new perennial colonies and also for planting annual plots.

Cucurbit seeds may also be useful as food. In Mexico the seeds of "calabacilla loca" are toasted and eaten. Seeds can also be prepared as you would prepare corn for tortillas, soaking them in "nixtamal" (a mixture of 3 handfuls of slaked lime in 10 quarts of water) and grinding them in a "metate," or mortar and pestle, to mix with tortilla mass). Clean seeds contain more protein $(50 \%)$ than soy beans (48.5\%). The seeds contain an edible oil that could be pressed out and used. The seed meal left after pressing contains protein that is useful for animal feed. There are projects to develop the seed oil content in Cucurbita foetidissima but this is usually perceived by the people as a secondary need when compared to the need for cooking fuel. However, if Cucurbita foetidissima is planted as a perennial crop for seed production, each plant can produce 100 gourds, and if planted on one meter centers in one hectare, 2500 plants will produce $1,250 \mathrm{~kg}$ of seeds, even allowing for non-productive plants.

\section{SPREADING THE WORD}

People who find and experiment with rootfuel are the best ones to spread the word about it. Since they. have been involved right from the beginning, they know more about it than anyone. They have a certain rightful pride in this labor-saving fuel and want to share it with others. Besides the traditional word-of-mouth method, there are other ways to diffuse the knowledge. If necessary, demonstrations can probably be held in villages, at fairs, or at marketplaces, using rootfuel to cook meals. It has been our experience that the cooks who try the fuel will tell others, who then want to use it.

The advantage of rootfuel is that it is an appropriate technology, easily understood. Growing it is as simple and familiar as growing ordinary squash or melon plants, which all farmers know. They can use their customary tools. Rootfuel is not capital-intensive and does not create dependency on outside funds or technology. With only a brief technical orientation, the concept of rootfuel is practically self-propagating.

Cucurbits do not need irrigation (in fact too much irrigation can quickly kill them). Also wild cucurbits do not need chemical fertilizers or pesticides. However, not enough is known about intensive cultivation to predict exactly which diseases or pests they might eventually 
attract or what its demands on soil are that could require additional nutrients. Normal precautions would include crop rotation for annual plantations to allow soil to recuperate, perhaps with a nitrogen-fixing crop, and to prevent disease pathology.

After an hour or so of testing for acceptability, village people know as much or more about using it than we do. Women who are suffering from a shortage of wood fuel, making long trips for wood-gathering, having to make dung-cakes, or sitting beside a fire feeding it quick-burning crop residues, immediately grasp the advantages that rootfuel offers. It makes good economic sense, furthermore, to have a "fuel farm" planted close-by the village, which relieves people of long hours and the physical burden of scavenging for wood fuel. This proximity also frees them for more productive activity and time with family.

\section{SOCIAL AND ECONOMIC ORGANIZATION}

The use of rootfuel does not require a reorganization of the social and economic siruciures of a community. It is adaptabie to existing patierns of society and cuiture. However, as with anything new, it may make people think about their way of doing things.

\section{Economic Structures}

If the community is organized on an individual family or scattered household basis, rootfuel can be grown and used by each family on its private land. If, on the other hand, the community is more traditionally organized as a communal enterprise, rootfuel can be grown on common lands and shared among families. Where cooperatives are functioning, rootfuel could become a commodity managed by the cooperative for the benefit of the members. In any of these economic systems, rootfuel can be grown and used or marketed according to the existing
structure.

If there is an excess of production of roots, this opens several economic options. Rootfuel could be marketed to other communities where there is a shortage of wood fuel. Another option might be to use the cucurbit for its other traditional uses if it has any. Cucurbita foetidissima, for example, can be used for seed oil and seed meal, soap, clothes bleach, and medicines (see Appendix C). Other cucurbits may have similar uses that may be used locally or marketed.

\section{Male/Female Roles}

The roles of men and women are distinctly drawn in most societies. In traditional rural settings, men's roles are typically defined in hunting, fishing, or farming terms while women's roles center around the home - as cooks, vegetable gardeners, weavers, and mothers. In some agricultural societies, women and children do pitch in at planting and harvest time to help the men. The introduction of a new technology often disrupts the social patterns and sometimes fails for this reason.

Introducing rootfuel will not necessarily disturb the traditionally accepted male/female roles, although it should make the work of women easier. However, when cucurbits are grown as an agricultural crop, this could change the roles slightly, since the fuel would be grown as a 
crop (usually men's work), not gathered from the forest or countryside (usually women's work). Who would plant, harvest, and prepare rootfuel becomes an interesting question, but we believe that this will be decided by each family or community in accordance with existing cultural norms and patterns.

Since rootfuel crosses the line, however, between traditional women's work (fuel gathering) and men's work (farming), perhaps this innovation will provide the opportunity for men and women to discuss who will do what. What is important is that these questions should be discussed by all involved in the family or community. These decisions should be. made locally, not imposed by outsiders. If, from the beginning, the rootfuel idea is developed from within each community by local people as the prime experimenters and promoters of the concept, it is more likely that the results will be more lasting.

Whichever way the roles are defined, we contend that rootfuel has the potential of lightening the burden of women

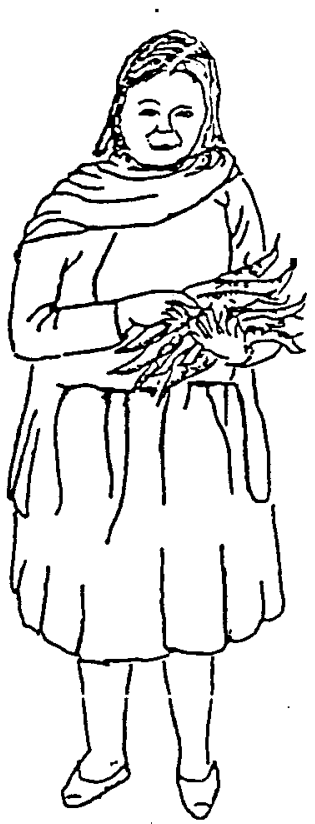
who are currently responsible for gathering wood for cooking.

The task cannot be harder on women than it currently is. In the same way, where men do cooking, the characteristics of rootfuel make it more desirable - less irritating smoke, coals for simmering food, and less fuel consumption to prepare a meal. By cultivating "energy farms" around villages, time and effort seeking wood fuel will be saved, erosion can be slowed on hillsides, and the pressure on increasingly scarce trees will be lessened.

\section{SOME FINAL THOUGHTS}

We trust that you will have good success using this handbook. If parts of it are not clear to you and you have any questions, please get in touch with the authors or with the Biomass Users Network. The addresses are found in the front of the handbook. There is much to be learned about rootfuel. Your experiences and knowledge will add to the information that we share with others in the drylands. Thank you for sending us your reports.

Feel free to copy this handbook and use it. Just give credit to the authors, Enable International, and the Biomass Users Network, and include the appropriate addresses so others can send their experiences and discoveries.

You may translate and adapt it to your language and culture so that others who might not read English can use it to find and use potential rootfuel sources. The drawings may not be understood easily by the local people, so perhaps they could help you draw pictures in their own way for a local version of the handbook. We would like to receive two copies of your translated version. 


\section{APPENDD A}

\section{A Wild Taprooted Old World Cucurbit: Citrullus colocynthis}

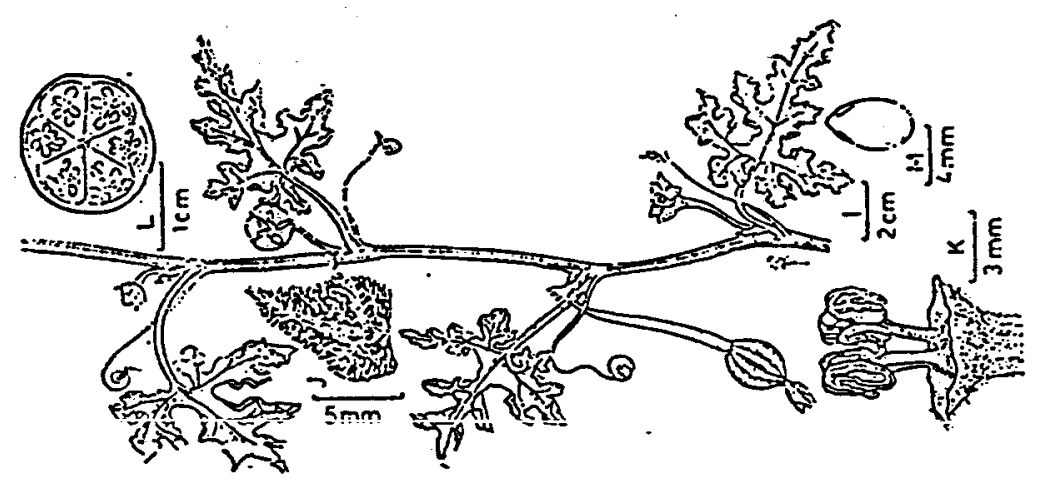

An important wild cucurbit of northern tropical Africa, Pakistan, northwest India, and Australia, is Citrullus colocynthis, widely found in all these regions. It is a drought-enduring plant that survives extremely dry conditions because of its long, stout taproot and additional rooting at nodes of the vines. Germination and growth rates are high; seed set is profuse.

The runners and leaves check soil erosion by the wind. Therefore, Citrullus colocynthis is a promising soil binder, especially for shifting sand dunes and highly erodible areas.

One common name for this cucurbit on the Indian subcontinent is mahendra varuni. Traditionally, the roots have been used as a purgative and for treatment of jaundice and rheumatism. The powdered seeds have been used to make sagra, a special kind of bread. 


\title{
APPENDIX B
}

\section{ROOTFUEL TEST REPORT}

COUNTRY: Mexico

PROVINCE: Estado de Mexico

TOWN OR VILLAGE: Dolores Hidalgo, San Felipe del Progreso

LINGUISTIC GROUP: Mazahua Indian

DATE: March 15, 1987 SEASON: Early rains, spring.

THE COOK: Claudia González de Moreno

THE OBSERVERS: Wayne G. Bragg and Eugene B. Shultz

\begin{abstract}
ADDRESS: Enable International
608 N. President St.

Wheaton, Ilinois 60187 USA
\end{abstract}

TELEPHONE: (708) 665-5958 (USA)

CUCURBIT USED: Cucurbita foetidissima (Buffalo gourd, calabacilla loca)

WEATHER: Dry. No wind, because the fire place was indoors.

STOVE OR FIREPLACE: A three-stone fireplace in the cooking house, a small room with open holes in the roof for smoke to escape.

FOODS: Rice with tomatoes and onions, cooked in clay pot; eggs scrambled on a metal sheet placed on the stones; tortillas cooked on the same metal sheet.

DESCRIPTION:

We took dried roots of Cucurbita foetidissima (native to southwest USA and northern Mexico) to a village near San Felipe del Progreso in the State of Mexico, two hours northwest of Mexico City. There Claudia González de Moreno readily accepted the challenge to use rootfuel to prepare the noon meal. We took rice, tomatoes, onions, eggs and cooking oil. She had corn meal for tortillas. Except for her audience and the new fuel, there was nothing changed in the process. We reminded her to make her meal as usual, and to make any comments about how the rootfuel behaved.

She started the fire with comstalks and twigs, and selected a pottery pot for the rice with tomatoes and onions. Claudia noted that rootfuel is slower to ignite than her usual fuels (animal dung cakes, crop residues, and dried maguey cactus leaves), and she blew on the smoldering flame until it caught. Within about five minutes, the fire was burning briskly. 
dung cakes, crop residues, and dried maguey cactus leaves), and she blew on the smoldering flame until it caught. Within about five minutes, the fire was buming briskly.

Shortly after Claudia put the pot on the stones, she noted that the pot was too high above the flame which was burning lower than her other fuels do. We had already observed that she needed.to lower the pot but did not say anything in order to see how she would react. In a few minutes, she took the pot off the fire and turned the stones on their sides, thus lowering the pot to the flame. She commented that the fire burned less rapidly and lower than her other fuels, adding, "Pero la cazuela se acostumbra al fuego; coge las mañas del fuego" [But the pot gets used to the fire; it takes on the characteristics of the fire]. "Con trastos de aluminio, estaria bien" [With aluminum pots this would be just fine], she commented. In this way Claudia explained to us the complex and intricate relationship of heat, distance, mass, and materials that goes into even simple cooking techniques.

About the smoke, she said, "No está picoso" [It is not irritating]. Later, when the rice was almost done, she volunteered about the rootfuel, "Me gusta, porque no hace humo." [I like it because it doesn't smoke much]. She reiterated, "El humo es mejor, porque no me irrita." [The smoke is better because it doesn't irritate my eyes].

Claudia continued, "Quema bonito; tiene braza, que maguey no hace" [It burns nicely; it has coals, which the maguey doesn't produce]. In response to our question "What will you use the coals for?" she replied, "Para preparar tortillas o fritar huevos y calientar agua" [To prepare tortillas or fry eggs, and to heat water].

Claudia took the pot of rice off the fire and put a square piece of sheet metal across the three stones to cook tortillas. The metal was about 20 to $25 \mathrm{~cm}$ above the coals. The tortillas responded slowly so she added more roots to the fire. In a few minutes, she remarked, "Es un poco lento " [It's a little slow]. When the tortillas were finished, Claudia scrambled some eggs.

Then all of us present enjoyed our first meal prepared on rootfuel. Claudia, her husband, Francisco, and their children, all confirmed that the foods tasted normal. We watched five-yearold Hugo's face as he ate with apparent relish, which was a good taste-test, since he would not hide his feelings in order to impress us.

The total cooking time had taken about ten minutes more than normal, but this is expected when trying out a fuel that is new and slower to ignite than wood or cornstalks.

Talking with Francisco and Claudia, we described the plant and showed them a picture. Claudia said that it looked like a plant that her mother had used to make soap, called "sanacoche" in Spanish or "tsa'to" in Mazahua. Francisco added that the men had used a solution from boiling the roots of this plant to rid the burros of intestinal worms. Since these were uses we knew to be associated with Cucurbita foetidissima, we asked them to take us to find some of these plants. We went to her home village and along the roadside we dug roots. A local agronomist identified it to be another species of cucurbit, Cucurbita radicans, with similar characteristics and appearance of Cucurbita foetidissima. 


\section{APPENDDX C \\ Some Traditional Uses of Cucurbita foetidissima \\ (Buffalo Gourd, calabacilla loca)}

In the ethnobotanical literature and by oral tradition, Cucurbita foetidissima is described as a plant with many uses. Native American groups of the southwestern United States and northern Mexico have used the gourd seed, pulp, and roots of this hardy arid land cucurbit for centuries, evidenced by archeological remains as well as by the traditional knowledge passed down from generation to generation by "elders." Contemporary people in the region used the plant until recently, and some still may. Older people can be found who remember its multiple uses.

The seeds are still toasted and eaten in Mexico, much like sunflower seeds. The seeds contain protein and an edible, polyunsaturated oil and can be prepared much as corn for mixing with corn meal for tortillas, as explained in the handbook.

The pulp in the gourd was used as a bleach or whitener for clothes.

From the root there are many products:

1. One is an anthelmintic (de-wormer) for animals - burros, horses, cattle, pigs, and others. A solution is made by boiling the roots, which is then forced into the animal's throat.

2. Another useful product is a soap for washing clothes, or as a hand soap or shampoo. Chunks of roots produce a foamy lather when used.

3. Indians in Mexico have used it as a mordant, or dye fixer, for wool cloth and weavings, like rugs, ponchos, and other clothing. They use pieces of fresh root like a bar of soap and wash new wool first before carding, which leaves it white and clean.

3. Used in an enema, it has a laxative effect in humans and may tend to reduce the worm-load in the lower intestine.

4. Small pieces of the root, containing a class of substances called cucurbitacins, have been reportedly used to treat tooth-aches. Apparently cucurbitacins have an analgesic or pain-killing effect on teeth and gums when applied directly to the affected tooth or gum.

5. Similarly, a bath solution made from boiling the roots is reported to have been used by "curanderos" or folk-doctors as a treatment for people suffering from "susto" (extreme fright or nervous disorder). 


\section{GLOSSARY}

AGROFORESTRY The practice of mixing crops with trees by inter-planting, or of producing woodfuel by intensive cultivation of trees.

ANNUALS

BIOMASS

BIORESOURCES
Plants that grow to maturity in one growing season and are harvested.

The amount of living matter from plant material or animal waste, used as a source of fuel.

Biological plants with potential as renewable sources of energy, food, feed, insect repellent, medicine, or for other human needs.

"CALABACILLA LOCA" Local Mexican name for Cucurbita foetidissima, which is a wild, bitter cucurbit gourd plant.

CLOROX

A product containing chlorine that serves as a disinfectant and prevents fungal growth.

CUCURBIT

A species of the Cucurbitaceae family of plants that includes melons, gourds, cucumbers, etc.

Cucurbita foetidissima A species of cucurbit that is native to the southwestern USA and Mexico and produces large roots, also called Buffalo Gourd in the USA.

CULTURAL ACCEPTABILITY A test of whether the people will use something new to them, including such things as ease of use, practicality, economic usefulness, and fitness for use.

EROSION

The wearing away of soil by the action of wind or water.

FUNGUS

A class of lower plants that includes molds, rust, mildew, smuts, mushrooms, and yeasts. It causes rot eventually it grows.

FUNGICIDE

An agent that destroys or inhibits fungus growth.

MORDANT

A substance used to fix color in wool or other textile fabrics, usually by washing.

NITROGEN

A colorless, odorless, tasteless gaseous substance found in all living things.

PERENNIALS

Plants that continue year after year, producing new growth each season.

ROOTFUEL

Fuel made from roots for cooking or heating.

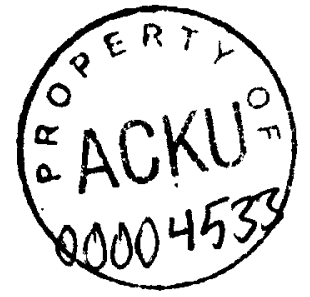

